

\title{
CONTRIBUCIÓN AL ESTUDIO DEL MODELADO MATEMÁTICO DE LA FERMENTACIÓN SÓLIDA DE HONGOS FILAMENTOSOS EN SOPORTES INERTES.
}

CONTENIDO

\author{
CONTENIDO
}

AGRADECIMIENTOS

RESUMEN

ABSTRACT

NOTACIÓN EMPLEADA

INTRODUCCIÓN

PARTE I: FERMENTACIÓN EN MEDIOS SÓLIDOS Y EN SOPORTES INERTES, BIORREACTORES Y MODELOS MATEMÁTICOS. OBJETIVOS Y ALCANCES DEL ESTUDIO.

A. FERMENTACIÓN EN MEDIOS SÓLIDOS Y SOPORTES INERTES

$\S 1$. Definiciones, importancia práctica, usos y aplicaciones 1

$\S 2$. Variables que inciden en los procesos 5

2.1 Humedad del medio y actividad de agua 5

2.2 Propiedades físicas de los materiales a transformar $\quad 7$

2.3 Temperatura y acumulación de calor $\quad 8$

§3. Soportes inertes 10

3.1 Características y aplicaciones potenciales 10

$\begin{array}{ll}3.2 \text { Tratamientos físicos } & 13\end{array}$

3.3 Tratamientos químicos 13

Resumen y conclusiones 14

B. BIORREACTORES Y MODELOS MATEMÁTICOS EN EL CAMPO DE LAS FERMENTACIONES EN MEDIOS SÓLIDOS

§4. Biorreactores para las fermentaciones en medios sólidos 15

4.1 Tipos de biorreactores 15

4.2 Diseño y escalamiento de biorrectores 17

§5. Modelos matemáticos 18

§6. Formulación y volumen elemental representativo 19

§7. Modelos de crecimiento en superficies 23

§8. Modelos para las fermentaciones en medios sólidos 26

§9. Modelos en sistemas experimentales ideales $\quad 29$

Resumen y conclusiones $\quad 32$

C. PRESENTACIÓN DEL PROBLEMA, OBJETIVOS

Y ALCANCES DEL ESTUDIO 33 


\section{PARTE II. DESARROLLO DE UN MODELO MATEMÁTICO GENERAL}

PARA LA FERMENTACIÓN EN MEDIO SÓLIDO SOBRE UN SOPORTE INERTE.

\section{A. DEFINICIONES E HIPÓTESIS DE TRABAJO}

\$10. Definición del sistema, las fases y los constituyentes 34

\$11. Hipótesis de trabajo 35

\$12. Definición de las variables del modelo y variables de estado: un enfoque fenomenológico

B. ECUACIONES DE BALANCE, RELACIONES CINÉTICAS Y DEDUCCIÓN DEL MODELO GENERAL EN COORDENADAS CILÍNDRICAS.

$\$ 13$. Balances de masa

§14. Balances de energía interna 41

$\$ 15$. Balance térmico. 43

\$16. Relaciones cinéticas $\quad 45$

$\$ 17$. Modelo general en coordenadas cilíndricas y estrategia de solución del modelo $\quad 48$

Resumen y conclusiones $\quad 52$

PARTE III. DESARROLLO, VALIDACION Y AJUSTE DE PARÁMETROS DE UN MODELO MATEMÁTICO SIMPLIFICADO

\section{A. DESARROLLO Y SOLUCIÓN DE UN MODELO SIMPLIFICADO}

§18. Hipótesis de trabajo: simplificaciones al modelo general 53

§19. Desarrollo del modelo simplificado 54

\$20. Evaluación teórica de los parámetros: Modelo simplificado 57

20.1 Parámetros físicos $\quad 57$

20.1.1 Propiedades del sistema $\quad 57$

20.1.2 Propiedades de los constituyentes $\quad 60$

20.2 Parámetros biológicos 63

20.2.1 Parámetros del crecimiento $\quad 64$

20.2.2 Coeficientes de mantenimiento 67

20.2.3 Rendimientos 67

20.3 Resumen de los parámetros a utilizar 69

\$21. Solución del modelo: Un problema de valor inicial 70

21.1 Estrategia de la solución numérica $\quad 70$

21.2 Condiciones iniciales $\quad 70$

21.3 Normalización del modelo simplificado 71

\$22. Resultados teóricos y discusión 74

22.1 Programas de simulación $\quad 75$

22.2 Simulación del proceso $\quad 79$

22.2.1 Producción de biomasa $\quad 80$

22.2.2 Consumo de azúcares $\quad 81$ 
22.2.3 Consumo y producción de agua

22.2.5 Producción de bióxido de carbono $\quad 82$

22.2.6 Evolución de la temperatura $\quad 82$

22.2.7 Ocupación de los espacios libres $\quad 84$

Resumen y conclusiones

\section{B. ESTIMACIÓN DE PARÁMETROS Y SENSIBILIDAD}

PARAMÉTRICA DEL MODELO.

\$23. Estrategia de estimación y sensibilidad paramétrica 86

\$24. Resultados experimentales 86

\$25. Estimación de los parámetros $\quad 91$

\$26. Análisis comparativo y sensibilidad paramétrica 93

26.1 Crecimiento celular. Efecto de $\mathrm{m}_{\mathrm{s}}, \mathrm{K}_{\mathrm{s}} \mathrm{y} \mathrm{K}_{\mathrm{i}}$

26.2 Consumo de sustrato. Efecto de $m_{\mathrm{s}}, \mathrm{K}_{\mathrm{s}}$ y $\mathrm{K}_{\mathrm{i}}$

$\begin{array}{ll}\text { Resumen y conclusiones } & 105\end{array}$

C. VALIDACIÓN DE RESULTADOS TEÓRICOS, AJUSTE DE PARÁMETROS Y ESTUDIO DE CASOS

$\begin{array}{ll}\$ 27 . \text { Validación y ajuste con otros resultados } & 107\end{array}$

$\begin{array}{ll}27.1 \text { Caso } 1 & 107\end{array}$

$\begin{array}{ll}27.2 \text { Caso } 2 & 109\end{array}$

$\begin{array}{ll}27.3 \text { Caso } 3 & 109\end{array}$

$\begin{array}{ll}\text { §28. Resumen de los parámetros } & 119\end{array}$

$\begin{array}{lr}\text { Resumen y conclusiones } & 119\end{array}$

\section{PARTE IV. SOLUCIÓN Y VALIDACIÓN DEL MODELO MATEMÁTICO GENERAL EN DOS DIMENSIONES.}

\section{A. DESARROLLO Y SOLUCIÓN DEL MODELO GENERAL.}

\$29. Planteamiento: Un problema de valor inicial y en la frontera 120

$\begin{array}{ll}29.1 \text { Simplificaciones e hipótesis de trabajo } & 120\end{array}$

$\begin{array}{ll}29.2 \text { Condiciones iniciales y en la frontera } & 123\end{array}$

$\begin{array}{ll}29.3 \text { Valores de los parámetros } & 124\end{array}$

$\begin{array}{ll}\S 30 \text { Selección y descripción del método de integración } & 125\end{array}$

30.1 Discretización del dominio de integración 126

30.2 Aproximación de las derivadas parciales $\quad 126$

30.3 Selección del esquema de integración 129

§31. Solución del modelo por el método de diferencias finitas 133

$\begin{array}{ll}31.1 \text { Estrategia de la solución } & 133\end{array}$

31.2 Discretización de las derivadas parciales $\quad 134$

31.3 Discretización del modelo 135

31.4 Discretización de los puntos interiores de integración 138

31.5 Discretización de las condiciones en la frontera 139 
§32 Programas de simulación

Resumen y conclusiones

B. VALIDACIÓN DEL MODELO GENERAL

$\S 33$ Producción de biomasa

$\S 34$ Consumo de azúcares

149

$\$ 35$ Consumo de oxígeno

151

\$36 Producción de bióxido de carbono

154

\$37 Evolución de la temperatura

158

Resumen y conclusiones

160

CONCLUSIONES GENERALES

162

REFERENCIAS BIBLIOGRÁFICAS

163

ANEXO I. Convenciones adoptadas en los índices y notaciones especiales

170

ANEXO II. Deducción de una función para $\rho_{\mathrm{v}}(\mathrm{T})$

172

ANEXO III. Deducción de una función para $\rho_{x M a x}$ que relaciona espacios vacios

174

ANEXO IV Listado de los programas de cálculo para el modelo simplificado

176

ANEXO V Listado de los programas de cálculo para el modelo general en dos dimensiones

185 
PARA PILA, MARIANO $Y$ ANDREA FOR EL AMOR Y LA PACIENCIA 



\section{AGRADECIMIENTOS}

Este trabajo se realizó en la Planta Piloto de Fermentación Sólida del Departamento de Biotecnología (DCBS) de la Universidad Autónoma Metropolitana-Iztapalapa (UAM-I). Bajo la dirección del Dr. Sergio Revah Moissev del Departamento de Ingeniería de Procesos e Hidráulica (DCBI) de la UAM-I y del Dr. Richard Auria del Institut Français de Recherche Scientifique pour le Developpement en Coopération (ORSTOM), Francia. Con el apoyo económico de la UAM-I y el Consejo Nacional de Ciencia y Tecnología (CONACyT).

Una parte del trabajo se realizó en el Laboratoire de Génie Civil, Université de Montpellier II, Francia, bajo la dirección del Dr. Jean-Claude Benet. Con el apoyo económico de la AUPELFUREF y ia ORSTOM, ambos de Francia.

A Sergio, Richard y Jean-Claude deseo expresarles un particular agradecimiento por haber aceptado dirigir la tesis e incursionar conmigo en el interesante campo de las ideas y la interdisciplina que representa este trabajo.

Un especial agradecimiento al Dr. Ernesto Favela Torres por la lectura minuciosa de este documento, por sus comentarios y críticas siempre constructivas $y$, por supuesto, por la amistad y el apoyo incondicional. Un amplio agradecimiento a los Doctores Sevastianos Roussos, Maurice Raimbault de la (ORSTOM) y Gustavo Viniegra González de la UAM-I por las discusiones y consejos siempre enriquecedores. A mis compañeros de la Planta Piloto de Fermentación Sólida, Doctores Gerardo Saucedo Castañeda y Sergio Huerta Ochoa, por la amistad y apoyo de siempre. A Rafael Maya por su auxilio y paciencia en la aplicación de algunos métodos numéricos. A mis estudiantes de la maestría en Biotecnología y a los de la carrera de Ingeniería Bioquímica Industrial de la UAM-I, a todos ellos gracias 



\section{RESUMEN}

En el campo de las fermentaciones en medios sólidos (FMS), los soportes inertes se utilizan como medios experimentales ideales en los que se absorben medios de cultivo específicos. En estos medios ideales, los microorganismos utilizan el agua y los nutrientes que contiene el soporte y colonizan las superficies disponibles para producir metabolitos de interés comercial. La utilización de soportes inertes de forma regular también resulta interesante como un medio ideal para la elaboración de modelos matemáticos

En este trabajo, se desarrolló la formulación, solución y validación de un modelo matemático que describe el crecimiento de un hongo filamentoso sobre el lecho empacado de un soporte inerte de forma esférica regular.

Para la formulación del modelo, se utilizó un enfoque fenomenológico local en un sistema constituido por un medio poroso heterogéneo o sopurte inerte que contiene agua y nutrientes en su interior. En la superficie de este medio poroso los microorganismos crecen intercambiando materia con la fase líquida del interior del soporte y, con la fase gaseosa continua que los rodea.

Con base en un conjunto de hipótesis, se desarrolló un modelo general constituido por seis variables de estado: (i) biomasa, (ii) azúcares solubles, (iii) agua, (iv) oxígeno, (v) bióxido de carbono, y (vi) temperatura del medio. El comportamiento de cada variable de estado, en el tiempo y en el espacio, se obtiene a partir de los balances de masa, los balances de energía interna y las relaciones cinéticas correspondientes. El modelo general quedó constituido por. (i) seis ecuaciones diferenciales parciales, seis condiciones iniciales y cinco condiciones frontera, (ii) 13 ecuaciones algebraicas asociadas a los balances y las relaciones cinéticas y, (iii) 43 parámetros que incluyen constantes fisicas, biológicas y las condiciones de operación particulares

La solución del modelo general se realizó resolviendo dos niveles de complejidad:

1. En el primer nivel, el modelo se transformó sólo dependiente del tiempo. Esta simplificación permitió reducir el modelo general hasta un modelo constituido por: (i) seis ecuaciones diferenciales ordinarias y seis condiciones iniciales, (ii) 13 ecuaciones algebraicas y, (iii) 36 parámetros. Los parámetros se estimaron en función de las características fisicas de los constituyentes, de una reacción estequiométrica de transformación de azúcares en biomasa y de las condiciones particulares de operación. El modelo se transformó a coordenadas cilíndricas, se adimensionalizó y se resolvió con el algoritmo de integración de Runge-Kutta de cuarto orden.

2. En el segundo nivel de complejidad, el modelo se conservó en su forma general i.e. dependiente del tiempo y del espacio. En este caso, se utilizaron los mismos valores de los parámetros encontrados para el modelo simplificado y se propusieron valores para los parámetros restantes. 

El modelo se transformó a coordenadas cilíndricas, se normalizó y se resolvió por el método de diferencias finitas, utilizando una estrategia de integración explícita en el tiempo, explícita en la coordenada axial e implícita en la coordenada radial.

Los resultados cualitativos y cuantitativos del modelo, en sus dos niveles de complejidad, mostraron congruencia con los principios físicos y biológicos en los que se fundamentó el modelo.

Para la validación y el ajuste, se utilizó el modelo en su forma simplificada. Se compararon las predicciones con resultados de experimentos realizados en pequeños reactores de lecho empacado, en escala de laboratorio y bajo diferentes condiciones de operación, incluyendo concentraciones crecientes de azúcares. Se encontró que los parámetros que afectan de manera clara las cinéticas de crecimiento celular y consumo de sustrato son los siguientes: (i) los rendimientos base producción de biomasa $\left(Y_{i}\right)$, (ii) el coeficiente de mantenimiento $\left(m_{s}\right)$, (iii) el coeficiente de afinidad por el sustrato $\left(\mathrm{K}_{\mathrm{s}}\right) \mathrm{y}$, (iv) el coeficiente de inhibición por el sustrato $\left(\mathrm{K}_{\mathrm{i}}\right)$. Se demostró que estos parámetros biológicos, no podían considerarse constantes y que debían cambiar con el tiempo de fermentación, i.e. con respecto a alguna variable de estado como los azúcares en el medio. También se demostró que, para ajustar satisfactoriamente los resultados experimentales, sería necesario incorporar diferentes valores en los parámetros cinéticos, tanto para el caso del crecimiento, como para el consumo de los azúcares, particularmente los parámetros $\mathrm{K}_{\mathrm{s}} \mathrm{y} \mathrm{m}_{\mathrm{s}}$. Por lo tanto, al tratar de ajustar los resultados del modelo, se encontró que el problema tenía múltiples soluciones. Para resolver este problema se utilizó una función que permitió asociar los rendimientos de biomasa $\mathrm{Y}_{\mathrm{i}}$ con los azúcares del medio. Esta función permitió emplear valores constantes de los tres parámetros $\mathrm{K}_{\mathrm{i}}, \mathrm{K}_{\mathrm{s}}$ y $\mathrm{m}_{\mathrm{s}}$ con ajustes satisfactorios a los resultados experimentales.

Prácticamente en todos los casos en los que se trató de validar el modelo con altas concentraciones iniciales de azúcares se observó, que se requiere incluir en el modelo al menos un término de formación de producto que justifique el crecimiento celular con el consumo de azúcares, el consumo de oxígeno, y la producción de bióxido de carbono y calor metabólico.

El modelo simplificado que se propone, es un simulador flexible de rápida respuesta, con un aceptable grado de fidelidad con los resultados experimentales. Es un modelo que puede contribuir: (i) a la explicación de aspectos físicos y fisiológicos del fenómeno global estudiado, (ii) al desarrollo de las estrategias de operación de biorreactores para otros cultivos en FMS, (iii) a establecer bases para el diseño, control y escalamiento de biorreactores y, (iv) al desarrollo de nuevos modelos más complejos, como es el caso de modelos que consideren los aspectos difusivos de los nutrientes y de los productos. 



\section{ABSTRACT}

In the solid state fermentation (SSF) field, inert supports are ideal experimental media in which specific culture media can be absorbed. In these ideal media, the microorganisms use the water and nutrients contained inside the support and colonize available surfaces producing commercial metabolites. Inert supports in a regular shape presentation are also particularly interesting as an ideal media in developing mathematical models.

In this work a mathematical model dealing with the growth of filamentous fungi on a packed bed of regular spherical shape inert support is developed, solved, and verified.

To develop the model, a local phenomenological approach for a system constituted by a porous heterogeneous medium or inert support containing water and nutrients is considered. Cell growth takes place on the surface of porous medium and microorganisms exchange mass with liquid phase, within the support, and with the surrounding continuos gaseous phase. The general model deals with six state-variables: (i) biomass, (ii) sugar, (iii) water, (iv) oxygen, (iv) carbon dioxide, and ( $v$ ) medium temperature; a set of hypotheses was taken account. The dynamic and spatial behavior of each state variable is derived from correspondent kinetics and mass and energy balances. The proposed general model involves: (i) six partial differential equations, six initial, and five boundary conditions, (ii) 13 kinetic and balances associated algebraic equations, and (iii) 43 parameters including physical and biological constants and the particular operation conditions.

In order to solve such a general model, two complexity levels were approached:

1. In the first level, the general model was simplified to an only time-dependent model. This simplification reduced the model to (i) six ordinary differential equation and six initial conditions, (ii) 13 algebraic equations, and (iii) 36 parameters. All parameters were estimated as a function of the physical characteristics of each constituent, the particular operation conditions, and a stoichiometrical reaction which transforms sugars into biomass. The model, in a cylindrical coordinate system, and in a normalized form was solved by using the fourth order Runge-Kutta numerical integration algorithm.

2. In the second level, the general model was retained as time and space-dependent. In this level, same values for parameters found in the simplified model were used and for the rest of parameters new values were searched. The model, in a cylindrical coordinate system, and in a normalized form was solved by using the finite differences method, in which an explicit in time, explicit in the axial ordinate, and implicit in the radial ordinate strategy was used.

Qualitative and quantitative results, in all of the two approaches, showed a good agreement with the physical and biological principles that encouraged the model. 

To validate and fit results the simplified model was used. Model predictions were compared to experimental results obtained under different operation conditions (increasing initial sugar concentrations were also included) by using small packed bed reactors at laboratory scale. It was found that sugar consumption and cell growth were clearly influenced by the following parameters (i) the biomass yields $\left(\mathrm{Y}_{\mathrm{i}}\right)$, (ii) the maintenance coefficient $\left(\mathrm{m}_{\mathrm{s}}\right)$, (iii) the affinity substrate cefficient $\left(\mathrm{K}_{\mathrm{s}}\right)$, and (iv) the inhibition constant $\left(\mathrm{K}_{\mathrm{i}}\right)$. It was shown that these biological parameters could not be considered as a constants but variables as a function of fermentation time, i.e. as a function of any state variable such as sugar in the medium. In order to fit experimental satisfactorily, it was shown that should be necessary to include different values for the kinetic parameters to fit cell growth and different values to fit sugar consumption, particularly in the cases of $\mathrm{K}_{\mathrm{s}}$ and $\mathrm{m}_{\mathrm{s}}$. Therefore, when trying to fit results always a multiple solutions problem was emerged. To solve such a problem the yields $Y_{i}$, were explicited as a function of sugar in the medium. The introduction of the $Y_{i}$ function in the model allowed to keep constant values for the rest of biological parameters producing satisfactory fittings.

In order to justify simulated cell growth patterns with, sugar and oxygen consumption, carbon dioxide, and metabolic heat evolution, it was shown, practically in all assayed cases in which high initial sugar concentration was used, that a product formation term is required in the model.

The proposed simplified model can be regarded as a flexible quick-response simulator with an acceptable accuracy to experimental data. Furthermore, the model could be a helpful simulation tool in: (i) explaining physical and physiological aspects involved in the studied phenomenon, (ii) developing the suitable bioreactor operating strategies for any other SSF culture, (iii) Setting up bases to the design, control and scale-up of bioreactors, and (iv) developing more complex models such as diffusive models. 


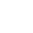




\section{NO'TACIÓN EMPLEADA}

Índices de los constituyentes y las fases:

a: Constituyente de la fase sólida.

c: Constituyente bióxido de carbono.

e: Constituyente agua.

$\mathrm{g}:$ Fase gaseosa.

i. $\quad$ Constituyente cualquiera.

f: $\quad$ Fase liquida.

N: Constituyente nitrógeno.

s: Constituyente sacarosa.

0 : Constituyente oxígeno.

ps: Conjunto de la fase estática.

$\mathrm{v}$ : Constituyente vapor de agua.

$\mathrm{x}$ : Constituyente de la fase biológica.

Literales:

$\mathrm{A}_{1}$ : Parámetro de la ecuación (16-1), $\mathrm{h}^{-1}$.

$\mathrm{A}_{2}$ : Parámetro de la ecuación (16-1), adimensional.

A3: Parámetro de la ecuación (27-1), adimensional.

$\mathrm{C}_{\mathrm{i}}$ : Tasa volumétrica de transformación de i por concepto de reacción, $\left(\mathrm{kg}\right.$ de i) $\mathrm{m}^{-3} \mathrm{~s}^{-1}$.

$\mathfrak{c}_{\mathrm{i}}$ : Calor másico de la fase o constituyente $\mathrm{i}$ a presión o volumen constante, $\mathrm{J}(\mathrm{kg} \text { de i K})^{-1}$.

$\mathrm{C}_{\mathrm{x} \text { Max }}$ Tasa máxima de producción de biomasa, $\mathrm{s}^{-1}$.

$\mathrm{E}_{\mathrm{a} 1}$ : $\quad$ Energía de activación de la biomasa, $\mathrm{J}$ (mol biomasa) ${ }^{-1}$.

$\mathrm{E}_{\mathrm{a} 2}$ : Energía de inactivación de la biomasa, $\mathrm{J}$ (mol biomasa) ${ }^{-1}$.

$\mathrm{fm}_{\mathrm{i}}$ : Fracción mol de $\mathrm{i}$ en la fase gaseosa, mol de $\mathrm{i}$ (mol de fase gaseosa, base seca $)^{-1}$.

$\mathrm{fp}_{\mathrm{i}}$ : Fracción en peso del constituyente i en la fase gaseosa,

$\mathrm{kg}$ de $\mathrm{i}\left(\mathrm{kg}\right.$ de fase gaseosa base húmeda) ${ }^{-1}$.

$\mathrm{G}$ : $\quad$ Masa velocidad de la fase gaseosa, $\mathrm{kg}$ aire $\left(\mathrm{m}^{2} \mathrm{~s}\right)^{-1}$.

hci: Coeficiente interno de transferencia de calor convectivo, $J\left(\mathrm{~m}^{2} \mathrm{~s} \mathrm{~K}\right)^{-1}$.

hco: Coeficiente externo de transferencia de calor convectivo, $\mathrm{J}\left(\mathrm{m}^{2} \mathrm{~s} \mathrm{~K}\right)^{-1}$.

$\mathrm{h}_{\mathrm{i}}$ : Calor de formación o transformación, del constituyente $\mathrm{i}, \mathrm{J}(\mathrm{kg} \text { seco de } \mathrm{i})^{-1}$.

$\mathrm{H}$ : Humedad absoluta del aire de la alimentación, $\mathrm{kg}$ agua ( $\mathrm{kg}$ aire seco $)^{-1}$.

$\mathrm{H}_{\mathrm{r}}$ : Humedad relativa del aire de la alimentación, (\%).

$\mathrm{J}_{\mathrm{qi}}{ }^{k}: \quad$ Flux de calor conductivo a través del constituyente $\mathrm{i}, \mathrm{J}\left(\mathrm{m}^{2} \mathrm{~s}\right)^{-1}$. 
$\mathrm{K}_{\mathrm{i}}$ : Constante de inhibición por sustrato, $\mathrm{kg}$ de azúcar $\mathrm{m}^{-3}$.

$\mathrm{K}_{\mathrm{s}}$ : Constante de afinidad por el azúcar, $\mathrm{kg}$ de azúcar $\mathrm{m}^{-3}$.

$\mathrm{k}_{\mathrm{v}}$ : $\quad$ Conductividad térmica del vidrio, $\mathrm{J}(\mathrm{m} \mathrm{s} \mathrm{K})^{-1}$.

L: $\quad$ Altura del biorreactor, $\mathrm{m}$.

$\mathrm{L}(\mathrm{T})$ : Calor latente de vaporización del agua, $\mathrm{J}$ ( $\mathrm{kg}$ vapor $)^{-1}$.

$\mathrm{m}_{\mathrm{o}}$ : Coeficiente de mantenimiento de oxígeno, $\left(\mathrm{kg}\right.$ de oxígeno) ( $\mathrm{kg}$ de biomasa húmeda)-1 $\mathrm{s}^{-1}$.

$\mathrm{m}_{\mathrm{s}}$ : Coeficiente de mantenimiento del azúcar, ( $\mathrm{kg}$ azúcar) ( $\mathrm{kg}$ de biomasa húmeda $)^{-1} \mathrm{~s}^{-1}$.

$\mathrm{PM}_{\mathrm{i}}$ : Peso molecular de i, $\left(\mathrm{kg}\right.$ de i) $(\mathrm{mol} \mathrm{de} \mathrm{i})^{-1}$.

P: Presión absoluta de operación, Pa.

$\mathrm{P}_{\mathrm{O}}$ : Presión al estado de referencia, $\mathrm{Pa}$.

$\mathrm{p}_{\mathrm{e}}^{*}$ : Presión de vapor del agua, $\mathrm{Pa}$.

$\mathrm{R}$ : Constante universal de los gases perfectos, $\mathrm{J}(\mathrm{mol} \mathrm{K})^{-1}$.

Ra: Radio del biorreactor, $\mathrm{m}$.

$\mathrm{R}_{\mathrm{cp}}$ : Máximo crecimiento superficial, ( $\mathrm{kg}$ biomasa húmeda) $\left(\mathrm{m}^{2} \text { de soporte inerte) }\right)^{-1}$.

$\mathrm{S}_{0}$ : Superficie especifica disponible de soporte a $t=0,\left(\mathrm{~m}^{2}\right.$ de soporte inerte $)\left(\mathrm{m}^{3} \text { de VER }\right)^{-1}$.

tf: Tiempo de referencia, durante la fermentación, $s$.

T: $\quad$ Temperatura, $\mathbf{K}$.

$\mathrm{T}_{\text {air }}$ : Temperatura del aire de alimentación, $\mathrm{K}$.

$T_{0}$ : Temperatura en el estado de referencia, $\mathrm{K}$.

$\mathrm{T}_{\text {in }}$ : Temperatura máxima permitida, constante, $\mathrm{K}$.

$T_{j}$ : Temperatura de la chaqueta del biorreactor, $K$.

$T_{p}: \quad$ Temperatura promedio entre $T_{\text {air }}$ y $T_{j}, K$.

$\mathrm{T}_{, \mathrm{k}}$ : Gradiente de Temperaturas, $\mathrm{K} \mathrm{m}^{-1}$.

$\mathrm{u}_{\mathrm{i}}$ : Energía interna másica del constituyente $\mathrm{i}, \mathrm{J}(\mathrm{kg} \text { de } \mathrm{i})^{-1}$.

$\hat{\mathrm{u}}_{\mathrm{i}} \quad$ Tasa volumétrica de aporte de calor al constituyente i proveniente de los otros constituyentes, $\mathrm{J} \mathrm{m}^{-3} \mathrm{~s}^{-1}$.

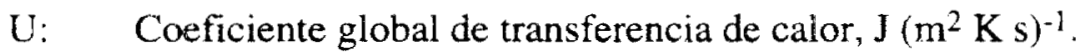

$\mathrm{v}_{\mathrm{i}}^{\mathrm{x}}$ : Velocidad fenomenológica del constituyente o la fase i en la dirección $\mathrm{x}, \mathrm{m} \mathrm{s}^{-1}$.

$\mathrm{v}_{\mathrm{g}}$ : Velocidad de la fase gaseosa, $\mathrm{m} \mathrm{s}^{-1}$.

W: Una función cualquiera del tiempo y de las coordenadas radial y axial.

$\mathrm{Y}_{\mathrm{i}}$ : Rendimiento teórico de la especie i en relación a la biomasa producida, ( $\mathrm{kg}$ de biomasa seca) $(\mathrm{kg} \text { de i })^{-1}$.

$\mathrm{Y}_{\mathrm{iMax}}$ : Rendimiento máximo esperado de la especie i en relación a la biomasa producida, ( $\mathrm{kg}$ de biomasa seca) $(\mathrm{kg} \text { de } \mathrm{i})^{-1}$.

$\mathrm{Y}_{\mathrm{p}}$ : Coeficiente estequiométrico de transformación total de azúcares, sólo 
en bióxido de carbono, $\left(\mathrm{kg} \mathrm{CO}_{2}\right)(\mathrm{kg} \text { de azúcar })^{-1}$.

Grupos Adimensionales:

i: Índice adimensional asociado a la coordenada radial.

$\mathrm{j}$ : Índice adimensional asociado a la coordenada axial.

$\mathrm{n}$ : Índice adimensional asociado al tiempo.

$N_{\text {axi }}$ : Grupo axial; ecuación: (29-14).

$N_{g}$ : Grupo que asocia la velocidad de la fase gaseosa con las dimensiones del biorreactor, ecuación (31-13).

$N_{\text {rad }}$ Grupo radial; ecuación: (29-15).

$N_{r e a}:$ Grupo de reacción; ecuación: (29-16).

$r$ : Radio del biorreactor.

$\boldsymbol{t}: \quad$ Tiempo.

T: Temperatura.

$z: \quad$ Altura del biorreactor.

$\rho_{i}: \quad$ Masa volumétrica del componente i.

Literales griegas:

$\delta: \quad$ Espesor de pared del biorreactor, $\mathrm{m}$.

$\varepsilon$ : Porosidad macroscópica o fracción de espacios vacíos, adimensional.

$\varepsilon_{0} \quad$ Porosidad macroscópica o fracción de espacios vacíos inicial, adimensional.

$\lambda$ : Conductividad térmica del conjunto de las fases y constituyentes, $\mathrm{J}\left(\mathrm{m} \mathrm{s} \mathrm{K}^{-1}\right.$.

$\Phi$ : Diámetro promedio de las esferas del soporte inerte, $\mathrm{m}$.

$\mu_{\mathrm{g}}$ : Viscosidad de la fase gaseosa, $\mathrm{kg} \mathrm{m}^{-1} \mathrm{~s}^{-1}$.

ф: Contenido de agua de los microorganismos, $\left(\mathrm{kg}\right.$ de agua)(kg biomasa húmeda) ${ }^{-1}$.

$\eta_{\mathrm{i}}$ : Coeficiente estequiométrico del reactivo o producto $\mathrm{i}$, número de moles de $\mathrm{i}$.

$\rho_{\text {air: }}$ Masa volumétrica real del aire, $(\mathrm{kg}$ de aire $)\left(\mathrm{m}^{3} \mathrm{de} \text { aire }\right)^{-1}$.

$\rho_{\mathrm{i}}$ : $\quad$ Masa volumétrica aparente de $\mathrm{i},\left(\mathrm{kg}\right.$ de i) $\mathrm{m}^{-3}$.

$\rho_{\mathrm{cMax}}$ : Masa volumétrica máxima de bióxido de carbono, ( $\mathrm{kg}$ de bióxido de carbono) $\mathrm{m}^{-3}$.

$\rho_{\mathrm{iMax}}$ : Masa volumétrica máxima aparente de $\mathrm{i},\left(\mathrm{kg}\right.$ de i) $\mathrm{m}^{-3}$.

$\rho_{\mathrm{i}}{ }^{0}$ : Masa volumétrica aparente de $\mathrm{i}$ al tiempo cero, $(\mathrm{kg}$ de i $) \mathrm{m}^{-3}$.

$\rho_{\mathrm{iz}}{ }^{0}$ : Masa volumétrica aparente de i en $\mathrm{z}$ igual a cero, $(\mathrm{kg} \mathrm{de} \mathrm{i}) \mathrm{m}^{-3}$.

$\rho_{\mathrm{i}}{ }^{*}: \quad$ Masa volumétrica real del constituyente o la fase $\mathrm{i},(\mathrm{kg}$ de $\mathrm{i}$, Base húmeda $)\left(\mathrm{m}^{3} \text { de i }\right)^{-1}$.

$\theta$ : coordenada angular en el sistema de coordenadas cilíndricas. 


\section{INTRODUCCIÓN}

Las FMS son cultivos tradicionales que se conocen desde tiempos remotos. Durante los últimos 20 años ha resurgido un claro interés por este tipo de cultivos. Los microorganismos filamentosos son los más estudiados, aunque las levaduras encuentran un espacio cada vez más relevante.

Las ventajas que presentan estos cultivos son muchas y las desventajas se superan cada vez a un ritrno más acelerado. Entre las desventajas que más se mencionan en la literatura especializada destacan la acumulación de calor metabólico y los problemas de transporte asociados que dificultan el diseño, control y escalamiento de biorreactores.

Estas desventajas han propiciado que la aplicación práctica de estos cultivos se haya limitado a sólo algunos ejemplos concretos. En el campo del diseño y escalamiento de los biorreactores, se conocen equipos desarrollados con base en la experiencia práctica, pero poco se conoce acerca de las bases teóricas que pudieran vincular a los fenómenos fundamentales que ocurren con los resultados macroscópicos que se esperan de los equipos. En la mayoría de los casos la acumulación de calor y la naturaleza del sustrato o del soporte, son los dos factores que han orientado el diseño y las estrategias de operación y control de los biorreactores.

Entre las ventajas que caracterizan a este tipo de cultivos, destaca la posibilidad de utilizar sustratos solubles endógenos en concentraciones tan elevadas que en otro tipo de cultivos sería imposible emplear. Esta particularidad de las FMS abre nuevas perspectivas de aplicación directamente asociadas al uso de soportes inertes.

El uso de soportes inertes en el terreno práctico y en el de la investigación es promisorio en tanto que aportan propiedades que mejoran las condiciones de las FMS. Los soportes que más atención han recibido son el bagazo de caña como una aplicación práctica y las resinas de intercambio iónico como un modelo de estudio. El bagazo de caña presenta desventajas que hacen que las resinas de intercambio resulten más atractivas, particularmente como un modelo experimental ideal en el campo de investigación básica y en la elaboración de modelos matemáticos que traten los fenómenos que ocurren en estos cultivos en forma teórica.

Para contribuir a la superación de las desventajas mencionadas aprovechando las ventajas que ofrece el uso de medios experimentales como los soportes inertes, resulta interesante desarrollar un estudio con bases teóricas firmes que incluyan las características físicas de los soportes en tanto medios porosos heterogéneos, las características biológicas de los microorganismos y las características del medio que los rodea. El estudio debe partir de concepciones teóricas bien formuladas y estructuradas y debe concluir en un modelo matemático que permita predecir el comportamiento de las variables que definen el estado del sistema y entender los fenómenos que 
ocurren en los cultivos de FMS. El principal interés por desarrollar este estudio estriba en situarlo dentro de una dimensión que permita extrapolar los resultados hasta las dimensiones microscópicas de los microorganismos o hasta las dimensiones macroscópicas de un biorreactor. Un modelo con estas bases y dimensiones permitiría abordar de manera clara y objetiva aspectos como la comprensión de los fenómenos o el diseño, el control y el escalamiento de biorreactores.

A la fecha poco se ha publicado sobre el modelado matemático en el campo de los cultivos para FMS. Se conocen importantes esfuerzos sobre el tema, pero aparentemente no han sido suficientes. Sin embargo, constituyen un buen punto de partida.

El trabajo esta dividido en cuatro partes. En la primera, se presenta un análisis bibliográfico sobre el tema de las FMS, el uso de soportes inertes y los biorreactores. Se incluye una discusión sobre los modelos matemáticos para las FMS, de donde surgen los objetivos y el alcance del trabajo.

En la segunda parte, se selecciona un sistema de FMS sobre un soporte inerte como modelo de estudio, se define el marco teórico en el que se sitúa el modelado i.e. se propone un conjunto de hipótesis de trabajo, las variables que contiene el modelo y se desarrollan los balances de masa y energía. El modelo se presenta en forma adimensional, en coordenadas cilíndricas y se propone una estrategia global para la solución del modelo general.

En la tercera parte, se proponen nuevas hipótesis que, permiten una simplificación del modelo matemático general. Después de calcular y aproximar valores a los parámetros, el modelo se resuelve y se presenta una discusión sobre los resultados preliminares. Las predicciones del modelo simplificado se comparan con resultados experimentales, se estudian cuatro casos concretos con los que se obtienen ajustes muy aceptables y se decide por un conjunto final de parámetros.

En la cuarta parte, se resuelve el modelo general, en dos dimensiones, utilizando los parámetros encontrados con el modelo simplificado que ajustan mejor los resultados experimentales.

El presente trabajo tiene tres motivaciones fundamentales: (i) una premisa que establece que en la medida que se conozca más sobre los fenómenos detallados que caracterizan a este tipo de cultivos, la probabilidad de aplicación será mayor, (ii) un intento serio para identificar los factores más relevantes que han limitado la formulación y solución de modelos matemáticos en este campo, y (iii) una contribución al conocimiento de los fenómenos detallados que ocurren, a través de un modelo matemático con diferentes niveles de simplificación. 



\section{PARTE I: FERMENTACIÓN EN MEDIOS SÓLIDOS Y EN SOPORTES INERTES, BIORREACTORES Y MODELOS MATEMÁTICOS. OBJETIVOS Y ALCANCES DEL ESTUDIO.}

En la parte I A se presenta una introducción conceptual a los aspectos más generales de las FMS: la importancia práctica de estos sistemas de cultivo, los microorganismos que participan, las variables que controlan estos procesos y las características y propiedades de los soportes inertes. En la Parte I B se presenta una revisión que se centra en los biorreactores para la FMS y a la importancia de modelos matemáticos en el campo del diseño, la simulación de los procesos y el escalamiento de los mismos. Se discuten algunos modelos de crecimiento en superficie, los modelos matemáticos utilizados directamente en las FMS y en medios ideales. En la parte I C se presentan los objetivos y el alcance de este trabajo.

\section{A. FERMENTACIÓN EN MEDIOS SÓLIDOS Y SOPORTES INERTES.}

\section{§1. Definiciones, importancia práctica, usos y aplicaciones.}

En este trabajo, el término fermentación se refiere a la transformación de materiales diversos mediante la utilización de microorganismos. El principal interés por estos sistemas se ha centrado en los productos del metabolismo. En la actualidad se producen, a niveles comerciales, compuestos tales como: antibióticos, hormonas, anticoagulantes, vitaminas y enzimas de interés para la industria farmacéutica; sabores, aromas, enzimas y ácidos orgánicos de interés para la industria alimentaria, entre otros. La lista se puede extender hasta más de 100 productos distintos en producción o estudio. Cerca de un $90 \%$ de estos productos se obtienen en cultivos líquidos, agitados continuamente en donde el agua se encuentra en exceso. La función del agua en estos sistemas de fermentación es:

1. Disolver los nutrientes homogéneamente y facilitar su acceso a las células.

2. Mantener homogéneas las condiciones de los cultivos: $\mathrm{pH}$, temperatura, etc.

3. Disolver los productos del metabolismo (cuando estos se exportan al medio de cultivo) y facilitar su extracción y purificación.

Los cultivos en medios líquidos se han estudiado intensamente, se conoce muy bien la fisiología, la bioquímica celular y los aspectos de ingeniería de los procesos. Sin embargo, el exceso de agua ha originado un buen número de problemas:

1. Grandes volúmenes de operación y las dificultades de espacio inherentes.

2. Obtención de productos diluidos, en donde los costos de separación y extracción llegan a constituir un lugar preponderante en la economía de estos procesos.

3. La cantidad de agua desechada obliga a la instalación de plantas especiales para el tratamiento de los efluentes. 
4. El transporte de masa y calor en los biorreactores se dificulta, no obstante el exceso de agua, cuando se presentan inconvenientes reológicos (los fluidos no newtonianos son muy comunes con hongos filamentosos y ciertas bacterias).

Existen procesos alternativos que permiten conservar las ventajas y minimizar las desventajas. Entre las alternativas más interesantes se encuentran las fermentaciones en medios de cultivo en donde el agua necesaria no se encuentra en exceso. A este tipo de cultivos se le conoce como Fermentaciones en Medios Sólidos (FMS). Las FMS son cultivos que se desarrollan, en su mayoría, en presencia de oxígeno en forma gaseosa y bajo condiciones controladas.

El interés por las FMS en los últimos 20 años ha sido creciente, en al Cuadro 1.1 se presenta la distribución, por año de publicación, de una muestra de 113 trabajos publicados sobre este tema.

\section{CUADRO 1.1. DISTRIBUCIÓN DE UNA MUESTRA DE TRABAJOS PUBLICADOS SOBRE FMS EN LOS ÚLTIMOS 20 AÑOS.}

\begin{tabular}{|c|c|c|}
\hline PERÍODO & $\begin{array}{c}\text { TRABAJOS } \\
\text { PUBLICADOS }\end{array}$ & $\begin{array}{c}\text { DISTRIBUCIÓN } \\
(\%)\end{array}$ \\
\hline $1970-1974$ & 1 & 0.88 \\
\hline $1975-1979$ & 11 & 9.73 \\
\hline $1980-1984$ & 29 & 25.68 \\
\hline $1985-1989$ & 47 & 41.59 \\
\hline $1990-1992$ & 25 & 22.12 \\
\hline TOTAL & 113 & 100 \\
\hline
\end{tabular}

Los microorganismos que se emplean con mayor frecuencia en las FMS son los hongos filamentosos. El análisis de una muestra de la bibliografía de los últimos 20 años sobre el tema indica que cerca del $50 \%$ de los trabajos publicados se realizó con hongos filamentosos (Ver Cuadro 1.2), aunque el interés por las levaduras ( $30 \%$ aprox) y por los actinomicetos (15\% aprox) tambiến es apreciable.

El interés por los hongos filamentosos se debe a que estos microorganismos reúnen una serie de características interesantes para los sistemas de FMS, entre las que destacan: (i) los requerimientos de agua son menores, (ii) la forma y la velocidad con que colonizan las superficies sólidas, (iii) la eficiencia con que transforman los sustratos, (iv) la diversidad de productos que se pueden obtener, y ( $v$ ) la facilidad para conservar y manejar las cepas en su forma esporulada.

Las ventajas que ofrecen las FMS, se han discutido ampliamente en la literatura (Hesseltine, 1972; Alazard y Raimbault, 1981; Saucedo-Castañeda, 1992) y los avances científicos y conocimientos 
acumulados son notables. Sin embargo, los problemas e incógnitas que aún están sin resoiver, se resumen a continuación

1. La regulación del metabolismo celular es diferente que en el caso de los cultivos líquidos (Ramesh y Lonsane, 1991; Solis et al, 1993) y se conoce poco al respecto (Alazard y Raimbault, 1981; Tani et al, 1988; Lonsane et al, 1992; Acuña-Arguelles, 1994b).

2. Los problemas de transferencia de masa (Lonsane et al, 1992), acumulación de calor (Saucedo-Castañeda et al, 1990) son considerables.

3. Por la heterogeneidad de estos cultivos, las variables que controlan estos procesos son dificiles de medir con precisión y no se conocen estrategias generales de control para los biorreactores (Lonsane, 1985; Durand y Chereau, 1988; Pandey, 1992)

4. Debido a que no existen biorreactores comerciales, tanto el diseño como las estrategias para el escalamiento a niveles comerciales, no han sido abordadas con la intensidad deseada (Lonsane et al 1992).

\section{CUADRO 1.2 DISTRIBUCIÓN DEL TIPO DE MICROORGANISMOS ESTUDIADOS EN LOS SISTEMAS DE FMS EN LOS ÚLTIMOS 20 AÑOS.}

\begin{tabular}{|c|c|c|}
\hline $\begin{array}{c}\text { TIPO DE } \\
\text { MICROORGANISMOS }\end{array}$ & $\begin{array}{c}\text { TRABAJOS } \\
\text { PUBLICADOS }\end{array}$ & $\begin{array}{c}\text { DISTRIBUCIÓN } \\
(\%)\end{array}$ \\
\hline Hongos filamentosos & 48 & 49.48 \\
\hline Actinimicetos & 14 & 14.44 \\
\hline Levaduras & 27 & 27.30 \\
\hline Bacterias & 8 & 8.22 \\
\hline T O T A L & 97 & 100 \\
\hline
\end{tabular}

Con el objeto de ejemplificar la importancia práctica de estos sistemas de cultivo, en el Cuadro 1.3 se muestran algunos de los productos de interés industrial que se han estudiado y que se pueden obtener a partir de diferentes sustratos y microorganismos. Los sistemas de FMS del Cuadro 1.3 tienen en común que se desarrollan en presencia de una cantidad mínima de agua. En la naturaleza los procesos biológicos proceden con una cantidad de agua suficiente y muchos sistemas celulares, en su hábitat original, operan con módulos de Thiele cercanos a la unidad (Weiz, 1973) i.e. las limitaciones difusionales y las limitaciones debidas a la reacción son del mismo orden de magnitud. Por lo tanto, es de particular importancia estudiar sistemas biológicos similares a los de la naturaleza (como las FMS) pero fuera de su hábitat natural en donde se esperan eficiencias menores atribuibles a las condiciones artificiales en que se desarrollan Para obtener resultados similares en eficiencia a los que se dan en la naturaleza es importante definir las variables que inciden en la eficiencia de los procesos de FMS. 


\section{CUADRO 1.3 PRODUCTOS DE INTERÉS INDUSTRIAL ESTUDIADOS EN DIFERENTES SISTEMAS DE FMS.}

\begin{tabular}{|c|c|c|c|}
\hline MICROORGANISMOS & SUSTRATOS & PRODUCTOS & REFERENCIAS \\
\hline Aspergillus niger & $\begin{array}{c}\text { Pulpa de café y } \\
\text { BC }\end{array}$ & Pectinasas & $\begin{array}{l}\text { Favela et al, 1990; Huerta et } \\
\text { al, 1994; Boccas et al, } 1994\end{array}$ \\
\hline Aspergillus niger & $\begin{array}{c}\mathrm{BC}, \text { glucosa } \mathrm{y} \\
\text { pectina }\end{array}$ & Pectinasas & $\begin{array}{l}\text { Solís et al, 1993; Acuña- } \\
\text { Arguielles et al 1994b }\end{array}$ \\
\hline Aspergillus niger & $\begin{array}{l}\text { Residuos de } \\
\text { manzana }\end{array}$ & Ácido cítrico & Hang y Woodams, 1987 \\
\hline Aspergillus niger & $\begin{array}{l}\text { Yuca, plátano, } \\
\text { Amberlita }\end{array}$ & Biomasa & $\begin{array}{l}\text { Raimbault, 1980; Auria et al } \\
1990\end{array}$ \\
\hline Aspergillus niger & Yuca & Amilasas & Oriol et al, $1988 \mathrm{~b}$ \\
\hline Aspergillus therreus & BC y melazas & Biomasa & González-Blanco et al, 1990 \\
\hline Giberella fujikuroi & $\begin{array}{c}\text { Centeno y } \\
\text { almidón soluble }\end{array}$ & Ácido giberélico & Kumar y Lonsane, 1987 \\
\hline Neurospora crassa & Paja de trigo & $\beta$-Glucosidasa & Macris et al 1987 \\
\hline Penicillium chrysogenum & BC y sacarosa & Penicilina G & Barrios-González et al, 1993 \\
\hline Penicillium roqueforti & $\mathrm{CL}$ & Aromas & Revah y Lebault, 1989 \\
\hline Rhizopus arrhizus & Yuca & Biomasa & Soccol et al 1993 \\
\hline Trichoderma harzianum & BC y glucosa & Celulasas, esporas & Roussos et al, 1991; 1992 \\
\hline Candida utilis & $\begin{array}{l}\mathrm{BC} \text {, salvado de } \\
\text { trigo, Amberlita }\end{array}$ & Biomasa & Christen et al 1993 \\
\hline Schwanniomyces castellii & BC y almidón & Biomasa, etanol & Saucedo et al 1992 \\
\hline Bacillus licheniformis & Centeno & $\alpha$-Amilasas & Ramesh y Lonsane, 1991 \\
\hline
\end{tabular}


\$2. Variables que inciden en los procesos.

La lista de variables es vasta, en general se aceptan las siguientes: (i) la composición y el pH de los medios de cultivo; (ii) el tamaño y las condiciones fisiológicas del inoculo; (iii) la humedad inicial del material a transformar y la cantidad de agua disponible durante el proceso; (iv) la cantidad, humedad y temperatura del aire; (v) las propiedades físicas del material a transformar i.e. espacios vacíos disponibles, capacidad de retención de agua, capacidad calorífica, y conductividad térmica, entre otras; (vi) la proporción de gases presente en el cultivo; y (vii) la acumulación de metabolitos.

Ante la gran cantidad de variables que se han estudiado, es difícil precisar el peso específico de unas con respecto a otras. Para poder ponderar variables sería necesario definir los objetivos de un proceso particular. A continuación se presenta una breve discusión del efecto que tienen las variables: humedad del medio y el agua disponible, las propiedades físicas del medio, la temperatura y la acumulación de calor en diferentes sistemas de FMS.

\subsection{Humedad del medio y actividad de agua.}

Los materiales que se utilizan en las FMS deben contener una humedad inicial que fluctúa entre 0.30 y $0.8 \mathrm{~kg}$ de agua $\mathrm{kg}^{-1}$ de material húmedo. El agua contenida cumple con una función distinta a medida que el proceso se lleva a cabo, se puede decir que el agua: (i) contiene a los nutrientes solubles en forma solvatada, (ii) hidrata las esporas, en el caso de los hongos filamentosos, y promueve la germinación, (iii) transporta nutrientes a las células desde la fase sólida, aquí el agua se incorpora al micelio como agua de reacción definida estequiométricamente, (iv) disuelve el oxígeno desde la fase gaseosa y lo incorpora a las células en forma soluble, y (v) disuelve los metabolitos producidos y es vehículo para la exportación de compuestos extra celulares.

En términos prácticos la carencia de agua disponible para las células se refleja en los rendimientos, de biomasa y la formación de productos (e.g. ácido cítrico), así como en el tiempo de germinación de las esporas y en la tasa máxima de crecimiento celular. Rodríguez et al, (1986) encontraron que la humedad inicial de residuos de cítricos incide de manera determinante en la formación de biomasa con $A$. niger, que una variación mínima de $6.6 \%$ en humedad incrementa hasta en un $30 \%$ la biomasa. Hang y Woodams (1987), con dos cepas de A. niger en residuos de manzanas encontraron que la humedad del medio afecta los rendimientos finales de ácido cítrico, los autores demostraron que cuando la humedad inicial disminuye de 65 a $45 \%$, los rendimientos disminuyen hasta en un $25 \%$, en presencia de metanol (3\%). Por otro lado, con yuca pregelatinizada y $A$. niger, Raimbault (1980) encuentra que el crecimiento celular se detiene, aún cuando el microorganismo dispone de un $30 \%$ de los azúcares iniciales. El autor atribuye este fenómeno a la 
falta de agua disponible aún cuando el contenido de humedad del sistema medio-micelio es superior cuando la FMS termina.

Para algunos autores (Narahara et al, 1982; Oriol et al, 1988a), la humedad del medio se debe distinguir de la actividad de agua (Aw) del medio. Aunque existe una dependencia clara de la Aw con la humedad del medio, se supone que mientras la humedad refleja el contenido total de agua disponible y no disponible, la Aw refleja sólo la disponible ya que es la que se encuentra en equilibrio con su entorno gaseoso, a esta agua se le considera disponible para el metabolismo.

Oriol et al, (1988a) estudiaron el efecto de diferentes valores de Aw (desde 0.98 hasta 0.86 , aumentando la concentración de glucosa en la fase líquida desde 37 hasta $477 \mathrm{~g} \mathrm{l}^{-1}$ ) sobre el tiempo de germinación y la tasa máxima de crecimiento de A. niger. Los autores encontraron que al disminuir la Aw, el tiempo de germinación aumenta (de 3 a 17 horas) y que la tasa máxima de crecimiento disminuye hasta un tercio en el rango mencionado de Aw.

Los trabajos de Oriol et al, (1988a y 1988b) y otros en el mismo sentido (Gervais et al, 1988) han motivado un nuevo interés por los cultivos en medio sólido i.e. la posibilidad de cultivar microorganismos bajo condiciones extremas de Aw propiciadas, en este caso, por elevadas concentraciones de azúcares que con cultivos sumergidos serían prohibitivas resulta muy interesante. Particularmente en la síntesis de metabolitos de interés comercial como lo demuestran Solís et al, (1993) en la síntesis de pectinasas utilizando elevadas concentraciones de glucosa y de sacarosa. Recientemente Acuña-Argüelles et al, (1994a) demostraron que cuando A. niger crece en FMS bajo diferentes condiciones de Aw (desde 0.98 hasta 0.90 con la adición de etilen glicol, como depresor de la $\mathrm{Aw}$ ), la proporción de enzimas pectinolíticas sintetizadas varía de manera considerable. Posiblemente debido a problemas de transporte de la fuente de carbono con las bajas Aw.

En las FMS el agua es escasa, por definición, desde un principio y si a esta particularidad se le suma la necesidad de incorporar aire en continuo, el riesgo de deshidratación esta siempre presente. Por lo tanto es prácticamente obligatorio incorporar siempre agua exógena. Para incorporar agua a los medios de cultivo para FMS, se han propuesto diversas estrategias tales como:

1 Humidificación del medio a través de la humedad del aire que se alimenta en continuo (Sato et al, 1982; Narahara et al, 1984; Sargantanis et al, 1993)

2 Adición directa de agua en sistemas con agitación (Prebois et al, 1984; Huerta-Ochoa et al, 1986; Durand y Chereau; 1988)

3 Incorporación de soportes inertes con alta capacidad de retención de agua (Oriol et al, 1988b; Raimbault et al, 1989; Huerta-Ochoa et al, 1994)

La incorporación de soportes inertes resulta la menos costosa y la más fácil de manejar. Las ventajas del uso de soportes inertes no se limita a mejorar la captación de agua para el medio 
sólido sino que también incide de manera positiva en las propiedades físicas del medio en su conjunto.

\subsection{Propiedades físicas de los materiales a transformar.}

Las propiedades físicas de los medios sólidos que mayor incidencia tienen en la eficiencia de las FMS, son: (i) capacidad de retención de agua, (ii) superficie y el espacio disponible para el crecimiento celular i.e. tamaño de partícula, geometría y compactación del soporte, y (iii) capacidad calorífica y conductividad térmica.

La capacidad de retención de agua de un material depende de su naturaleza y del tratamiento. En el Cuadro 2.1 se muestra la composición aproximada de los materiales que más se utilizan como sustratos, los materiales son heterogéneos constituidos por tres fases: (i) una líquida que contiene nutrientes y metabolitos disueltos y disponibles; (ii) una sólida constituida por una matriz porosa que contiene a la fase líquida, y (iii) una fase gaseosa, en continuo cambio, constituida por gases producidos, gases que se consumen y vapor de agua. Asociados a las fases sólida y líquida, los microorganismos que constituyen una cuarta fase independiente (Gutiérrez-Rojas, 1991; Auria et al, 1993).

\section{CUADRO 2.1. COMPOSICIÓN ${ }^{1}$ DE MATERIALES AGROINDUSTRIALES.}

\begin{tabular}{|c|c|c|c|c|c|c|}
\hline MATERIAL & CELULOSA & LIGNINA & ALMIDÓN & NITRÓGENO & CENIZAS & REFERENCIAS \\
\hline $\begin{array}{c}\text { Bagazo, Caña } \\
\text { (médula) }\end{array}$ & 41.2 & 21.7 & ND & TR & 5.5 & López R. (1989) \\
\hline $\begin{array}{c}\text { Bagazo, Caña } \\
\text { (cachaza) }\end{array}$ & 15 & 6.5 & ND & 2.4 & 10.0 & López R. (1989) \\
\hline Pulpa, café & 15.5 & 3.7 & ND & 1.3 & 8.2 & Zuluoaga (1989) \\
\hline Cascarilla, arroz & 35.6 & 8.5 & ND & TR & 17.3 & López R. (1989) \\
\hline Sémola, maíz & 1.3 & ND & 78.2 & 1.12 & 1.7 & $\begin{array}{c}\text { Sargantanis et al, } \\
1993\end{array}$ \\
\hline Harina, yuca & TR & ND & 90 & 0.4 & 3.5 & Raimbault (1980) \\
\hline
\end{tabular}

${ }^{1}$ La composición se expresa en porciento, base seca.

2 Como se obtiene en la industria

NR: No reportado

ND: No disponible

TR: Trazas

Las propiedades físicas de estos medios se pueden estudiar desde dos puntos de vista: uno macroscópico en donde estas propiedades dependen directamente de la proporción de cada una 
de las fases presentes y otro microscópico que es función de la naturaleza y composición de cada una de las fases.

En relación al enfoque macroscópico, utilizando una resina de intercambio iónico como soporte inerte, se han estudiado propiedades tales como: (i) la porosidad interparticular del medio, a través de la determinación continua de la caída de presión, (Auria et al, 1990, 1993) y (ii) el intercambio gaseoso, a través de la determinación de los coeficientes efectivos de difusión de bióxido de carbono y oxígeno (Auria et al, 1992). En estos estudios se ha encontrado una buena correlación entre la biomasa presente y las propiedades estudiadas.

En relación al enfoque microscópico, se conocen pocos trabajos. Esto se debe a la dificultad inherente a la medición continua de propiedades que varían en el transcurso de la fermentación, algunas son: la conductividad térmica, la difusividad de un compuesto en un medio determinado, la capacidad calorífica. Hasta ahora estas propiedades se estiman en función de la composición aproximada del medio. Por ejemplo, Sargantanis et al, (1993) estiman la capacidad calorífica de sémola de maíz precocida en donde crece Rizhopus oligosporus en función de las variaciones de la materia seca y del contenido de agua en el medio.

Las propiedades físicas, sean macroscópicas o microscópicas, están siempre asociadas a los fenómenos de transporte que ocurren en estos procesos, de aquí la importancia del conocimiento, de la medición y, sobre todo, de la interacción mutua de estas variables.

\subsection{Temperatura y acumulación de calor.}

La temperatura es una de las variables que más inciden en la eficiencia de los procesos de FMS. Mucho se ha documentado respecto al calor que se genera como producto de la actividad microbiana o calor metabólico (Finger et al, 1976; Raimbault, 1980; Rathbun y Shuler, 1983; Narahara et al, 1984; Saucedo-Castañeda et al, 1990; Sargantanis et al, 1993). La acumulación de calor se debe a las concentraciones elevadas de sustrato y microorganismos, al bajo contenido en agua, a la ausencia de mezclado en las FMS estáticas así como a la baja conductividad térmica de los materiales biológicos (Moo-Young et al, 1983; Grajek, 1988; Barstow et al, 1988; Saucedo-Castañeda, 1990; González-Blanco et al, 1990). Cuando el calor metabólico se acumula favorece tres aspectos negativos que se pueden cuantificar: (i) la actividad microbiana se desacelera o se detiene; (ii) deshidrata el medio sólido y (iii) el metabolismo se desvía como un mecanismo de defensa ante el calor o ante la deshidratación. El exceso de calor se ha tratado de controlar utilizando métodos de remoción convencionales y recientemente los llamados no convencionales. 
Los métodos convencionales incluyen la remoción de calor vía conducción y vía convección forzada. Se ha demostrado que los primeros no son tan efectivos como los segundos (SaucedoCastañeda et al, 1990). Los métodos de remoción de calor convectivo, para ser efectivos, requieren de elevadas tasas de aireación (Rathbun y Shuler, 1983) que, con frecuencia, deshidratan el medio.

Los métodos no convencionales se refieren a la utilización del calor latente de vaporización del agua para eliminar el calor metabólico de manera rápida y efectiva (Barstow et al 1988), que incluye la incorporación de aire saturado parcialmente y a baja temperatura. Se ha demostrado la efectividad del método utilizando un reactor giratorio de laboratorio (Ryoo et al 1991) con sémola de maíz como substrato y $R$. oligosporus como microorganismo filamentoso. Recientemente, con el mismo equipo, Sargantanis et al (1993) lograron demostrar que el enfriamiento del medio aprovechando la evaporación de agua es el método más eficiente y que la modificación de los coeficientes de transferencia de calor y las tasas de aireación tienen un fuerte efecto en la morfología de $R$. oligosporus. Esto último podría ser un serio inconveniente del método ya que los cambios morfológicos, debidos a los cambios bruscos de temperatura, podrían ser un reflejo de cambios metabólicos no necesariamente deseados.

El control de la temperatura es uno de los problemas que se ha detectado desde siempre en las FMS y que, a la fecha, no tiene una solución clara. En función de las condiciones de cultivo, se han reportado diversos gradientes de temperatura dentro del lecho de fermentación: $3{ }^{\circ} \mathrm{C} \mathrm{cm}^{-1}$ (Rathbun y Shuler, 1983); $2.5^{\circ} \mathrm{C} \mathrm{cm}^{-1}$ (Raimbault, 1980); $4-5^{\circ} \mathrm{C} \mathrm{cm}^{-1}$ (Saucedo-Castañeda et al, 1990; González-Blanco et al, 1990). Poco se conoce sobre la cuantificación del calor metabólico generado en las FMS. En la mayoría de los casos se concretan a un valor constante, e.g. Rathbun y Shuler, (1983) proponen que se producen hasta $15.9 \times 10^{6} \mathrm{~J} \mathrm{~kg}^{-1}$ de materia seca, mientras que la velocidad de generación de calor es del orden de $3.3 \times 10^{5} \mathrm{~J} \mathrm{hr}^{-1} \mathrm{~kg}^{-1}$ de materia seca (Raimbault, 1980). Esto puede provocar un sobre calentamiento en la masa de la FMS, que influye negativamente sobre la actividad microbiana. En el transcurso de la fermentación la cantidad de calor generado cambia y será menor al principio y mayor durante la fase de crecimiento rápido. Aparentemente existe un compromiso entre las soluciones drásticas y efectivas (métodos no convencionales) versus las menos efectivas (métodos convencionales) pero que respeten la integridad del sistema biológico en su conjunto. 


\section{§3. Soportes inertes.}

En 1967, van Wezel utilizó micro acarreadores (resinas de intercambio iónico) con células de mamíferos, con resultados que condujeron a la producción industrial del interferón para consumo humano. Poco después Fujishima et al, (1972) ensayaron con esponjas naturales que utilizaron como matrices inertes que mejoraban las características del salvado de trigo $\mathrm{y}$, con esto, producir enzimas a partir de hongos filamentosos. Otros trabajos (Gbewoyno y Wang, 1983), en cultivos líquidos, para la producción de antibióticos aprovechan la facultad de Penicillium chrysogenum para crecer sobre soportes inertes (tierras de diatomeas) para evitar los problemas reológicos que se presentan en estos cultivos.

3.1 Características y aplicaciones potenciales.

La utilización de soportes inertes se ha probado en cultivos sólidos con ventajas considerables. En el Cuadro 3.1, se presentan algunos de los soportes inertes probados con más éxito en cultivos sumergidos y en FMS.

\section{CUADRO 3.1. EJEMPLOS DE APLICACIÓN DE LOS SOPORTES INERTES EN CULTIVOS MICROBIANOS Y DE CÉLULAS.}

\begin{tabular}{|c|c|c|c|}
\hline SOPORTE INERTE & $\begin{array}{l}\text { TIPO DE } \\
\text { CULTIVO }\end{array}$ & $\begin{array}{c}\text { MICROORGANISMO O } \\
\text { CÉLULAS }\end{array}$ & REFERENCIAS \\
\hline $\begin{array}{c}\text { Resinas } \\
\text { de intercambio } \\
\text { iónico }\end{array}$ & $\begin{array}{l}\text { Sumergido } \\
\text { Sólido } \\
\text { Sólido }\end{array}$ & $\begin{array}{c}\text { Células animales } \\
\text { Aspergillus niger } \\
\text { Saccharomyces cereviseae }\end{array}$ & $\begin{array}{l}\text { van Wezel } 1967 \\
\text { Auria et al, 1990;1992;1993 } \\
\text { Christen } \text { et al, } 1993\end{array}$ \\
\hline Tierra de diatomeas & $\begin{array}{l}\text { Sumergido } \\
\text { Sumergido }\end{array}$ & $\begin{array}{l}\text { Penicillium chrysogenum } \\
\text { Pseudomonas auruginosa }\end{array}$ & $\begin{array}{l}\text { Gbewoyno y Wang, } 1983 \\
\text { Jones et al, } 1993\end{array}$ \\
\hline Bagazo de caña & $\begin{array}{l}\text { Sólido } \\
\text { Sólido } \\
\text { Sólido } \\
\text { Sólido } \\
\text { Sólido }\end{array}$ & $\begin{array}{c}\text { Trichoderma harzianum } \\
\text { Aspergillus niger } \\
\text { Aspergillus niger } \\
\text { Schwanniomyces castelii } \\
\text { Saccharomyces cereviseae }\end{array}$ & $\begin{array}{l}\text { Prebois et al, } 1985 \\
\text { Oriol et al, 1988a } \\
\text { Raimbault et al, } 1989 \\
\text { Saucedo-Castañeda, } 1991 \\
\text { Christen et al, } 1993\end{array}$ \\
\hline Vidrio poroso & Sólido & Penicillium roquefortii & Larroche y Gross, 1989 \\
\hline Fibras sincéticas & Sumergido & & Endo et al, 1987 \\
\hline Partículas de cerámica & Sólido & Penicillium roquefortii & Larroche y Gross, 1989 \\
\hline $\begin{array}{c}\text { Poliuretano de baja } \\
\text { densidad }\end{array}$ & Sumergido & Hongos filamentosos & Endo et al, 1987 \\
\hline Esponjas naturales & $\begin{array}{c}\text { Sumergido } \\
\text { Sólido }\end{array}$ & $\begin{array}{l}\text { Hongos filamentosos } \\
\text { Hongos filamentosos }\end{array}$ & $\begin{array}{l}\text { Endo et al, } 1987 \\
\text { Fujishima et al, } 1972\end{array}$ \\
\hline
\end{tabular}


Como se aprecia, el bagazo de caña es el que mayor atención ha recibido, en cultivos sólidos, principalmente por su alta capacidad de retención de agua: hasta $4 \mathrm{~kg}$ de agua $\mathrm{kg}^{-1}$ bagazo seco (Oriol et al, 1988b). A modo de comparación: la pulpa de café y la harina de yuca retienen, $2.0 \mathrm{y}$ $1.3 \mathrm{~kg}$ de agua $\mathrm{kg}^{-1}$ de material seco respectivamente, mientras que la resina de intercambio iónico (Amberlita IRA-900) que proponen Auria et al, (1990) puede absorber $1.5 \mathrm{~kg}$ de agua $\mathrm{kg}^{-1} \mathrm{de}$ resina seca. Sin embargo, la capacidad de retención de agua no determina totalmente la eficiencia de un soporte para la FMS, por ejemplo: la ocupación de agua por unidad de volumen de reactor, mientras para el bagazo de caña es de $0.2 \mathrm{~m}^{3}$ de agua $\mathrm{m}^{-3}$ reactor, para la Amberlita es de aproximadamente el doble. Esto se debe a que, mientras el primero absorbe mucha agua y ocupa mucho espacio, el segundo absorbe menos agua pero también ocupa menos volumen de reactor.

Los soportes inertes deben reunir ciertas características fundamentales, tales como una gran disponibilidad y un bajo costo en el mercado; un fácil manejo y almacenamiento, y reunir ciertas propiedades físicas y biológicas. Además, un soporte inerte debe satisfacer ciertas especificaciones técnicas. En el Cuadro 3.2 se proponen algunas de las propiedades físicas y biológicas más importantes, así como las especificaciones deseables que debe reunir un soporte.

\section{CUADRO 3.2 ESPECIFICACIONES QUE DEBE CUMPLIR UN SOPORTE PARA SU UTILIZACIÓN EN FMS.}

\begin{tabular}{|c|c|}
\hline PROPIEDAD & ESPECIFICACIONES \\
\hline Toxicidad & Ausente $100 \%$ \\
\hline $\begin{array}{c}\text { Absorción de agua por unidad de } \\
\text { volumen de reactor }\end{array}$ & La máxima posible \\
\hline Resistencia mecánica & $\begin{array}{c}\text { Soportar, sin deformación, el empaque en } \\
\text { columnas }\end{array}$ \\
\hline Hidrofobicidad & Ausente $100 \%$ \\
\hline $\begin{array}{c}\left.\text { Porosidad macroscópica }{ }^{*}\right) \\
\text { Diámetro de poros } \\
\text { microscópicos }\end{array}$ & $\begin{array}{c}\text { Mínimo: } 0.6 \mathrm{~m}^{3} \text { poros macroscópicos } \mathrm{m}^{-3} \\
\text { sorte húmedo al diámetro de una espora }\end{array}$ \\
\hline $\begin{array}{c}\text { Superficie específica } \\
(*)\end{array}$ & $\begin{array}{c}\left.{ }^{*}\right) \\
1.0 \mathrm{~m}^{2} \text { superficie disponible } \mathrm{m}^{-3} \mathrm{espacio}^{2} \text { vacío } \\
\text { inerte disponible } \mathrm{kg}^{-1} \text { soporte }\end{array}$ \\
\hline
\end{tabular}

(*) Esta información corresponde a una caja Petri. Ver texto. 
Las propiedades que requieren una mayor atención son: (i) la toxicidad, en definitiva ningún soporte puede ser tóxico o inhibitorio a los microorganismos que se pretenden desarrollar; (ii) la retención de agua por unidad de volumen de reactor, ésta debe ser la mayor posible sin que el agua absorbida escurra y quede libre; (iii) la resistencia mecánica a la deformación, esta es una propiedad que no necesariamente se debe cumplir en todos los casos, e.g. cuando se requiera empacar el soporte en columnas o agitar mecánicamente será indispensable poner arención a este factor; (iv) la hidrofobicidad, en tanto que el solvente universal en estos sistemas de cultivo es el agua, este factor debe estar ausente siempre; (v) la porosidad macroscópica, se refiere a los espacios vacíos que deja el soporte inerte una vez impregnado e inoculado; (vi) el diámetro de poros microscópicos es una dimensión que debe permitir a los microorganismos alojarse en el interior del soporte y colonizarlo; (vii) la superficie específica se refiere a la efectividad del soporte en cuanto a la superficie que puede ofrecer por unidad de volumen o peso ocupado en un biorreactor.

Para el cálculo de los valores que se presentan señalados $\left(^{*}\right)$ en el Cuadro 3.2 se consideró que el crecimiento superficial que se realiza mejor es aquel que se lleva a cabo en una caja de Petri (Pirt, 1967; Trinci, 1971), por lo que se le consideró como ideal y los cálculos corresponden al espacio vacío de una caja de Petri de $10 \mathrm{~cm}$ de diámetro que contiene $15 \mathrm{~g}$ de agar húmedo. El agar ocupa un volumen que cubre $0.8 \mathrm{~cm}$ de altura de la caja (la altura de la caja es de $2.0 \mathrm{~cm}$ ), estos valores calculados son los considerados como los mínimos indispensables que debe satisfacer un soporte inerte.

Cuando el soporte se somete a algún pretratamiento (molienda, lavado, tratamiento térmico, etc.), la capacidad de retención aumenta considerablemente. En trabajos recientes (Barrios-González et al, 1993; Barrios-González 1994) con Penicillium Chrysogenum se demuestra que la presencia de bagazo de caña pretratado, en proporciones bien definidas, aumenta la producción de antibióticos. Estos autores encontraron que una relación 5 a $7 \mathrm{~kg}$ de agua junto con 1.1 a $2.0 \mathrm{~kg}$ de nutrientes por $\mathrm{kg}$ de bagazo seco incrementan la síntesis de penicilina $\mathrm{G}$ hasta en cuatro veces, respecto a sus formulaciones originales. Estos resultados se pueden explicar tomando en cuenta que el bagazo de caña: (i) contiene agua y nutrientes disponibles para el cultivo durante toda la fermentación, incluyendo la fase estacionaria; (ii) conforma una matriz húmeda y hueca que facilita el intercambio gaseoso; (iii) proporciona la superficie y el espacio disponible para favorecer el crecimiento superficial y aéreo que se requiere en el cultivo de microorganismos filamentosos.

Saucedo-Castañeda (1991) demostró que estos conceptos también se aplican a cultivos de levaduras. Este autor realiza una serie de estudios del control del metabolismo de 
Schwanniomyces castellii en FMS modificando el intercambio gaseoso, en aerobiósis y en anaerobiósis, con la ayuda de bagazo de caña como soporte inerte.

En relación a la superficie y el espacio disponible, desde 1985, Laukevics et al, proponen que la morfología y el metabolismo de los cultivos miceliares dependen directamente de estos dos factores. Aparentemente, cuando la superficie disponible se agota, los microorganismos cambian el metabolismo para colonizar el espacio aéreo y cuando el espacio disponible se agota los microorganismos cambian el metabolismo a la síntesis de metabolitos secundarios o bien a iniciar la etapa de conidiación.

\subsection{Tratamientos físicos.}

Estos tratamientos incluyen: (i) disminución del tamaño de las partículas; con esto se incrementa la superficie específica; (ii) lavado del soporte; para la eliminación de sustancias solubles que pudieran interferir en el proceso que se pretende; y (iii) tratamiento térmico con el que se busca incrementar el diámetro de los poros microscópicos y, por lo tanto, mejorar la capacidad de retención de agua del material.

Saucedo-Castañeda (1991) propone un tamaño de partícula de 0.3 a $0.8 \mathrm{~mm}$ para bagazo de caña en cultivos con Schwanniomyces castelii. Para Barrios-González (1994) el tamaño de partícula de bagazo de caña no incide en la síntesis de penicilina $\mathrm{G}$, pero propone un tamaño de partícula entre 0.35 y $0.81 \mathrm{~mm}$, además de un lavado intenso. En general, con bagazo de caña de azúcar un tratamiento térmico (por ejemplo $100^{\circ} \mathrm{C}$ durante $45 \mathrm{~min}$ ) permite abatir cuentas microbianas en bagazo de caña e hinchar las fibras de celulosa lo suficiente como para permitir que un hongo filamentoso como Trichoderma harzianum se desarrolle produciendo satisfactoriamente enzimas celulasas (Roussos et al, 1992).

\subsection{Tratamientos químicos.}

En lo que respecta a los materiales lignocelulósicos, los tratamientos térmicos exclusivamente pueden resultar insuficientes; en cuyo caso se recurre al auxilio de tratamientos químicos, incluyendo al hidróxido de sodio, amoniaco y ácidos fuertes, entre otros. Estos tratamientos se utilizan solos o combinados y, en general, lo que se pretende es hinchar las fibras de celulosa para así incrementar el área de contacto, esto se logra mediante la hidrólisis o disolución de la lignina y de otros compuestos estructurales.

Otro tipo de tratamiento químico es el que se propone para las resinas de intercambio iónico. En este caso el tratamiento consiste en lavar exhaustivamente la resina, filtrar y tratar con algún ion como fosfatos (Auria et al, 1990) o con el mismo medio de cultivo que se utilizará después 
(Córdova 1994). Estos tratamientos pretenden estabilizar la capacidad de intercambio de la resina mediante la saturación de sus sitios activos.

El bagazo de caña presenta las mejores características: Disponibilidad en el mercado mexicano, costos, nula toxicidad, capacidad de retención de agua aceptable, elevados espacios vacíos $(0.7$ $\mathrm{m}^{3}$ vacíos $\mathrm{m}^{-3}$ de bagazo húmedo). Algunas desventajas son: por su contenido de lignina, interfiere con algunas técnicas analíticas y, por su naturaleza fibrosa, es de composición y forma irregular.

Otros soportes que han recibido mucha atención son las resinas de intercambio iónico. Lás ventajas de las resinas son: por su producción industrial, están disponibles siempre; nula toxicidad, excelente capacidad de retención de agua por unidad de volumen de reactor, moderados espacios vacíos $\left(0.4 \mathrm{~m}^{3}\right.$ vacíos $\mathrm{m}^{-3}$ de resina húmeda), inerte en cuanto a que no se disuelven sustancias que interfieran con las técnicas analíticas, tiene presentación esférica y composición uniforme siempre, se conocen con precisión los valores de los parámetros fisicoquímicos del soporte: diámetro promedio de partículas, masa volumétrica, y su distribución en un lecho empacado, entre otros. Las desventajas de las resinas son los costos y la fragilidad de la resina deshidratada.

\section{Resumen y conclusiones.}

Se presenta una breve discusión del estado del arte de las FMS. Iniciando con una serie de definiciones y conceptos generales en donde se pretende justificar el estudio de cultivos en FMS. Los microorganismos filamentosos son los más estudiados, aunque las levaduras encuentran un espacio cada vez más relevante. Entre los problemas detectados destaca el del transporte de calor. El problema de la acumulación de calor se conoce desde siempre en las FMS, sin embargo se ha estudiado poco. Hace falta cuantificar el calor generado y la contribución parcial de los diferentes mecanismos de remoción (conducción, convección y evaporación). Entre las ventajas que caracterizan a las FMS destaca el hecho de poder utilizar sustratos solubles en concentraciones tan elevadas que en cultivos sumergidos seria imposible emplear. Esta particularidad abre nuevas perspectivas de aplicación directamente asociada al uso de soportes inertes. El uso de soportes inertes en el terreno práctico y en el de la investigación es promisorio en tanto que aportan propiedades que mejoran las condiciones de las FMS. Se proponen algunas especificaciones para poder aceptar a un soporte o rechazarlo. Los soportes que más atención han recibido son el bagazo de caña y las resinas de intercambio iónico. El bagazo presenta ventajas y desventajas que hacen que las resinas de intercambio resulten con mayores atractivos, particularmente como un modelo ideal en el campo de investigación básica y en la elaboración de modelos matemáticos que traten el problema global de las FMS en forma teórica. 


\section{B. BIORREACTORES Y MODELOS MATEMÁTICOS EN EL CAMPO DE LAS FERMENTACIONES EN MEDIOS SÓLIDOS.}

\section{\$4. Biorreactores para las fermentaciones en medios sólidos.}

En este trabajo el término biorreactor y fermentador se utilizan como sinónimos. En función de la cantidad de agua que contienen los biorreactores se pueden clasificar en aquellos destinados a cultivos líquidos y aquellos que transforman en cultivos sólidos.

Los biorreactores para cultivos líquidos son los más empleados en la industria. La mayoría son biorreactores del tipo no agitados y anaerobios, $86 \%$; mientras que un $13 \%$ son agitados y aeróbios y los del tipo no agitados y aeróbios representan apenas un $11 \%$ del total cuantificado por Cliffe en 1988 para los Estados Unidos. Debido a que todos estos procesos están controlados por la cinética de las reacciones, los fenómenos de transporte se han considerado menos importantes e inclusive despreciables (Veschoor 1985).

\subsection{Tipos de biorreactores.}

En los biorreactores para las FMS el crecimiento celular es fundamentalmente superficial, por lo que la difusión de nutrientes, incluyendo al agua, y el espacio disponible son papel determinantes. La heterogeneidad natural de los medios de cultivo o soportes empleados impiden la difusión simple de calor, por lo que en este caso no es posible afirmar que los fenómenos de transporte sean despreciables, particularmente cuando éstos inciden directamente en la fisiología y bioquímica celular (Georgiou y Shuler, 1986; Tani et al, 1988; Solís et al, 1993). La acumulación de calor y la naturaleza del sustrato o del soporte, son los dos factores más relevantes que han conducido la investigación en el campo de las FMS, particularmente en lo que se refiere a los estudios de diseño y operación de los biorreactores.

Para este tipo de cultivos se conocen cinco tipos de biorreactores: (i) de columna empacada, (ii) de charolas o bandejas, (iii) de tambor o tazón rotatorio, (iv) tubular con agitación interna y (v) de lecho fluidizado aire-sólido. Estos biorreactores pueden clasificarse en dos grupos: estáticos y dinámicos.

Biorreactores estáticos. Son aquellos en donde el material permanece sin agitación y están provistos de calefacción y aireación. Estos equipos se pueden empacar de manera horizontal (el caso de las bandejas o los lechos de los equipos para la producción de koji) o bien de manera vertical (el caso de las columnas empacadas). Recientemente se ha demostrado la eficiencia de un diseño especial de un reactor de empaque vertical en una escala de $50 \mathrm{~kg}$ de materia húmeda, para la producción de esporas y celulasas (Prebois et al, 1985; Roussos et al, 1991, 1992, 1993) y de 
pectinasas (Huerta-Ochoa et al, 1994). El biorreactor, está construido en acero inoxidable y esta provisto de una serie de placas de intercambio de calor, el control de la temperatura, es automático y se registra la temperatura del lecho empacado. La eliminación del calor acumulado se logra por medio del agua que circula por las placas y mediante la incorporación de aire frío y seco o caliente y saturado. El control de la temperatura del proceso se mantiene convenientemente alrededor de los $35^{\circ} \mathrm{C}$ (Roussos et al, 1993).

La principal desventaja de estos equipos es que la remoción de calor conductiva es muy costosa y que cuando se les trata de escalar a un nivel de operación mayor, generalmente se requieren equipos sumamente grandes ya que tienen como límite de empaque axial entre 0.5 y $0.8 \mathrm{~m}$.

En relación a los biorreactores horizontales o de charolas, se conocen muchos trabajos, realizados con diferentes materiales y microorganismos (Ghildyal et al, 1981; Ahmed et al, 1987). La principal desventaja de estos biorreactores son los gradientes de temperatura y de concentración de gases. Para evitar estos problemas, recientemente Gowthaman et al, (1993) sugieren la utilización de biorreactores verticales con ventilación forzada; ellos logran mejorar la productividad de amiloglucosidasas de $A$. niger con la eliminación de los gradientes de calor y bióxido de carbono.

Biorreactores agitados. Son aquellos que se pueden agitar de manera continua o intermitente. En este caso la remoción del calor metabólico se realiza además por la vía convectiva. En estos biorreactores, se alimenta el material a fermentar en forma continua o semicontinua (Gibbons $e t$ al, 1986), o en forma de lotes (Huerta-Ochoa et al, 1986; Durand y Chereu, 1988). Durante el proceso el material se mezcla, con movimientos suaves (1-5 r.p.m.). Existen otros tipos de biorreactores para FMS que no se pueden clasificar como dinámicos estrictamente, debido a que el movimiento del material a fermentar no es de tipo mecánico, estos son los lechos fluidizados con aire (Hong et al, 1989).

El biorreactor agitado que más se utiliza es el fermentador de tambor rotatorio. Principalmente para la producción de alcohol y de metabolitos secundarios. Existen prototipos que permiten efectuar dentro del fermentador diferentes etapas de lavado de granos, cocimiento e inoculación. Estos fermentadores alcanzan hasta $2.0 \mathrm{~m}$ de diámetro y $4.0 \mathrm{~m}$ de largo (Steinkraus, 1984). La presencia de mamparas sobre la pared interna evita la formación de aglomerados y elevaciones locales de temperatura. El fermentador se enfría con adición de agua externa. La temperatura interna, la humedad y el $\mathrm{pH}$ se controlan en continuo.

Los biorreactores agitados presentan las siguientes desventajas: (i) la fragilidad del micelio es la principal limitante, (ii) las propiedades físicas del material en cultivo se pueden alterar de manera 
negativa i.e. principalmente compactación, (iii) los costos de agitación en relación a la cantidad de material a procesar pueden ser muy elevados.

\subsection{Diseño y escalamiento de biorrectores.}

La eficiencia de los procesos de FMS depende directamente del diseño de los biorreactores. Aunque este aspecto se reconoce como uno de los más relevantes a estudiar se encuentra apenas en vías de desarrollo. El diseño de un biorreactor para FMS depende de aspectos tales como (Mitchell et al, 1992): (i) si se requiere o no algún tipo de mezclado, (ii) la intensidad de aireación, (iii) la tasa de remoción de calor, (iv) las necesidades de medición y control de parámetros del proceso, (v) el tipo de sustrato o soporte a tratar, (vi) las necesidades de esterilización y prevención de contaminaciones, (vii) el régirnen de operación deseado, i.e. lotes o continuo, (viii) la inversión y los costos de operación y (ix) los criterios de escalamiento que se deben emplear.

El escalamiento de reactores se define como el conjunto de técnicas y procedimientos que permiten diseñar un equipo en una escala mayor, partiendo de los resultados de un equipo de escala menor (Koosen y Oosterhuis, 1981). El éxito del escalamiento depende siempre del manejo y de la conservación de ciertos criterios que predominen en los equipos de las dos escalas. Para una aplicación práctica de estos sistemas se requieren estudios detallados que permitan el diseño y control de los biorreactores en cualquier escala de operación. Desafortunadamente esta información es escasa (Lonsane, et al. 1992) o no está disponible . Las razones por las que los biorreactores para cultivos sólidos no han sido considerados en escala industrial son dos: la primera es de tipo comercial, los reactores líquidos se diseñaron desde hace casi 50 años y desde entonces se comercializan con éxito. La segunda razón es que no existe un prototipo generalizado único (Gutiérrez-Rojas, et al, 1989) como es el caso del reactor agitado en los procesos líquidos. La ausencia total de un criterio uniforme, entre los diferentes grupos de investigación, en la definición exacta de las características que deben reunir estos biorreactores ha sido determinante en el retraso de la aplicación comercial de estos procesos. En términos prácticos el diseño y el escalamiento de biorreactores se puede situar en cuatro niveles con diferente grado de desarrollo (Mitchell et al, 1992b):

- La utilización de reglas empíricas simples en donde el criterio que predomina es la similitud geométrica. En este caso se conocen muchos ejemplos en los que se ha logrado escalar a niveles importantes de operación con excelentes resultados, iguales o mayores que en las escalas de laboratorio: en la producción de pectinasas, amilasas, catalasas y renina (Lonsane et 
al, 1985; Karant y Lonsane, 1989), en la producción de pectinasas, esporas y celulasas (Roussos et al, 1993; Huerta-Ochoa et al, 1994).

- La utilización de reglas semi-fundamentales con las que se pretende establecer criterios de escalamiento más firmes y reproducibles basados en fenómenos de transporte macroscópicos. Entre las aproximaciones que se han reportado se pueden mencionar: (i) los estudios de transferencia de masa entre partículas (Auria et al, 1992), (ii) mantener la relación de transporte de calor conductivo/convectivo constante (Saucedo-Castañeda et al, 1990), y (iii) mantener el balance de calor y de agua constantes (Saucedo-Castañeda et al, 1992). Así como los modelos matemáticos mecanísticos para transporte de masa propuestos por Mitchell et al, (1991), constituyen, en su conjunto un buen punto de partida para todo el trabajo que resta por desarrollar.

- La utilización de grupos adimensionales de parámetros de operación con los que se han desarrollado los reactores para cultivos líquidos, en el caso de las FMS no ha recibido atención alguna y, por tanto, el mejor número adimensional no ha sido aún identificado.

- La utilización de reglas fundamentales con las que, de manera ideal, debería desarrollarse el escalamiento y el diseño de biorreactores, resolviendo las ecuaciones fundamentales de transferencia de momentum, masa y calor. Sin embargo, aún la interacción de los fenómenos que se presentan en las FMS es lo suficientemente desconocida y compleja como para abordarse a este nivel.

Una estrategia global para la selección de criterios de escalamiento y diseño de estos reactores, debería de basarse tanto en estudios de transferencia de masa y calor, como en los resultados y experiencias acumuladas en las FMS (Gutiérrez-Rojas et al, 1989). La estrategia debería considerar la posibilidad de utilizar modelos matemáticos (Mitchell et al, 1992a) que contemplaran los fenómenos de transporte acoplados a la físiología celular, incluyendo modelos cinéticos de crecimiento celular, consumo de azúcares, intercambio gaseoso, temperatura del medio sólido, y formación de productos, entre otros.

\section{\$. Modelos matemáticos.}

Un modelo se puede definir como una aproximación física o abstracta que pretende representar un fenómeno que ocurre en la naturaleza, i.e. un modelo matemático es la aproximación de un fenómeno determinado, escrita en un lenguaje matemático.

La concepción de un modelo matemático se inicia con un conjunto de observaciones experimentales. Las observaciones experimentales se centran en la búsqueda de correlaciones de 
causa y efecto entre un conjunto de variables relevantes e.g. aquellas variables que definen el estado del sistema o variables de estado. El conjunto de variables de estado deben definirse en el momento en que se define el dominio espacial, o sistema, en el que se desarrolla el fenómeno que se estudia.

Los modelos matemáticos están constituidos por un conjunto de ecuaciones, cada una definida para cada variable de estado. Las ecuaciones se obtienen a partir de: (i) balances de materia y energía, (ii) relaciones cinéticas, (iii) relaciones fenomenológicas y, (iv) resultados empíricos restringidos a ciertas condiciones. Las ecuaciones resultantes siempre contienen constantes o parámetros que dependen de las condiciones globales bajo las que se desarrolla la experimentación. Las ecuaciones resultantes pueden expresar a las variables de estado de manera explícita o implícita y, dependiendo de esto, se resuelven directa o indirectamente. La solución de un modelo se obtiene, dependiendo de la complejidad del mismo, utilizando técnicas analíticas o numéricas. Los métodos analíticos conducen a soluciones exactas, mientras que los métodos numéricos conducen a soluciones aproximadas. Independientemente del método utilizado, la solución de un modelo matemático refleja siempre los cambios de una variable de estado con respecto a una o más variables independientes, de aquí que la utilización de modelos matemáticos constituye una herramienta útil de trabajo en tanto que: (i) facilitan el estudio de uno o varios fenómenos, por separado o en su conjunto, (ii) complementan los conocimientos de un fenómeno situándolo en un contexto más general, (iii) permiten predecir resultados bajo condiciones de operación diferentes a las experimentadas, y (iv) permiten establecer estrategias globales para el control y el escalamiento (Trambouze, 1979).

\section{§6. Formulación y volumen elemental representativo.}

Para la formulación de un modelo matemático, Luyben, (1973) propone que se deben cubrir, de manera sistemática, al menos las etapas que se resumen a continuación:

- Descripción de las bases del modelo. El modelado se inicia con la definición exacta del sistema y de las variables de estado que participan. Esto incluye variables físicas, químicas y bioquímicas. Una vez definidas es necesario seguir su curso (entradas, salidas, aparición y desaparición) dentro del sistema, mediante balances globales totales y parciales para cada especie.

- Proposición de hipótesis de trabajo. Estas son consideraciones hipotéticas que pretenden simplificar la complejidad del modelo con base en observaciones experimentales. Obviamente un modelo extremadamente riguroso que incluya todos los fenómenos en una escala microscópica sería tan complejo que su solución podría tomar mucho tiempo o bien ser 
imposible. Para ilustrar la importancia de la selección apropiada de la escala del sistema de trabajo y su relación con la aplicación de los modelos matemáticos, en el Cuadro 6.1 se presenta un resumen de los modelos conocidos, el contenido y aplicaciones según su escala. Como se puede apreciar, a medida que se desciende en el cuadro, el grado de complejidad del modelo disminuye. Esto último no invalida a los modelos macroscópicos en relación a los microscópicos, simplemente indica que ambos tipos de modelos son útiles en casos distintos. Siempre será necesario resolver un compromiso de ingeniería entre una descripción muy rigurosa y la obtención de respuestas que se puedan considerar como suficientes para los objetivos finales del modelo en cuestión. En esta etapa es necesario listar las hipótesis y traducirlas a un lenguaje matemático que puedan incorporarse en las ecuaciones de balance.

- Análisis de consistencia del modelo. Una vez que todas las ecuaciones se han escrito es muy importante asegurarse que se dispone del mismo número de variables que de ecuaciones y que el sistema de ecuaciones es consistente desde un punto de vista dimensional.

- Solución de las ecuaciones del modelo. El conjunto de ecuaciones que resulta contiene algún tipo de ecuaciones algebraicas, diferenciales ordinarias y diferenciales parciales o una combinación de las mismas. Para la solución generalmente se recurre a uno o varios métodos numéricos. Los métodos numéricos, a diferencia de los métodos analíticos puros, producen valores aproximados que deben tomarse con cierta precaución en la interpretación final de resultados. Para facilitar la comprensión y la solución del modelo con frecuencia se recurre a la introducción de nuevas variables adimensionales o normalizadas. Con la normalización de variables se producen agrupaciones de variables o números adimensionales siempre con un claro significado físico útil en la interpretación y entendimiento del problema.

- Verificación. La etapa final del modelado matemático es la validación del conjunto de hipótesis y consideraciones teóricas con las que se formuló y resolvió el modelo. Esta etapa consiste en confrontar las predicciones del modelo con los resultados y observaciones experimentales. En la mayoría de los casos ésta es la etapa crítica. Esto se debe a que sólo ciertos parámetros y variables de estado se podrán medir directa o indirectamente, mediante experimentos independientes, mientras que las otras se deben estimar.

De la discusión anterior se deduce la importancia de la selección de la escala con la que se realiza el estudio. Un análisis cuidadoso del Cuadro 6.1 sugiere que una dimensión entre la escala de gradiente múltiple y la escala de gradiente máximo sería la más adecuada para un sistema de FMS como el que se desarrolla en este trabajo. En el mismo sentido, con el enfoque de la termodinámica de los procesos irreversibles en materiales porosos heterogéneos, Benet, (1981) propone que entre la dimensión microscópica y la macroscópica se puede situar a un volumen 
intermedio apropiado para este tipo de estudios. Este volumen intermedio se denomina Volumen Elemental Representativo (VER).

\section{CUADRO 6.1. EJEMPLOS DE APLICACIÓN DE LOS MODELOS MATEMÁTICOS SEGÚN LA ESCALA DE ESTUDIO.}

\begin{tabular}{|c|c|c|c|}
\hline $\begin{array}{l}\text { ESCALA DE } \\
\text { ESTUDIO }(\mathrm{m})\end{array}$ & $\begin{array}{l}\text { EJEMPLO DE } \\
\text { LA ESCALA }\end{array}$ & DESCRIPCIÓN & $\begin{array}{l}\text { CAMPOS DE } \\
\text { APLICACIÓN }\end{array}$ \\
\hline $\begin{array}{l}\text { Atómica o molecular } \\
\qquad\left(10^{-12}\right)\end{array}$ & $\begin{array}{l}\text { Diámetro de una } \\
\text { molécula o de } \\
\text { un átomo }\end{array}$ & $\begin{array}{c}\text { Trata entidades discretas. Está } \\
\text { constituido de funciones de } \\
\text { distribución }\end{array}$ & $\begin{array}{l}\text { Estudios fundamentales } \\
\text { de mecánica cuántica, } \\
\text { mecánica estadística y } \\
\text { teoría cinética }\end{array}$ \\
\hline $\begin{array}{c}\text { Microscópica } \\
\qquad\left(10^{-6}\right)\end{array}$ & $\begin{array}{l}\text { Diámetro de un } \\
\text { microorganismo }\end{array}$ & $\begin{array}{l}\text { Fenómenos de transporte en } \\
\text { régimen laminar, transporte de } \\
\text { nutrientes a través de } \\
\text { membranas celulares. Difusión } \\
\text { de nutrientes. Coeficientes de } \\
\text { transporte fenomenológicos. }\end{array}$ & $\begin{array}{c}\text { Estudios fundamentales. } \\
\text { Metabolismo de } \\
\text { microorganismos. } \\
\text { Cinética y regulación } \\
\text { microbiana. }\end{array}$ \\
\hline $\begin{array}{l}\text { Gradiente múltiple } \\
\qquad\left(10^{-1}\right)\end{array}$ & $\begin{array}{l}\text { Biorreactores de } \\
\text { laboratorio. } \\
\text { Columnas } \\
\text { empacadas } \\
\end{array}$ & $\begin{array}{c}\text { Fenómenos de transporte en } \\
\text { régimen laminar y turbulento. } \\
\text { Coeficientes de transporte } \\
\text { "efectivos" }\end{array}$ & $\begin{array}{l}\text { Estudios de transporte } \\
\text { en medios porosos } \\
\text { heterogéneos. }\end{array}$ \\
\hline $\begin{array}{l}\text { Gradiente máximo } \\
\qquad\left(10^{0}\right)\end{array}$ & $\begin{array}{l}\text { Biorreactores } \\
\text { piloto }\end{array}$ & $\begin{array}{l}\text { Fenómenos de transporte en } \\
\text { régimen laminar y turbulento. } \\
\text { Coeficientes de transporte de } \\
\text { interfase, constantes cinéticas. }\end{array}$ & $\begin{array}{c}\text { Estudios de sistemas de } \\
\text { flujo continuo, diseño de } \\
\text { biorreactores e ingeniería } \\
\text { de procesos }\end{array}$ \\
\hline $\begin{array}{l}\text { Macroscópica } \\
\qquad\left(10^{1}\right)\end{array}$ & $\begin{array}{l}\text { Biorreactores } \\
\text { comerciales }\end{array}$ & $\begin{array}{c}\text { Operaciones unitarias. } \\
\text { Coeficientes de transporte de } \\
\text { interfase, constantes cinéticas } \\
\text { macroscópicas, factores de } \\
\text { fricción. }\end{array}$ & $\begin{array}{l}\text { Diseño de biorreactores } \\
\text { e ingeniería de procesos }\end{array}$ \\
\hline
\end{tabular}

Adaptado de Himmelblau y Bischoff (1976).

Un VER, por definición, es un volumen de magnitud intermedia dentro del cual es posible realizar mediciones macroscópicas representativas y confiables de una cierta variable de estado. En la Figura 6.1 se muestra gráficamente el concepto. Se observa que el VER existe dentro de una región limitada y la validez del modelo se circunscribe a esta región, en donde las fluctuaciones de medición de una variable, e.g. la temperatura, son mínimas. En estudios más recientes (Fras, 1989) se demuestra matemáticamente la validez de esta aproximación, en donde se supone que 
cada fase del sistema se puede definir como un medio continuo y que cada constituyente de la fase se puede considerar también como un medio continuo. El concepto supone que a cada uno de estos medios es posible asociarle uno o varios campos de variables intensivas fenomenológicas. Las variables asociadas son capaces de definirlo en todo tiempo y en todo punto espacial mediante el uso de promedios de magnitudes reales macroscópicas o microscópicas. Finalmente, la macroscopización de la escala intermedia de un VER se logra extrapolando las predicciones obtenidas dentro del dominio espacial del mismo, hasta el dominio macroscópico de un biorreactor.

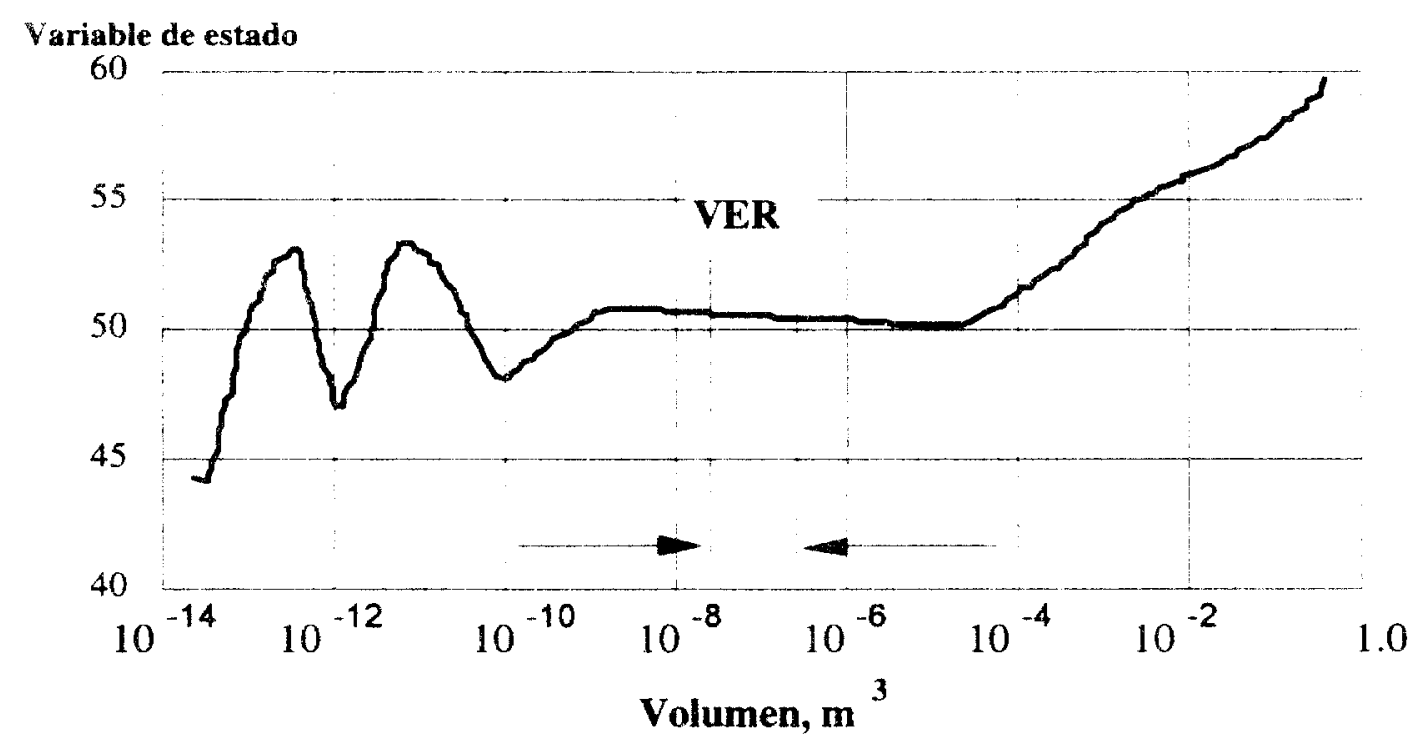

\section{FIGURA 6.1. Representación esquemática del concepto de un volumen elemental representativo (Fras, 1989).}

En el campo de las FMS, se conocen pocos trabajos de modelado matemático que contengan asociadas variables microscópicas y macroscópicas. Para Carrizales y Jaffe, (1986) ésta es una de las razones que explican porqué los avances de las FMS, como una tecnología apropiada para los países en vías de desarrollo, son muy limitados.

Entre los aspectos que se espera que aclaren los modelos matemáticos en este campo son predecir: (i) la eficiencia global de los biorreactores, esto incluye las tasas de reacción, las concentraciones, productividad y tiempos óptimos para la cosecha; (ii) el efecto de factores físicos externos tales como la cantidad, temperatura y humedad del aire que se alimenta a los 
biorreactores, en la optimización de la eficiencia global; (iii) el efecto de factores físicos internos tales como la proporción de espacios vacíos en los lechos de fermentación; (iv) el efecto del agua y los nutrientes; (v) el efecto simultáneo de los diferentes fenómenos tanto físicos como biológicos. Con este tipo de predicciones entender mejor los fenómenos que ocurren en los cultivos sólidos.

Actualmente se conocen tres tipos de modelos matemáticos relacionados directa o indirectamente con las FMS: (i) los modelos desarrollados para explicar el crecimiento en superficies, principalmente cultivos en cajas de Petri, (ii) los modelos para los cultivos heterogéneos de las FMS, y (iii) los modelos en sistemas experimentales ideales. Estos temas se desarrollan por separado en los capitulos que siguen.

\section{\$7. Modelos de crecimiento en superficies.}

Los modelos en cultivos sobre cajas Petri o en superficies se han abordado con un enfoque totalmente microscópico atendiendo, en su mayoría, cinéticas de crecimiento y el modo de colonización de hongos filamentosos. En los primeros intentos descriptivos (Pirt, 1967; Trinci, 1971) se estudia la colonización de cajas de Petri inoculadas en el centro. Se observan esporas que germinan produciendo un tubo germinal que se ramifica en hifas que se extienden de manera apical, siguiendo leyes exponenciales (Pirt, 1967) o lineares (Righelato, 1975). Las hifas se distribuyen radialmente y forman colonias circulares (Bull y Trinci, 1977). A medida que la colonia se expande se forman gradientes de nutrientes en el medio. El crecimiento se detiene primero en el centro de la colonia y se inicia un proceso de autólisis (Oliver y Trinci, 1985), posiblemente debido al agotamiento de nutrientes que limitan los cultivos, y simultáneamente se producen conidias y esporas. También se ha observado que la densidad o peso específico por unidad de área de las colonias, cambia a medida que el radio de la caja cambia (Koch, 1975). Observaciones, con técnicas de inoculación sobre toda la superficie de las cajas (Georgiou y Shuler, 1986), demostraron que el sustrato (glucosa), inicialmente en altas concentraciones, difunde libremente hasta las células en la superficie de las cajas. En el Cuadro 7.1 se muestra un resumen de algunos de los modelos cinéticos correspondientes a estas observaciones microscópicas.

En general estos modelos no muestran evidencias de asociación con variables macroscópicas del crecimiento celular o de extrapolarse a los sistemas de FMS. 


\section{CUADRO 7.1 MODELOS CINÉTICOS DE CRECIMIENTO EN SUPERFICIES.}

\begin{tabular}{|c|c|c|}
\hline $\begin{array}{l}\text { VARIABLE QUE SE } \\
\text { MODELA } \\
\text { (SISTEMA } \\
\text { EXPERIMENTAL) }\end{array}$ & $\begin{array}{c}\text { MODELO PROPUESTO } \\
\text { (REFERENCIA) }\end{array}$ & NOMENCLATURA ${ }^{1}$ \\
\hline $\begin{array}{c}\text { Expansión logarítmica de } \\
\text { la colonia } \\
\text { (Caja Petri con inoculación } \\
\text { al centro) }\end{array}$ & $\begin{array}{l}\ln r=\frac{\mu t}{2}+\ln r_{0} \\
(\text { Pirt, 1967) }\end{array}$ & $\begin{array}{l}r, \quad \text { radio de la colonia } \\
t, \quad \text { tiempo } \\
\mu, \text { tasa esp. de crecimiento } \\
r_{0}, \text { radio de la colonia a } t=0\end{array}$ \\
\hline $\begin{array}{c}\text { Expansión linear de la } \\
\text { colonia } \\
\text { (Caja Petri con inoculación } \\
\text { al centro) }\end{array}$ & $\begin{array}{l}r=\mu w\left(t-t_{e}\right)+r_{e} \\
\text { (Righelato, 1975) }\end{array}$ & $\begin{array}{l}\mathrm{w}, \text { ancho de la zona periférica } \\
\mathrm{r}_{\mathrm{e}} \text {, radio de la colonia cuando } \\
\text { inicia crecimiento linear } \\
\mathrm{t}_{\mathrm{e}} \text {, tiempo de inicio crec. lin. }\end{array}$ \\
\hline $\begin{array}{c}\text { Cambio en el peso de la } \\
\text { biomasa } \\
\text { (Caja Petri con inoculación } \\
\text { al centro) }\end{array}$ & $\begin{array}{c}\frac{d W}{d A}=\frac{S e^{\lambda \Delta T}}{K-S+S e^{\lambda \Delta T}} h \\
\Delta T=(T-t) \\
(K o c h, 1975)\end{array}$ & $\begin{array}{l}\mathrm{W} \text {, peso de biomasa } \\
\mathrm{A} \text {, área infinitesimal } \\
\mathrm{h} \text {, altura máxima de colonia } \\
\mathrm{S} \text {, densidad inicial de micelio } \\
\mathrm{K} \text {, densidad máxima biomasa } \\
\lambda \text {, tasa esp. máx. de crec. } \\
\mathrm{T} \text {, tiempo total del exp. }\end{array}$ \\
\hline $\begin{array}{l}\text { Consumo de sustrato } \\
\text { (Caja Petri con inoculación } \\
\text { sobre toda la superficie) }\end{array}$ & $\begin{array}{c}C=C_{0} \frac{\mu X_{0}}{Y_{0} D S_{0}} \\
\left(\frac{-D}{\mu L}+\sqrt{\frac{D}{\mu}} \operatorname{coth}\left(\sqrt{\frac{D L}{\mu}}\right) e^{\mu t}-\frac{2 D}{L} A\right) \\
A=\sum \frac{e^{\alpha}}{\alpha+\mu} ; \alpha=\left(\frac{-n^{2} \pi^{2} D t}{L^{2}}\right) \\
n=1,2, \ldots, \infty \\
\text { (Georgiou y Shuler, 1986) }\end{array}$ & $\begin{array}{l}\mathrm{C} \text {, conc. de glucosa en la sup. } \\
\mathrm{C}_{0} \text {, conc. glucosa inicial } \\
\mu \text {, tasa especifica de } \\
\text { crecimiento durante el } \\
\text { crecimiento exponencial } \\
\mathrm{X}_{n}, \text { biomasa en el inoculo } \\
\mathrm{S}_{n} \text {, área superficial inoculada } \\
\mathrm{D} \text {, difusividad de la glucosa } \\
\mathrm{Y}_{n} \text {, rendimiento biomasa base } \\
\text { sustrato } \\
\mathrm{L} \text {, altura del lecho del sustrato }\end{array}$ \\
\hline
\end{tabular}

${ }^{1}$ La notación es la misma que se emplea en las referencias originales.

Recientemente, en cajas de Petri, Viniegra-González et al, (1993; 1994) presentan un modelo (ver Cuadro 7.1) que establece una clara interacción entre variables micrascópicas tales como el diámetro de las hifas, los nodos de ramificación y la velocidad promedio de extensión de micelio con variables macroscópicas como la tasa específica de crecimiento. Estos autores utilizan el modelo de Okazaki et al, (1980) con un exponente de auto inhibición, las predicciones del modelo 
se ajustan bien con resultados experimentales para $A$. niger var. hennebergii tanto de cajas Petri como de sustratos sólidos heterogéneos como las partículas de yuca gelatinizada.

\section{CUADRO 7.1 MODELOS CINÉTICOS DE CRECIMIENTO EN SUPERFICIES (CONTINUA).}

\begin{tabular}{|c|c|c|}
\hline $\begin{array}{l}\text { VARIABLE QUE SE } \\
\text { MODELA } \\
\text { (SISTEMA } \\
\text { EXPERIMENTAL) }\end{array}$ & $\begin{array}{c}\text { MODELO PROPUESTO } \\
\text { (REFERENCIA) }\end{array}$ & NOMENCLATURA ${ }^{1}$ \\
\hline $\begin{array}{l}\text { Tasas de crecimiento } \\
\text { (Caja de Petri con } \\
\text { inoculación al centro y en } \\
\text { FMS) }\end{array}$ & $\begin{array}{c}\mu_{\mathrm{x}}=\mu_{\mathrm{e}} \frac{\left(\mathrm{X}+\mathrm{X}_{\mathrm{c}}\right)}{\mathrm{X}}\left(1-\left(\frac{\mathrm{X}}{\mathrm{X}_{\mathrm{m}}}\right)\right) \\
\mu_{\mathrm{e}}=\frac{0.693 \mathrm{u}_{\mathrm{r}}}{\beta \mathrm{L}_{\mathrm{a} y} \ln \left(\frac{\beta \mathrm{L}_{\mathrm{ar}}}{\mathrm{D}_{\mathrm{h}}}\right)} \\
\text { (Viniegra-González et al, 1993; 1994) }\end{array}$ & $\begin{array}{l}\mu_{\mathrm{x}}, \text { tasa esp. de crec. para un } \\
\quad \text { cultivo miceliar dado } \\
\mu_{\mathrm{e}} \text {, tasa esp. de crec. en est. est. } \\
\mathrm{X} \text {, biomasa } \\
\mathrm{X}_{r}, \text { biomasa crítica } \\
\mathrm{X}_{\mathrm{m}}, \text { biomasa máxima } \\
\mathrm{n} \text {, coef. de auto-inhibición } \\
\mathrm{u}_{\mathrm{r}} \text {, velocidad promedio de } \\
\quad \text { extensión miceliar } \\
\mathrm{L}_{a v} \text {, longitud promedio de } \\
\quad \text { segmentos distales } \\
\beta \text {, constante } \\
\mathrm{D}_{\mathrm{h}} \text {, diámetro de las hifas }\end{array}$ \\
\hline $\begin{array}{l}\text { Consumo de glucosa y } \\
\text { producción de biomasa } \\
\text { (Caja de Petri con } \\
\text { inoculación al centro y } \\
\text { tubos de vidrio) }\end{array}$ & $\begin{array}{c}\frac{\partial \mathrm{B}}{\partial \mathrm{t}}=\alpha \mathrm{C}_{\mathrm{s}}-\beta_{\mathrm{NM}}+\mathrm{D}_{\mathrm{B}} \frac{1}{\mathrm{r}} \frac{\partial}{\partial \mathrm{r}}\left(\mathrm{r} \frac{\partial \mathrm{B}}{\partial \mathrm{r}}\right) \\
\frac{\partial \mathrm{G}}{\partial \mathrm{t}}=-\mathrm{P}_{\mathrm{s}}+\mathrm{D}_{\mathrm{G}} \frac{1}{\mathrm{r}} \frac{\partial}{\partial \mathrm{r}}\left(\mathrm{r} \frac{\partial \mathrm{G}}{\partial \mathrm{r}}\right) \\
\text { (Molin et al, 1993) }\end{array}$ & $\begin{array}{l}\mathrm{B}, \quad \text { biomasa } \\
\mathrm{C}_{\mathrm{s}}, \quad \text { conc. de glucosa } \\
\mathrm{B}_{\mathrm{NM}}, \text { biomasa sin mantenimiento } \\
\mathrm{D}_{\mathrm{B}}, \quad \text { coef. difusión de biomasa } \\
\mathrm{r}, \quad \text { radio de la colonia } \\
\alpha, \quad \text { coef. de conversión de } \\
\quad \quad \text { glucosa a biomasa } \\
\beta, \quad \text { tasa de muerte de la } \mathrm{B}_{\mathrm{NM}} \\
\mathrm{G}, \quad \text { glucosa } \\
\mathrm{P}_{\mathrm{s}}, \quad \text { glucosa consumida } \\
\mathrm{D}_{\mathrm{G}}, \quad \text { coef. difusión de glucosa }\end{array}$ \\
\hline
\end{tabular}

${ }^{1}$ La notación es la misma que se emplea en las referencias originales.

También en cajas Petri, Molin et al, (1993) desarrollan un modelo en el que acoplan dos ecuaciones que describen el consumo de glucosa y el crecimiento, incluyen el fenómeno de lísis de la biomasa. En el modelo se introduce el concepto de superficie máxima para el consumo de glucosa, como un concepto relevante en los cultivos de FMS. Este modelo toma en cuenta la difusión de la glucosa y los autores determinan los coeficientes (mantenimiento, rendimientos, etc.) experimentalmente. En una comparación entre las predicciones del modelo y los resultados experimentales con $R$. oligosporus y con $T$. viride los autores encuentran una buena correlación 
con $T$. viride y un ajuste regular con $R$. oligosporus, esto último atribuido a la formación de metabolitos secundarios que no fueron considerados en el modelo.

§8. Modelos para las fermentaciones en medios sólidos.

Uno de los primeros intentos por modelar simultáneamente más de una cinética en cultivos sólidos, fue realizado con Aspergillus oryzae en la producción de koji por Okazaki et al, (1980). Los autores aproximan el crecimiento celular con una ecuación empírica llamada logística, a la que asocian la producción de bióxido de carbono (ver Cuadro 8.1). En este modelo incluyen una constante similar, en el concepto, al coeficiente de mantenimiento propuesto antes por Pirt, (1975). Posteriormente, este modelo se ha utilizado con excelentes resultados en muchos trabajos. Otro modelo que también ha encontrado aplicaciones en diferentes cultivos de FMS es el propuesto en 1983 por Sato et al, los autores sugieren que el consumo de oxígeno está asociado a la formación de biomasa y al mantenimiento. Proponen, de manera implícita, que el crecimiento puede depender de algún nutriente o condición limitante como el agua incluyendo el modelo logístico de Okazaki et al, (1980).

Se han publicado modelos prácticos y de fácil aplicación, e.g. el que permite controlar el contenido de humedad de un lecho con agitación intermitente, simplemente controlando la temperatura ambiente (Narahara et al, 1984); el modelo de Laukevics et al, (1985) que predice la máxima concentración celular en función de la densidad de empaque i.e. de los espacios vacíos en lechos estáticos. Los principales elementos de los dos modelos se presentan en el Cuadro 8.1.

Los dos ejemplos anteriores resultan demasiado simples y limitados a casos aislados. Sin embargo, los conceptos que manejan se pueden asociar a otros modelos y enriquecerlos.

Uno de los modelos más completos, por que incluye balances de calor, es el que proponen Saucedo-Castañeda et al, (1990). El modelo se resuelve en estado no estacionario y se supone que: (i) el crecimiento de $A$. niger sobre yuca gelatinizada sigue un comportamiento de tipo logístico (Okazaki et al, 1980), (ii) el consumo de azúcares se distribuye en biomasa y mantenimiento, (iii) la producción de bióxido de carbono depende del consumo de azúcares, (iv) los perfiles de temperatura en la dirección axial son despreciables y sólo se consideran los perfiles radiales, y ( $v$ ) la tasa específica de crecimiento depende fuertemente de la temperatura siguiendo un comportamiento doble logarítmico (Esener et al, 1981). El modelo predice gradientes radiales de temperatura que coinciden bien con los experimentales, toma en cuenta la naturaleza heterogénea de los materiales porosos. Sin embargo, en el modelo falta incluir otras variables físicas como los cambios de las propiedades físicas del medio, el calor metabólico generado con respecto al tiempo y la humedad o la actividad del agua. 


\section{CUADRO 8.1 MODELOS MATEMÁTICOS EN CULTIVOS HETEROGÉNEOS DE FMS.}

\begin{tabular}{|c|c|c|}
\hline $\begin{array}{c}\text { SISTEMA } \\
\text { EXPERIMENTAL }\end{array}$ & $\begin{array}{c}\text { MODELO PROPUESTO } \\
\text { (REFERENCLA) }\end{array}$ & NOMENCLATURA ${ }^{!}$ \\
\hline $\begin{array}{l}\text { - Aspergillus oryzae } \\
\text { - Arroz precocido } \\
\text { Lechos con aireación } \\
\text { continua y agitación } \\
\text { intermitente }\end{array}$ & $\begin{array}{l}\frac{\mathrm{dm}}{\mathrm{dt}}=\mu \mathrm{m}\left(1-\frac{\mathrm{m}}{\mathrm{N}}\right) \\
\frac{\mathrm{dA}}{\mathrm{dt}}=\mathrm{k}_{1} \frac{\mathrm{dm}}{\mathrm{dt}}-\mathrm{k}_{2} \mathrm{~m} \\
\text { (Okazaki et al, 1980) }\end{array}$ & $\begin{array}{ll}\mathrm{m}, & \text { peso seco del micelio } \\
\mathrm{t}, & \text { tiempo } \\
\mu, & \text { tasa esp. de crecimiento } \\
\mathrm{N}, & \text { máximo peso seco micelio } \\
\mathrm{A}, & \mathrm{CO}, \text { producido } \mathrm{mg}^{-1} \text { de } \\
& \text { materia seca } \\
\mathrm{k}_{1}, & \mathrm{CO}, \text { producido } \mathrm{mg}^{-1} \text { micelio } \\
\mathrm{k}_{2}, & \mathrm{CO}, \text { producido debido a la } \\
& \text { respiración } \mathrm{mg}^{-1} \text { micelio }\end{array}$ \\
\hline $\begin{array}{l}\text { - Candida lipolytica } \\
\text { - Pulpa de madera } \\
\text { impregnada de un } \\
\text { medio de cultivo } \\
\text { - Lechos estáticos } \\
\end{array}$ & $\begin{array}{c}\text { OUR }=\frac{1}{\mathrm{M}_{0}}\left(\frac{1}{\mathrm{Y}_{\mathrm{x} / \mathrm{o}}} \frac{\mathrm{dX}}{\mathrm{dt}}+\mathrm{mX}\right) \\
\text { (Sato et al, 1983) }\end{array}$ & $\begin{array}{l}\text { OUR, tasa de consumo de oxígeno } \\
\mathrm{M}_{0}, \text { materia seca en el reactor } \\
\mathrm{Y}_{\mathrm{x} / \mathrm{h}} \text {, rendimiento celular base } \mathrm{O}, \\
\mathrm{X}, \quad \text { biomasa total en el reactor } \\
\mathrm{m}, \quad \text { tasa esp. consumo } \mathrm{O} \text {, mant. }\end{array}$ \\
\hline $\begin{array}{l}\text { - Aspergillus onzae } \\
\text { - Arroz precocido } \\
\text { - Lechos con aireación } \\
\text { continua y agitación } \\
\text { intermitente }\end{array}$ & $\begin{array}{c}\mathrm{T}_{\text {surt }}=\mathrm{T}_{\text {out }}+1.03 \Delta \mathrm{T}-131 \Delta \mathrm{PCO}_{2} \\
\Delta \mathrm{T}=\left(\mathrm{T}_{\text {out }}-\mathrm{T}_{\text {in }}\right) \\
\text { (Narahara et al, 1984) }\end{array}$ & $\begin{array}{l}\mathrm{T}_{\mathrm{cilr}}, \text { temp. que rodea al reactor } \\
\mathrm{T}_{\mathrm{sin}}, \text { temp. salida del aire } \\
\mathrm{T}_{\text {in }} \text {, temp. entrada del aire } \\
\Delta \mathrm{PCO}_{2} \text {, diferencia en la presión } \\
\quad \mathrm{CO} \text {, a la entrada y la salida }\end{array}$ \\
\hline $\begin{array}{l}\text { - Trichoderma reesi } \\
\text { Trichoderma lignorum } \\
\text { Chaetomium } \\
\text { cellulolyticum } \\
\text { - Paja de trigo } \\
\text { - Lechos empacados } \\
\text { estáticos }\end{array}$ & $\begin{array}{c}\mathrm{X}=\mathrm{m}_{\mathrm{x}} \rho_{\mathrm{x}} \mathrm{V}_{\mathrm{x}} \Psi_{\mathrm{x}} \\
\text { (Laukevics et al, 1985) }\end{array}$ & $\begin{array}{ll}\mathrm{X}, & \text { biomasa seca } \mathrm{I}^{-1} \text { sustrato } \\
\mathrm{m}_{\mathrm{x}}, & \text { fracc. de mat seca en biom. } \\
\rho_{\mathrm{x}}, & \text { densidad de la biomasa } \\
& \text { húmeda } \\
V_{\mathrm{x}} & \text { fracción del volumen del } \\
& \text { reactor, disponible } \\
\Psi_{\mathrm{x}}, & \text { densidad del empaque }\end{array}$ \\
\hline
\end{tabular}

\footnotetext{
${ }^{1}$ La notación es la misma que se emplea en las referencias originales.
} 


\section{CUADRO 8.1 MODELOS MATEMÁTICOS EN CULTIVOS HETEROGÉNEOS DE FMS (CONTINUACIÓN)}

\begin{tabular}{|c|c|c|}
\hline $\begin{array}{c}\text { SISTEMA } \\
\text { EXPERIMENTAL }\end{array}$ & $\begin{array}{l}\text { MODELO PROPUESTO } \\
\text { (REFERENCLA) }\end{array}$ & NOMENCLATURA $^{1}$ \\
\hline $\begin{array}{l}\text { - Aspergillus niger } \\
\text { - Yuca gelatinizada } \\
\text { - Columnas empacadas }\end{array}$ & $\begin{array}{c}\mathrm{R}_{\mathrm{x}}=\mu_{\max } \mathrm{X}\left(1-\frac{\mathrm{X}}{\mathrm{X}_{\max }}\right) \Phi \\
\mathrm{R}_{\mathrm{s}}=\frac{\mathrm{R}_{\mathrm{x}}}{\mathrm{Y}_{\mathrm{x} / \mathrm{s}}}+\mathrm{m} \mathrm{X} \Phi \\
\mu_{\max }=\frac{\mathrm{A} \exp \left(\frac{-\mathrm{E}_{\mathrm{al}}}{\mathrm{RT}^{*}}\right)}{1+\mathrm{B}\left(\frac{-\mathrm{E}_{\mathrm{a} 2}}{\mathrm{RT}^{*}}\right)} \\
\text { (Saucedo-Castañeda et al, 1990) }\end{array}$ & 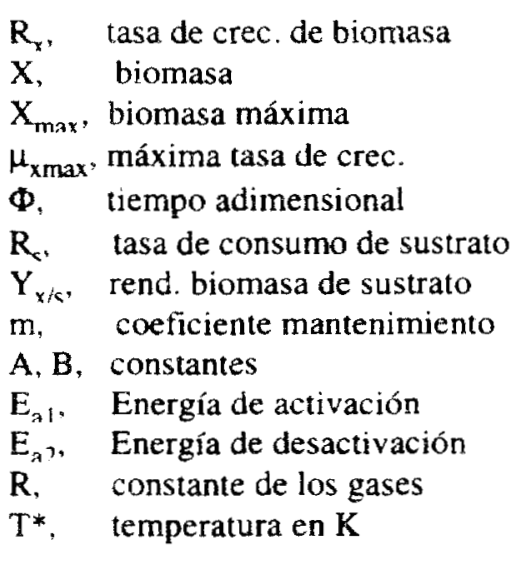 \\
\hline $\begin{array}{l}\text { - Rhizopus oligosporus } \\
\text { - Salvado de maíz } \\
\text { molido y cocido, } \\
\text { biorreactor de tambor } \\
\text { giratorio }\end{array}$ & $\begin{array}{c}\frac{\mathrm{dx}_{1}}{\mathrm{dt}}=\mu_{\mathrm{m}}\left(1-\frac{\mathrm{x}_{1}}{\mathrm{x}_{\mathrm{m}}}\right) \mathrm{x}_{1} \\
\frac{\mathrm{dx}}{\mathrm{dt}}=\frac{\mathrm{Y}_{\mathrm{S} / \mathrm{X}}\left(\frac{\mathrm{dx_{1 }}}{\mathrm{dt}}\right)+\mathrm{mx}_{1}}{1-\mathrm{x}_{1} \mathrm{Y}_{\mathrm{S} / \mathrm{X}}} \mathrm{x}_{2} \\
\mathrm{x}_{2} \frac{\mathrm{dx_{3 }}}{\mathrm{dt}}=\mathrm{F}(\text { Hin-Hout })+\mathrm{x}_{1} \mathrm{Y}_{\mathrm{H} 2 \mathrm{O}} \frac{\mathrm{dx_{2 }}}{\mathrm{dt}}+\mathrm{x}_{2} \frac{\mathrm{dx_{1 }}}{\mathrm{dt}} \\
+\mathrm{m}_{\mathrm{H} 2 \mathrm{O}} \mathrm{x}_{1} \mathrm{x}_{2}-\mathrm{x}_{3} \frac{\mathrm{dx_{2 }}}{\mathrm{dt}} \\
\text { (Sargantanis et al, 1993) }\end{array}$ & 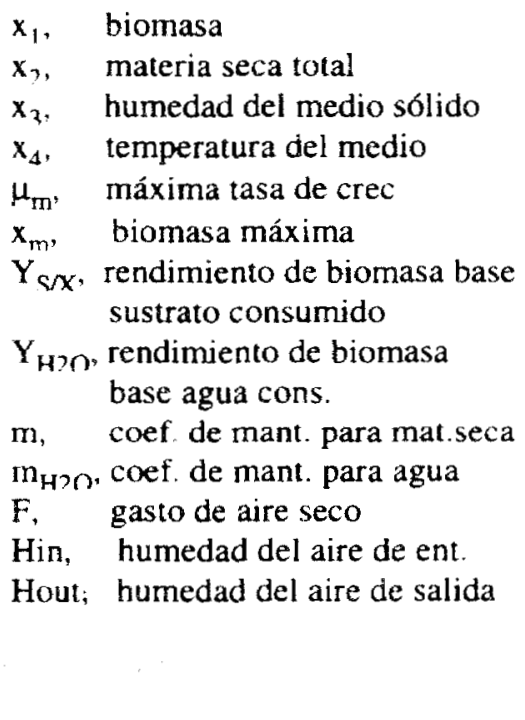 \\
\hline
\end{tabular}

${ }^{1}$ La notación es la misma que se emplea en las referencias originales. 
Recientemente Sargantanis et al, (1993) proponen un modelo menos formal y completo que el de Saucedo-Castañeda et al, (1990), pero de una importancia indudable en tanto que lo aplican al control en línea de un pequeño biorreactor rotatorio con capacidad de 1.3 litros, completamente instrumentado. Estos autores desarrollan un modelo, estado no estacionario, en el que asocian variables macroscópicas y se plantean el problema de controlar la temperatura del material. Algunas de las ecuaciones que se proponen para el modelo se muestran en el Cuadro 8.1. Los aspectos más relevantes del modelo de Sargantanis et al, (1993) son: (i) describe el crecimiento celular con la ecuación logística de Okazaki et al (1980), (ii) el sustrato se distribuye en catabolismo y anabolismo, (iii) la fase sólida se trata como materia seca (esto incluye a la biomasa), (iv) utilizan coeficientes estequiométricos de transformación de azúcares en biomasa y bióxido de carbono, (v) los balances de calor incluyen pérdidas de calor por evaporación, y (vi) algunos de los parámetros como la capacidad calorífica del medio sólido, varían con las variaciones de agua del medio. Logran demostrar que la mayor cantidad de calor se remueve vía evaporación, con lo cual se cumple el objetivo de este grupo de investigación. Entre las limitaciones del modelo destaca la dificultad que encontraron para extrapolar resultados para biomasa y las tasas de crecimiento celular.

Como se aprecia, la formulación de modelos matemáticos directamente para cultivos de FMS esta muy limitada. Para Mitchell (1992) se pueden distinguir tres limitaciones: (i) el complejo tridimensional que se forma entre crecimiento de los hongos filamentosos y el sustrato, (ii) la complejidad del sustrato por sí mismo, y (iii) las dificultades para medir biomasa directamente sin interferencias. Una alternativa interesante para poder explicar y predecir los fenómenos que se presentan en los cultivos en FMS es la utilización de sistemas de trabajo modelo o modelos experimentales ideales, en donde sea posible minimizar las imprecisiones y que las hipótesis emitidas sean congruentes, en la medida de lo posible con la realidad.

§9. Modelos en sistemas experimentales ideales.

Los sistemas experimentales ideales o sistemas modelo son aquellos que presentan simplificaciones de sistemas complejos. Los sistemas modelo permiten caracterizar condiciones y variables que en sistemas complejos o sistemas reales no sería posible. Sin embargo, un sistema modelo debe conservar las principales características del sistema real.

Los trabajos con sistemas modelo no son recientes pero tampoco son abundantes. Una discusión sobre estos sistemas experimentales, que tratan de imitar las condiciones y aspectos más relevantes de los cultivos en FMS, se presenta en el capítulo $\$ 3$ de la parte I A de este trabajo. 
Destacan, entre otros, el uso de esponjas naturales (Fujishima ef al, 1972, Endo et al, 1987) poliuretano de baja densidad (Endo et al, 1987), vidrio poroso (Larroche y Gross, 1989), bagazo de caña (Oriol, 1988a; Saucedo-Castañeda, 1991) y resinas de intercambio iónico (Auria et al, 1990, Christen et al, 1993). Sin embargo, la formulación de modelos matemáticos a partir de sistemas experimentales ideales es apenas reciente y por lo tanto escasa.

El primer modelo matemático propuesto para los cultivos en FMS, a partir de sistemas ideales (Mitchell et al, 1986, 1988; 1991), se fundamenta en observaciones experimentales realizadas en un sustrato constituido por almidón y nutrientes absorbidos en una matriz gelificada de $\mathrm{K}$ carragenina. El gel absorbido permite elaborar diversas formas, excepto la esférica. Los autores utilizan $R$. oligosporus y estudian la síntesis de glucoamilasas asociadas al crecimiento del hongo. En el modelo mecanístico incluyen los siguientes aspectos: (i) exportación de las glucoamilasas en la superficie, (ii) difusión de las enzimas en el medio hacia el almidón, de acuerdo con la ley de Fick, (iii) hidrólisis de almidón y liberación de glucosa (iv) difusión de la glucosa hacia el hongo, y (v) incorporación de la glucosa al micelio y formación de nuevas células. En el Cuadro 9.1 se presentan los principales elementos del modelo matemático de Mitchell et al (1991)

El modelo matemático más reciente que se ha propuesto para cultivos en FMS, a partir de sistemas ideales es el de Auria et al, (1990). En este caso, el sistema modelo está constituido por sacarosa y medio de cultivo absorbido en una resina de intercambio iónico (Amberlita IRA 900) de forma esférica regular, i.e. la forma regular más deseable en la formulación de modelos matemáticos (Mitchell et al, 1988). El modelo de Auria et al, (1990) establece una correlación clara entre el crecimiento de Aspergillus niger con variables fisicas como la caida de presión en columnas empacadas. Aplicando la ley de Darcy obtienen una correlación muy aceptable entre ambos parámetros. En trabajos posteriores (Auria et al, 1992) correlacionan los coeficientes de permeabilidad efectivos de la difusión del oxigeno o del bióxido de carbono en columnas con los cambios de los espacios vacios de las mismas. En el Cuadro 9.1 se presentan los principales elementos del modelo difusivo propuesto por Auria et al, (1992) en donde destacan tres elementos: (i) la difusión de los gases es principalmente unidireccional, (ii) la variación de los coeficientes difusivos efectivos depende de la biomasa que ocupa los espacios interparticulares del soporte ideal, y (iii) los rendimientos de los gases y los coeficientes de mantenimiento son constantes. Estas simplificaciones permitieron correlacionar los coeficientes de difusión del oxígeno y bióxido de carbono, en pequeñas columnas empacadas, con concentraciones de biomasa hasta de $30 \mathrm{mg}$ biomasa seca $\mathrm{g}^{-1}$ soporte seco. Posteriormente establecieron (Auria et al, 1994), en un reactor convectivo empacado, una relación entre la permeabilidad intrínseca del sistema con concentraciones de biomasa hasta de $104 \mathrm{mg}$ biomasa seca $\mathrm{g}^{-1}$ soporte seco. 


\section{CUADRO 9.1 MODELOS MATEMÁTICOS EN CULTIVOS CON SISTEMAS EXPERIMENTALES IDEALES}

\begin{tabular}{|c|c|c|}
\hline $\begin{array}{c}\text { SISTEMA } \\
\text { EXPERIMENTAL }\end{array}$ & $\begin{array}{c}\text { MODELO PROPUESTO } \\
\text { (REFERENCLA) }\end{array}$ & NOMENCLATURA ${ }^{1}$ \\
\hline $\begin{array}{l}\text { - Rhizopus oligosporus } \\
\text { Almidón, nutrientes } \\
\text { absorbidos en Kapa- } \\
\text { carragenina con } \\
\text { diversas formas } \\
\text { geométricas. } \\
\text { Recipientes con } \\
\text { ventilación forzada, } \\
\text { humedad controlada }\end{array}$ & $\begin{array}{c}\left.\mathrm{D}_{\mathrm{E}} \frac{\partial \mathrm{E}}{\partial \mathrm{x}}\right|_{\delta}=\mathrm{RH}\left(\mathrm{t}_{\mathrm{E}}-\mathrm{t}\right) \\
\frac{\partial \mathrm{E}}{\partial \mathrm{t}}=\mathrm{D}_{\mathrm{E}} \frac{\partial^{2} \mathrm{E}}{\partial \mathrm{x}^{2}} \\
-\frac{\partial \mathrm{S}}{\partial \mathrm{t}}=\frac{\mathrm{k}_{\mathrm{cat}} \mathrm{E} \mathrm{S}}{\mathrm{K}_{\mathrm{m}}+\mathrm{S}} \\
\frac{\partial \mathrm{G}}{\partial \mathrm{t}}=\frac{\mathrm{k}_{\mathrm{cat}} \mathrm{E} \mathrm{S}}{\mathrm{k}_{\mathrm{m}}+\mathrm{S}}+\mathrm{D}_{\mathrm{G}} \frac{\partial^{2} \mathrm{G}}{\partial \mathrm{x}^{2}} \\
\frac{\partial \mathrm{X}}{\partial \mathrm{t}}=-\left.\mathrm{Y}_{\mathrm{X} / \mathrm{G}} \mathrm{D}_{\mathrm{G}} \frac{\partial \mathrm{G}}{\partial \mathrm{x}}\right|_{\delta} \\
\text { (Mitchell et al, 1991) }\end{array}$ & 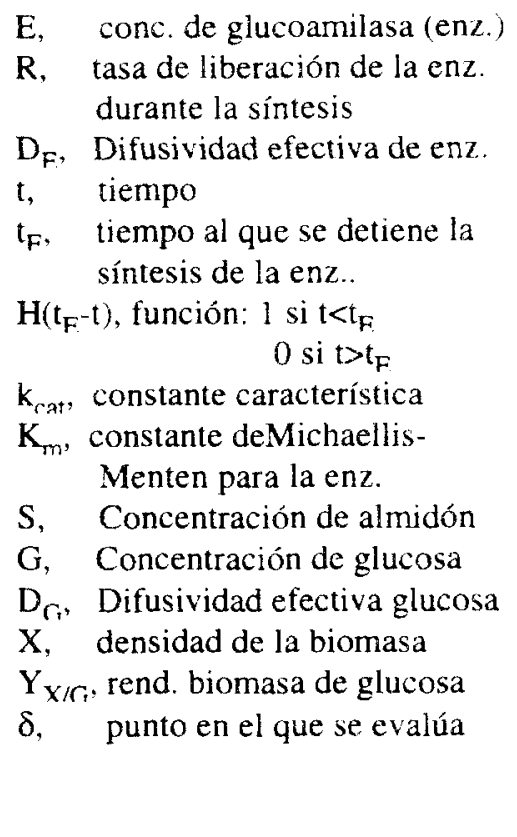 \\
\hline $\begin{array}{l}\text { - Aspergillus niger } \\
\text { Sacarosa, nutrientes } \\
\text { absorbidos en una } \\
\text { resina de intercambio } \\
\text { iónico (Amberlita IRA } \\
\text { 900) de forma esférica. } \\
\text { - Columnas empacadas } \\
\text { con ventilación } \\
\text { forzada en la parte } \\
\text { superior de las } \\
\text { columnas. }\end{array}$ & $\begin{array}{c}\rho_{\mathrm{g}} \frac{\partial \varepsilon \mathrm{C}_{\alpha}}{\partial \mathrm{t}}=\rho_{\mathrm{g}} \frac{\partial J_{\alpha}}{\partial \mathrm{z}}-\mathrm{R} \alpha \\
J_{\alpha}=-\mathrm{D}_{\alpha} \frac{\partial \varepsilon \mathrm{C}_{\alpha}}{\partial \mathrm{z}} \\
\mathrm{R} \alpha=\frac{1}{\mathrm{Vr}}\left(\frac{1 \partial \mathrm{Xd}}{\mathrm{Y}_{\alpha} \partial \mathrm{t}}+\mathrm{m}_{\alpha} \mathrm{Xd}\right. \\
\mathrm{Xd}=\rho_{\mathrm{x}} \mathrm{W}_{\mathrm{s}} \operatorname{Vr}\left(\varepsilon_{0}-\varepsilon\right) \\
\text { (Auria et al, 1992) }\end{array}$ & $\begin{array}{ll}\mathrm{C}_{r r}, & \text { concentración del gas, } \\
\alpha & \text { oxígeno o bióxido de carbono } \\
\varepsilon, & \text { porosidad interparticular } \\
\varepsilon_{0}, & \text { porosidad interpart. inicial } \\
t, & \text { tiempo } \\
\mathrm{z}, & \text { coordenada axial } \\
\rho_{g}, & \text { densidad del gas } \\
J_{r}, & \text { flux de la fase gaseosa } \\
\mathrm{R}_{r}, & \text { tasa de consumo del gas } \\
\mathbf{D}_{r}, & \text { difusividad efectiva del gas } \\
\mathrm{V}_{\mathrm{r}}, & \text { volumen del reactor } \\
\mathrm{Y}_{r}, & \text { rend. biomasa base } \mathrm{O}, \mathrm{o} \mathrm{CO}, \\
\mathrm{m}_{r}, & \text { coef. de mant. baseO, o } \mathrm{CO}, \\
\mathrm{Xd}, & \text { biomasa seca } \\
\mathrm{W}_{\mathrm{s}}, & \text { materia seca en la biomasa }\end{array}$ \\
\hline
\end{tabular}

${ }^{1}$ La notación es la misma que se emplea en las referencias originales. 


\section{Resumen y conclusiones.}

Se presenta una revisión bibliográfica sobre lo que se conoce en el tema de los biorreactores para cultivos en FMS, los tipos de biorreactores y los principios de diseño y escalamiento de los mismos. La acumulación de calor y la naturaleza del sustrato o del soporte, son los dos factores que han orientado el diseño y operación de los diferentes tipos de biorreactores que se conocen. El diseño y el escalamiento de biorreactores ha surgido fundamentándose en un balance que se inclina mucho a las bases empíricas y poco a las bases teóricas de la física, la termodinámica y la bioquímica. Es necesario desarrollar modelos de estudio con bases más teóricas firmes. Es necesario desarrollar estudios que incluyan propiedades microscópicas de los soportes-sustratos sin olvidar la dimensión macroscópica de los reactores, con esto se esperaría abordar de manera clara y objetiva el diseño y el escalamiento de bioerreactores. Estos estudios deberían partir de concepciones teóricas bien formuladas y estructuradas o modelos matemáticos que permitan predecir y entender los fenómenos que ocurren en los cultivos de FMS. A la fecha, poco se ha publicado sobre el modelado matemático en el campo de los cultivos para FMS. Se conocen esfuerzos encomiables, pero aislados y aparentemente insuficientes, que, sin embargo, constituyen un buen punto de partida. 


\section{PRESENTACIÓN DEL PROBLEMA, OBJETIVOS Y ALCANCES DEL ESTUDIO}

Una explicación a la limitada aplicación comercial de los cultivos sólidos es la carencia de modelos teóricos que permitan (i) predecir la interacción de las diferentes variables que participan, (ii) entender la importancia relativa de unas variables con otras y (iii) extrapolar resultados a otros sistemas experimentales similares. Uno de los factores que explican esta carencia de modelos matemáticos teóricos es la dificultad inherente a la naturaleza heterogénea de los medios sólidos. Una alternativa interesante es la utilización de sistemas experimentales modelo que conserven las principales características de los cultivos en medios sólidos, que permitan utilizar concentraciones elevadas de sustratos solubles y que permitan simplificar el tratamiento teórico del problema mediante la utilización de hipótesis de trabajo apegadas a la realidad experimental. Por lo que el objetivo y alcances del trabajo son los siguientes:

\section{Objetivo:}

Formular, resolver y validar un modelo matemático basado en observaciones provenientes de un sistema experimental ideal constituido por una resina de intercambio iónico (Amberlita IRA-900), una fase líquida con sustratos solubles concentrados, un hongo filamentoso (Aspergillus niger) y una fase gaseosa continua.

\section{Alcances del estudio:}

1. La formulación se concretará a un modelo de tipo puntual en torno a un volumen elemental representativo en donde, a partir de una serie de simplificaciones hipotéticas, intervendrán variables que definirán todo estado del sistema. Mediante el uso de términos cinéticos, de relaciones estequiométricas; y de balances de masa y energía se generará un modelo teórico que será capaz de predecir el comportamiento de las siguientes variables: Biomasa, azúcares solubles, agua, oxígeno, bióxido de carbono y temperatura del medio. El modelo deberá contemplar las principales características de estos cultivos i.e. los espacios interparticulares y la posibilidad de incrementar la concentración inicial de nutrientes.

2. La solución del modelo se realizará resolviendo dos niveles de complejidad (i) uno sencillo (dependiente sólo del tiempo) que permita evaluar parámetros, valores iniciales y dar una idea clara de los alcances del modelo, y (ii) uno más complejo (dependiente del tiempo y del espacio) que permita conocer variaciones distribuidas en el espacio.

3. La validación del modelo se realizará confrontando las predicciones con resultados experimentales realizados bajo diferentes condiciones de operación en reactores de laboratorio. 


\section{PARTE II. DESARROLLO DE UN MODELO MATEMÁTICO GENERAL PARA LA FERMENTACIÓN EN MEDIO SÓLIDO SOBRE UN SOPORTE INERTE.}

En la segunda parte de este trabajo se define el marco teórico en el que se sitúa al sistema de fermentación sólida sobre un soporte inerte. Se propone un conjunto de hipótesis de trabajo que justifica el modelo que se desarrolia más adelante, también se definen las variables que contiene el modelo y las variables que se consideran como las más importantes o variables de estado. En los capitulos $\$ 13$ y $\$ 14$ se desarrollan los balances de masa y energía para cada una de las variables de estado seleccionadas. Los balances de energía se reducen a un balance térmico en el capítulo $\$ 15$ y en el capítulo $\$ 16$ se muestran las relaciones cinéticas contenidas en los balances de masa y energía. Al conjunto de ecuaciones generadas se le identifica como modelo matemático general. El modelo matemático general se presenta en coordenadas cilindricas. Finalmente se discute la estrategia para la solución de este modelo matemático

El objetivo explicito de esta segunda parte es proponer y discutir un conjunto de hipótesis de trabajo obtenidas del conocimiento práctico de los sistemas de FMS y traducirlas a un lenguaje matemático, a través de ecuaciones de conservación, que permitan obtener un modelo general como punto de partida.

\section{A DEFINICIONES E HIPÓTESIS DE TRABAJO.}

$\S 10$. Definición del sistema, las fases y los constituyentes

El sistema esta constituido por un material poroso heterogéneo que contiene una mezcla de microorganismos, soporte y medio de cultivo, localizados dentro de un espacio bien delimitado y bajo condiciones controladas. Para fines prácticos del modelado matemático, el sistema se reduce a un VER que representa una dimensión media conceptual. Esta dimensión es demasiado grande en relación al diámetro de los poros del soporte y pequeña en relación a las dimensiones de un biorreactor, es una dimensión más próxima al diámetro de las partículas que contiene. La geometría del sistema, en principio es cilíndrica y el volumen del orden de $10 \mathrm{ml}$ ( $\pm 3.0 \mathrm{~g}$ de soporte seco). En un VER, como el que se define será posible medir: (i) las pérdidas de presión que aumentan con el crecimiento de los microorganismos, (ii) la producción de $\mathrm{CO}_{2}$ y el consumo de oxigeno, (iii) la biomasa producida, (iv) el consumo de los nutrientes solubles, (v) la temperatura y (vi) la producción de metabolitos volátiles o solubles. El VER es un sistema que se caracteriza por que contiene cuatro fases

- La fase sólida indeformable constituida de esferas (soporte). Las esferas son autónomas entre si. 
- La fase biológica, constituida por los microorganismos Independientemente de su estado fisiológico.

- La fase líquida constituida por agua, sustancias solubles del medio de cultivo y gases en forma soluble. Toda la fase se encuentra atrapada dentro de las esferas del soporte

- La fase gaseosa, siempre en movimiento entre las esferas del soporte, constituida por aire húmedo saturado que transporta oxígeno, bióxido de carbono y los metabolitos volátiles producidos por los microorganismos.

\section{\$11. Hipótesis de trabajo.}

H:1 Los microorganismos constituyen una fase autónoma o fase biótica, cuyo particular estado de agregación está determinado por las condiciones ambientales y el tiempo

NOTA Aunque cerca del $90 \%$ de su peso es agua, no sería posible considerarlos como parte de la fase liquida ya que se trata de agua estructurada y no libre; de la misma manera no es posible considerarlos como parte de la fase sólida.

H:2 El soporte es un medio bifásico constituido por una matriz sólida indeformable -al menos durante la fermentación- saturada por el medio liquido de cultivo

H:3 El espacio interparticular esta ocupado por la fase gaseosa y por la fase biológica. La fase líquida esta ausente entre las esferas del soporte.

NOTA: Esta hipótesis queda satisfecha desde el momento en que no se observa escurrimiento macroscópico (Auria et al, 1990).

H:4 El soporte empleado es inerte biológicamente, no contiene inhibidores del crecimiento microbiano y su matriz sólida no es metabolizable.

H:5 Existe al menos una reacción química compleja entre los constituyentes de las fases: liquida, gaseosa y biológica. Esta reacción es el crecimiento microbiano superficial, es una reacción irreversible limitada por algún factor físico o por algún nutriente. El crecimiento al interior de las esferas del soporte no se toma en cuenta. Toda el agua requerida para el crecimiento proviene del interior del soporte.

NOTA: El tamaño promedio de los poros es de $25-25 \times 10^{-6} \mathrm{~m}$ y el diámetro de las esporas fluctúa entre 12 y $20 \times 10^{-6} \mathrm{~m}$, por lo que el crecimiento al interior se puede considerar despreciable (Auria et al, 1990)

H:6 Existe un equilibrio térmico entre las cuatro fases, por lo que se considera una sola temperatura local.

H:7 La masa inicial de agua no varía durante la fermentación, la distribución de la misma si podrá cambiar 
H:8 La presión de la fase gaseosa es siempre constante y prácticamente igual a la presión atmosférica. Durante la fermentación, el aire permanece siempre saturado en vapor de agua.

H:9 En la fase gaseosa, todos los constituyentes tienen la misma velocidad fenomenológica.

H:10 La viscosidad de la fase gaseosa es despreciable y las fuerzas internas estan caracterizadas por las presiones parciales de la fase gaseosa.

H:11 La contribución de la radiación a la energía interna se puede despreciar.

H:12 El crecimiento microbiano depende directamente de los siguientes factores: (i) la temperatura, (ii) la concentración de los microorganismos, (iii) la disponibilidad de los espacios vacíos, y (iv) la cantidad de azúcares presentes incluyendo alguna inhibición.

H:13 Los microorganismos consumen la fuente de carbono para satisfacer dos funciones biológicas el crecimiento microbiano y el mantenimiento celular.

H:14 La producción de bióxido de carbono y el consumo de oxígeno (tanto para el crecimiento como para el mantenimiento), dependen del crecimiento celular y de los azúcares consumidos para las funciones propias del mantenimiento celular.

§12. Definición de las variables del modelo y variables de estado:

un enfoque fenomenológico

Para poder representar adecuadamente al sistema de FMS o medio real, se decide por una aproximación fenomenológica (Benet, 1981). Este tipo de aproximación supone que existe una superposición macroscópica de los medios que ocupan todo el espacio geométrico. Los medios se identificarán de la manera siguiente:

- Fase sólida indeformable: soporte inerte.

- Fase biológica: microorganismos.

- Fase líquida: agua y azúcar.

- Fase gaseosa: vapor de agua, nitrógeno, oxígeno y bióxido de carbono.

Esta aproximación supone que cada fase es un medio continuo y que cada constituyente se puede considerar también como un medio continuo. A cada uno de estos medios es posible asociarle uno o varios campos de variables intensivas fenomenológicas que sean capaces de definirlo en todo punto mediante el uso de promedios de magnitudes reales microscópicas dentro de un volumen elemental representativo (Fras; 1989). 
Variables del modelo y definiciones. Para el desarrollo del modelo se emplearán las siguientes variables y subíndices, en el ANEXO I se presenta un resumen de las convenciones adoptadas:

1. Masa aparente por unidad de volumen, representada por: $\rho$

Para cada constituyente $i$, la masa aparente por unidad de volumen $\rho_{i}$ se define como:

$\rho_{\mathrm{i}}=\frac{\text { Masa del constituyente } \mathrm{i} \text { dentro de un volumen geométrico } \mathrm{V}}{\text { volumen de } \mathrm{V}}$

Para una fase $\alpha$ que contiene i constituyentes, la masa aparente por unidad de volumen $\rho_{\alpha}$, está dada por la siguiente expresión:

$$
\rho_{\alpha}=\Sigma \rho_{\alpha i}
$$

La masa aparente total por unidad de volumen del conjunto de las fases $\rho$ es:

$$
\rho=\sum_{\alpha} \rho_{\alpha}=\sum_{\alpha} \sum_{i} \rho_{\alpha i}
$$

2. La velocidad fenomenológica del constituyente i, de la fase $\alpha$, está representada por:

$\mathrm{v}_{\alpha i}{ }^{\mathrm{k}}$

que corresponde a un flujo de masa del constituyente i dentro de $\alpha$, y está dado por:

$$
\rho_{\alpha i} v_{\alpha i}{ }^{k}
$$

3. La velocidad baricéntrica del medio se representa como $v^{k}$, que corresponde a un flujo de masa del conjunto de las fases, se define como:

$$
\rho v^{k}=\sum_{\alpha} \sum_{i} \rho_{\alpha i} v_{\alpha i}^{k}
$$

4. La velocidad baricéntrica de la fase $\alpha, v_{\alpha}{ }^{k}$, está asociada al flujo de masa de la fase $\alpha$ como sigue:

$$
\rho_{\alpha} v_{\alpha}{ }^{k}=\sum_{i} \rho_{\alpha i} v_{\alpha i}{ }^{k}
$$

5. El flux másico total para el conjunto de las fases del sistema, de las ecuaciones (12-5) y (12-6) se puede ver que está dado por

$$
\rho v^{k}=\sum \rho_{\alpha} v_{\alpha}^{k}
$$

6. La energía interna, representada por u, que se asocia a la energía interna másica pu.

Para el constituyente i de la fase $\alpha ; \rho_{\alpha i} u_{\alpha i}$ y para la fase $\alpha$, que contiene i especies:

$$
\rho_{\alpha} u_{\alpha}=\Sigma \rho_{\alpha i} u_{\alpha i}
$$


La energía interna másica total para el conjunto de las fases del sistema, está dada por:

$$
\rho \mathrm{u}=\sum_{\alpha} \rho_{\alpha} \mathrm{u}_{\alpha}=\underset{\alpha i}{\Sigma} \rho_{\alpha \mathrm{i}} \mathrm{u}_{\alpha \mathrm{i}}
$$

7. La temperatura representada por: $T$

Variables de estado. Para una mayor simplicidad se omite la notación con dobles índices, por lo tanto, las variables seleccionadas para describir el estado del sistema son las siguientes:

- Las masas aparentes por unidad de volumen:

$\rho_{a}$ masa aparente de la fase sólida,

$\rho_{\mathrm{x}}$ masa aparente de la fase biológica,

$\rho_{s}$ masa aparente del azúcar - fase líquida-

$\rho_{\mathrm{e}}$ masa aparente del agua - fase líquida-

$\rho_{N}$ masa aparente del nitrógeno - fase gaseosa-

$\rho_{\mathrm{v}}$ masa aparente del vapor de agua - fase gaseosa-

$\rho_{0}$ masa aparente del oxígeno - fase gaseosa-

$\rho_{\mathrm{c}}$ masa aparente del bióxido de carbono - fase gaseosa-

- La temperatura, T

A continuación se demostrará que las masas por unidad de volumen $\rho_{a}$ y $\rho_{N}$, podrán considerarse constantes y que el estado del sistema quedará definido con las siguientes variables:

$$
\rho_{x}, \rho_{s}, \rho_{e}, \rho_{v}, \rho_{o}, \rho_{c y} T
$$




\section{B. ECUACIONES DE BALANCE, RELACIONES CINÉTICAS Y DEDUCCIÓN DEL MODELO GENERAL EN COORDENADAS CILÍNDRICAS.}

\section{$\S 13$. Balances de masa}

La forma general del balance de masa para un constituyente i cualquiera, es la siguiente:

$$
\frac{\partial \rho_{i}}{\partial t}=-\left(\rho_{i} v_{i}^{k}\right)_{, k}+C_{i}
$$

donde: $\mathrm{C}_{\mathrm{i}}$ es el aporte de masa del constituyente 1 por unidad de volumen y tiempo, representa la tasa volumétrica de producción del mismo constituyente, como producto de la biorreacción. Para las convenciones utilizadas con los índices ver el ANEXO I.

Para las fases y los constituyentes del sistema:

Fase sólida. Tomando en cuenta las hipótesis H:2 y H:4, el balance de masa de la fase sólida es:

$$
\frac{\partial \rho_{\mathrm{a}}}{\partial \mathrm{t}}=0
$$

Fase biológica. Según la hipótesis H:1 esta fase esta constituida por los microorganismos que colonizan superficialmente (hipótesis H:5) el soporte impregnado. Toda variación en la biomasa es producto de la biorreacción, es decir:

$$
\frac{\partial \rho_{x}}{\partial t}=C_{x}
$$

Fase líquida. En tanto que estos constituyentes permanecen inmóviles siempre en el interior del soporte, es decir $\mathrm{v}_{\mathrm{s}}{ }^{\mathrm{k}}=\mathrm{v}_{\mathrm{e}}{ }^{\mathrm{k}}=0$; Los balances de masa para los constituyentes de esta fase (azúcar y agua.) son los siguientes:

Para el azúcar, el signo menos de la ecuación (13-4) se debe a que este constituyente se consume siempre:

$$
\frac{\partial \rho_{s}}{\partial t}=-C_{s}
$$

Para el agua, según la hipótesis H:5 y considerando que al interior del soporte no hay cambio de fase:

$$
\frac{\partial p_{e}}{\partial t}=C_{e}
$$


El balance de masa para la fase líquida esta dado por:

$$
\begin{aligned}
\frac{\partial \rho_{1}}{\partial t} & =C_{1} \\
\text { donde: } \quad C_{1} & =C_{s}+C_{e} \\
\rho_{l} & =\rho_{e}+\rho_{s}
\end{aligned}
$$

Fase gaseosa. Los balances de masa de esta fase son:

Para el nitrógeno, en tanto inerte:

$$
\frac{\partial \rho_{\mathrm{N}}}{\partial \mathrm{t}}=0
$$

Para el vapor de agua, según la hipótesis H:8, el aire permanece saturado en vapor durante la fermentación, por lo que el balance de masa se puede anotar como:

$$
\frac{\partial \rho_{\mathbf{v}}}{\partial t}=-\left(\rho_{\mathbf{v}} \mathbf{v}_{\mathbf{v}}{ }^{k}\right)_{, k}
$$

por otro lado, según las hipótesis H:9 y H:10:

$$
\rho_{v}=\left(\rho_{N}+\rho_{o}+\rho_{c}\right) \frac{\text { PMe } p_{e}^{*}}{\text { PMaire }\left(P-p_{e}^{*}\right)}
$$

de donde, la presión de vapor del agua se puede aproximar con la ecuación termodinámica:

$$
\mathrm{Pe}^{*}=\exp \left(25.775-\frac{5281.1}{\mathrm{~T}}\right)
$$

NOTA: para la deducción de las ecuaciones (13-11) y (13-12), ver ANEXO II.

Para el oxigeno, el balance de masa es:

$$
\frac{\partial \rho_{0}}{\partial t}=-\left(\rho_{0} v_{0}^{k}\right)_{k}-C_{0}
$$

Para el bióxido de carbono:

$$
\frac{\partial \rho_{c}}{\partial t}=-\left(\rho_{c} v_{c}^{k}\right)_{k}+C_{c}
$$

Las hipótesis H:9 y H:10, implican que:

$$
\mathrm{v}_{\mathrm{N}}^{\mathrm{k}}=\mathrm{v}_{\mathrm{v}}^{\mathrm{k}}=\mathrm{v}_{\mathrm{o}}^{\mathrm{k}}=\mathrm{v}_{\mathrm{c}}^{\mathrm{k}}=\mathrm{v}_{\mathrm{g}}^{\mathrm{k}}
$$

donde: $v_{\mathrm{g}}{ }^{\mathrm{k}}$ es la velocidad fenomenológica de la fase gaseosa. 
Sustituyendo (13-15) en las ecuaciones (13-13) y (13-14), se obtiene:

$$
\begin{aligned}
& \frac{\partial \rho_{0}}{\partial t}=-\left(\rho_{o} v_{g}^{k}\right)_{{ }_{k}}-C_{o} \\
& \frac{\partial \rho_{c}}{\partial t}=-\left(\rho_{o} v_{g}^{k}\right)_{{ }_{k}}+C_{c}
\end{aligned}
$$

Finalmente, el balance de masa para la fase gaseosa en su conjunto se puede expresar como:

$$
\frac{\partial \rho_{g}}{\partial t}=-\left(\rho_{g} v_{g}^{k}\right)_{, k}+C_{g}
$$

donde.

$$
\begin{aligned}
& \rho_{g}=\rho_{N}+\rho_{v}+\rho_{o}+\rho_{c} \\
& C_{g}=C_{c}+C_{o}
\end{aligned}
$$

$\S 14$. Balances de energía interna

La forma general del balance para un constituyente i, considerando las hipótesis $\mathbf{H : 1 0}$ y $\mathbf{H : 1 1}$, se puede anotar como:

$$
\frac{\partial}{\partial t}\left(\rho_{i} u_{i}\right)=-\left(\rho_{i} u_{i} v_{i}^{k}+J_{q i} k\right)_{\cdot k}+\hat{u}_{i}+C_{i} u_{i}
$$

donde: $u_{i}$ es la energía interna másica del constituyente i.

$\rho_{\mathrm{i}} \mathrm{u}_{\mathrm{i}}$ es la energía interna del constituyente $\mathrm{i}$, por unidad de volumen.

$\rho_{i} u_{i} v_{i}{ }^{k}$ es el flux de energía interna del constituyente $i$.

$J_{\mathrm{q} i \mathrm{i}}{ }^{\mathrm{k}}$ es el flux de calor conductivo a través del constituyente $\mathrm{i}$.

$\left(p_{i} u_{i} v_{i}^{k}+J_{q 1}^{k}\right)_{, k}$ es la divergencia del vector flux de energía.

$\hat{u}_{i}$ es la tasa de aporte de calor, por unidad de volumen, hacia el constituyente $i$, originada por los otros constituyentes.

$\mathrm{C}_{\mathrm{i}} \mathrm{u}_{\mathrm{i}}$ es la tasa de aporte de calor, por unidad de volumen, debida a la reacción de los otros constituyentes, para producir i.

Balances de energía interna para las fases y constituyentes del sistema

Fase sólida. Tomando en cuenta las hipótesis $\mathrm{H}: 2$ y H:4 y en tanto que: $\mathrm{v}_{\mathrm{a}}{ }^{\mathrm{k}}=0$ y $\mathrm{C}_{\mathrm{a}}=0$, el balance de energía interna para el soporte inerte es el siguiente:

$$
\frac{\partial}{\partial t}\left(\rho_{\mathrm{a}} \mathrm{u}_{\mathrm{a}}\right)=-\left(\mathrm{J}_{\mathrm{qa}}^{\mathrm{k}}\right)_{, \mathrm{k}}+\hat{\mathrm{u}}_{\mathrm{a}}
$$

Fase biológica. Si $_{x}{ }^{k}=0$, el balance queda como: 


$$
\frac{\partial}{\partial t}\left(\rho_{x} u_{x}\right)=-\left(J_{q x}^{k}\right)_{k}+\hat{u}_{x}+C_{x} u_{x}
$$

Fase líquida. Para la sacarosa y el agua, en tanto $v_{s}{ }^{k}=v_{e}{ }^{k}=0$, los balances respectivos de energía son:

$$
\begin{aligned}
& \frac{\partial}{\partial t}\left(\rho_{s} u_{s}\right)=-\left(J_{q s} k\right)_{, k}+\hat{u}_{s}-C_{s} u_{s} \\
& \frac{\partial}{\partial t}\left(\rho_{e} u_{e}\right)=-\left(J_{q e} k\right)_{, k}+\hat{u}_{e}+C_{e} u_{e}
\end{aligned}
$$

El balance de energía para toda la fase líquida se obtiene sumando las ecuaciones (14-4) y (14-5):

$$
\frac{\partial}{\partial t}\left(\rho_{1} u_{1}\right)=-\left(J_{q s} k+J_{q e}{ }^{k}\right)_{k}+\hat{u}_{1}+C_{l} u_{1}
$$

donde: $\rho_{1}=\rho_{\mathrm{s}}+\rho_{\mathrm{e}}$

$$
\begin{aligned}
& \hat{u}_{l}=\hat{u}_{s}+\hat{u}_{e} \\
& C_{l} u_{l}=-C_{s} u_{s}+C_{e} u_{e}
\end{aligned}
$$

Fase gaseosa. Los balances de energía para los constituyentes nitrógeno, vapor de agua, oxígeno y bióxido de carbono:

Para el nitrógeno, con $\mathrm{C}_{\mathrm{N}}=0$ ya que no participa en la reacción, el balance es el siguiente:

$$
\frac{\partial}{\partial t}\left(\rho_{N} u_{N}\right)=-\left(\rho_{N} u_{N} v_{N}^{k}+J_{q N}\right)_{, k}+\hat{u}_{N}
$$

Para el vapor de agua, en tanto que $C_{v}=0$ y además no hay cambios de fase internos, ver hipótesis H:6, el balance es:

$$
\frac{\partial}{\partial t}\left(\rho_{v} u_{v}\right)=-\left(\rho_{v} u_{v} v_{v}^{k}+J_{q v} k\right)_{, k}+\hat{u}_{v}
$$

Para el oxígeno:

$$
\frac{\partial}{\partial t}\left(\rho_{o} u_{o}\right)=-\left(\rho_{o} u_{o} v_{o}^{k}+J_{q o}^{k}\right)_{k}+\hat{u}_{o}-C_{o} u_{o}
$$

Para el bióxido de carbono:

$$
\frac{\partial}{\partial t}\left(\rho_{c} u_{c}\right)=-\left(\rho_{c} u_{c} v_{c}^{k}+J_{q c} k\right)_{, k}+\hat{u}_{c}+C_{c} u_{c}
$$

El balance de energía interna para toda la fase gaseosa, se obtiene sumando desde la ecuación (14-8) hasta la (14-11) y tomando en cuenta a la ecuación (13-15): 


$$
\frac{\partial}{\partial t}\left(\rho_{g} u_{g}\right)=-\left(\rho_{g} u_{g} v_{g}^{k}+J_{q g}^{k}\right)_{, k}+\hat{u}_{g}+C_{g} u_{g}
$$

donde:

$$
\begin{aligned}
& \rho_{g}=\rho_{N}+\rho_{v}+\rho_{o}+\rho_{c} \\
& \rho_{g} u_{g}=\rho_{N} u_{N}+\rho_{v} u_{v}+\rho_{o} u_{o}+\rho_{c} u_{c} \\
& \hat{u}_{g}=\hat{u}_{N}+\hat{u}_{v}+\hat{u}_{o}+\hat{u}_{c} \\
& C_{g} u_{g}=C_{N} u_{N}+C_{v} u_{v}-C_{o} u_{o}+C_{c} u_{c}
\end{aligned}
$$

Finalmente, el balance global de energía interna para el conjunto de las fases se puede escribir como sigue:

$$
\sum \frac{\partial}{\partial t}\left(\rho_{i} u_{i}\right)=-\Sigma\left(\rho_{i} u_{i} v_{i}^{k}+J_{q i}{ }^{k}\right)_{, k}+\sum\left(\hat{u}_{i}+C_{i} u_{i}\right)
$$

en donde: $\quad i=a, x, s, e, N, r, o, c$

\section{§15. Balance térmico.}

En la ecuación global de energía interna para el conjunto de las fases (14-14), el último término que representa la suma del intercambio de energía entre las fases y los constituyentes, se reduce a cero, es decir:

$$
\Sigma\left(\hat{u}_{i}+C_{i} u_{i}\right)=0
$$

Esta reducción se debe a que no puede haber generación autónoma de energía interna por el primer principio de la termodinámica. Por lo que (14-14) queda como:

$$
\sum_{i} \frac{\partial}{\partial t}\left(\rho_{i} u_{i}\right)=-\sum_{i}\left(\rho_{i} u_{i} v_{i}^{k}\right)_{, k}-\sum_{i}\left(J_{q i}{ }^{k}\right)_{, k}
$$

El término de la izquierda de (15-2) se puede descomponer como sigue:

$$
\sum \frac{\partial}{\partial t}\left(\rho_{i} u_{i}\right)=\Sigma\left(\rho_{i} \frac{\partial u_{i}}{\partial t}+u_{i} \frac{\partial \rho_{i}}{\partial t}\right)
$$

sustituyendo la ecuación del balance global de masa (13-1), la ecuación (15-3) se transforma en: 


$$
\sum \frac{\partial}{\partial t}\left(\rho_{i} u_{i}\right)=\Sigma\left(\rho_{i} \frac{\partial u_{i}}{\partial t}+u_{i}\left(\left(-\rho_{i} v_{i}^{k}\right)_{k}+C_{i}\right)\right)
$$

Sustituyendo (15-4) en (15-2)

$$
\sum \rho_{i} \frac{\partial}{\partial t} u_{i}=-\Sigma\left(\left(\rho_{i} u_{i} v_{i}^{k}\right)_{,_{k}}+\left(J_{q i}^{k}\right)_{,_{k}}-u_{i}\left(\rho_{i} v_{i}^{k}\right)_{,_{k}}\right)-\Sigma C_{i} u_{i}
$$

de donde:

$$
\left(\rho_{i} u_{i} v_{i}^{k}\right)_{, k}=\rho_{i} v_{i}^{k}\left(u_{i}\right)_{k}+u_{i}\left(\rho_{i} v_{i}^{k}\right)_{, k}
$$

por lo que la ecuación se (15-5) se convierte en:

$$
\sum_{i} \rho_{i} \frac{\partial}{\partial t} u_{i}=-\sum_{i}\left(\rho_{i} v_{i}^{k}\left(u_{i}\right)_{r_{k}}+\left(J_{q i}\right)_{,_{k}}\right)-\sum_{i} C_{i} u_{i}
$$

si las energías internas se escriben en términos de los respectivos calores específicos másicos a presión y volumen constante $c_{i}$, esto es: $u_{j}=c_{i}\left(T-T_{0}\right)$, entonces el término de la izquierda en la ecuación (15-7) se transforma en:

$$
\sum \rho_{i} \frac{\partial}{\partial t} u_{i}=\Sigma \rho_{i} c_{i} \frac{\partial T}{\partial t}
$$

en el primer miembro de la derecha de la ecuación (15-7) o término CONVECTIVO, $\mathrm{v}_{\mathrm{i}}^{\mathrm{k}}$ en todos los casos es cero, excepto para los constituyentes de la fase gaseosa, por lo tanto, si $v_{i}{ }^{k}=v_{g}{ }^{k}$ (constante) el término queda:

$\sum_{i} \rho_{i} v_{i}{ }^{k}\left(u_{i}\right)_{, k}=\left(\rho_{N} v_{g}{ }^{k} c_{N}+\rho_{v} v_{g}{ }^{k} c_{v}+\rho_{o} v_{g}{ }^{k} c_{o}+\rho_{c} v_{g}{ }^{k} c_{c}\right)\left[T_{s_{k}}\right]=\rho_{g} c_{g} v_{g}{ }^{k}\left[T_{, k}\right]$

donde: $\rho_{g} c_{g}=\rho_{N} c_{N}+\rho_{v} c_{v}+\rho_{o} c_{o}+\rho_{c} c_{c}$

el segundo miembro de la derecha de la ecuación (15-7) o término CONDUCTIVO, según la ley de Fourier, se puede escribir de la manera siguiente:

$$
\sum\left(J_{q 1}^{k}\right)_{, k}=\left(\lambda\left[T_{, k}\right]\right)_{, k}
$$

donde: $\lambda$ es la conductividad térmica del conjunto de las fases y constituyentes. Sustituyendo las ecuaciones (15-8) a la (15-10) en (15-7) se obtiene la siguiente expresión: 


$$
\sum_{i} \rho_{i} c_{i} \frac{\partial T}{\partial t}=-\rho_{g} c_{g} v_{g}^{k}\left[T_{, k}\right]-\left(\lambda\left[T_{, k}\right]\right)_{, k}-\underset{i}{-} C_{i} u_{i}
$$

El tercer miembro de la derecha de la ecuación (15-11) es el calor generado debido a la reacción que se realiza entre los constituyentes reactivos. Este término también se conoce como calor de metabólico. Generalmente este cantidad de calor liberado se asocia a la cantidad de fuente de carbono que será oxidada por los microorganismos en presencia de oxígeno, lo cual conduce a asociarlo a los calores de formación de cada constituyente que se produce. El calor de formación de un compuesto cualquiera es igual a la suma de los calores de formación de los productos de la oxidación del mismo, por lo que:

$$
\sum C_{i} u_{i}=\underset{i}{\sum C_{i} h_{i}}
$$

donde: $h_{i}$ es el calor de formación del constituyente i, expresado en $J(k g \text { de } i)^{-1}$.

sustituyendo (15-12) en (15-11) se obtiene:

$$
\Sigma \rho_{i} c_{i} \frac{\partial T}{\partial t}=-\rho_{g} c_{g} v_{g}{ }^{k}\left[T_{r_{k}}\right]-\left(\lambda\left[T_{, k}\right]\right)_{,_{k}}-\Sigma C_{i} h_{i}
$$

La ecuación (15-13) representa la ecuación global de transporte de calor en este sistema en la que queda incluido el calor metabólico generado por los microorganismos.

\section{\$16. Relaciones cinéticas.}

A continuación se desarrollan las expresiones correspondientes a los términos cinéticos representados por $\mathrm{C}_{\mathrm{i}}$ definidos en las ecuaciones de balance y que describen matemáticamente la producción o desaparición del constituyente i respectivo.

Producción de biomasa. Considerando la hipótesis H:12, la producción de biomasa por unidad de volumen, depende:

(i) De la temperatura, mediante la variación de la tasa máxima de producción de biomasa $\mathrm{C}_{\mathrm{xMax}}$ (en s$~^{-1}$ ) expresada por la ecuación doble logarítmica propuesta por Esener et al (1981) y aplicada a este tipo de cultivos (Saucedo-Castañeda et al 1990):

$$
C_{x M a x}=\left(\frac{A_{1} \exp \left(-\frac{E_{a 1}}{R T}\right)}{1+A_{2} \exp \left(-\frac{E_{a 2}}{R T}\right)}\right)
$$


donde:

T es la temperatura absoluta.

$R$ es la constante universal de los gases.

$\mathrm{E}_{\mathrm{a} 1}$ y $\mathrm{E}_{\mathrm{a} 2}$ se pueden definir como las energías respectivas de activación y desactivación, del crecimiento microbiano.

$A_{1}$ y $A_{2}$ son constantes características

(ii) De la concentración de los microorganismos, siguiendo la ecuación logística propuesta por Okasaki et al (1980) y aplicada a este tipo de cultivos (Saucedo-Castañeda et al 1990; Auria et al 1990; Sargantanis et al, 1992):

$$
C_{x} \propto \rho_{x}\left(1-\frac{\rho_{x}}{\rho_{x M a x}}\right)
$$

donde:

$\rho_{x M a x}$ es la máxima cantidad de biomasa que puede alojarse en un volumen determinado.

(iii) De la disponibilidad de espacios vacios, a través de la siguiente ecuación:

$$
\rho_{x \operatorname{Max}}=\left(\frac{6\left(1-\varepsilon_{0}\right)}{1-\emptyset}\right)\left(\frac{R_{c p}}{\Phi}\right)
$$

donde:

$\varepsilon_{0}$ es una fracción del volumen total que denota los espacios vacíos, $\emptyset$ es el contenido de agua de la biomasa , $\mathrm{R}_{\mathrm{cp}}$ es la máxima capacidad de colonización de un microorganismo en una superficie y $\Phi$ del diámetro de las partículas del soporte inerte.

Nota: Para la deducción de la ecuación (16-3) y la definición de cada uno de los términos, ver el ANEXO III.

(iv) De la cantidad de azúcares presentes, mediante la utilización de una expresión de saturación convencional del tipo Monod, en donde se incluye un término que considera una inhibición producida por altas concentraciones de azúcar, como sigue:

$$
\mathrm{C}_{\mathrm{x}} \propto\left(\frac{\rho_{\mathrm{s}}}{\mathrm{K}_{\mathrm{s}}+\frac{\mathrm{ps}_{\mathrm{s}}^{2}}{\mathrm{~K}_{\mathrm{j}}}+\rho_{\mathrm{s}}}\right)
$$

donde:

$\mathrm{K}_{\mathrm{s}}$ es la constante de afinidad de la fase biológica por el sustrato.

$\mathrm{K}_{\mathrm{i}}$ es la constante de inhibición por sustrato. 
Combinando las ecuaciones (16-1) a la (16-4), el término de formación de biomasa esta dada por:

$$
C_{x}=C_{x M a x} \rho_{x}\left(1-\frac{\rho_{x}}{\rho_{x M a x}}\right)\left(\frac{\rho_{s}}{K_{s}+\frac{\rho_{s}^{2}}{K_{i}}+\rho_{s}}\right)
$$

La ecuación (16-5) contiene los efectos simultáneos de la temperatura, la biomasa, los espacios vacíos, la cantidad de azúcares disponibles para el crecimiento celular y contiene un término de inhibición por sustrato.

Consumo de azúcares. Según la hipótesis H:13 los azúcares que se consumen tienen como destino el crecimiento celular y el mantenimiento, esta hipótesis se traduce en la ecuación clásica (Pirt, 1975) siguiente:

$$
C_{S}=\left(\frac{(1-\emptyset)}{Y_{s}}\right) C_{x}+m_{s} \rho_{x}
$$

donde:

$Y_{\mathrm{S}}$ es la conversión de azúcar en biomasa o rendimiento específico y $\mathrm{m}_{\mathrm{s}}$ es el coeficiente de mantenimiento.

En la ecuación (16-6) el primer sumando es el consumo debido al crecimiento y el segundo es el que se refiere al consumo debido a otras funciones celulares diferentes del crecimiento.

Consumo y producción de agua. De acuerdo con la hipótesis H:7 la composición de los microorganismos es siempre constante e igual a una cierta fracción ø expresada en ( $\mathrm{kg}$ de agua) ( $\mathrm{kg}$ de biomasa húmeda) ${ }^{-1}$, así que el consumo biológico de agua será $\emptyset$ veces la producción de la biomasa, es decir: $\left(-\emptyset \mathrm{C}_{\mathrm{x}}\right)$. La síntesis de biomasa también implica producción de agua. El agua producida por la biorreacción se puede aproximar con el rendimiento $\mathrm{Y}_{\mathrm{e}}$, esto es:

$$
\left(\frac{(1-\emptyset)}{Y_{e}}\right) C_{x} \text {. }
$$

por lo que el consumo neto de agua está dado por la suma de los dos términos anteriores, como sigue:

$$
C_{e}=\left(\frac{(1-\emptyset)}{Y_{e}}-\emptyset\right) C_{x}
$$

Consumo de oxígeno. De acuerdo a la hipótesis H:14, el oxígeno que se consume tiene dos destinos: el crecimiento celular, a través del rendimiento correspondiente y el mantenimiento que depende de qué tantos azúcares se consuman para este fin, i.e. dependerá de la magnitud del 
coeficiente de mantenimiento $m_{s}$ y la presencia de la biomasa. Por analogía con la ecuación (166), se tiene:

$$
C_{0}=\left(\frac{(1-\phi)}{Y_{0}}\right) C_{x}+m_{o} \rho_{x}
$$

donde:

$\mathrm{m}_{0}$ es el coeficiente de mantenimiento correspondiente al oxígeno.

Producción de bióxido de carbono. Según la hipótesis H:14, el bióxido de carbono se produce por (i) el crecimiento celular a través del rendimiento correspondiente $Y_{c}$ (primer miembro de la derecha de la ecuación 16-9), y (ii) los azúcares consumidos para el mantenimiento $\mathrm{m}_{\mathrm{s}}$ (segundo sumando de 16-9), es decir:

$$
C_{c}=\left(\frac{(1-\phi)}{Y_{c}}\right) C_{x}+Y_{p} m_{s} \rho_{x}
$$

donde:

$Y_{p}$ es el coeficiente estequiométrico de transformación total de azúcares en bióxido de carbono.

\$17. Modelo general en coordenadas cilíndricas y estrategia de solución del modelo.

Antes de realizar la integración numérica del modelo general desarrollado se decidió expresarlo en un sistema de coordenadas bien definido que permitiera una más fácil comprensión y manejo. Se seleccionaron las coordenadas cilíndricas debido a que son las más utilizadas en reactores.

Las coordenadas se definen como sigue:

$$
\begin{array}{ll}
r & \text { coordenada radial } \\
\theta & \text { coordenada angular } \\
z & \text { coordenada axial }
\end{array}
$$

Oxígeno. Considerando el balance de masa para este constituyente, ecuación (13-13) y en tanto que: $v_{0}{ }^{k}$ es igual a $v_{g}{ }^{k}$ se obtiene la siguiente expresión:

$$
\frac{\partial \rho_{o}}{\partial t}=-\left(\rho_{o} v_{g}^{k}\right), k-C_{o}
$$

la divergencia del vector $\rho_{\mathrm{o}} \mathrm{v}_{\mathrm{g}}{ }^{\mathrm{k}}$, en coordenadas $(r, \theta, z)$, también se puede escribir como:

$$
\left(\rho_{o} v_{g}^{k}\right)_{, k}=\frac{1}{r} \frac{\partial}{\partial r}\left(r \rho_{o} v_{g}^{r}\right)+\frac{1}{r} \frac{\partial}{\partial \theta}\left(\rho_{o} v_{g}{ }^{\theta}\right)+\frac{\partial}{\partial z}\left(\rho_{o} v_{g}{ }^{2}\right)
$$


considerando que la componente de la velocidad en la dirección axial es la predominante, la ecuación anterior se reduce a:

$$
\left(\rho_{o} v_{g}{ }^{k}\right)_{k}=\frac{\partial}{\partial z}\left(\rho_{0} v_{g}{ }^{2}\right)
$$

derivando el miembro de la derecha, para el caso general en que la velocidad de la fase gaseosa es constante e igual a $v_{g}$ entonces la expresión (17-3) queda como sigue:

$$
\left(\rho_{\mathrm{o}} \mathrm{v}_{\mathrm{g}}^{\mathrm{k}}\right)_{\mathrm{k}_{\mathrm{k}}}=\mathrm{v}_{\mathrm{g}} \frac{\partial \rho_{\mathrm{o}}}{\partial \mathrm{z}}
$$

sustituyendo (17-4) en la ecuación (17-1), se obtiene:

$$
\frac{\partial \rho_{o}}{\partial t}=-v_{g} \frac{\partial \rho_{o}}{\partial z}-C_{o}
$$

Bióxido de carbono. Con un tratamiento análogo al aplicado al constituyente oxígeno, se obtiene la siguiente expresión:

$$
\frac{\partial \rho_{c}}{\partial t}=-v_{g} \frac{\partial \rho_{c}}{\partial z}+C_{c}
$$

Temperatura. Partiendo de la ecuación (15-13), esto es:

$$
\sum_{i} \rho_{i} c_{i} \frac{\partial T}{\partial t}=-\rho_{g} c_{g} v_{g}^{k}\left[T_{, k}\right]-\left(\lambda\left[T_{, k}\right]\right)_{k}-\sum_{i} C_{i} h_{i}
$$

en donde el término convectivo (primero del lado derecho), en las coordenadas ( $r, \theta, z$ ) ver ANEXO I, se puede escribir como sigue:

$$
\begin{gathered}
\rho_{g} c_{g} v_{g}^{k}\left[T_{, k}\right]=\rho_{g} c_{g}\left(\begin{array}{c}
v_{g}{ }_{g} \\
v_{g} \\
v_{g} z
\end{array}\right)\left(\begin{array}{c}
\frac{\partial T}{\partial r} \\
\frac{\partial T}{\partial \theta} \\
\frac{\partial T}{\partial z}
\end{array}\right)= \\
\rho_{g} c_{g}\left(v_{g} \frac{\partial T}{\partial r}+v_{g} \theta \frac{1}{r} \frac{\partial T}{\partial \theta}+v_{g} z \frac{\partial T}{\partial z}\right)
\end{gathered}
$$

considerando que la componente en $z$ del vector $v_{g}$ es predominante sobre las componentes radial y angular, la ecuación (17-7) se transforma en: 


$$
\rho_{g} c_{g} v_{g}^{k}\left[T,_{k}\right]=\rho_{g} c_{g}\left(v_{g} \frac{\partial T}{\partial z}\right)
$$

En el segundo miembro de la derecha en la ecuación (15-13) o término conductivo, la divergencia del vector de derivadas también se puede escribir como:

$$
\left(\lambda\left[\mathrm{T}_{{ }_{k}}\right]\right)_{i_{\mathrm{k}}}=\frac{1}{\mathrm{r}} \frac{\partial}{\partial \mathrm{r}}\left(\mathrm{r} \lambda \frac{\partial \mathrm{T}}{\partial \mathrm{r}}\right)+\frac{1}{\mathrm{r}} \frac{\partial}{\partial \theta}\left(\frac{\lambda}{\mathrm{r}} \frac{\partial \mathrm{T}}{\partial \theta}\right)+\frac{\partial}{\partial z}\left(\lambda \frac{\partial \mathrm{T}}{\partial z}\right)
$$

para una simetría cilíndrica, $(17-9)$ se reduce a:

$$
\left(\lambda\left[\mathrm{T}_{\mathrm{k}_{\mathrm{k}}}\right]\right)_{\mathrm{k}}=\frac{1}{\mathrm{r}} \frac{\partial}{\partial \mathrm{r}}\left(\mathrm{r} \lambda \frac{\partial \mathrm{T}}{\partial \mathrm{r}}\right)+\frac{\partial}{\partial z}\left(\lambda \frac{\partial \mathrm{T}}{\partial \mathrm{z}}\right)
$$

en donde el primer término de la derecha se puede expresar como:

$$
\frac{1}{\mathrm{r}} \frac{\partial}{\partial \mathrm{r}}\left(\mathrm{r} \lambda \frac{\partial \mathrm{T}}{\partial \mathrm{r}}\right)=\frac{1}{\mathrm{r}}\left(\mathrm{r} \lambda \frac{\partial^{2} \mathrm{~T}}{\partial \mathrm{r}^{2}}+\frac{\partial \mathrm{T}}{\partial \mathrm{r}}\left(\mathrm{r} \frac{\partial \lambda}{\partial \mathrm{r}}+\lambda\right)\right)
$$

Si se considera que las variaciones de la conductividad térmica con respecto al radio son despreciables y que $\lambda$ es una constante, entonces:

$$
\frac{1}{\mathrm{r}} \frac{\partial}{\partial \mathrm{r}}\left(\mathrm{r} \lambda \frac{\partial \mathrm{T}}{\partial \mathrm{r}}\right)=\lambda\left(\frac{1}{\mathrm{r}} \frac{\partial_{\mathrm{T}}}{\partial \mathrm{r}}+\frac{\partial^{2} \mathrm{~T}}{\partial \mathrm{r}^{2}}\right)
$$

en la dirección axial la conducción de calor puede considerarse despreciable, en relación a la convección en la misma dirección, cuyo caso el segundo término de la derecha en la ecuación (1710) es cero:

$$
\frac{\partial}{\partial z}\left(\lambda \frac{\partial T}{\partial z}\right)=0
$$

así, sustituyendo (17-12) y (17-13) en (17-10), se obtiene la siguiente expresión:

$$
\left(\lambda\left[\mathrm{T}_{,_{\mathrm{k}}}\right]\right)_{,_{\mathrm{k}}}=\lambda\left(\frac{1}{\mathrm{r}} \frac{\partial \mathrm{T}}{\partial \mathrm{r}}+\frac{\partial^{2} \mathrm{~T}}{\partial \mathrm{r}^{2}}\right)
$$

finalmente, sustituyendo las ecuaciones (17-8) y (17-14) en la ecuación original (15-13), se obtiene la ecuación siguiente:

$$
\sum_{i} \rho_{i} c_{i} \frac{\partial T}{\partial t}=-\rho_{g} c_{g} v_{g}\left(\frac{\partial T}{\partial z}\right)-\lambda\left(\frac{1}{r} \frac{\partial T}{\partial r}+\frac{\partial^{2} T}{\partial r^{2}}\right)-\underset{i}{\sum} c_{i} h_{i}
$$


en donde queda expresado el transporte global de calor con un término convectivo, uno conductivo y la generación de calor, en coordenadas cilíndricas.

Estrategia de solución del modelo.

Para resolver el modelo general de manera directa es necesario conocer: (i) valores de los parámetros, (ii) resultados coherentes de la simulación con modelos simplificados -derivados del modelo general- $y$, sobre todo, (iii) resultados experimentales que permitan obtener índices de confianza para después retomar el modelo general u otros más complicados. Para poder resolver satisfactoriamente se propone una estrategia de solución que debe cubrirse por etapas. Los principales elementos de esta metodología se presentan de manera gráfica en la Figura 17.1 y son los siguientes:

- Primera etapa. Simplificación de las ecuaciones del modelo. Para lo que se debe postular un conjunto de nuevas hipótesis que permita reducir su complejidad. Estas hipótesis no deben oponerse a las hipótesis que dieron origen al modelo general.

- Segunda etapa. Asignación de los valores correspondientes a todos los parámetros. Parte de esta información se encuentra en la literatura publicada, parte se obtiene a partir de experimentos particulares que incluyen : las condiciones experimentales y las cinéticas de las variables en estudio. En esta etapa se proponen y aplican métodos de solución numérica al modelo simplificado.

- Tercera etapa: Validación de resultados teóricos, sensibilidad paramétrica y ajuste de parámetros. Esto mediante una comparación con resultados experimentales obtenidos bajo condiciones de operación bien definidas.

- Cuarta etapa. Solución del modelo general completo. Esto mediante la aplicación de métodos numéricos y el apoyo de los parámetros evaluados y ajustados antes con el modelo simplificado.

- Quinta etapa. Evaluación del alcance y las limitaciones del modelo general. Los resultados emitidos por el modelo matemático general se comparan con los experimentales y se establecen los alcances del mismo en términos prácticos. 


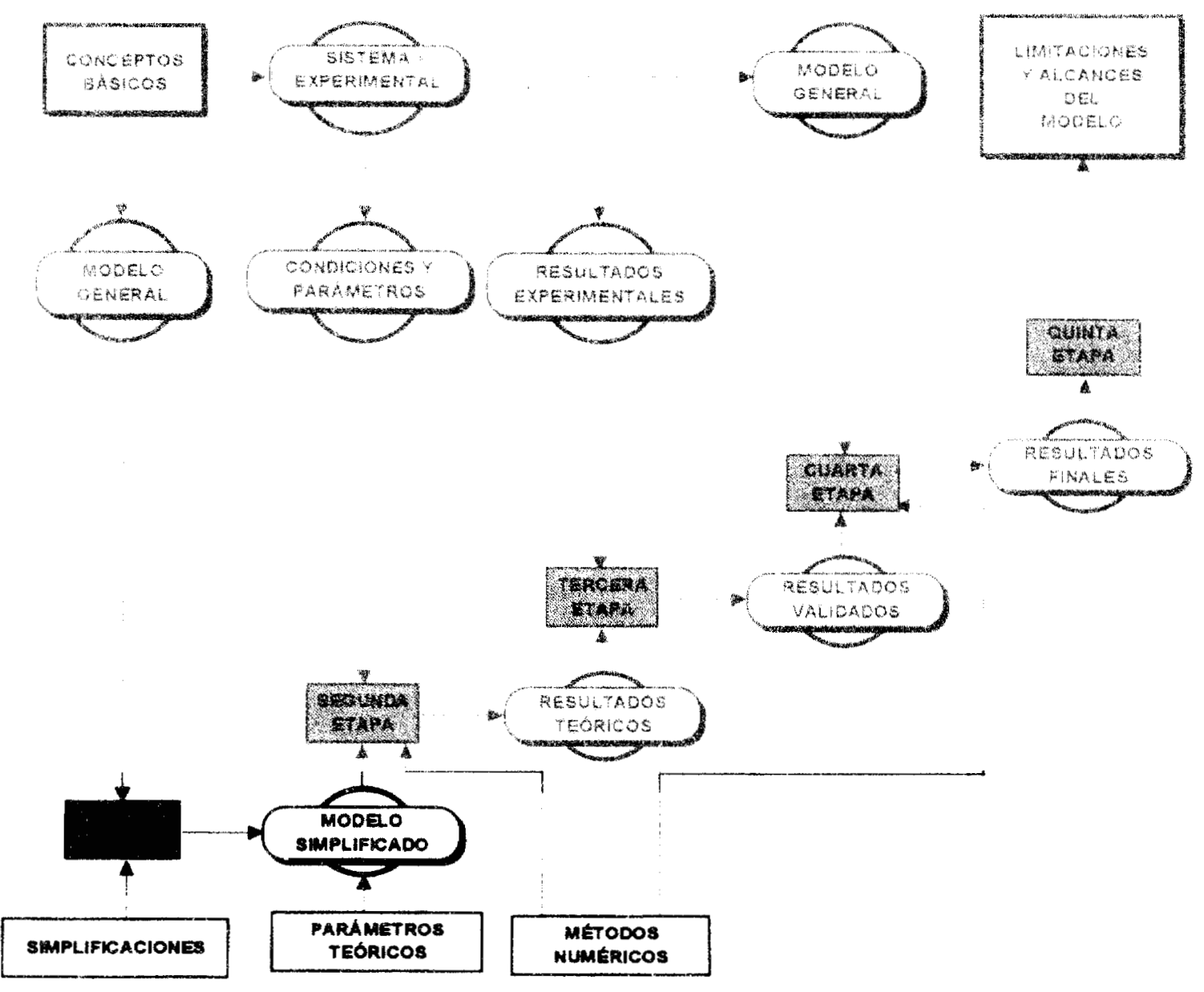

FIGURA 17.1. Diagrama esquemático de la estrategia propuesta para la solución del modelo general a través de cinco etapas. Para la descripción de cada etapa ver texto.

Resumen y conclusiones.

Se propone un modelo matemático general constituido por siete variables de estado: $\rho_{\mathrm{x}}, \rho_{\mathrm{s}}, \rho_{\mathrm{e}}$, $\rho_{v}, \rho_{o}, \rho_{c}$ y $T$ cuyo comportamiento en el tiempo y en el espacio esta definido por los balances de masa, los balances de energía interna que originaron el balance térmico y las respectivas relaciones cinéticas. Estos balances se apegaron al conjunto de hipótesis discutidas antes. El modelo general desarrollado contiene un total de 43 parámetros que incluyen constantes físicas, condiciones de operación, rendimientos y constantes biológicas. En el ANEXO III, se presenta un resumen de las ecuaciones del modelo matemático y una lista completa de los parámetros implicados.

Se propone también una estrategia de solución numérica que comprende cinco etapas. Estas etapas van desde la simplificación del modelo general hasta evaluación de los resultados finales, vía limitaciones y bondades de! modelo, pasando por la solución del modelo. 


\section{PARTE III. DESARROLLO, VALIDACIÓN Y AJUSTE DE PARÁMETROS DE UN MODELO MATEMÁTICO SIMPLIFICADO}

En la tercera parte de este trabajo se proponen algunas simplificaciones al modelo matemático general para generar un modelo simplificado que simula los cambios de las variables de estado con respecto al tiempo, en independencia de la localización espacial. El modelo simplificado representa variaciones puntuales que equivalen a las variaciones del proceso de fermentación cuando la escala de experimentación corresponde a las pequeñas columnas de vidrio (Raimbault, 1980; Alazard y Raimbault, 1981) discutidas en la primera parte de este trabajo. En el capitulo $\$ 20$ se listan y se evalúan teóricamente los parámetros que intervienen en el modelo, distinguiendo a los parámetros fisicos de los biológicos. En el capítulo $\$ 21$ se resuelve el modelo con métodos numéricos y se muestran los resultados (capítulo \$22). En los capitulos $\$ 23$ al $\$ 26$ se presentan y discuten resultados experimentales obtenidos con un sistema de trabajo análogo al que origina al modelo simpiificado. En el capítulo $\$ 26$ se muestra un análisis de sensibilidad del modelo a parámetros como la constante de inhibición por sustrato, el coeficiente de mantenimiento celular y la constante de afinidad por el sustrato. Finalmente, el modelo se somete a un ajuste de parámetros con tres casos de cultivo sólido en donde se destacan las limitaciones y el alcance del modelo.

El objetivo de esta parte del trabajo es proponer un modelo de trabajo, que permita: (i) comparar sus predicciones con resultados experimentales; (ii) ajustar los parámetros que intervienen en el modelo y (iii) conocer el alcance y las limitaciones del mismo.

\section{A. DESARROLLO Y SOLUCIÓN DE UN MODELO SIMPLIFICADO}

§18. Hipótesis de trabajo: simplificaciones al modelo general.

Para simplificar el modelo general se parte de la base de que las hipótesis $\mathrm{H}: 1$ a la H:14, siguen siendo válidas y sólo se adicionarán las siguientes hipótesis particulares:

H:15 El VER es lo suficientemente pequeño como para que las variaciones de la masa de cada constituyente en el espacio sean despreciables, de tal manera que las variables de estado sólo cambian en el tiempo.

H:16 Las variaciones de la temperatura del VER con respecto al tiempo dependen de: (i) los cambios de entalpia de la fase gaseosa en la entrada y en la salida del VER; (ii) los 
gradientes entre la temperatura de la chaqueta (isotérmica) y la temperatura del interior del VER y (iii) el calor metabólico generado por las células.

Estas consideraciones conducen a reducir el modelo a un conjunto de ecuaciones algebraicas y diferenciales ordinarias con una única variable independiente: el tiempo.

A continuación se incorporan estas hipótesis al modelo matemático general.

§19. Desarrollo del modelo simplificado.

Fase sólida. Constituida exclusivamente por Amberlita, permanece sin cambios durante todo el proceso, es decir, la masa volumétrica aparente del soporte inerte $\rho_{a}$ es siempre la misma que la inicial $\rho_{\mathrm{a}}{ }^{\mathrm{O}}$

$$
\rho_{\mathrm{a}}=\rho_{\mathrm{a}}{ }^{0}
$$

Fase biológica. La biomasa producida dentro del VER, se deberá exclusivamente a los cambios cinéticos:

$$
\frac{d \rho_{x}}{d t}=C_{x}
$$

donde $C_{x}$ está dada por la ecuación (16-1) y las ecuaciones (16-3) y (16-5) definidas antes. Fase líquida. Constituida por glucosa y agua, los balances se mantienen tal y como se definieron anteriormente:

Para los azúcares:

$$
\frac{d p_{s}}{d t}=-C_{s}
$$

donde $\mathrm{C}_{\mathrm{s}}$ está definida por la ecuación (16-6).

Para el agua

$$
\frac{d \rho_{e}}{d t}=C_{e}
$$

donde $C_{e}$ se calcula según la ecuación (16-7)

Fase gaseosa. Esta fase esta constituida por vapor de agua hasta la saturación, nitrógeno, oxígeno y bióxido de carbono, la composición detallada se presenta más adelante.

A continuación se desarrollan las ecuaciones correspondientes para cada uno de los constituyentes de esta fase: 
Para el vapor de agua. Considerando que no forma parte de las reacciones y que sus variaciones son debidas a los cambios de temperatura dentro del VER, el término $\rho_{v}$ se calculará según la ecuación (13-11) auxiliándose de la ecuación (13-12) definidas antes, es decir:

$$
\rho_{v}=\left(\rho_{N}+\rho_{o}+\rho_{c}\right) \frac{\text { PMe } p_{e}^{*}}{\text { PMaire }\left(\text { P- } p_{e}{ }^{*}\right)}
$$

donde $\mathrm{p}_{\mathrm{e}}{ }^{*}$ está definida antes por la ecuación (13-12)

Para el nitrógeno. Si se considera que la acumulación de este constituyente se aproxima a cero, ya que no reacciona ni se produce, entonces la masa de nitrógeno durante el proceso, se puede aproximar en función de la fracción en peso $\mathrm{fp}_{\mathrm{N}}$ que se alimenta en el aire de entrada (ver Cuadro 19-1) y de los espacios vacíos ( $\varepsilon$ ) en el VER, es decir:

donde:

$$
\rho_{\mathrm{N}}=\mathrm{fp}_{\mathrm{N}} \rho_{\text {aire }} \varepsilon
$$

$\varepsilon=1-\left(\frac{\rho_{a}^{0}}{\rho_{a}{ }^{*}}+\frac{\rho_{x}}{\rho_{x}{ }^{*}}+\frac{\rho_{l}^{0}}{\rho_{l}^{*}}\right)$

con:

$\rho_{\mathrm{a}}{ }^{0}$, masa aparente de la fase sólida por unidad de volumen de reactor al tiempo cero.

$\rho_{\mathrm{x}}$, masa aparente de la fase biológica por unidad de volumen de reactor a cualquier $\mathrm{t}$.

$\rho_{l}^{0}$, masa aparente de la fase líquida por unidad de volumen de reactor al tiempo cero.

$\rho_{\mathrm{i}}{ }^{*}$, es la masa real del constituyente o la fase $\mathrm{i}$, por unidad de volumen ocupado por $\mathrm{i}$

Para el oxígeno. La acumulación de este constituyente dentro del VER se debe a la diferencia entre la masa de oxígeno que entra y la que sale y al consumido por el término cinético, es decir, la ecuación (17-5), en coordenadas cilíndricas, se reduce a:

$$
\frac{d \rho_{0}}{d t}=-\left(\frac{v_{g}}{L}\right)\left(f_{o} \rho_{\text {aire }} \varepsilon-\rho_{0}\right)-C_{o}
$$

donde $\mathrm{C}_{\mathrm{o}}: \quad$ se calcula según la ecuación (16-8)

L: $\quad$ es la altura del VER, en metros

fpo: es la fracción en peso de oxígeno que se alimenta (ver Cuadro 19-1)

Para el bióxido de carbono. La acumulación se puede estimar de manera análoga que en el caso anterior y la ecuación (17-6) se transforma en la siguiente expresión:

$\frac{d \rho_{c}}{d t}=-\left(\frac{v_{g}}{L}\right)\left(f_{c} \rho_{\text {aire }} \varepsilon-\rho_{c}\right)+C_{c}$ 
donde $\mathrm{C}_{\mathrm{c}}$ : $\quad$ se calcula según la ecuación (16-9)

$f_{p}: \quad$ es la fracción en peso de bióxido de carbono que se alimenta (ver Cuadro 19-1)

Para la temperatura. La acumulación de calor dentro del VER, lado izquierdo de la ecuación $(17-15)$, se expresa como:

$$
\rho_{i} c_{i} \frac{\partial T}{\partial t}=\rho_{i} c_{i} \frac{d T}{d t}
$$

donde:

$$
\rho_{i} c_{1}=\rho_{a} c_{a}+\rho_{x} c_{x}+\rho_{l} c_{l}+\rho_{N} c_{N}+\rho_{v} c_{v}+\rho_{o} c_{o}+\rho_{c} c_{c}
$$

Considerando que el nuevo balance térmico debe contener los tres términos definidos en (17-15): el convectivo, el conductivo y el del calor metabólico. Con la incorporación de las últimas hipótesis, cada uno de estos términos se reduce de la siguiente manera:

(i) Transporte de calor por convección. Este intercambio de calor se debe a la diferencia entre la temperatura del aire que entra por la parte baja del VER (Taire) y la temperatura de salida de la fase gaseosa -la temperatura del conjunto de las fases $T$-, es decir:

$$
-\rho_{g} c_{g} v_{g}\left(\frac{\partial T}{\partial z}\right)=-\rho_{g} c_{g}\left(\frac{v_{g}}{L}\right)(\text { Taire }-T)
$$

donde:

$$
\rho_{g} c_{g}=\rho_{N} c_{N}+\rho_{v} c_{v}+\rho_{o} c_{o}+\rho_{c} c_{c}
$$

(ii) Transporte de calor por conducción. Este intercambio de calor se debe a la diferencia entre la temperatura del baño $T_{j}$ y la temperatura del conjunto de las fases $T$, a través de un coeficiente global de transporte de calor U y el área de transferencia específica Aesp, como sigue:

$$
-\lambda\left(\frac{1}{r} \frac{\partial T}{\partial r}+\frac{\partial^{2} T}{\partial r^{2}}\right)=-U \operatorname{Aesp}\left(T_{j}-T\right)
$$

pero:

$$
\text { Aesp }=\left(\frac{\text { Area lateral de transporte de calor }}{\text { Volumen del VER }}\right)=\left(\frac{\pi 2 \mathrm{Ra} L}{\pi \mathrm{Ra}^{2} \mathrm{~L}}\right)=\left(\frac{2}{\mathrm{Ra}}\right)
$$

por lo tanto:

$$
-\lambda\left(\frac{1}{\mathrm{r}} \frac{\partial \mathrm{T}}{\partial \mathrm{r}}+\frac{\partial^{2} \mathrm{~T}}{\partial \mathrm{r}^{2}}\right)=-\mathrm{U}\left(\frac{2}{\mathrm{Ra}}\right)(\mathrm{Tj}-\mathrm{T})
$$

donde: $\mathrm{R}$ a es el radio del VER, en metros 
(iii) Calor metabólico producido por la reacción. Este término se mantiene sin cambios:

Sustituyendo (19-9), (19-10) y (19-12) en la ecuación del balance térmico original (17-15), se obtiene la siguiente expresión:

$$
\rho_{i} c_{i} \frac{d T}{d t}=-\rho_{g} c_{g}\left(\frac{v_{g}}{L}\right)(\text { Taire }-T)-U\left(\frac{2}{R a}\right)\left(T_{j}-T\right)-C_{i} h_{i}
$$

o bien:

$$
\frac{\mathrm{dT}}{\mathrm{dt}}=-\left(\frac{\rho_{\mathrm{g}} \mathrm{c}_{\mathrm{g}}}{\rho_{\mathrm{i}} \mathrm{c}_{\mathrm{i}}}\right)\left(\frac{\mathrm{v}_{\mathrm{g}}}{\mathrm{L}}\right)(\text { Taire }-\mathrm{T})-\left(\frac{\mathrm{U}}{\rho_{\mathrm{i}} \mathrm{c}_{\mathrm{i}}}\right)\left(\frac{2}{\mathrm{Ra}}\right)(\mathrm{T} \mathrm{j}-\mathrm{T})-\left(\frac{\mathrm{C}_{\mathrm{i}} \mathrm{h}_{\mathrm{i}}}{\rho_{\mathrm{i}} \mathrm{c}_{\mathrm{i}}}\right)
$$

El modelo simplificado queda constituido por las ecuaciones definidas como:

$$
(13-2),(19-2),(19-3),(19-4),(19-6),(19-7) \text { y }(19-13)
$$

En los Cuadros 20.1 y 20.2 se presentan los parámetros que intervienen en el modelo simplificado.

Los valores de los parámetros se pueden encontrar de dos maneras: (i). una evaluación teórica, ya sea asignando valores publicados para sistemas razonablemente parecidos o bien calculándolos con base en principios fundamentales de la física y (ii) mediante una evaluación experimental directa o indirecta. En tanto que esta última alternativa no siempre es posible, en este trabajo se emplean los dos métodos de evaluación.

\section{\$20. Evaluación teórica de los parámetros: Modelo simplificado}

Por su naturaleza, el conjunto de parámetros del modelo simplificado que se desarrolló en el capítulo anterior puede dividirse en dos grandes grupos: los parámetros físicos y los parámetros biológicos.

\subsection{Parámetros físicos}

Este grupo de parámetros físicos se divide en dos subgrupos: las propiedades del sistema y las propiedades de los constituyentes.

\subsubsection{Propiedades del sistema}

El sistema se encuentra a una presión de operación que apenas excede en un $10 \%$ a la presión atmosférica, por lo que a $35^{\circ} \mathrm{C}$ (con $585 \mathrm{~mm} \mathrm{Hg}$ de la Ciudad de México) la presión absoluta es: 


$$
\mathrm{P}=92633 \mathrm{~Pa}
$$

el sistema simula el comportamiento real de pequeñas columnas experimentales de aprox. $10 \mathrm{ml}$ de configuración cilíndrica de vidrio cuyas dimensiones son:

$$
\begin{aligned}
\mathrm{L} & =0.1 \mathrm{~m} \\
\mathrm{Ra} & =0.0055 \mathrm{~m}
\end{aligned}
$$

el soporte inerte húmedo contenido en las columnas es de forma regular esférica con un diámetro promedio:

$$
\Phi=0.00064 \mathrm{~m}
$$

En los sistemas experimentales en que se apoya este trabajo (ver $\$ 24$ ) la temperatura para el crecimiento de $A$. niger es de $30^{\circ} \mathrm{C}$ o de $35^{\circ} \mathrm{C}$, con una tasa de aireación constante de $0.037 \mathrm{ml}$ de aire por $\mathrm{ml}$ de empaque en la columna por segundo (medido a $0.1 \mathrm{~kg} \mathrm{~cm}^{-2} \mathrm{man}$.), por lo que:

$$
\begin{aligned}
\text { Taire } & =\mathrm{T}_{\mathrm{j}}=303.18 \mathrm{~K} \text { o bien } 308.13 \mathrm{~K} \\
\mathrm{v}_{\mathrm{g}} & =0.0039 \mathrm{~m} \mathrm{~s}^{-1}
\end{aligned}
$$

Coeficiente global de transferencia de calor. El coeficiente U, se estimó como sigue:

(i) Considerando que el coeficiente global de transporte de calor $U$, es consecuencia de tres resistencias al transporte: la interna, la de la pared del biorreactor y la externa, entonces:

$$
\frac{1}{\mathrm{U}}=\frac{1}{\mathrm{hci}}+\frac{\delta}{\mathrm{k}_{\mathrm{v}}}+\frac{1}{\mathrm{hco}_{\mathrm{O}}}
$$

donde: hci: es el coeficiente interno de transporte de calor.

$\mathrm{k}_{\mathrm{v}}$ : es la conductividad térmica del material de construcción, vidrio.

$\delta$ : es el espesor de la pared del material de construcción del biorreactor.

hco: es el coeficiente externo de transferencia de calor convectivo.

(ii) Evaluación de hci. Para columnas empacadas con circulación de gases en régimen laminar, Calderbank y Pogerski ( Perry, 1984. p. 10-46), proponen la siguiente ecuación:

$$
\mathrm{hci}_{\mathrm{i}}=3.6 \frac{\lambda_{\mathrm{g}}}{\Phi}\left(\frac{\Phi \mathrm{G}}{\mu_{\mathrm{g}} \varepsilon}\right)^{0.365}
$$

donde: $\Phi$ : es el diámetro promedio de las esferas del soporte inerte húmedo $=0.00064 \mathrm{~m}$

$\lambda_{\mathrm{g}}$ : es la conductividad térmica de la fase gaseosa $=0.026 \mathrm{~J}\left(\mathrm{~m} \mathrm{~s} \mathrm{~K}^{-1}\right.$

$\mathrm{G}$ : es la masa velocidad de la fase gaseosa $=0.005 \mathrm{~kg}$ aire $\left(\mathrm{m}^{2} \mathrm{~s}\right)^{-1}$

$\varepsilon$ : es la fracción de espacios vacíos dentro del reactor $=0.6$ adimensional

$\mu_{\mathrm{g}}$ : es la viscosidad de la fase gaseosa @ $30^{\circ} \mathrm{C}=1.8 \mathrm{E}-05 \mathrm{~kg}$ aire $(\mathrm{m} \mathrm{s})^{-1}$ 


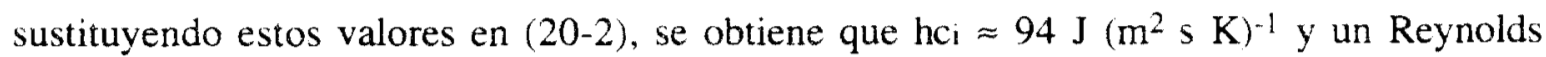
$(\mathrm{Re})$ evidentemente laminar, calculado con la ecuación:

$$
\operatorname{Re}=\left(\frac{\Phi G}{\mu_{\mathrm{g}} \varepsilon}\right) \approx 0.3
$$

\section{CUADRO 20.1 PARÁMETROS FÍSICOS DEL MODELO SIMPLIFICADO}

\begin{tabular}{|c|c|}
\hline Símbolo & Especificación y unidades en que se expresa \\
\hline \multicolumn{2}{|c|}{ - $\quad$ PROPIEDADES DEL SISTEMA } \\
\hline$P$ & Presión total del sistema, $\mathrm{Pa}$ \\
\hline $\mathrm{L}$ & Altura del VER, $m$ \\
\hline $\mathrm{Ra}$ & Radio del VER, $m$ \\
\hline$\Phi$ & Diámetro promedio de las esferas del soporte inerte, $m$ \\
\hline $\mathrm{R}$ & Constante universal de los gases, $8.314 \mathrm{~J}(\mathrm{~mol} \mathrm{~K})^{-1}$ \\
\hline $\mathrm{T}_{\mathrm{j}}$ & Temperatura de la chaqueta, $\mathrm{K}$ \\
\hline Taire & Temperatura del aire de entrada al VER, $K$ \\
\hline $\mathrm{U}$ & Coeficiente global de transporte de calor, $J\left(\mathrm{~m}^{2} \mathrm{~s} \mathrm{~K}\right)^{-\mathrm{T}}$ \\
\hline$v_{g}$ & Velocidad de ascenso de la fase gaseosa, $\mathrm{m} \mathrm{s}^{-1}$ \\
\hline \multicolumn{2}{|c|}{ - $\quad$ PROPIEDADES DE LOS CONSTITUYENTES } \\
\hline $\mathrm{c}_{\mathrm{a}}$ & Calor másico: Amberlita a presión constante, $\mathrm{J}(\mathrm{kg} \text { de Amberlita } \mathrm{K})^{-1}$ \\
\hline $\mathrm{c}_{\mathrm{g}}$ & Calor másico, fase gaseosa a presión o vol. constante, $\mathrm{J}(\mathrm{kg} \text { de } \mathrm{g} \mathrm{K})^{-1}$ \\
\hline$c_{1}$ & Calor másico: fase líquida a presión constante, $\mathbf{J}(\mathrm{kg} \text { de líquido } \mathrm{K})^{-1}$ \\
\hline$c_{x}$ & Calor másico: biomasa a presión constante, $\mathrm{J}(\mathrm{kg} \text { de biomasa } \mathrm{K})^{-1}$ \\
\hline $\mathrm{h}_{\mathrm{c}}$ & Calor de formación de $\mathrm{CO}_{2}, \mathrm{~J}\left(\mathrm{~kg} \text { de } \mathrm{CO}_{2}\right)^{-1}$ \\
\hline$h_{e}$ & Calor de formación de agua, $J(\mathrm{~kg} \text { de agua })^{-1}$ \\
\hline$h_{n}$ & Calor de transformación de oxígeno, $\mathrm{J}(\mathrm{kg} \text { de oxígeno })^{-1}$ \\
\hline $\mathrm{h}_{\mathrm{s}}$ & Calor de transformación de glucosa, $\mathrm{J}(\mathrm{kg} \text { de glucosa })^{-1}$ \\
\hline $\mathrm{h}_{\mathbf{x}}$ & Calor de formación de biomasa, $J$ (kg de biomasa seca) $)^{-1}$ \\
\hline$\rho_{a}^{*}$ & Masa volumétrica real, $\mathrm{kg}$ Amberlita húmeda $\left(\mathrm{m}^{3} \text { de Amberlita }\right)^{-1}$ \\
\hline$\rho_{1}^{*}$ & 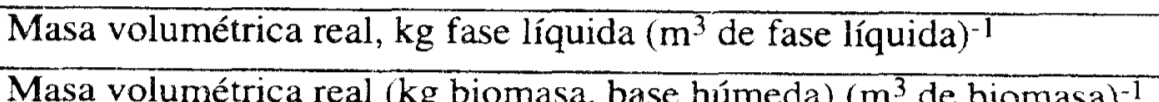 \\
\hline$\rho_{\mathrm{x}}^{*}$ & Masa volumétrica real ( $\mathrm{kg}$ biomasa, base húmeda) $\left(\mathrm{m}^{3} \text { de biomasa }\right)^{-1}$ \\
\hline
\end{tabular}


(iii) Evaluación de hco. Para el caso de un banco de columnas $(0.011 \mathrm{~m}$ de diámetro externo), sumergidas en un baño de temperatura constante $\left(30^{\circ} \mathrm{C}\right)$ en donde la velocidad del agua del baño recircula a $0.2 \mathrm{~m} \mathrm{~s}^{-1}$, en Perry, (1984 p. 10-19) se propone la siguiente ecuación:

$$
\text { hco }=986[1.21+0.0067(30)]\left(\frac{0.2^{0.6}}{0.011^{0.4}}\right)=3217 \mathrm{~J}\left(\mathrm{~m}^{2} \mathrm{~s} \mathrm{~K}\right)^{-1}
$$

(iv) Finalmente, con: $\mathrm{k}_{\mathrm{v}}=1.1 \mathrm{~J}(\mathrm{~m} \mathrm{~s} \mathrm{~K})^{-1}$, conductividad térmica del vidrio y $\delta=0.001 \mathrm{~m}$, espesor del vidrio, sustituyendo en (20-1) se obtiene:

$$
\frac{1}{\mathrm{U}}=\frac{1}{94}+\frac{0.001}{1.1}+\frac{1}{3217}
$$

de donde: $\mathrm{U} \approx 84 \mathrm{~J}\left(\mathrm{~m}^{2} \mathrm{~s} \mathrm{~K}\right)^{-1}$

El valor estimado para el coeficiente global es ligeramente mayor al determinado experimentalmente por Raimbault (1980) de $72 \mathrm{~J} \mathrm{~m}^{-2} \mathrm{~s}^{-1} \mathrm{~K}^{-1} \mathrm{en}$ un sistema de fermentación sólida en columnas de vidrio sumergidas en un baño y empacadas con harina de yuca.

20.1.2 Propiedades de los constituyentes.

Capacidad calorífica de los constituyentes. Se estiman de la manera siguiente:

(i) Soporte inerte. Para la Amberlita IRA-900, en ausencia de información directa, se adopta un promedio de calores específicos de materiales razonablemente parecidos (Perry, 1984, p. 3-133), expresados en $\mathrm{J}(\mathrm{kg} \text { base seca } \mathrm{K})^{-1}$ tales como: baquelita (1462), poliuretano (1050). polímeros de la piroxolina (1505) y criolita (1057):

$$
c_{a}=1268 \mathrm{~J}(\mathrm{~kg} \text { base seca } \mathrm{K})^{-1}
$$

(ii) Fase gaseosa. Se considera la capacidad calorífica del aire y que ésta prácticamente no varía entre 0 y $100^{\circ} \mathrm{C}$ :

$$
c_{\mathrm{g}}=720 \mathrm{~J}(\mathrm{~kg} \mathrm{~K})^{-1}
$$

(iii) Fase líquida. Esta fase se puede considerar como una solución en donde el agua siempre predomina, por lo que la capacidad calorífica de esta fase, entre 20 y $60^{\circ} \mathrm{C}$ se aproxima a la del agua es decir que, para fines prácticos:

$$
c_{1}=4180 \mathrm{~J}(\mathrm{~kg} \mathrm{~K})^{-1}
$$


(iv) Fase biológica. En tanto que la fracción de agua en esta fase es siempre constante y aproximadamente de un $80 \%$, la capacidad calorifica de la biomasa es:

$$
c_{\mathrm{x}}=0.8(4180)=3344 \mathrm{~J}(\mathrm{~kg} \text { base húmeda } \mathrm{K})^{-1}
$$

Energías de formación. Se estiman a partir de las energías de oxidación de los constituyentes reactivos, se considera (ver hipótesis $\mathbf{H : 5}$ ) que la producción de la fase biológica, a expensas de la oxidación de la fuente de carbono, es estequiométrica y que sigue la reacción que se detalla más adelante en el Cuadro 20.4, según esta reacción los productos son: biomasa, bióxido de carbono y agua, que se generan a expensas de la energía de consumo de la glucosa. Esta energía se considera igual a la calculada para la combustión total de la misma según la reacción siguiente

$$
\mathrm{C}_{6} \mathrm{H}_{12} \mathrm{O}_{6}+6 \mathrm{O}_{2} \Longrightarrow 6 \mathrm{CO}_{2}+6 \mathrm{H}_{2} \mathrm{O}
$$

La cantidad de calor que libera cada electrón-equivalente que se transfiere en la reacción (20-3) a un enlace del tipo metano es de $26.05 \mathrm{kcal}$ Así para los cuatro electrones equivalentes de un mol de oxígeno, se liberarán $104.2 \mathrm{kcal}$ por mol, por tanto el calor de combustión, por $\mathrm{kg}$ de glucosa se calcula como sigue

$$
\begin{aligned}
& \mathrm{hs}_{\mathrm{s}}=-104.2\left(\frac{\mathrm{kcal}}{\mathrm{mol} \mathrm{O}_{2}}\right) 6\left(\frac{\mathrm{mol} \mathrm{O}_{2}}{\text { mol glucosa }}\right) \frac{1000}{180}\left(\frac{\mathrm{mol} \text { glucosa }}{\mathrm{kg} \text { glucosa }}\right) 4184\left(\frac{\mathrm{J}}{\mathrm{kcal}}\right) \\
& h_{s}=-14.532 \mathrm{E} 06 \mathrm{~J}(\mathrm{~kg} \text { glucosa })^{-1}
\end{aligned}
$$

Los calores de formación para el agua y el $\mathrm{CO}_{2}$ a $25^{\circ} \mathrm{C}$ (Weast, 1977, pag. D-279) son:

$$
\begin{aligned}
& \mathrm{h}_{\mathrm{e}}=15.88 \times 10^{6} \mathrm{~J}(\mathrm{~kg} \text { de agua })^{-1} \\
& \mathrm{~h}_{\mathrm{c}}=8.943 \times 10^{6} \mathrm{~J}(\mathrm{~kg} \text { de bióxido de carbono })^{-1}
\end{aligned}
$$

El calor de formación de la fase biológica se estimó partiendo del principio que establece que el calor de formación de un compuesto cualquiera es igual a la suma de los calores de formación de los productos de su combustion menos el calor de combustión del componente mismo (Daubert, 1985: pp. 65-68). Considerando que la composición promedio de la biomasa de hongos filamentosos, según Roels, (1980) es: $\mathrm{C}_{10} \mathrm{H}_{18} \mathrm{O}_{5} \mathrm{~N}_{2}$, su peso molecular $246 \mathrm{~g}$ (mol biomasa)-1, y si la reacción de oxidación total de la biomasa es la siguiente

$$
\mathrm{C}_{10} \mathrm{H}_{18} \mathrm{O}_{5} \mathrm{~N}_{2}+12 \mathrm{O}_{2}===>10 \mathrm{CO}_{2}+9 \mathrm{H}_{2} \mathrm{O}+\mathrm{N}_{2}
$$


entonces, por estequiometría de la reacción (20-4), los calores de formación de los productos bióxido de carbono y agua, por kg de biomasa seca, son:

- para el bióxido de carbono:

$$
\begin{gathered}
8.943 \times 10^{6}\left(\frac{\mathrm{J}}{\mathrm{kg} \mathrm{CO}_{2}}\right) 10\left(\frac{\mathrm{mol} \mathrm{CO}}{\text { mol biomasa }}\right) \frac{44}{1000}\left(\frac{\mathrm{kg} \mathrm{CO}_{2}}{\mathrm{~mol} \mathrm{CO}_{2}}\right) \frac{1000}{246}\left(\frac{\mathrm{mol} \text { biomasa }}{\mathrm{kg} \text { biomasa }}\right)= \\
15.996 \times 10^{6} \mathrm{~J}(\mathrm{~kg} \text { biomasa })^{-1}
\end{gathered}
$$

- para el agua:

$$
\begin{gathered}
15.880 \times 10^{6}\left(\frac{\mathrm{J}}{\mathrm{kg} \mathrm{H}_{2} \mathrm{O}}\right) 9\left(\frac{\mathrm{mol} \mathrm{H}_{2} \mathrm{O}}{\text { mol biomasa }}\right) \frac{18}{1000}\left(\frac{\mathrm{kg} \mathrm{H}_{2} \mathrm{O}}{\text { mol H}_{2} \mathrm{O}}\right) \frac{1000}{246}\left(\frac{\text { mol biomasa }}{\mathrm{kg} \text { biomasa }}\right)= \\
10.458 \times 10^{6} \mathrm{~J}(\mathrm{~kg} \text { biomasa })^{-1}
\end{gathered}
$$

de donde, la suma de ambos calores de formación es:

$$
15.996 \times 10^{6}+10.458 \times 10^{6}=26.454 \times 10^{6} \mathrm{~J}_{(\mathrm{kg} \text { biomasa })^{-1}}
$$

El calor de combustión de la biomasa se estima siguiendo el mismo procedimiento empleado para la glucosa. Partiendo de la reacción (20-4), se obtiene:

$104.2\left(\frac{\mathrm{kcal}}{\mathrm{mol} \mathrm{O}_{2}}\right) 12\left(\frac{\mathrm{mol} \mathrm{O}_{2}}{\mathrm{~mol} \text { biomasa }}\right) \frac{1000}{246}\left(\frac{\text { mol biomasa }}{\mathrm{kg} \text { biomasa }}\right) 4184\left(\frac{\mathrm{J}}{\mathrm{kcal}}\right)=21.267 \times 10^{6} \mathrm{~J}(\mathrm{~kg} \text { biomasa })^{-1}$

de donde la diferencia con los calores de formación calculados antes es:

$$
26.454 \times 10^{6}-21.267 \times 10^{6}=5.187 \times 10^{6} \mathrm{~J}(\mathrm{~kg} \text { biomasa })^{-1}
$$

corrigiendo este valor por concepto del contenido de sales inorgánicas medidas como cenizas en la biomasa ( $10 \%)$, finalmente resulta:

$$
\mathrm{h}_{\mathrm{x}}=5.187 \times 10^{6}(0.9)=4.668 \times 10^{6} \mathrm{~J}(\mathrm{~kg} \text { de biomasa })^{-1}
$$

Para distinguir entre la formación y el consumo de los constituyentes reactivos, se incluye un signo menos para el calor que se produce cuando la glucosa desaparece.

Densidad volumétrica real de los constituyentes o las fases. Los valores aproximados son:

(i) Soporte inerte. Se incluye el valor proporcionado por el fabricante de Amberlita.

$$
\rho_{\mathrm{a}}^{*}=1070 \mathrm{~kg} \text { de Amberlita seca }\left(\mathrm{m}^{3} \text { de soporte seco }\right)^{-1}
$$

(ii) Fase líquida. La densidad de esta fase varia con la concentración de glucosa o de algún otro azúcar soluble, se utilizaron las siguientes aproximaciones polinomiales, en $\mathrm{kg}$ fase líquida $\left(\mathrm{m}^{3} \text { de fase líquida }\right)^{-1}$ : 
Para glucosa como fuente de carbono (Honig, 1967; p. 93)

$\rho_{1}^{*}=998.4+378.8\left(\frac{\rho_{\mathrm{s}}}{\rho_{\mathrm{s}}+\rho_{\mathrm{e}}}\right)+141.2\left(\frac{\rho_{\mathrm{s}}}{\rho_{\mathrm{s}}+\rho_{\mathrm{e}}}\right)^{2}$

Para sacarosa como fuente de carbono (Honig, 1967; pp. 52-53)

$\rho_{1}{ }^{*}=998.4+368.46\left(\frac{\rho_{s}}{\rho_{s}+\rho_{e}}\right)+172.61\left(\frac{\rho_{s}}{\rho_{s}+\rho_{e}}\right)^{2}$

En ambos casos el término entre paréntesis representa la concentración del constituyente azúcar soluble en el medio acuoso.

(iii) Fase biológica. Se adopta un valor experimental para A. niger medido después de centrifugar biomasa húmeda.

$\rho_{\mathrm{x}}^{*}=1150 \mathrm{~kg}$ de biomasa húmeda $\left(\mathrm{m}^{3} \text { de biomasa húmeda }\right)^{-1}$

20.2 Parámetros biológicos.

En el Cuadro 20.2 se listan los parámetros biológicos del modelo simplificado. Este grupo de parámetros se divide en dos subgrupos con características comunes:(i) parámetros que inciden directamente en el crecimiento celular y (ii) coeficientes de mantenimiento y los rendimientos.

\section{CUADRO 20.2 PARÁMETROS BIOLÓGICOS DEL MODELO SIMPLIFICADO.}

\begin{tabular}{|c|c|}
\hline Símbolo & Especificación y unidades \\
\hline \multicolumn{2}{|r|}{ - $\quad$ PARÁMETROS DEL CRECIMIENTO } \\
\hline$\emptyset$ & Contenido de agua en microorganismos, ( $\mathrm{kg}$ de agua) ( $\mathrm{kg}$ biomasa húmeda) ${ }^{-1}$. \\
\hline$A_{1}$ & Constante de frecuencia, $\mathrm{s}^{-1}$ \\
\hline $\mathrm{A}_{2}$ & Constante adimensional \\
\hline$E_{a \perp}$ & Energía de activación de la biomasa, $\mathrm{J}$ (mol biomasa) ${ }^{-1}$ \\
\hline$E_{\mathrm{a} 2}$ & Energía de desactivación de la biomasa, $\mathrm{J}$ (mol biomasa) ${ }^{-1}$ \\
\hline $\mathrm{R}_{\mathrm{cn}}$ & Máximo crecimiento superficial, ( $\mathrm{kg}$ biomasa húmeda) $\left(\mathrm{m}^{2} \text { de soporte inerte) }\right)^{-1}$ \\
\hline $\mathrm{K}_{\mathrm{s}}$ & Constante de afinidad por el glucosa, $\mathrm{kg}$ de glucosa $\mathrm{m}^{-3}$ \\
\hline$K_{i}$ & Constante de inhibición por glucosa, $\mathrm{kg}$ de glucosa $\mathrm{m}^{-3}$ \\
\hline
\end{tabular}




\section{CUADRO 20.2 PARÁMETROS BIOLÓGICOS DEL MODELO SIMPLIFICADO (CONTINUA).}

\begin{tabular}{|c|c|}
\hline Símbolo & Especificación y unidades \\
\hline - & COEFICIENTES DE MANTENIMIENTO Y RENDIMIENTOS \\
\hline $\mathrm{m}_{\mathrm{s}}$ & Coeficiente de mantenimiento glucosa, $\left(\mathrm{kg}\right.$ glucosa) $(\mathrm{kg} \text { biomasa húmeda })^{-1} \mathrm{~s}^{-1}$ \\
\hline $\mathrm{m}_{\mathrm{o}}$ & Coeficiente de mantenimiento oxígeno, (kg oxígeno) (kg biomasa húmeda $)^{-1} \mathrm{~s}^{-1}$ \\
\hline$Y_{S}$ & Rendimiento teórico máximo: glucosa, (kg biomasa seca) (kg glucosa $)^{-1}$ \\
\hline$\overline{Y_{\mathrm{e}}}$ & Rendimiento teórico máximo: agua, (kg biomasa seca) $(\mathrm{kg} \text { agua })^{-1}$ \\
\hline $\mathrm{Y}_{\mathrm{o}}$ & Rendimiento teórico máximo: oxígeno, (kg biomasa seca)(kg oxígeno $)^{-1}$ \\
\hline$Y_{c}$ & Rendimiento teórico máximo: $\mathrm{CO}_{7},(\mathrm{~kg}$ biomasa seca $)(\mathrm{kg} \mathrm{CO},)^{-1}$ \\
\hline $\mathrm{Y}_{\mathrm{p}}$ & $\begin{array}{l}\text { Coeficiente estequiométrico de transformación total de azúcares a } \mathrm{CO}_{2} \text {, en ausencia } \\
\text { de crecimiento: }\left(\mathrm{kg} \mathrm{CO}_{2}\right)(\mathrm{kg} \text { de glucosa })^{-1}\end{array}$ \\
\hline
\end{tabular}

\subsubsection{Parámetros del crecimiento.}

Contenido de agua en la biomasa. Este parámetro se utiliza con mucha frecuencia en las ecuaciones cinéticas para pasar de la base húmeda a la base seca. Evidentemente este parámetro no puede ser constante ya que durante las primeras 10 horas de la fermentación la biomasa es un conjunto de esporas en pleno proceso de germinación. Además, algunos factores ambientales como la temperatura, la concentración de azúcares en el medio y la relación carbono:nitrógeno también influyen en el contenido de agua de la biomasa (Laukevics et al, 1985). Por simplicidad se considera que la cantidad de agua contenida en la biomasa, independientemente de la edad de las células o las condiciones ambientales, es siempre constante e igual a aquella encontrada experimentalmente en la biomasa en forma de micelio:

$$
\emptyset=0.8 \text { ( } \mathrm{kg} \text { de agua) ( } \mathrm{kg} \text { biomasa húmeda) })^{-1} \text {. }
$$

Crecimiento celular. Anteriormente se estableció que este fenómeno dependía de tres factores: la temperatura, los espacios vacíos y la glucosa presente.

- La dependencia de la temperatura se modeló con una función doble exponencial, ver ecuación (16-1), en donde se presenta la tasa máxima de crecimiento $C_{x M a x}$ en función de la temperatura. En la ecuación aparecen cuatro parámetros: $A_{1}, A_{2}, E_{a 1}$ y $E_{a 2}$. Los valores que se adoptan para estos parámetros son los mismos utilizados por Saucedo-Castañeda $e t$ al, (1990) para A. niger C10, que es el mismo microorganismo con el que se valida 
experimentalmente este trabajo. En la Figura 20.1 se muestra la ecuación (16-1) graficada con los siguientes parámetros:

$$
\begin{array}{ll}
\mathrm{A}_{1}=2.7 \times 10^{11} \mathrm{~h}^{-1} & \mathrm{~A}_{2}=1.38 \times 10^{47} \text { adimensional } \\
\left.\mathrm{E}_{\mathrm{a} 1}=70255 \mathrm{~J} \text { (mol biomasa) }\right)^{-1} & \mathrm{E}_{\mathrm{a} 2}=283256 \mathrm{~J}(\mathrm{~mol} \text { biomasa) })^{-1}
\end{array}
$$

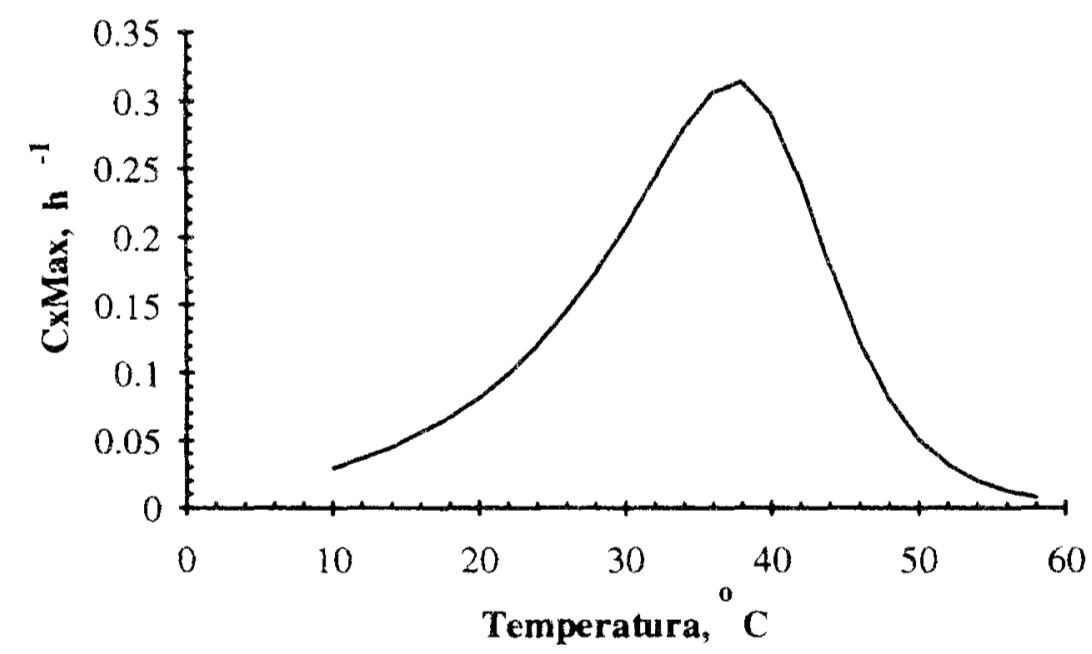

Figura 20.1 Representación gráfica de la función, doble exponencial, del crecimiento microbiano (CxMax) con la temperatura. Ver ecuación (16-1).

- La dependencia de los espacios vacíos incluye al parámetro biológico $R_{c p}$, definido antes como es la máxima capacidad de colonización de un microorganismo en una superficie disponible, este factor se determinó experimentalmente creciendo A. niger C10 sobre Amberlita tratada y con el medio de cultivo que se describe en el capítulo $\$ 24$ sobre cajas Petri. El valor promedio encontrado fue: $0.017 \mathrm{~kg}$ de biomasa húmeda $\mathrm{m}^{-2}$. Este valor en relación a otros encontrados en la literatura (ver Cuadro 20.3) es 17 veces mas bajo que el promedio de todos los valores inferiores que se muestran, pero solamente 1.4 veces menor que los encontrados por Larralde-Corona, et al (1993) con la misma cepa de A. niger con que se desarrolló este trabajo. 


\section{CUADRO 20.3. COMPARACIÓN DE VALORES DE $R_{\mathrm{cp}}$ PARA DIFERENTES MICROORGANISMOS.}

\begin{tabular}{|c|c|c|c|}
\hline $\mathrm{R}_{\mathrm{cp}}{ }^{(1)}$ & MICROORGANISMO & TIPO DE CULTIVO & REFERENCIAS \\
\hline $0.25-0.5$ & Aspergillus nidulans & Cajas Petri/Agar & Georgiou y Shuler (1986) \\
\hline $0.08-0.16$ & Sclerotium rofsii & Cajas Petri/Agar & Edelstein, et al (1983) \\
\hline $0.025-0.045$ & Aspergillus niger & Cajas Petri/Agar & Larralde-C., et al (1993) \\
\hline 0.017 & Aspergillus niger & Cajas Petri/Amberlita & Este trabajo \\
\hline
\end{tabular}

(1) $\mathrm{kg}$ de biomasa húmeda $\mathrm{m}^{-2}$. Calculados considerando $80 \%$ de humedad en la biomasa

- La dependencia del sustrato presente. Este factor esta definido en la ecuación (16-4):

$$
C_{x} \propto\left(\frac{\rho_{s}}{K_{s}+\frac{\rho_{s}^{2}}{K_{i}}+\rho_{s}}\right)
$$

como se observa, el crecimiento depende de dos parámetros: (i) uno del tipo de la constante de saturación de Monod $\left(\mathrm{K}_{\mathrm{s}}\right)$ y (ii) otro de inhibición $\left(\mathrm{K}_{\mathrm{i}}\right)$ debido a la concentración del sustrato. Como uno de los objetivos implícitos en este trabajo es el de modelar tomando en cuenta elevadas concentraciones iniciales de sustrato y en tanto que no se encuentran disponibles en la literatura valores de $\mathrm{K}_{\mathrm{s}}$ ni de $\mathrm{K}_{\mathrm{i}}$ para este tipo de cultivos, se decidió utilizar ambos parámetros para ajustar con los resultados experimentales de corridas con diferentes concentraciones iniciales de sustrato. Por lo tanto los siguientes valores son tentativos:

Para establecer estos rangos de variación se consideró que: (i) la concentración inicial de azúcar $\left(\rho_{\mathrm{s}}^{0}\right)$, a partir de la cual se produce una disminución de la tasa máxima de crecimiento en experimentos con harina de yuca, bagazo de caña y glucosa (Oriol et al,

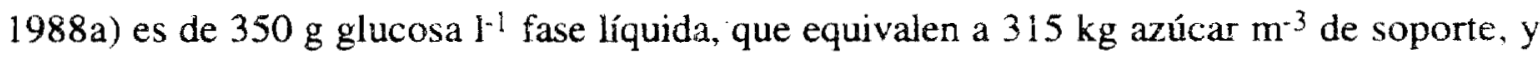
(ii) en cultivos sumergidos, cuando la concentración inicial de sustrato se eleva hasta valores superiores a los mínimos de la constante de saturación e.g. 10 a 20 veces mayor $\mathrm{K}_{\mathrm{s}}$ (Marison, 1988; p. 194), la tasa de crecimiento disminuye debida a una inhibición por sustrato. En cultivos sólidos en donde las concentraciones iniciales de sustrato son del 
orden de 30 a $150 \mathrm{~kg}$ azúcar $\mathrm{m}^{-3}$ de soporte, se esperarían valores de $\mathrm{K}_{\mathrm{s}}$ entre 2.0 y $10 \mathrm{~kg}$ azúcar $\mathrm{m}^{-3}$ de soporte, por lo que se proponen los siguientes rangos de variación:

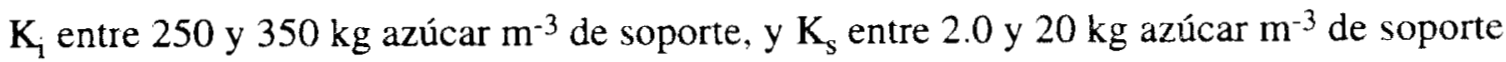

\subsubsection{Coeficientes de mantenimiento.}

En las hipótesis H:13 y H:14 se establece que una fracción de los azúcares consumidos se destinan funciones diferentes del crecimiento celular, i.e. también se destina una fracción del oxígeno estequiométricamente equivalente a la oxidación de esta fracción de los azúcares. Para el coeficiente de mantenimiento para los azúcares se decidió por el valor siguiente:

$$
\mathrm{m}_{\mathrm{s}}=2.24 \times 10^{-7}\left(\mathrm{~kg} \text { de glucosa) }(\mathrm{kg} \text { de biomasa húmeda })^{-1} \mathrm{~s}^{-1}\right.
$$

que corresponde al encontrado por Raimbault (1980) para la misma cepa pero con almidón como fuente carbonada, aunque menor al reportado para $R$. oligosporus (Molin et al, 1993) en tubos con agar y glucosa de 7.73E-07 (kg de glucosa) (kg de biomasa húmeda) ${ }^{-1} \mathrm{~s}^{-1}$.

El coeficiente de mantenimiento para el oxígeno corresponde a la cantidad equivalente para oxidar, hasta bióxido de carbono y agua, a esta fracción de glucosa. Partiendo de la reacción (203 ), para consumir los $m_{5}(\mathrm{~kg} \text { de glucosa) ( } \mathrm{kg} \text { de biomasa húmeda })^{-1} \mathrm{~s}^{-1}$, se requerirán:

$\mathrm{m}_{\mathrm{S}}\left(\frac{\mathrm{kg} \text { glucosa }}{\mathrm{kg} \text { biomasa húmeda s }}\right) 6\left(\frac{\mathrm{mol} \mathrm{O}_{2}}{\text { mol glucosa }}\right)\left(\frac{1000}{180}\right)\left(\frac{\mathrm{mol} \mathrm{glucosa}}{\mathrm{kg} \text { glucosa }}\right)\left(\frac{32}{1000}\right)\left(\frac{\mathrm{kg} \mathrm{O}_{2}}{\mathrm{~mol} \mathrm{O}_{2}}\right)=1.066 \mathrm{~m}_{\mathrm{s}}$

sustituyendo el valor para $\mathrm{m}_{\mathrm{S}}$ encontrado por Raimbault (1980), se obtiene que:

$$
\mathrm{m}_{\mathrm{o}}=2.37 \times 10^{-7}(\mathrm{~kg} \text { de oxígeno })(\mathrm{kg} \text { de biomasa húmeda })^{-1} \mathrm{~s}^{-1}
$$

que es casi igual al obtenido por gasometría por Soccol et al (1993) para $R$. oligosporus con almidón como sustrato de 2.2E-07 ( $\mathrm{kg}$ de oxígeno) ( $\mathrm{kg}$ de biomasa húmeda) ${ }^{-1} \mathrm{~s}^{-1}$.

\subsubsection{Rendimientos}

Para calcular los rendimientos teóricos, según la hipótesis $\mathbf{H : 5}$, se utiliza la reacción del Cuadro 20.4 , en donde la base de cálculo es un mol de biomasa seca y un rendimiento de azúcares de 0.5 $\mathrm{kg}$ de biomasa seca producida por $\mathrm{kg}$ de glucosa consumida. A partir de estas dos restricciones, empleando los valores de los coeficientes estequiométricos $\eta_{i}$ y con los pesos moleculares $\left(\mathrm{PM}_{\mathrm{i}}\right)$ respectivos, cada rendimiento se calcula a partir de : 


$$
Y_{i}=\left(\frac{\eta_{4} P_{4}}{\eta_{i} M_{4}}\right)
$$

de donde se obtienen los valores de cada rendimiento para cada especie reactiva. Los valores que se obtienen son:

$$
\begin{array}{ll}
Y_{s}=0.50 \mathrm{~kg} \text { biomasa seca }(\mathrm{kg} \text { glucosa })^{-1} & Y_{\mathrm{e}}=1.10 \mathrm{~kg} \text { biomasa seca }(\mathrm{kg} \text { agua })^{-1} \\
Y_{\mathrm{o}}=1.30 \mathrm{~kg} \text { biomasa seca }(\mathrm{kg} \text { oxígeno })^{-1} & Y_{\mathrm{c}}=0.876 \mathrm{~kg} \text { biomasa seca }(\mathrm{kg} \mathrm{CO})^{-1}
\end{array}
$$

Para la producción de bióxido de carbono en ausencia de crecimiento celular, el rendimiento correspondiente se calcula a partir de la información estequiométrica de la reacción (20-3) con:

$$
Y_{p}=\left(\frac{6}{1.0}\right)\left(\frac{44}{180}\right)=1.466 \mathrm{~kg} \mathrm{CO}_{2} \mathrm{~kg}^{-1} \text { glucosa }
$$

En el Cuadro 20.4 se incluye un balance estequiométrico de masa, en el que se puede observar que se satisface el principio de conservación:

\begin{tabular}{|c|c|c|c|c|c|c|c|c|c|c|}
\hline GLUCOSA & + & $\begin{array}{c}\text { FUENTE } \\
\text { DE } \\
\text { NITRÓGENO }\end{array}$ & + & OXÍGENO & $\Rightarrow$ & BIOMASA & + & $\begin{array}{c}\text { BIÓXIDO } \\
\text { DE } \\
\text { CARBONO }\end{array}$ & + & AGUA \\
\hline PM: 180 & & PM: 35 & & PM: 32 & & PM: 246 & & PM: 44 & & PM: 18 \\
\hline$\eta_{1} \mathbf{C}_{6} \mathbf{H}_{12} \mathbf{O}_{6}$ & + & $\eta_{2} \mathrm{NH}_{4} \mathrm{OH}$ & + & $\eta_{3} O_{2}$ & $\Rightarrow$ & $\eta_{4} \mathrm{C}_{10} \mathbf{H}_{18} \mathrm{O}_{5} \mathbf{N}_{2}$ & + & $\eta_{5} \mathrm{CO}_{2}$ & + & $\eta_{6} \mathbf{H}_{2} \mathrm{O}$ \\
\hline$\eta_{1}=2.73$ & & $\eta_{2}=2.0$ & & $\eta_{3}=5.88$ & & $\eta_{4}=1.0$ & & $\eta_{5}=6.38$ & & $\eta_{6}=12.38$ \\
\hline BALANCE & & DE MASA: & & & & & & & & \\
\hline 0.491 & + & 0.070 & + & 0.188 & $\Rightarrow$ & 0.246 & + & 0.280 & + & 0.223 \\
\hline kg de glucosa & & $\mathrm{kg} \mathrm{NH}_{4} \mathrm{OH}$ & & $\mathrm{kg} \mathrm{O}_{2}$ & & $\mathrm{~kg}$ Biomasa & & $\mathrm{kgCO}_{2}$ & & kg Agua \\
\hline & & TOTAI & & $0.749 \mathrm{~kg}$ & $\Longrightarrow$ & $0.749 \mathrm{~kg}$ & & TOTAL & & \\
\hline
\end{tabular}

$$
\Sigma\left(\eta_{i} \mathrm{PM}_{\mathrm{i}}\right)_{\text {reactivos }}-\Sigma\left(\eta_{\mathrm{i}} \mathrm{PM}_{\mathrm{i}}\right)_{\text {productos }}=0
$$

\section{CUADRO 20.4 BALANCE ESTEQUIOMÉTRICO DE MASA Y ENERGÍA EN LA REACCIÓN DE FORMACIÓN DE BIOMASA.}

BASE: Producción de un mol de biomasa y un rendimiento de $0.5 \mathrm{~kg}$ biomasa seca ( $\mathrm{kg}$ de sustrato consumido $)^{-1}$ $\mathrm{PM}_{\mathrm{i}}$ : Peso molecular del constituyente $\mathrm{i}, \mathrm{g}$ de $\mathrm{i}(\mathrm{mol} \text { de } \mathrm{i})^{-1}$

$\eta_{i}$ : Número de moles del constituyente $i$, mol de $i$ 
20.3 Resumen de los parámetros a utilizar.

Tentativamente, el conjunto (36 parámetros) con el que se valida más adelante el modelo simplificado es el siguiente:

Parámetros físicos:

$$
\begin{aligned}
& \mathrm{fp}_{\mathrm{N}}=0.75443 \mathrm{~kg} \text { nitrógeno }(\mathrm{kg} \text { aire húmedo })^{-1} \\
& \mathrm{fp}_{0}=0.21143 \mathrm{~kg} \text { oxígeno }(\mathrm{kg} \text { aire húmedo })^{-1} \\
& \mathrm{fp}_{\mathrm{c}}=0.00045 \mathrm{~kg} \text { bióxido de carbono }(\mathrm{kg} \text { aire húmedo })^{-1} \\
& \mathrm{P}=92633 \mathrm{~Pa} \\
& \mathrm{~L}=0.1 \mathrm{~m} \\
& \mathrm{Ra}=0.0055 \mathrm{~m} \\
& \Phi=0.00064 \mathrm{~m} \\
& \mathrm{~T}_{\mathrm{j}}=308.13 \mathrm{~K} \\
& \text { Taire }=308.13 \mathrm{~K} \\
& \mathrm{v}_{\mathrm{g}}=0.0039 \mathrm{~m} \mathrm{~s}^{-1} \\
& \mathrm{U}=83 \mathrm{~J}^{\left(\mathrm{m}^{2} \mathrm{~s} \mathrm{~K}\right)^{-1}} \\
& c_{\mathrm{a}}=1268 \mathrm{~J}(\mathrm{~kg} \text { base seca } \mathrm{K})^{-1} \\
& c_{\mathrm{g}}=720 \mathrm{~J}(\mathrm{~kg} \mathrm{~K})^{-1} \\
& c_{1}=4180 \mathrm{~J}(\mathrm{~kg} \mathrm{~K})^{-1} \\
& c_{x}=3320 \mathrm{~J}(\mathrm{~kg} \text { base húmeda } \mathrm{K})^{-1} \\
& \mathrm{hs}=-14.532 \times 10^{6} \mathrm{~J}(\mathrm{~kg} \text { de glucosa })^{-1} \\
& \text { he }=15.88 \times 10^{6} \mathrm{~J}(\mathrm{~kg} \text { de agua })^{-1} \\
& \mathrm{~h}_{\mathrm{c}}=8.943 \times 10^{6} \mathrm{~J}(\mathrm{~kg} \text { de bióxido de carbono })^{-1} \\
& \mathrm{~h}_{\mathrm{x}}=4.668 \times 10^{6} \mathrm{~J}(\mathrm{~kg} \text { de biomasa })^{-1} \\
& \rho_{\mathrm{a}}{ }^{*}=1070 \mathrm{~kg} \text { de Amberlita seca }\left(\mathrm{m}^{3} \text { de Amberlita seca }\right)^{-1} \\
& \rho_{1}^{*}=\text { Variable según las ecuaciones (20-5) o (20-6) } \\
& \rho_{\mathrm{x}}{ }^{*}=1150 \mathrm{~kg} \text { de biomasa húmeda }\left(\mathrm{m}^{3} \text { de biomasa húmeda }\right)^{-1}
\end{aligned}
$$

Parámetros biológicos:

$$
\begin{aligned}
& \emptyset=0.8(\mathrm{~kg} \text { de agua) (kg biomasa húmeda) })^{-1} \\
& A_{1}=2.7 \times 10^{11} \mathrm{~h}^{-1} \\
& A_{2}=1.38 \times 10^{47} \text { adimensional } \\
& E_{a 1}=70255 \mathrm{~J}(\text { mol de biomasa })^{-1} \\
& \left.E_{a 2}=283256 \mathrm{~J} \text { (mol de biomasa }\right)^{-1} \\
& \left.R_{c p}=0.017 \mathrm{~kg} \text { de biomasa húmeda ( } \mathrm{m}^{2} \text { de soporte inerte) }\right)^{-1}
\end{aligned}
$$




$$
\begin{aligned}
& \mathrm{K}_{\mathrm{s}}=2.0-20 \mathrm{~kg} \text { de glucosa } \mathrm{m}^{-3} \text { de empaque } \\
& \mathrm{K}_{\mathrm{i}}=250-350 \mathrm{~kg} \text { de glucosa } \mathrm{m}^{-3} \text { de empaque } \\
& \mathrm{m}_{\mathrm{s}}=2.24 \times 10^{-7}(\mathrm{~kg} \text { de glucosa })(\mathrm{kg} \text { de biomasa húmeda })^{-1} \mathrm{~s}^{-1} \\
& \mathrm{~m}_{\mathrm{o}}=2.37 \times 10^{-7}\left(\mathrm{~kg} \text { de Oxígeno) }(\mathrm{kg} \text { de biomasa húmeda })^{-1} \mathrm{~s}^{-1}\right. \\
& \mathrm{Y}_{\mathrm{s}}=0.50 \mathrm{~kg} \text { biomasa seca }(\mathrm{kg} \text { glucosa })^{-1} \\
& \mathrm{Y}_{\mathrm{e}}=1.10 \mathrm{~kg} \text { biomasa seca }(\mathrm{kg} \text { agua })^{-1} \\
& \mathrm{Y}_{\mathrm{o}}=1.30 \mathrm{~kg} \text { biomasa seca }(\mathrm{kg} \text { oxígeno })^{-1} \\
& \mathrm{Y}_{\mathrm{c}}=0.876 \mathrm{~kg} \text { biomasa seca }(\mathrm{kg} \text { bióxido de carbono })^{-1} \\
& \mathrm{Y}_{\mathrm{p}}=1.466 \mathrm{~kg} \mathrm{CO}(\mathrm{kg} \text { glucosa })^{-1}
\end{aligned}
$$

\section{\$21. Solución del modelo: Un problema de valor inicial.}

El modelo simplificado que se propone, representa un problema de valores iniciales, a partir de los cuales se deberán calcular los valores de las variables de estado, en cada tiempo $t$, con métodos numéricos. A continuación se presenta una idea global de la estrategia de solución numérica, seguida de un conjunto de condiciones iniciales propuestas con las que después se detalla el procedimiento empleado de normalización del modelo antes de resolverlo.

\subsection{Estrategia de la solución numérica}

Para resolver el modelo simplificado se propone la siguiente metodología global: (i) asignar una condición inicial a cada variable de estado, es decir asignar el valor (constante) que debe adoptar ésta en el tiempo igual a cero, (ii) definir, a partir de las variables originales, un conjunto de nuevas variables de estado adimensionales utilizando las condiciones iniciales u otros parámetros que resulten convenientes (iii) sustituir las nuevas variables adimensionales en el modelo simplificado original (iv) resolver el sistema de ecuaciones resultante con el algoritmo de integración de Runge-Kutta.

\subsection{Condiciones iniciales.}

Las condiciones iniciales con las que se resuelve el problena, i.e. los valores de los parámetros al tiempo cero, para cada variable de estado, se presentan resumidos en el Cuadro 21.1 que sigue. 


\section{CUADRO 21.1 CONDICIONES INICIALES PARA LA SOLUCIÓN DEL MODELO SIMPLIFICADO}

\begin{tabular}{|c|c|}
\hline VARIABLE & VALOR PROPUESTO@ $@ \mathrm{t}=0$ \\
\hline Amberlita & $\rho_{\mathrm{a}}=\rho_{\mathrm{a}}{ }^{0}=250 \mathrm{~kg}$ Amberlita seca $\mathrm{m}^{-3}$ \\
\hline Biomasa & $\rho_{x}=\rho_{x}^{0}=0.2 \mathrm{~kg}$ biomasa húmeda $\mathrm{m}^{-3}$ \\
\hline Glucosa & $\rho_{\mathrm{s}}=\rho_{\mathrm{s}}^{0}=37 \mathrm{~kg}$ Glucosa $\mathrm{m}^{-3}$ \\
\hline Agua & $\rho_{\mathrm{c}}=\rho_{\mathrm{e}}{ }^{0}=350 \mathrm{~kg}$ agua $\mathrm{m}^{-3}$ \\
\hline Agua vapor & $\begin{aligned} \rho_{V}=\rho_{v}{ }^{0}= & \left(\rho_{N}{ }^{0}+\rho_{o}^{0}+\rho_{e}^{0}\right) \frac{\text { PMe } p_{e}^{*}}{\text { PMaire }\left(P+p_{e}^{*}\right)} \\
& \text { donde } p_{e}^{*} \text { se calcula a } T_{p}\end{aligned}$ \\
\hline Nitrógeno & $\rho_{\mathrm{N}}=\rho_{\mathrm{N}}{ }^{0}=0.3893 \mathrm{~kg}$ Nitrógeno $\mathrm{m}^{-3}$ \\
\hline Oxígeno & $\rho_{\mathrm{o}}=\rho_{\mathrm{o}}{ }^{0}=0.10909 \mathrm{~kg}$ Oxígeno $\mathrm{m}^{-3}$ \\
\hline $\begin{array}{l}\text { Bióxido de } \\
\text { carbono }\end{array}$ & $\rho_{c}=\rho_{c}^{0}=0.00023 \mathrm{~kg}$ Bióxido de carbono $\mathrm{m}^{-3}$ \\
\hline Temperatura & $\mathrm{T}=\mathrm{T}_{\mathrm{p}}=308.13 \mathrm{~K}$ \\
\hline
\end{tabular}

21.3 Normalización del modelo simplificado.

Para la elaboración del modelo en términos adimensionales, así como para facilitar su manejo y solución, en el Cuadro 21.2 se proponen las variables adimensionales y nuevas condiciones iniciales para cada variable de estado, incluyendo a la variable independiente, donde: $t_{f}$ es el tiempo total de fermentación, expresado en segundos. Los términos de máxima producción de biomasa y máxima temperatura permisible, se definieron antes en la ecuación (16-3) y en el Cuadro 21.1 respectivamente. En el caso de la máxima producción de bióxido de carbono, $\rho_{\mathrm{cmax}}$, se considera que ésta se dará cuando la máxima cantidad de biomasa esté presente y se calcula mediante la ecuación siguiente:

$$
\rho_{c \operatorname{Max}}=\left(\frac{(1-\varnothing)}{Y_{c}}\right) \rho_{x \operatorname{Max}}
$$


Para una mayor facilidad de aquí en adelante las nuevas variables adimensionales se distinguirán por presentarse en letras itálicas y negritas.

CUADRO 21.2 CONDICIONES INICIALES PARA CADA VARIABLE NORMALIZADA

\begin{tabular}{|c|c|c|c|}
\hline VARIABLE i & $\begin{array}{c}\text { CONDICIONES } \\
\text { INICIALES } \\
\rho_{\mathrm{i}} @ \mathrm{t}=0\end{array}$ & $\begin{array}{c}\text { VARIABLE } \\
\text { (Adimensional) }\end{array}$ & $\begin{array}{c}\text { NUEVAS } \\
\text { CONDICIONES } \\
\text { INICIALES } \\
\rho_{i} @ \mathrm{t}=0\end{array}$ \\
\hline$\rho_{a}$ & $\rho_{a}^{0}$ & $\rho_{a}=\frac{\rho_{a}}{\rho_{a}{ }^{0}}$ & $\rho_{a}=1.0$ \\
\hline$\rho_{x}$ & $\rho_{x}^{0}$ & $\rho_{x}=\frac{\rho_{x}}{\rho_{x \operatorname{Max}}}$ & $\rho_{x}=\frac{\rho_{x}^{0}}{\rho_{x} \operatorname{Max}}$ \\
\hline$\rho_{\mathrm{s}}$ & $\rho_{s}{ }^{0}$ & $\rho_{s}=\frac{\rho_{s}}{\rho_{s}^{0}}$ & $\rho_{s}=1.0$ \\
\hline$\rho_{\mathrm{e}}$ & $\rho_{\mathrm{e}}^{0}$ & $\rho_{e}=\frac{\rho_{e}}{\rho_{e}^{0}}$ & $\rho_{e}=1.0$ \\
\hline$\rho_{\mathrm{N}}$ & $\rho_{N}^{0}$ & $\rho_{N}=\frac{\rho_{N}}{\rho_{N}^{0}}$ & $\rho_{N}=1.0$ \\
\hline$\rho_{v}$ & $\rho_{\mathrm{v}}{ }^{0}$ & $\rho_{v}=\frac{\rho_{v}}{\rho_{v}{ }^{0}}$ & $\rho_{v}=1.0$ \\
\hline$\rho_{\mathrm{o}}$ & $\rho_{0}{ }^{0}$ & $\rho_{o}=\frac{\rho_{0}}{\rho_{0}^{0}}$ & $\rho_{o}=1.0$ \\
\hline$\rho_{c}$ & $\rho_{c}^{0}$ & $\rho_{c}=\frac{\rho_{c}}{\rho_{c M a x}}$ & $\rho_{c}=0$ \\
\hline $\mathrm{T}$ & $\mathrm{T}_{\mathrm{P}}$ & $T=\frac{T-T p}{\operatorname{Tin}-T p}$ & $\boldsymbol{T}=0$ \\
\hline $\mathrm{t}$ & $t=0$ & $t=\frac{\mathrm{t}}{\mathrm{t}_{\mathrm{f}}}$ & $t=0$ \\
\hline
\end{tabular}

Tin: Temperatura máxima permisible, $50^{\circ} \mathrm{C}$

A partir de las variables normalizadas que se presentan en el Cuadro 21-2, a continuación se presenta el modelo simplificado en su forma adimensional. 
Fase biológica. Sustituyendo el cambio de variable propuesto en el Cuadro 21.2 y la ecuación (21-1) en la ecuación (19-2), se obtiene la siguiente expresión:

$$
\frac{d \rho}{d t}=\frac{t f}{\rho_{x M a x}} C_{x}
$$

donde $\mathrm{C}_{\mathrm{x}}$ según la ecuación (16-5) con el cambio de variables queda como sigue:

$$
\mathrm{C}_{\mathrm{x}}=\mathrm{C}_{\mathrm{x} \operatorname{Max}} \rho_{\mathrm{xMax}} \rho_{x}\left(1-\rho_{x}\right)\left(\frac{\rho_{s} \rho_{s}^{0}}{\mathrm{~K}_{\mathrm{s}}+\frac{\left(\rho_{\mathrm{s}}^{0} \rho_{s}\right)^{2}}{\mathrm{~K}_{\mathrm{i}}}+\rho_{\mathrm{s}}{ }^{0} \rho_{s}}\right)
$$

donde: $C_{x M a x}$ se calcula con la ecuación (16-1).

Fase líquida. Para glucosa, sustituyendo el cambio de variable propuesto en la ecuación (19-3), se obtiene la siguiente expresión:

$$
\frac{d \rho_{s}}{d t}=-\frac{t_{f}}{\rho_{s}^{0}} C_{s}
$$

donde $\mathrm{C}_{\mathrm{s}}$ se modifica, a partir de la ecuación (16-6), en:

$$
C_{s}=\left(\frac{(1-\phi)}{Y_{s}}\right) C_{x}+m_{s} \rho_{x} \rho_{x M a x}
$$

Para el agua, partiendo de la ecuación (19-4), se obtiene:

$$
\frac{\mathrm{d} \rho_{e}}{\mathrm{~d} t}=\frac{\mathrm{tf}}{\rho_{\mathrm{e}}{ }^{0}} \mathrm{C}_{\mathrm{e}}
$$

donde $C_{e}$ se modifica a partir de la ecuación (16-7) y la ecuación (21-3).

Fase gaseosa. Para el oxígeno, a partir de las definiciones del Cuadro 21-2 y de las ecuaciones (19-6) y (21-3), se obtiene la siguiente expresión:

$$
\frac{\mathrm{d} \rho_{o}}{\mathrm{~d} t}=\left(\frac{\mathrm{t}_{\mathrm{f}}}{\rho_{\mathrm{o}}{ }^{0}}\right)\left(\frac{\mathrm{v}_{\mathrm{g}}}{\mathrm{L}}\left(\rho_{\mathrm{o}}^{0} \rho_{o}-\mathrm{fp}_{\mathrm{o}} \rho_{\text {aire }} \varepsilon\right)-\mathrm{C}_{\mathrm{o}}\right)
$$


donde $C_{0}$ : se convierte, según (16-8), en:

$$
C_{o}=\left(\frac{(1-\not)}{Y_{o}}\right) C_{x}+m_{o} \rho_{x M a x} \rho_{x}
$$

Para el bióxido de carbono, por analogía con el oxígeno:

$$
\frac{d \rho_{c}}{d t}=\left(\frac{t_{f}}{\rho_{c M a x}}\right)\left(\frac{v_{g}}{L}\left(\rho_{c M a x} \rho_{c}-f_{c} \rho_{\text {aire }} \varepsilon\right)+C_{c}\right)
$$

donde $C_{c}:$ se convierte, según (16-9), en:

$$
C_{c}=\left(\frac{(1-\emptyset)}{Y_{c}}\right) C_{x}+Y_{p} m_{s} \rho_{x M a x} \rho_{x}
$$

Temperatura. A partir de los balances de calor, ecuación (19-13), sustituyendo la temperatura y el tiempo adimensional, se obtiene la siguiente expresión:

$$
\begin{gathered}
\frac{d T}{d t}=-\left(\frac{\rho_{g} c_{g}}{\rho_{i} c_{i}}\right)\left(\frac{v_{g}}{L} t_{f}\right)\left(\frac{\left(T_{\text {aire }}-T_{p}\right)}{\left(T_{i n}-T_{p}\right)}-T\right)-\left(\frac{U}{\rho_{i} c_{i}}\right)\left(\frac{2}{R a} t_{f}\right)\left(\frac{\left(T_{j}-T_{p}\right)}{\left(T_{i n}-T_{p}\right)}-T\right)- \\
\frac{t_{f}}{\left(T_{i n}-T_{p}\right)}\left(\frac{C_{i} h_{i}}{\rho_{i} c_{i}}\right)
\end{gathered}
$$

El conjunto de ecuaciones diferenciales ordinarias por resolver numéricamente esta constituido por las ecuaciones:

$(21-2),(21-4),(21-6),(21-7),(21-9)$ y $(21-11)$

\section{§22. Resultados teóricos y discusión.}

Para resolver el sistema de ecuaciones diferenciales ordinarias desarrolladas en el capítulo anterior, se utilizó el algoritmo de Runge-Kutta de cuarto orden con un paso de integración constante igual a 0.006 veces el tiempo de residencia de la fase gaseosa en el VER. El programa se elaboró en el lenguaje de programación Turbo Pascal 6.0 en el modo de doble precisión utilizando variables del tipo "pointer" que dejaban libre la memoria cuando esto se requería. El programa se resolvió con la ayuda de una computadora personal (IBM-compatible) con un 
coprocesador 486 y 40 MHertz. A continuación se detallan las principales características del programa.

22.1 Programa de simulación.

El programa esta constituido por un total de nueve procedimientos que se invocan a través de un programa principal. En el Cuadro 22.1 se presenta una lista de los programas y una breve descripción de la función de cada uno.

CUADRO 22.1 DESCRIPCIÓN DE LOS PROGRAMAS UTILIZADOS EN LA SIMULACIÓN DEL MODELO SIMPLIFICADO

\begin{tabular}{|c|c|}
\hline PROGRAMA & DESCRIPCIÓN \\
\hline PRINCIPAL.PAS & $\begin{array}{l}\text { Define constantes, tipos, variables y todos los procedimientos } \\
\text { que se emplearán. Invoca a todos los procedimientos. Calcula las } \\
\text { condiciones iniciales y establece las reglas de impresión y } \\
\text { almacenamiento de datos. Detecta la finalización del proceso y } \\
\text { detiene la simulación. }\end{array}$ \\
\hline LECTURA.PAS & Asigna valores a 41 variables. Lo invoca PRINCIPAL.PAS. \\
\hline VALIDA.PAS & $\begin{array}{l}\text { Calcula condiciones de operación y permite la modificación de } \\
25 \text { variables previamente leídas, esto mediante la presentación de } \\
\text { cinco pantallas. Cada pantalla tiene la doble opción de modificar } \\
\text { o aceptar todos los valores. Al final recalcula conforme a las } \\
\text { modificaciones propuestas por el usuario. Lo invoca } \\
\text { PRINCIPAL.PAS. }\end{array}$ \\
\hline ABRE.PAS & $\begin{array}{l}\text { Abre un archivo con un nombre asignado por ei usuario. } \\
\text { Imprime un encabezado con los valores de nueve parámetros y la } \\
\text { fecha. Imprime el encabezado para siete columnas y las } \\
\text { condiciones iniciales. Lo invoca PRINCIPAL.PAS. }\end{array}$ \\
\hline IMPRESIÓN.PAS & $\begin{array}{l}\text { Imprime en la pantalla la misma información que el } \\
\text { procedimiento ABRE.PAS. Lo invoca PRINCIPAL.PAS. }\end{array}$ \\
\hline DERIVA.PAS & $\begin{array}{l}\text { Define variables propias del procedimiento. Calcula las nuevas } \\
\text { condiciones de operación y los valores de cada una de las } \\
\text { derivadas empleando el vector de variables dependientes } \\
\text { evaluado en el tiempo anterior. Entrega el vector de derivadas y } \\
\text { otras variables. Lo invocan PRINCIPAL.PAS y RK4.PAS }\end{array}$ \\
\hline
\end{tabular}




\section{CUADRO 22.1 DESCRIPCIÓN DE LOS PROGRAMAS UTILIZADOS EN LA SIMULACIÓN DEL MODELO SIMPLIFICADO (CONTINUA)}

\begin{tabular}{|c|l|}
\hline PROGRAMA & \multicolumn{1}{|c|}{ DESCRIPCIÓN } \\
\hline RK4.PAS & $\begin{array}{l}\text { Utiliza al vector de derivadas evaluadas en el tiempo anterior y } \\
\text { calcula, dividiendo en cuatro intervalos el paso de integración. } \\
\text { En cada etapa invoca a DERIVA.PAS. Acumula los valores y } \\
\text { entrega el nuevo vector de variables dependientes. A este } \\
\text { procedimiento lo invoca PRINCIPAL.PAS. }\end{array}$ \\
\hline ANALISIS.PAS & $\begin{array}{l}\text { Utiliza al vector de variables dependientes producido por } \\
\text { RK4.PAS y compara los valores calculados con valores } \\
\text { establecidos, sea para asignar nuevos valores o para detener el } \\
\text { crecimiento ol programa. Ver texto. A este procedimiento lo } \\
\text { invoca PRINCIPAL.PAS. }\end{array}$ \\
\hline A_PANTALLA.PAS & $\begin{array}{l}\text { Imprime en la pantalla el vector de resultados al tiempo t. Lo } \\
\text { invoca PRINCIPAL.PAS. }\end{array}$ \\
\hline A_DISCO.PAS & $\begin{array}{l}\text { Almacena en el archivo preparado por ABRE.PAS, el vector de } \\
\text { resultados al tiempo t.. Lo invoca PRINCIPAL.PAS. }\end{array}$ \\
\hline
\end{tabular}

El proceso de simulación se inicia con la declaración de constantes, tipos, procedimientos y las variables principales. Realiza una lectura de valores de los parámetros discutidos en el capítulo \$21. Presenta una lista de los parámetros para dar la opción al usuario de modificarlos o aceptarlos. Abre un archivo en donde almacenará la información producida y presenta en la pantalla, a medida que calcula. Cuando los parámetros han sido modificados o aceptados por el usuario, el programa recalcula las condiciones de operación y se inicia la solución numérica del sistema de ecuaciones evaluando un nuevo vector de derivadas con el vector de variables dependientes correspondientes al tiempo anterior. La técnica de solución que se empleó demostró una gran estabilidad numérica y rápida respuesta ( 80 horas de fermentación se simulan en $5 \mathrm{~min}$ ).

En la Figura 22.1 se muestra un diagrama de la lógica con que opera el programa. Como se puede apreciar, cuando el programa sale del procedimiento RK4.PAS el procedimiento ANALISIS.PAS compara los valores recién calculados de: las masas volumétricas adimensionales glucosa, agua y oxígeno; temperatura adimensional y la fracción de espacios disponibles, contra valores límite o condiciones límite establecidos previamente. 


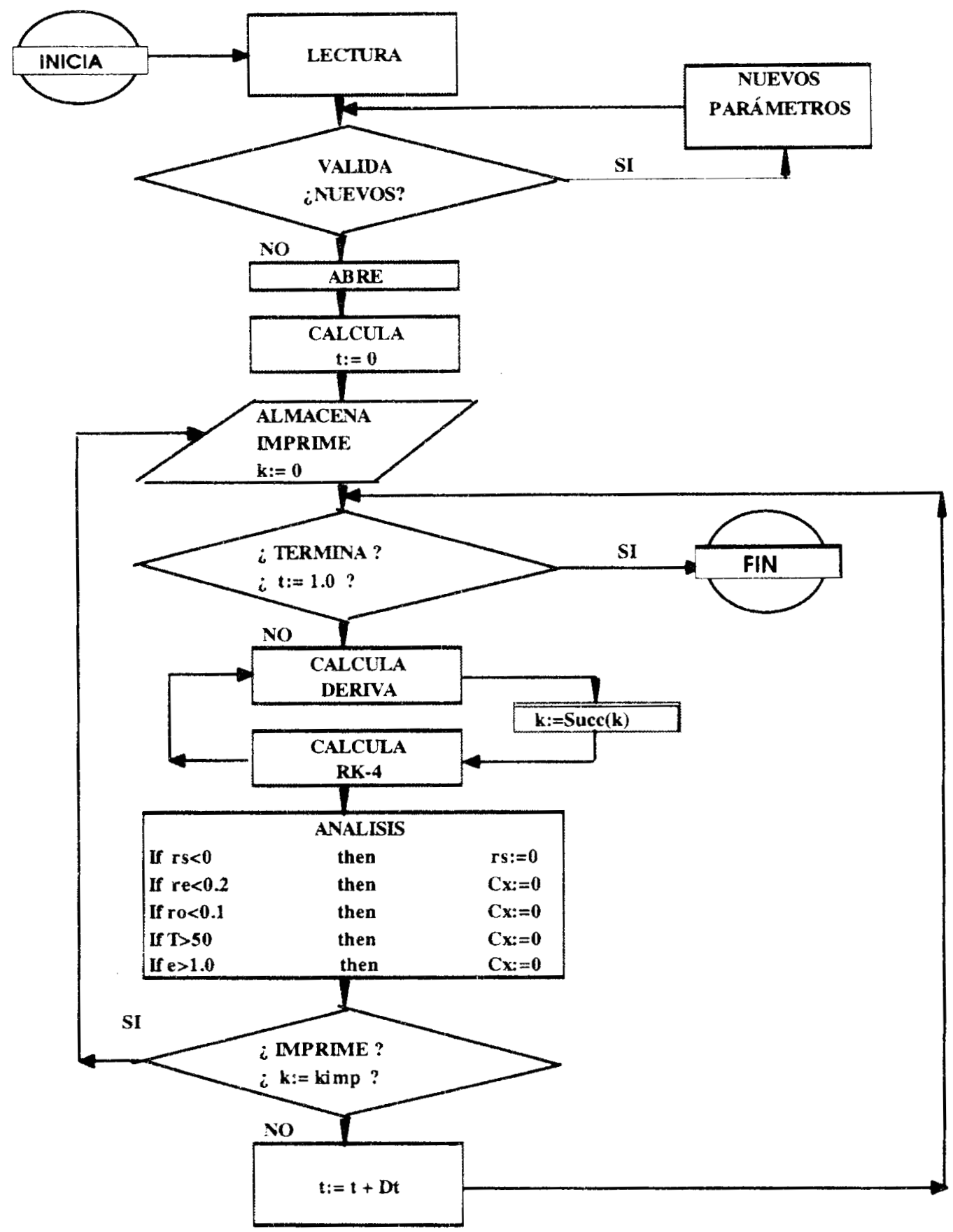

Figura 22.1 Lógica de cálculo del programa para la simulación del proceso empleando el modelo simplificado. Diagrama de bloques. 
Cuando alguna de las variables se agotó o adquirió algún valor que pudiera producir algún efecto irreversible sobre el crecimiento celular, entonces se ejecuta una determinada acción. Las variables comparadas y la condición que se debe cumplir para ejecutar las acciones respectivas se muestran en el Cuadro 22.2. Si alguna de estas condiciones se cumple, al menos una vez, la acción correspondiente se realiza siempre, es decir, en ningún caso el crecimiento se puede restablecer aún cuando el valor de la variable se restituyera a un valor normal. Estas condiciones evitan, por ejemplo, que se produzcan valores negativos para los sustratos consumidos, temperaturas más altas que la máxima establecida o crecimiento aún cuando el agua o los espacios vacios ya no estén disponibles.

\section{CUADRO 22.2. CONDICIONES QUE DEBEN SATISFACERSE PARA QUE EL PROGRAMA DE CÁLCULO SE DETENGA. COMPARACIONES REALIZADAS POR EL PROCEDIMIENTO ANALISIS.PAS}

\begin{tabular}{|c|c|l|}
\hline $\begin{array}{c}\text { CONDICIÓN A } \\
\text { CUMPLIR }\end{array}$ & $\begin{array}{c}\text { ACCIÓN QUE } \\
\text { REALIZA }\end{array}$ & \multicolumn{1}{|c|}{ COMENTARIOS } \\
\hline$\rho_{s}<=0$ & $\rho_{s}=0$ & $\begin{array}{l}\text { La masa de glucosa no puede ser } \\
\text { negativa }\end{array}$ \\
\hline$\rho_{e}<=0.2$ & $\mathrm{C}_{\mathrm{x}}=0$ & $\begin{array}{l}\text { El crecimiento se detiene cuando el agua } \\
\text { disponible llega a este valor: } 20 \% \text { del } \\
\text { inicial }\end{array}$ \\
\hline$\rho_{o}<=0.1$ & $\mathrm{C}_{\mathrm{x}}=0$ & $\begin{array}{l}\text { El crecimiento se detiene cuando el } \\
\text { oxígeno llega, al menos una vez, a este } \\
\text { valor: 10\% del inicial }\end{array}$ \\
\hline$T>=1.0$ & $\mathrm{C}_{\mathrm{x}}=0$ & $\begin{array}{l}\text { El crecimiento se detiene cuando la } \\
\text { temperatura llega, al menos una vez, a } \\
50^{\circ} \mathrm{C}\end{array}$ \\
\hline$\varepsilon>=1.0$ & $\mathrm{C}_{\mathrm{x}}=0$ & $\begin{array}{l}\text { El crecimiento se detiene cuando el } \\
\text { espacio vacío llega a ocuparse } \\
\text { totalmente. }\end{array}$ \\
\hline
\end{tabular}

En el ANEXO IV, se presentan los listados de los programas para la solución del modelo simplificado. Los listados corresponden a los procedimientos siguientes: (i) PRINCIPAL.PAS, (ii) LECTURA.PAS, (iii) ANALISIS.PAS, (iv) RK4.PAS, y (v) DERIVA.PAS. 


\subsection{Simulación del proceso.}

Los resultados que emite el programa en la pantalla y en el archivo, se presentan tabulados en siete columnas: el tiempo, las seis variables dependientes y, en ocasiones, la fracción de espacios vacíos. en el Cuadro 22.3 se puede observar la impresión de resultados de un ejemplo para una corrida de simulación cualquiera.

\section{CUADRO 22.3 EMISIÓN DE RESULTADOS EN PANTALLA: EJEMPLO DE SIMULACIÓN}

\begin{tabular}{|c|c|c|c|c|c|c|}
\hline \multicolumn{7}{|c|}{ Fecha: $30 / 11 / 1993$} \\
\hline $\begin{array}{l}\text { Taire } \\
\text { Área de } \\
\mathrm{K}_{\mathrm{s}} \\
\mathrm{ms} \\
\mathrm{mo}\end{array}$ & $\begin{array}{l}=35.00 \mathrm{C} \\
\text { Transf }=400 \\
=37.0 \mathrm{~kg} \mathrm{~m} \\
=2.2 \mathrm{E}-7 \mathrm{~kg} \\
=2.5 \mathrm{E}-7 \mathrm{~kg}\end{array}$ & $\begin{array}{l}0 \mathrm{~m}^{2} \mathrm{n} \\
\\
\text { luc. } / \mathrm{kg} \\
\text { xígeno }\end{array}$ & $\begin{array}{l}\text { húm. s } \\
\text { m. húm }\end{array}$ & $\begin{aligned} \text { Gasto } & = \\
\rho_{\mathrm{S}}{ }^{0} & = \\
\mathrm{Ki} & = \\
\mathrm{U} & =\end{aligned}$ & $\begin{array}{l}15 \mathrm{~m}^{3} \text { aire } \\
7.0 \mathrm{~kg} \mathrm{~m}^{-3} \\
000 \mathrm{~kg} \mathrm{~m}^{-3}\end{array}$ & $x^{-1}$ \\
\hline $\begin{array}{c}\text { Tiempo } \\
\text { (horas) }\end{array}$ & hoX & RhoS & RhoE & RhoO & $\begin{array}{l}\text { RhoC } \\
\text { X1000 } \\
\end{array}$ & $\begin{array}{l}\text { Temp } \\
\left({ }^{\circ} \mathrm{C}\right)\end{array}$ \\
\hline 0.6 & 0 & 0 & 00 & 1.000000 & 03401 & 35.00000 \\
\hline 4.5 & 0.000756 & 0.999517 & 0.999592 & 0.974847 & 0.003732 & 35.00378 \\
\hline 8.99 & 0.001460 & 0.998585 & 0.998804 & 0.974633 & 0.004119 & 35.00729 \\
\hline 13.49 & 0. & 0.996788 & 0.9 & .974220 & 0.00 & \\
\hline 17.99 & 0.005432 & 0.993330 & 0.994363 & 0.973429 & 0.006287 & 35.02698 \\
\hline 22.48 & 0.010432 & 0.986711 & 0.988772 & 0.971929 & 0.008983 & 35.05144 \\
\hline 26.98 & 0.019902 & 0.974169 & 0.978183 & 0.969137 & 0.013981 & 35.09679 \\
\hline 31.48 & 0.037492 & 0.950843 & 0.958514 & 0.964115 & 0.022897 & 35.17757 \\
\hline 35.98 & 0.069001 & 0.908961 & 0.923281 & 0.955671 & 0.037639 & 35.31078 \\
\hline 40.47 & 0.121857 & 0.838379 & 0.864179 & 0.943141 & 0.058731 & 35.50019 \\
\hline 44.97 & 0.201240 & 0.731415 & 0.775414 & 0.928270 & 0.081652 & 35.70255 \\
\hline 49.47 & 0.302492 & 0.592604 & 0.662195 & 0.916211 & 0.095678 & 35.81765 \\
\hline 53.96 & 0.408302 & 0.442826 & 0.543880 & 0.911679 & 0.092939 & 35.77379 \\
\hline 58.46 & 0.499299 & 0.306512 & 0.442128 & 0.914212 & 0.077439 & 35.61162 \\
\hline
\end{tabular}

Con el conjunto de parámetros propuestos en el capítulo $\$ 20$, el modelo simplificado produce los resultados que se detallan y discuten a continuación. 


\subsubsection{Producción de biomasa.}

La cinética del crecimiento celular se muestra en la Figura 22.1 Se puede apreciar una fase de adaptación de aproximadamente 10 horas, seguida de un rápido aumento en la masa celular que se prolonga hasta alrededor de las 25 horas. A partir de las 26 horas de cultivo el crecimiento se detiene. De acuerdo a la estructura con que se elaboró el modelo, las razones por las que el crecimiento se puede interrumpir son: (i) algún sustrato vital (glucosa, oxigeno, agua) se termina o deja de estar disponible, (ii) la temperatura del sistema se incrementa hasta provocar daños irreversibles en la biomasa, (iii) el espacio disponible se agota.
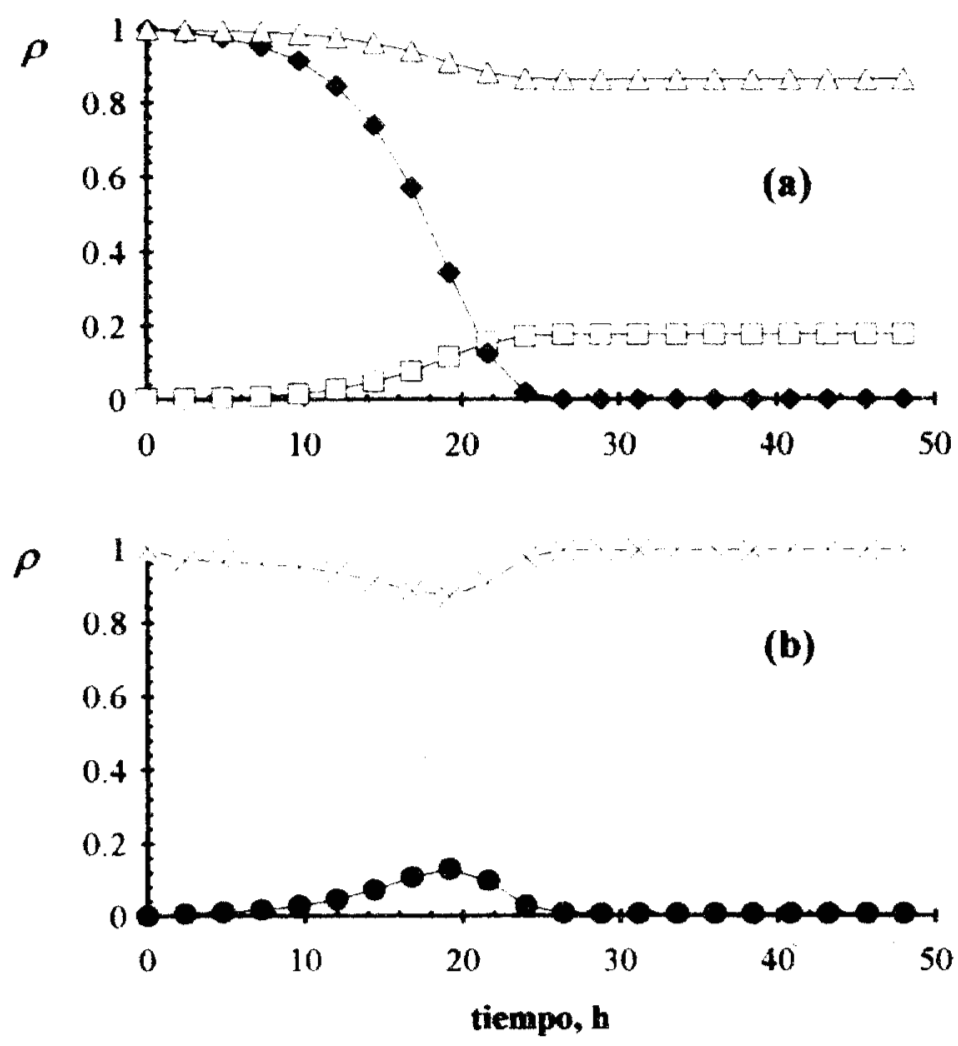

Figura 22.1 Resultados teóricos producidos por el modelo simplificado: (a) (-- - , producción de biomasa; $(--)$, consumo de axúcares; $(-\Delta-)$, consumo de agua. (b) (-X-), Consumo de oxígeno; (-૯-), producción de bióxido de carbono $\mathbf{1 0}^{-3}$. 


\subsubsection{Consumo de azúcares.}

En la Figura 22.1 (a) se muestra el acoplamiento entre el crecimiento celular y el consumo de los azúcares. Se puede observar que desde antes de las 10 horas los azúcares desaparecen de manera rápida hasta hacerse cero (aproximadamente a las 26 horas de cultivo) coincidiendo plenamente con la interrupción del crecimiento celular. Aparentemente este es el factor que limita la producción de la biomasa.

\subsubsection{Consumo y producción de agua.}

Como se puede apreciar en la Figura 22.1 (a) la variable adimensional correspondiente al agua se incorpora a la biomasa siempre en cantidades estequiométricas y constantes (la composición de la biomasa se consideró constante siempre con un $80 \%$ de agua). Debido a esto el perfil mostrado sigue a la producción de biomasa como un imagen especular y el consumo de agua se detiene cuando el crecimiento celular cesa. Al detenerse el crecimiento, la masa de agua presente corresponde a cerca de un $85 \%$ del total de agua adicionada al principio, por lo que al estar siempre en un exceso, el agua no es el factor que limita la producción de la biomasa.

\subsubsection{Consumo de oxígeno.}

Esta cinética se presenta en la Figura 22.1 (b), en donde se aprecia un ligero descenso cercano a las 30 horas en donde solamente se consume un $10 \%$ del total que se incorpora en la corriente gaseosa, sin embargo es suficiente para soportar el rápido consumo de los azúcares mostrado en la Figura 22.1 (a), como se demuestra a continuación:

- Independientemente del destino de los azúcares, según el balance estequiométrico del cuadro 20.4, por cada $\mathrm{kg}$ de glucosa que consumen las células se requieren $0.383 \mathrm{~kg}$ de oxígeno.

- Como se puede ver en la Figura 22.1 (a), entre las 8 y las 26 horas de cultivo se consumen el $90 \%$ del total de azúcares adicionados en un principio $\left(\rho_{\mathrm{s}}{ }^{0}\right)$, es decir:

$$
0.9 \rho_{\mathrm{s}}^{0}=0.82(37)=33.3 \mathrm{~kg} \text { de glucosa } \mathrm{m}^{-3}
$$

- Por lo tanto, para consumir $33.3 \mathrm{~kg}$ de glucosa $\mathrm{m}^{-3}$ se requieren:

$$
33.3\left(\frac{\mathrm{kg} \text { de glucosa }}{\mathrm{m}^{3}}\right) 0.383\left(\frac{\mathrm{kg} \text { de oxígeno }}{\mathrm{kg} \text { de glucosa }}\right)=12.75 \frac{\mathrm{kg} \text { de oxígeno }}{\mathrm{m}^{3}}
$$

- En 20 horas de cultivo se suministran (ver 20.1.1): 


$$
\begin{gathered}
0.037\left(\frac{\mathrm{m}^{3} \text { aire }}{\mathrm{m}^{3} \mathrm{~s}}\right)\left(\frac{3600 \mathrm{~s}}{1 \mathrm{~h}}\right) 0.21\left(\frac{\mathrm{m}^{3} \text { oxígeno }}{\mathrm{m}^{3} \text { aire }}\right) 0.97\left(\frac{\mathrm{kg} \text { oxígeno }}{\mathrm{m}^{3} \text { oxígeno }}\right) 20 \mathrm{~h}=542\left(\frac{\mathrm{kg} \text { oxígeno }}{\mathrm{m}^{3}}\right) \\
\text { es decir: }\left(\frac{542}{11.61}\right) \approx 42 \text { veces más oxígeno del requerido estequiométricamente }
\end{gathered}
$$

Por lo tanto el oxígeno, como en el caso del agua libre, se encuentra en exceso siempre sugiriendo que no es el factor que limita el crecimiento celular que se simula.

\subsubsection{Producción de bióxido de carbono.}

En la Figura 22.1(b) se observa que la producción de bióxido de carbono se desarrolla siguiendo al crecimiento celular de manera más o menos paralela hasta la mitad de la fase exponencial, produciéndose un máximo alrededor de las 20 horas de iniciado el cultivo. Este máximo de bióxido de carbono coincide con el mínimo de oxígeno presente. Con un razonamiento similar al desarrollado en 22.2.4 para el oxígeno, a continuación se demuestra que las cantidades producidas de bióxido de carbono corresponden bien a las consumidas de oxígeno

- Según el balance estequiométrico del cuadro 20.4 , por cada $\mathrm{kg}$ de oxígeno consumido por las células se producen $1.49 \mathrm{~kg}$ de bióxido de carbono.

- $\quad$ Como se puede ver en la Figura 22.1 (b), a las 20 horas de cultivo $\rho_{a}=0.87$ y $\rho_{c}=1.3 \times 10^{-4}$

- Las ecuaciones (21-7) y (21-9) para el consumo de oxígeno y la producción de bióxido de carbono total respectivamente, en el estado estacionario se pueden escribir como:

$$
\begin{aligned}
& \text { Oxígeno consumido }=\frac{\mathrm{v}_{\mathrm{g}}}{\mathrm{L}}\left(\mathrm{fp}_{\mathrm{o}} \rho_{\mathrm{aire}} \varepsilon-\rho_{\mathrm{o}}^{0} \rho_{o}\right) \\
& \text { Bióxido de carbono producido }=\frac{\mathrm{v}_{\mathrm{g}}}{\mathrm{L}}\left(\mathrm{fp}_{\mathrm{c}} \rho_{\text {aire }} \varepsilon-\rho_{\mathrm{cMax}} \rho_{c}\right)
\end{aligned}
$$

- Sustituyendo los valores de los parámetros y variables correspondientes, al dividir la ecuación (22-2) entre (22-1) se obtienen $2.51 \mathrm{~kg}$ de bióxido de carbono producidos por $\mathrm{kg}$ de oxígeno consumido, es decir, el modelo genera resultados de bióxido de carbono, del mismo orden de magnitud de los estequiométricos pero $(2.51 / 1.49)=1.7$ veces mayores que los esperados estequiométricamente. La discrepancia entre ambos valores puede deberse a que se subestimaron los coeficientes de mantenimiento.

\subsubsection{Evolución de la temperatura.}

En la Figura 22.2 (a) se muestra la cinética de la temperatura del medio. El máximo que se produce coincide con el máximo para el $\mathrm{CO}_{2}$ producido y con el mínimo de $\mathrm{O}_{2}$ consumido en la 
etapa final del crecimiento exponencial. El modelo predice un incremento máximo en temperatura cercano a un grado centígrado. Este valor parece demasiado grande para las pequeñas dimensiones del sistema que se modela. Sin embargo, si se considera que la distancia mayor en la dirección radial i.e. entre el centro y la pared del VER -una columna de vidrio- es de $0.5 \mathrm{~cm}$, entonces el aumento relativo de la temperatura sería de $2.0{ }^{\circ} \mathrm{C} \mathrm{cm}^{-1}$, valor que se puede comparar con los gradientes de temperatura más elevados que encontraron Rathbun y Shuller, (1983) y Saucedo-Castañeda et al, (1990) de 3.0 y $4.5^{\circ} \mathrm{C} \mathrm{cm}^{-1}$ respectivamente. Como se ve, el aumento en temperatura que predice el modelo no sería determinante para detener el crecimiento celular.
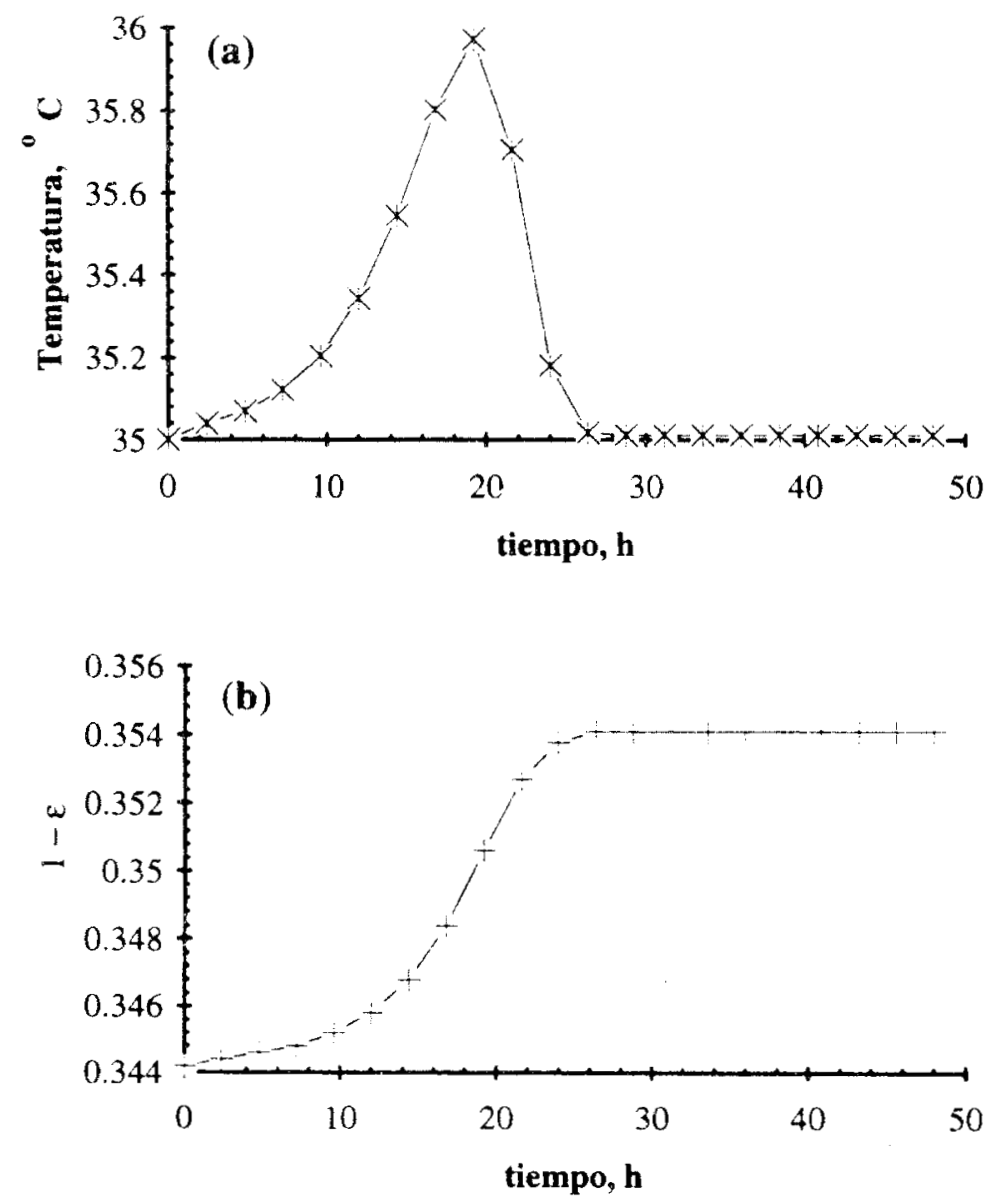

Figura 22.2 Resultados teóricos producidos por el modelo simplificado. (a) Temperatura y (b) ocupación de los espacios libres. 


\subsubsection{Ocupación de los espacios libres.}

Aunque ésta no es una de las variables de estado, resulta interesante simular la manera como la biomasa ocupa la porosidad macroscópica o huecos interparticulares en una columna empacada con Amberlita. En la Figura 22.2 (b) se puede observar un evolución del tipo sigmoidal idéntica a la curva del crecimiento celular. La función de espacios vacíos que se utiliza en el modelo fue definida en el ANEXO III con la ecuación (III-4) conforme a la hipótesis H:2 para el tiempo cero. La misma ecuación está incluida en el programa con la siguiente modificación que permite evaluar los espacios libres $\varepsilon$ para todo tiempo de cálculo:

$$
1-\varepsilon=\left(\frac{\rho_{a}^{0}}{\rho_{a}{ }^{*}}+\frac{\rho_{x M a x} \rho_{x}}{\rho_{x}{ }^{*}}+\frac{\left(\rho_{s}^{0} \rho_{s}+\rho_{e}{ }^{0} \rho_{e}\right)}{\rho_{1}{ }^{*}}\right)
$$

Los cambios de 1 - $\varepsilon$ con respecto al tiempo indican que la biomasa ocupa apenas una fracción del total de espacios disponibles, cercana al $10 \%$ y que, para las condiciones de operación simuladas, los espacios libres no limitan el crecimiento celular. Sin embargo, si se considera que la máxima ocupación de espacios libres se lleva a cabo cuando la biomasa producida es la máxima, lo que es posible sólo cuando los azúcares y el agua disponible en la fase líquida son muy próximos a cero, con la ecuación (22-1) se puede encontrar un valor aproximado para los epacios ocupados, caso hipotético en que $\rho_{x}$ tienda a ser uno, en este caso, $1-\varepsilon=0.71$. Lo que implica que la ocupación de espacios, en el mejor de los casos, se incrementaría de 0.34 hasta casi el doble: 0.71 . El máximo valor teórico debería ser UNO, que correspondería a $\varepsilon=0$; i.e. si en algun momento se lograra una colonización total de la superficie disponible, prevista con el término $\rho_{x M a x}$ todavía habría un $29 \%$ de espacios libres disponibles.

\section{Resumen y conclusiones.}

La incorporación de dos nuevas hipótesis (H:15 y H:16) permitió reducir el modelo general planteado hasta un modelo simplificado constituido por: (i) seis ecuaciones diferenciales ordinarias: (19-2), (19-3), (19-4), (19-6), (19-7) y (19-13) y 13 ecuaciones algebraicas asociadas en los términos cinéticos y balances, y (ii) 36 parámetros de los cuales 22 son parámetros físicos y 14 son biológicos. Los parámetros se estimaron en función de las condiciones de operación, las características físicas de los constituyentes y de una reacción de transformación de azúcares en biomasa. El modelo resultante se normalizó mediante la definición de nuevas variables adimensionales y se resolvió con el algoritmo de Runge-Kutta de cuarto orden.. Los resultados teóricos producidos por el modelo simplificado permitieron concluir: 
- Desde un punto de vista cualitativo, los resultados emitidos por el modelo evolucionan conforme a lo esperado.

- Desde un punto de vista cuantitativo, los resultados emitidos son congruentes entre sí y responden satisfactoriamente a los principios fundamentales en los que se basa el modelo.

- Con las condiciones de operación y el conjunto de parámetros ensayado, aparentemente el crecimiento celular se detiene debido al agotamiento de los azúcares y no a las otras variables de estado: agua, oxígeno, espacios libres o la temperatura. 


\section{B. ESTIMACIÓN DE PARÁMETROS Y SENSIBILIDAD \\ PARAMÉTRICA DEL MODELO.}

§23. Estrategia de estimación y sensibilidad paramétrica.

La estrategia de validación que se propone parte de la suposición de que los valores asignados a los parámetros en la Parte III A de este trabajo, requieren de ajustes razonables. Un ajuste razonable se refiere a cualquier cambio en el valor de uno o varios parámetros que aproxime mejor los resultados teóricos a los experimentales. Estos ajustes deben darse dentro de un cierto dominio en el que no se pierda el significado físico o biológico del parámetro en cuestión. La estrategia que se propone comprende tres etapas: (i) comparación preliminar del modelo con resultados experimentales, (ii) aproximación de los resultados del modelo a los experimentales, incluyendo un análisis de sensibilidad paramétrico, y (iii) ajuste final de resultados, incluyendo comparaciones con otros sistemas experimentales.

\section{§24. Resultados experimentales.}

La metodología que se utilizó en estos experimentos, se diseñó con el propósito de aproximarse lo más posible a los supuestos teóricos en que se apoya el modelo simplificado, incluyendo experimentos con concentraciones crecientes de fuente de carbono inicial. Los resultados fueron obtenidos por Córdova, (1994) con Amberlita-IRA 900, en pequeñas columnas de vidrio de 0.011 $\mathrm{m}$ de diámetro y $0.106 \mathrm{~m}$ de altura empacada. Cada columna se empacó con $7.0 \mathrm{~g}$ de resina impregnada e inoculada. La densidad de empaque fue de $0.69 \mathrm{~g}$ de soporte impregnado e inoculado $\mathrm{ml}^{-1}$ ocupado en la columna y el microorganismo fue Aspergillus niger No. 10 . Se utilizaron los cinco medios de cultivo que se describen en el Cuadro 24.1.

CUADRO 24.1. COMPOSICIÓN DE LOS MEDIOS DE CULTIVO UTILIZADOS.

\begin{tabular}{|l|c|c|c|c|c|}
\hline \multicolumn{1}{|c|}{ CONSTITUYENTE } & $\begin{array}{c}\text { MEDIO M-A(*) } \\
\left(\mathrm{g} \mathrm{I}^{-1}\right)\end{array}$ & $\begin{array}{c}\text { MEDIO M-B } \\
\left(\mathrm{g} \mathrm{I}^{-1}\right)\end{array}$ & $\begin{array}{c}\text { MEDIO M-C } \\
\left(\mathrm{g} \mathrm{l}^{-1}\right)\end{array}$ & $\begin{array}{c}\text { MEDIO M-D } \\
\left(\mathrm{g} \mathrm{I}^{-1}\right)\end{array}$ & $\begin{array}{c}\text { MEDIO M-E } \\
\left(\mathrm{g} \mathrm{I}^{-1}\right)\end{array}$ \\
\hline Glucosa & 30.000 & 50.000 & 100.000 & 200.000 & 400.000 \\
\hline$\left(\mathrm{NH}_{4}\right)_{2} \mathrm{SO}_{4}$ & 2.200 & 6.600 & 6.600 & 6.600 & 6.600 \\
\hline $\mathrm{K}_{2} \mathrm{HPO}_{4}$ & 2.470 & 2.470 & 2.470 & 2.470 & 2.470 \\
\hline $\mathrm{CaCl}_{2}$ & 0.485 & 0.485 & 0.485 & 0.485 & 0.485 \\
\hline $\mathrm{MgSO}_{4} .7 \mathrm{H}_{2} \mathrm{O}$ & 0.380 & 0.380 & 0.380 & 0.380 & 0.380 \\
\hline $\mathrm{NaCl}^{\text {RELACIÓN (C/N) }}$ & 0.320 & 0.320 & 0.320 & 0.320 & 0.320 \\
\hline
\end{tabular}

${ }^{(*)}$ Medio de propagación. 
Las columnas se incubaron a $35^{\circ} \mathrm{C}$ durante $50-70 \mathrm{~h}$. A cada columna se alimentó una corriente de

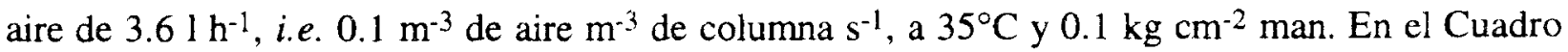
24.2 se presenta la proporción de cada uno de los constituyentes del sistema, en las unidades y terminología con que se desarrolló el modelo.

\section{CUADRO 24.2 PROPORCIÓN DE LOS CONSTITUYENTES EN EL SISTEMA DE EXPERIMENTACIÓN $\left(^{*}\right.$.}

\begin{tabular}{|c|c|c|c|c|}
\hline Constituyente & Medio M-B & Medio M-C & Medio M-D & Medio M-E \\
\hline Amberlita & 278.0 & 278.0 & 278.0 & 278.0 \\
\hline Glucosa & 17.4 & 41.7 & 83.5 & 167.0 \\
\hline Agua & 399.4 & 375.1 & 333.3 & 249.8 \\
\hline Sales & 4.3 & 4.3 & 4.3 & 4.3 \\
\hline MASA TOTAL & 699.1 & 699.1 & 699.1 & 699.1 \\
\hline
\end{tabular}

${ }^{*}$ Todo se expresa en $\mathrm{kg}$ del constituyente por $\mathrm{m}^{3}$ de columna.

En el Cuadro 24.3 se muestra un ejemplo de resultados obtenidos con el medio de cultivo M-B. En las columnas (1) y (2) se presentan los promedios de cuatro determinaciones analíticas para biomasa y glucosa respectivamente, ambas expresadas en miligramos de constituyente por gramo de resina seca original.

CUADRO 24.3. RESULTADOS EXPERIMENTALES PARA BIOMASA Y GLUCOSA, OBTENIDOS CON EL MEDIO DE CULTIVO M-B.

\begin{tabular}{|c|c|c|c|c|c|c|}
\hline & $\mathbf{1}$ & $\mathbf{2}$ & $\mathbf{3}$ & $\mathbf{4}$ & $\mathbf{5}$ & $\mathbf{6}$ \\
\hline TIEMPO & BIOMASA & GLUCOSA & BIOMASA & GLUCOSA & BIOMASA & GLUCOSA \\
\hline$(\mathrm{h})$ & $\left(\mathrm{mg} \mathrm{g}^{-1}\right.$ R.S. $)$ & $\left(\mathrm{mg} \mathrm{g}^{-1}\right.$ R.S. $)$ & $\left(\mathrm{kg} \mathrm{BH} \mathrm{m}^{-3}\right)$ & $\left(\mathrm{kg} \mathrm{BS} \mathrm{m}^{-3}\right)$ & (adimensional) & (adimensional \\
& & & & & \\
\hline 0 & 0.022774 & 75.54579 & 0.031883 & 21.00173 & 0.000062 & 1.000000 \\
\hline 11.5 & 0.060791 & 73.15264 & 0.085108 & 20.33643 & 0.000166 & 0.968322 \\
\hline 20.5 & 0.883755 & 68.30306 & 1.237257 & 18.98825 & 0.002417 & 0.904128 \\
\hline 26.6 & 6.490348 & 50.80082 & 9.086488 & 14.12263 & 0.017747 & 0.672451 \\
\hline 32.187 & 34.74016 & 36.24634 & 48.63622 & 10.07648 & 0.094993 & 0.479793 \\
\hline 38.5 & 46.55051 & 10.5347 & 65.17071 & 2.928646 & 0.127287 & 0.139448 \\
\hline 44.5 & 55.19169 & 5.055524 & 77.26836 & 1.405436 & 0.150915 & 0.06692 \\
\hline 47.83 & 52.52036 & 4.404705 & 73.5285 & 1.224508 & 0.14361 & 0.058305 \\
\hline 52.4 & 48.31529 & 6.779247 & 67.6414 & 1.884631 & 0.132112 & 0.089737 \\
\hline
\end{tabular}


En las columnas (3) y (4) los constituyentes biomasa y glucosa se expresan en las unidades de $\rho_{x}$ y $\rho_{\mathrm{s}}$ del modelo. En las dos últimas columnas, los mismos valores se expresan de manera adimensional $\left(\rho_{x}\right.$ y $\left.\rho_{s}\right)$, calculados con:

$$
\rho_{x}=\frac{\rho_{x}}{\rho_{\mathrm{xMax}}} ; \quad y \quad \rho_{s}=\frac{\rho_{\mathrm{s}}}{\rho_{\mathrm{s}}^{0}}
$$

donde, según el Cuadro $24.2, \rho_{\mathrm{s}}{ }^{0}=17.4 \mathrm{~kg}$ de glucosa $\mathrm{m}^{-3}$ de empaque. El valor calculado para la máxima biomasa teórica $\rho_{x M a x}$ es de $512 \mathrm{~kg}$ de biomasa húmeda $\mathrm{m}^{-3}$ de empaque, este valor teórico para la máxima biomasa es muy próximo al que se obtiene aplicando el modelo de Laukevics et al, (1985), los autores encuentran un valor de $476 \mathrm{~kg}$ de biomasa húmeda $\mathrm{m}^{-3}$ de empaque. Estos cálculos se repitieron para todos los medios de cultivo.

En la Figura 24.1 (a) se presentan las cinéticas de producción de biomasa para cada medio de cultivo. La ordenada adimensional se calcula de la misma manera que en la columna (5) del Cuadro 24.3. De la figura se puede decir que, para las concentraciones de glucosa ensayadas:

1. La duración de la fase de germinación de esporas no se ve afectada por la composición del medio, confirmando la predominancia de tipo sigmoidal propuesta en el modelo a través de la ecuación logística para el crecimiento.

2. La tasa de crecimiento, durante la fase exponencial, aumenta ligeramente cuando aumenta la concentración inicial de glucosa, sugiriendo una ligera dependencia del término $\mathrm{C}_{\mathrm{xMax}}$ con respecto a la concentración inicial de azúcares.

3. Los valores de máxima biomasa que se logran en las diferentes corridas son muy parecidos entre sí, en independencia de la composición del medio de cultivo. 

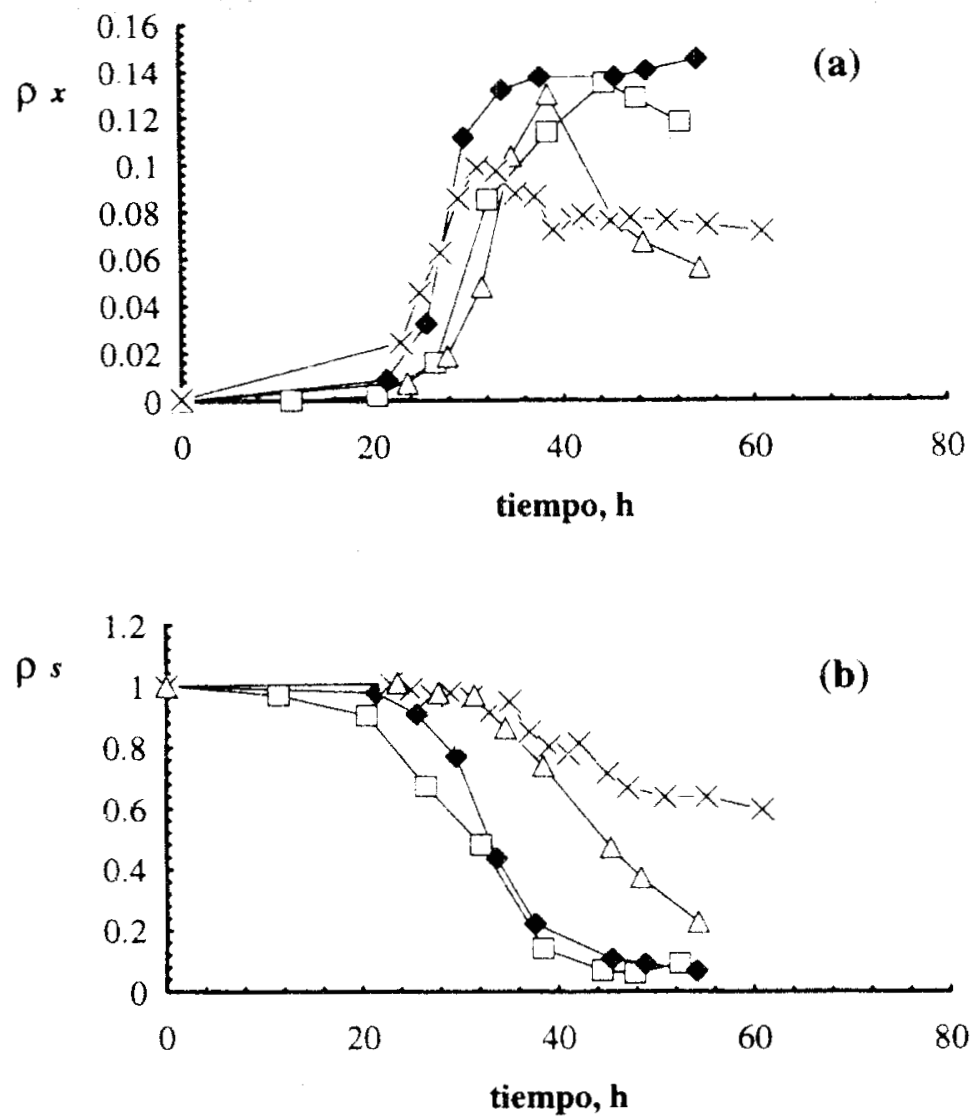

FIGURA 24.1. Cinéticas de (a) crecimiento celular, y (b) consumo de glucosa en Amberlita. Resultados experimentales con los medios : (-b-) M-B; (- -) M-C; (- $\Delta \cdot)$ M-D; (-X-) M-E (ver Cuadros 24.1 y 24.2)

4. En los medios de cultivo con menos glucosa (medios $\mathrm{B}$ y $\mathrm{C}$ ), el crecimiento celular se detiene aproximadamente a las $45 \mathrm{~h}$ de cultivo, aún en presencia del $10 \%$ de la glucosa inicial. Este resultado sugiere que el crecimiento celular se detiene debido a la limitación de algún otro factor no previsto hasta ahora.

5. En los medios M-D y M-E el crecimiento celular se detiene aún en presencia de un fuerte exceso de glucosa, sugiriendo una inhibición por sustrato.

6. En los medios de cultivo con más glucosa, se observa una fase de disminución brusca de la biomasa, que sustituye a la fase estacionaria final. Este fenómeno, aparentemente debido a una lísis que antecede siempre a la etapa de esporulación (Smith, 1977), no esta contemplado en el presente modelo matemático. 
En la Figura 24.1 (b) se muestran las cinéticas de consumo de azúcares con la ordenada normalizada. Se puede observar que, para las concentraciones de glucosa inicial ensayadas:

1. El consumo del sustrato se inicia antes para los mediosM-B y M-C, sólo en el caso de estos medios el consumo coincide con el inicio y la fase exponencial del crecimiento. Con los medios M-D y M-E el consumo de glucosa y el crecimiento parecen estar desacoplados.

2. En el caso de los medios menos concentrados las máximas tasas de consumo son prácticamente paralelas. Sólo el medio M-E muestra un comportamiento diferente.

3. Cuando el crecimiento se detiene el consumo de glucosa continua. Este efecto es más marcado a medida que el medio contiene más glucosa. Este fenómeno sugiere la síntesis de algún metabolito de reserva o algún ácido orgánico que pudiera estar asociado parcialmente al crecimiento.

Estos resultados sugieren que, a partir de una cierta concentración inicial de glucosa, se presenta un desacoplamiento en el metabolismo. Este desacoplamiento se aprecia con más claridad en la Figura 24.2 en donde se presentan, para cada medio de cultivo, las tasas específicas de consumo de sustrato y crecimiento celular. Las derivadas puntuales se evaluaron a partir de polinomios que se ajustaron a los resultados experimentales.

En los medios con baja concentración de glucosa (M-B y M-C), ambas curvas evolucionan paralelamente y el máximo se presenta aproximadamente al mismo tiempo de cultivo. En los medios M-D y M-E el comportamiento es completamente distinto al de los medios M-B y MC, inclusive se observa que cuando la tasa de crecimiento celular se hace cero, la tasa de consumo de glucosa continúa. Este fenómeno se puede explicar a través de la síntesis de algún producto del metabolismo que se produce a expensas de la glucosa consumida, sin necesariamente reflejarse en el crecimiento.

La discusión del desacoplamiento metabólico con estas concentraciones de glucosa en el mismo sistema experimental motivó la publicación de un trabajo reciente (Gutiérrez-Rojas et al, 1994b) en el que se demuestra que $A$. niger en Amberlita IRA-900, con los medios M-D y M-E produce cantidades importantes de ácido cítrico, glicerol y eritrol. El efecto de estos resultados se toma en cuenta en las discusiones, pero su demostración y orígenes quedan fuera del alcance del presente trabajo. 


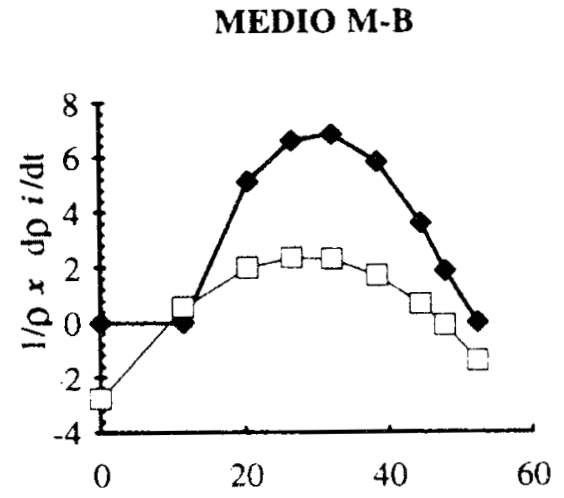

MEDIO M-D

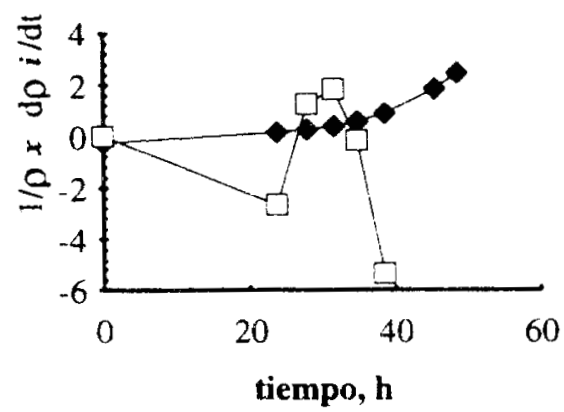

MEDIO M-C

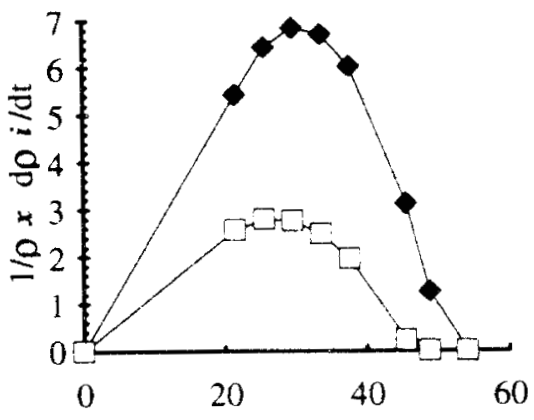

MEDIO M-E

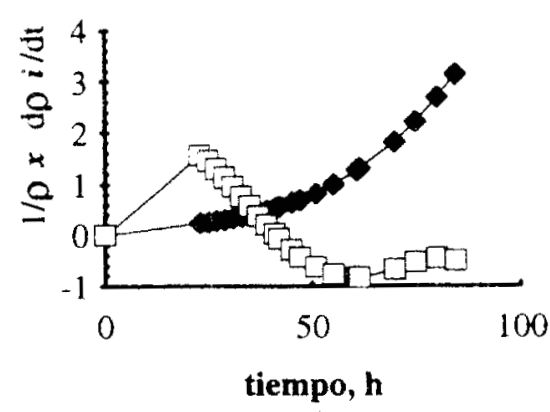

FIGURA 24.2. Tasas especificas de (- - - $)$ crecimiento celular y, (- - ) consumo de sustrato en función del tiempo con los diferentes medios de cultivo (ver Cuadros 24.1 y 24.2).

§25. Estimación de los parámetros.

Para estimar los valores numéricos del rendimiento celular $\left(\mathrm{Y}_{\mathrm{s}}\right)$ y del coeficiente de mantenimiento $\left(m_{s}\right)$, se utilizó la información experimental del capítulo anterior y las ecuaciones (19-3) y (16-6) del modelo simplificado, esto es:

$$
\frac{d \rho_{s}}{d t}=-C_{s}=\left(\frac{(1-\emptyset)}{Y_{s}}\right) C_{x}+m_{s} \rho_{x}
$$

de donde, dividiendo entre $\rho_{x}$, se obtiene:

$$
-\frac{C_{s}}{\rho_{x}}=\left(\frac{(1-\emptyset)}{Y_{s}}\right) \frac{C_{x}}{\rho_{x}}+m_{s}
$$

Al sustituir los valores experimentales correspondientes de $\rho_{x}$ y $\rho_{s}$ para los mismos tiempos se obtienen rectas cuya ordenada al origen es $m_{s}$ y la pendiente es: 


$$
\left(\frac{(1-\emptyset)}{Y_{S}}\right)
$$

Los resultados se muestran en forma gráfica en la Figura 25.1, en donde se puede una clara lineatidad asociada al acoplamiento metabólico encontrado en los medios M-B y M-C. Con los otros medios no se encontró lineatidad y por eso no se muestran en la Figura 25.1.

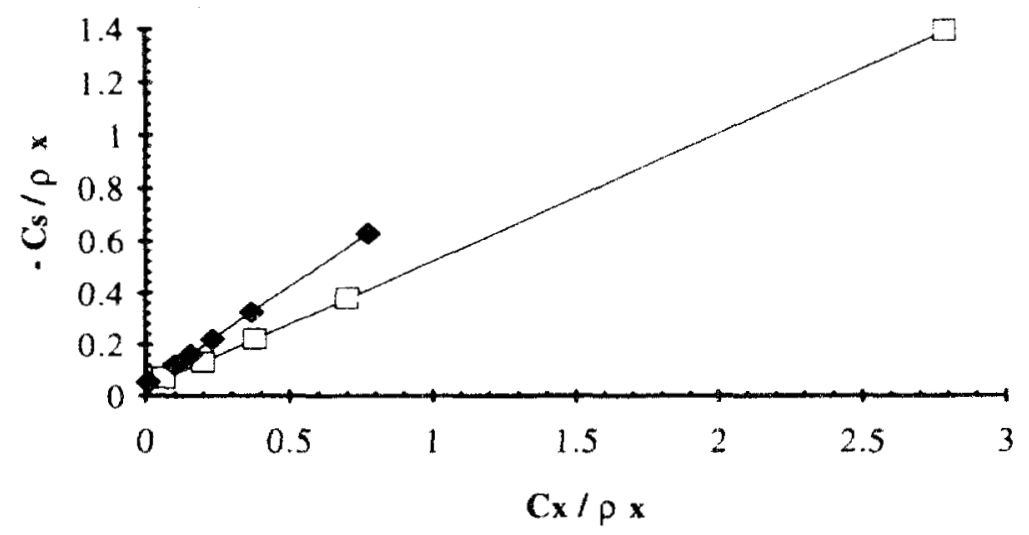

FIGURA 25.1. Tasas específicas de consumo de sustrato con respecto a las tasas específicas de crecimiento para los medios (-ם-) M-B y (- -) M-C definidos antes.

Los valores numéricos que se obtienen de la información graficada en la Figura 25.1 se muestran en el Cuadro 25.1, en donde se comparan con los valores teóricos propuestos antes (ver 20.2.2 y el Cuadro 20.4). Como se aprecia, los valores teóricos para los dos parámetros se deben modificar y apegarse más a los obtenidos con cualquiera de los dos medios de cultivo.

CUADRO 25.1 COMPARACIÓN ENTRE LOS VALORES EXPERIMENTALES Y LOS TEÓRICOS PARA LOS COEFICIENTES DE MANTENIMIENTO Y RENDIMIENTO

\begin{tabular}{|c|c|c|c|}
\hline COEFICIENTE & MEDIO & EXPERIMENTAL & TEÓRICO \\
\hline$Y_{s}, \mathrm{~kg}$ biomasa B.S. (kg glucosa $)^{-1}$ & $\begin{array}{l}\text { M-B } \\
\text { M-C }\end{array}$ & $\begin{array}{l}0.396 \\
0.250\end{array}$ & 0.50 \\
\hline $\mathrm{m}_{\mathrm{s}}, \mathrm{kg}$ glucosa (kg biomasa B.H. s) ${ }^{-1}$ & $\begin{array}{l}\text { M-B } \\
\text { M-C }\end{array}$ & $\begin{array}{l}2.1 E-6 \\
2.6 E-6\end{array}$ & $2.24 \mathrm{E}-07$ \\
\hline
\end{tabular}


Para continuar con el estudio de ajuste de parámetros, se selecciona el medio M-C. Se selecciona porque es el que produce la fase exponencial y la fase estacionaria más estables. A partir del análisis de los resultados experimentales, se modifica el rendimiento base sustrato consumido $\left(\mathrm{Y}_{\mathrm{S}}\right.$ ), a $0.25 \mathrm{~kg}$ biomasa B.S. ( $\mathrm{kg}$ glucosa) ${ }^{-1}$ y por lo tanto los demás valores estequiométricos asociados también cambian. Los nuevos valores que se obtienen a partir de la estequiometría del Cuadro 20.4 son : $Y_{\mathrm{e}}, 0.475 \mathrm{~kg}$ biom. seca kg-1 agua; $\mathrm{Y}_{0}, 0.34 \mathrm{~kg}$ biom. seca kg-1 oxígeno; y $\mathrm{Y}_{\mathrm{c}}$, $0.245 \mathrm{~kg}$ biom. seca $\mathrm{kg}^{-1}$ bióxido de carbono.

§26. Análisis comparativo y sensibilidad paramétrica.

Para continuar con el estudio de estimación de parámetros, en este capítulo se presenta un análisis comparativo utilizando como referencia los resultados generados con el medio de cultivo M-C. Se mantiene sin variación el rendimiento $\mathrm{Y}_{\mathrm{s}}$, calculado a partir de los resultados experimentales, así como los rendimientos $\mathrm{Y}_{\mathrm{e}}, \mathrm{Y}_{\mathrm{o}}$ y $\mathrm{Y}_{\mathrm{c}}$, evaluados teóricamente a partir de $\mathrm{Y}_{\mathrm{s}}$. Como variables de respuesta se utilizan el crecimiento celular y el consumo de glucosa y cada variable se analiza por separado en los subcapítulos 26.1 y 26.2, respectivamente. En ambos casos se estudia la sensibilidad del modelo a los parámetros: $\mathrm{m}_{\mathrm{s}}$ (coeficiente de mantenimiento de glucosa), $\mathrm{K}_{\mathrm{s}}$ (coeficiente de afinidad de las células por el sustrato) y $\mathrm{K}_{\mathrm{i}}$ (coeficiente de inhibición por sustrato).

\subsection{Crecimiento celular. Efecto de $m_{s}, K_{s} y_{\mathrm{i}}$.}

En la Figura 26.1 se presentan las cinéticas de crecimiento del modelo y las experimentales con el medio M-C. En todos los casos, los parámetros calculados y estimados en el capítulo $\$ 20$ se conservan sin modificación. Los parámetros iniciales que se modifican, para simular una equivalencia con el medio $\mathrm{M}-\mathrm{C}$, son:

$$
\begin{array}{lll}
\rho_{\mathrm{a}}{ }^{0}=278 & \mathrm{~kg} \text { de soporte } \mathrm{m}^{-3} \\
\rho_{\mathrm{s}}{ }^{0}=41.7 & \mathrm{~kg} \text { de glucosa } \mathrm{m}^{-3} \\
\rho_{\mathrm{e}}{ }^{0}=375.1 & \mathrm{~kg} \text { de agua } \mathrm{m}^{-3}
\end{array}
$$

En la Figura 26.1 (a) se muestra un ejemplo del efecto de las variaciones del parámetro $\mathrm{m}_{\mathrm{s}}$ en el crecimiento, conservando $\mathrm{K}_{\mathrm{s}}$ y $\mathrm{K}_{\mathrm{i}}$ se conservan constantes en los valores centrales propuestos en el capítulo $\$ 20$, i.e. 3.0 y $300 \mathrm{~kg}$ de glucosa $\mathrm{m}^{-3}$, respectivamente. En estas simulaciones, el valor de $m_{s}$ que hace que la predicción del modelo se aproxime mejor a la biomasa máxima experimental es:

$$
\mathrm{m}_{\mathrm{s}}=3.6 \mathrm{E}-6 \mathrm{~kg} \text { de glucosa } \mathrm{kg}^{-1} \text { biom. húm. } \mathrm{s}^{-1}
$$


este valor se aproxima mucho al determinado a partir de los datos experimentalas (ver Cuadro 25.1) con el medio $\mathrm{M}-\mathrm{C}$ y por lo tanto se mantiene constante en las simulaciones que siguen.
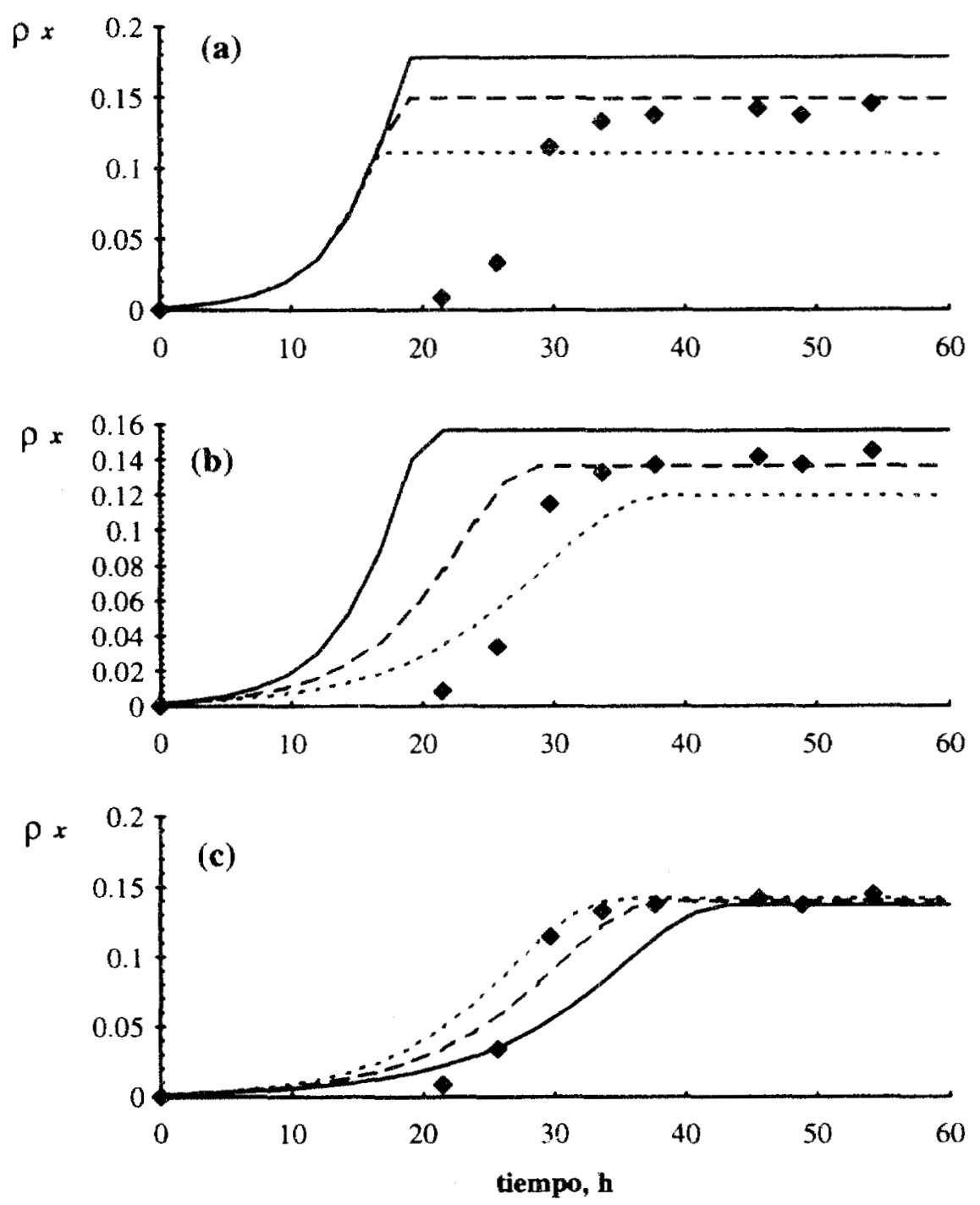

FIGURA 26.1. Crecimiento celular. Comparación de resultados experimentales, ( $\bullet$ ) y teóricos: (a) Constantes $K_{s}$ y $K_{i}\left(2.0\right.$ y 300 de glucosa $\left.\mathrm{m}^{-3}\right)$, variable $m_{s}$, en $\mathbf{k g}$ glucosa $\mathbf{k g}^{-1}$ biom. húm. s'-1: (- 2.6E-6 (- - 8.0E-6 (----) 2.0E-5. (b) Constantes $\mathrm{m}_{\mathrm{s}}=3.6 \mathrm{E}-6 \mathrm{~kg}$

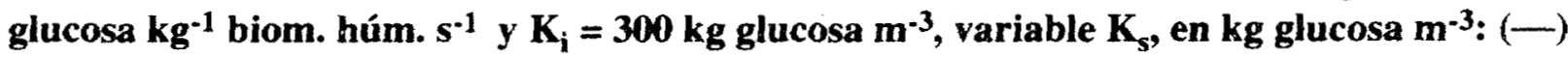
5, (- -) 20, (-..-) 40. (c) Constantes $\mathrm{m}_{\mathrm{s}}=3.6 \mathrm{E}-6 \mathrm{~kg}$ glucosa $\mathrm{kg}^{-1}$ biom. húm. $\mathrm{s}^{-1}$ y $\mathrm{K}_{\mathrm{s}}=$

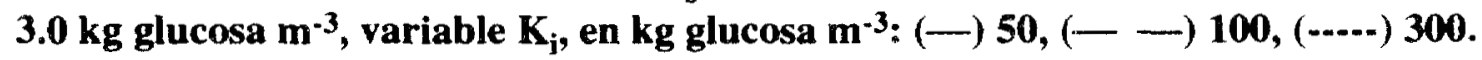


En la Figura 26.1 (b) se presenta el efecto de las variaciones de $\mathrm{K}_{\mathrm{s}}$ en el crecimiento, conservando $\mathrm{m}_{\mathrm{s}} \mathrm{y} \mathrm{K}_{\mathrm{i}}$ constantes en $3.6 \mathrm{E}-6 \mathrm{~kg}$ de glucosa $\mathrm{kg}^{-1}$ biom. húm. $\mathrm{s}^{-1}$ y $300 \mathrm{~kg}$ de glucosa m $\mathrm{m}^{-3}$, respectivamente. Como se puede observar los valores bajos de $\mathrm{K}_{\mathrm{s}}$ simulan mejor la forma sigmoidal de la cinética experimental del medio $\mathrm{M}-\mathrm{C}$, aunque se alejan de la cinética experimental. A medida que se incrementa el valor de $K_{s}$ el modelo se aproxima mejor en detrimento de la forma sigmoide. Para continuar con las simulaciones se seleccionó un valor de $\mathrm{K}_{\mathrm{s}}$ que asegure la forma de la cinética experimental de $3.0 \mathrm{~kg}$ glucosa $\mathrm{m}^{-3}$.

En la Figura 26.1 (c) se puede ver el efecto de las variaciones de $\mathrm{K}_{\mathrm{i}}$ en el crecimiento, conservando $\mathrm{m}_{\mathrm{s}}$ y $\mathrm{K}_{\mathrm{s}}$ constantes en $3.6 \mathrm{E}-6 \mathrm{~kg}$ de glucosa $\mathrm{kg}^{-1}$ biom. húm. $\mathrm{s}^{-1}$ y $3.0 \mathrm{~kg}$ de glucosa $\mathrm{m}^{-3}$, respectivamente. Como se observa un valor muy bajo para la constante de inhibición, entre 100 y $300 \mathrm{~kg}$ de glucosa $\mathrm{m}^{-3}$, se aproxima bien a la cinética experimental. Esta discusión se complementa en el apartado que sigue en donde se presenta el efecto los mismos parámetros sobre el consumo de sustrato, como variable de respuesta.

\subsection{Consumo de sustrato. Efecto de $m_{s}, K_{s} \cdot y K_{i}$.}

En la Figura 26.2 se muestran las cinéticas de consumo de glucosa bajo las mismas condiciones descritas en el apartado 26.1. Es interesante notar en la Figura 26.2 (a) que las tasas de consumo de glucosa son menos sensibles, en el dominio simulado, a las variaciones del coeficiente de mantenimiento que para el caso del crecimiento celular. Por el contrario, en la Figura 26.2 (b) se ve que el consumo de sustrato resulta mucho más sensible a las variaciones de $\mathrm{K}_{\mathrm{s}}$ que en el caso del crecimiento y los valores más altos de $\mathrm{K}_{\mathrm{s}}$ que se simularon aproximan mejor al modelo a los resultados experimentales. En la Figura 26.2 (c) se puede ver que los valores más bajos en la constante de inhibición son los que mejor aproximan al modelo a los resultados experimentales.

Al comparar los mejores valores de los parámetros para la cinética de crecimiento con respecto a los mejores valores para la cinética de consumo de glucosa, se puede apreciar fácilmente que no son los mismos, inclusive las tendencias son opuestas. Para resolver este problema de estimación de parámetros y tratar de explicar el fenómeno, se estudiaron las tres alternativas excluyentes que siguen:

1. La cinética de consumo de sustrato debe modelarse con parámetros cinéticos cuyos valores deben ser diferentes a los valores de los parámetros cinéticos para el crecimiento.

2. Los tres parámetros de estudio, $\mathrm{K}_{\mathrm{s}}, \mathrm{K}_{\mathrm{i}} \mathrm{y} \mathrm{m}_{\mathrm{s}}$, no son constantes y cambian durante el tiempo de fermentación, i.e. dependen de al menos una variables de estado. 
3. Las variaciones de los tres parámetros de estudio, $\mathrm{K}_{\mathrm{s}}, \mathrm{K}_{\mathrm{i}} \mathrm{y} \mathrm{\textrm {m } _ { \mathrm { s } }}$, se pueden mantener constantes siempre y cuando un parámetro global, como el rendimiento de biomasa base sustrato, cambie con el tiempo de fermentación i.e. con respecto a una variable de estado.
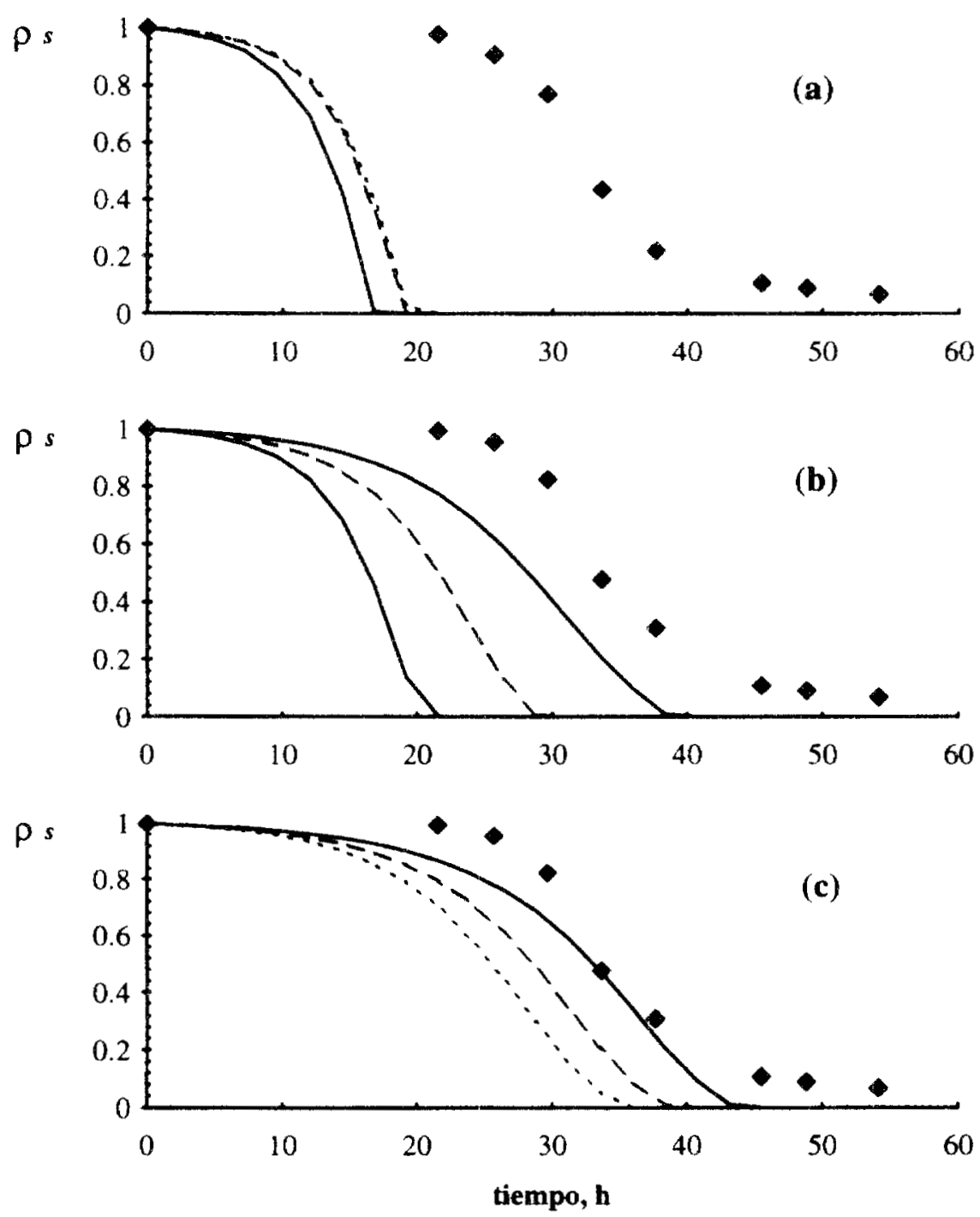

FIGURA 26.2. Consumo de glucosa. Comparación de resultados experimentales, $(\bullet)$ y

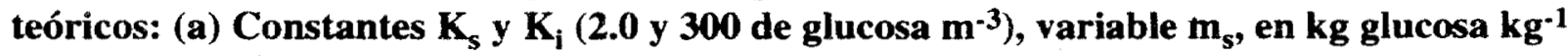
biom. húm. $\mathrm{s}^{-1}$ : ( $\longrightarrow$ ) 2.6E-6 (- $\rightarrow$ 8.0E-6 (----) 2.0E-5. (b) Constantes $\mathrm{m}_{\mathrm{s}}=3.6 \mathrm{E}-6 \mathrm{~kg}$ glucosa $\mathrm{kg}^{-1}$ biom. húm. $\mathrm{s}^{-1}$ y $\mathrm{K}_{\mathrm{i}}=300 \mathrm{~kg}$ glucosa $\mathrm{m}^{-3}$, variable $\mathrm{K}_{\mathrm{s}}$, en $\mathrm{kg}$ glucosa $\mathrm{m}^{-3}$ : (一) 5 , ( - - 20, (--.-) 40. (c) Constantes $\mathrm{m}_{\mathrm{s}}=3.6 \mathrm{E}-6 \mathrm{~kg}$ glucosa $\mathrm{kg}^{-1} \mathrm{biom}$. húm. $\mathrm{s}^{-1}$ y $\mathrm{K}_{\mathrm{s}}=$

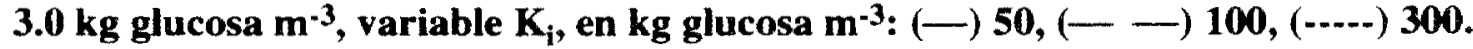


Los resultados del estudio de las tres alternativas se presentan a continuación:

Alternativa 1.

Los términos $C_{x}$ y $C_{5}$ del modelo simplificado se modifican de la manera que sigue:

Para el crecimiento celular, la ecuación (16-5) establece que:

$$
C_{x}=C_{x M a x} \rho_{x}\left(1-\frac{\rho_{x}}{\rho_{x M a x}}\right)\left(\frac{\rho_{s}}{K_{s}+\frac{\rho_{s}^{2}}{K_{i}}+\rho_{s}}\right)
$$

Para el consumo de sustrato, la ecuación (16-6) establece que:

$$
C_{s}=-\left(\frac{(1-\emptyset)}{Y_{s}}\right) C_{x}+m_{s} \rho_{x}
$$

Para el crecimiento celular, la ecuación (16-5) se modifica como sigue:

$$
C_{x}=C_{x M a x} \rho_{x}\left(1-\frac{\rho_{x}}{\rho_{x M a x}}\right)\left(\frac{\rho_{s}}{K_{s}{ }^{I}+\frac{\rho_{s}^{2}}{K_{i}^{I}}+\rho_{s}}\right)
$$

donde: $\mathrm{K}_{\mathrm{s}}{ }^{\mathrm{l}}$; constante de afinidad de las células por la glucosa, para el crecimiento.

$\mathrm{K}_{\mathrm{i}} \mathrm{I}_{\text {; }}$ constante de inhibición del crecimiento debida a la concentración de glucosa

Para el consumo de sustrato, a partir de la ecuación (16-5) y (16-6):

$$
C_{s}=-\left(\frac{(1-\emptyset)}{Y_{s}}\right) C_{x M a x} \rho_{x}\left(\frac{\rho_{s}}{K_{s}{ }^{I}+\frac{\rho_{s}^{2}}{K_{i}{ }^{I}}+\rho_{s}}\right)+m_{s} \rho_{x}
$$

donde: $\mathrm{K}_{\mathrm{s}}{ }_{\mathrm{I}}$; constante de afinidad de las células por la glucosa, para el consumo.

$\mathrm{K}_{\mathrm{i}}{ }^{\mathrm{II}}$; constante de inhibición del consumo debida a la concentración de glucosa

La ecuación (26-2) implica que el consumo de sustrato no depende de los espacios libres contenido en el término logístico, lo cual parece razonable. Con estas modificaciones, i.e. incluyendo las ecuaciones (26-1) y (26-2) en el programa y con los valores (ver apartado 26.2) de los parámetros, siguientes:

$$
\begin{array}{ll}
\mathrm{m}_{\mathrm{s}} & =3.6 \mathrm{E}-6 \mathrm{~kg} \text { de glucosa } \mathrm{kg}^{-1} \text { biom. húm. } \mathrm{s}^{-1} \\
\mathrm{~K}_{\mathrm{s}} \mathrm{I} & =3.0 \mathrm{~kg} \text { de glucosa } \mathrm{m}^{-3} \\
\mathrm{~K}_{\mathrm{i}}^{\mathrm{I}} & =300 \mathrm{~kg} \text { de glucosa } \mathrm{m}^{-3} \\
\mathrm{~K}_{\mathrm{s}}^{\text {II }} & =45 \mathrm{~kg} \text { de glucosa } \mathrm{m}^{-3} \\
\mathrm{~K}_{\mathrm{i}}^{\text {II }} & =50 \mathrm{~kg} \text { de glucosa } \mathrm{m}^{-3}
\end{array}
$$


Los resultados de estas simulaciones se muestran en la Figura 26.3. Como se aprecia, el modelo ajusta de manera aceptable para el crecimiento celular, pero en el consumo de sustrato la respuesta del modelo presenta un defasamiento de cerca de cinco horas con respecto a los resultados experimentales. Para aproximar la cinética de consumo de glucosa a los valores experimentales, fue necesario incorporar valores de $K_{i}{ }_{i}^{I I}$ hasta valores cercanos a los de $K_{i}{ }^{1}$. Sin embargo, no resulta fácil explicar una supuesta independencia entre el consumo de sustrato y el crecimiento, como tampoco resulta fácil explicar el significado biológico que implica obtener el mismo valor para la constante de inhibición del crecimiento que el de la constante de afinidad para el consumo de sustrato. Por estas dificultades la Alternativa 1 se descartó.

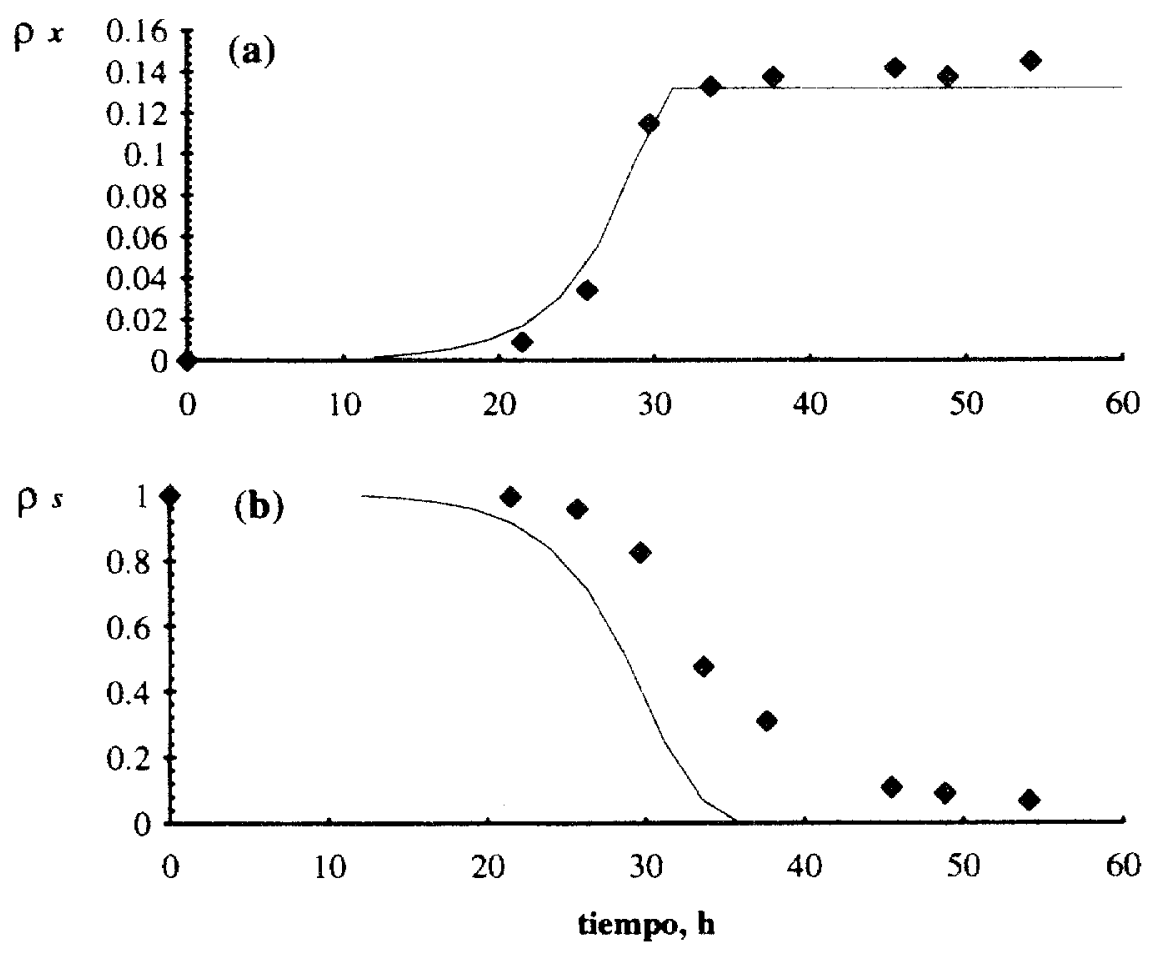

Figura 26.3. Comparación de resultados experimentales $(\bullet)$ y teóricos. Modificación al modelo según la Alternativa 1. Para los valores de los parámetros, ver texto.

Alternativa 2.

Para estudiar esta alternativa se requería encontrar una función capaz de asociar los cambios de $\mathrm{K}_{\mathrm{s}}, \mathrm{K}_{\mathrm{j}}$ y $\mathrm{m}_{\mathrm{s}}$ con respecto al tiempo de fermentación. Para simplificar el problema se decidió mantener constante el valor de $\mathrm{K}_{\mathrm{i}}$ en $300 \mathrm{~kg}$ de glucosa $\mathrm{m}^{-3}$ y modificar los otros. La metodología 
empleada fue la siguiente: (i) con los programas de cálculo antes descritos, el programa principal se hizo evolucionar dentro del dominio de valores para $K_{\mathrm{s}}$ y $\mathrm{m}_{\mathrm{s}}$ que se sugieren en las Figuras 26.1 y 26.2, (ii) el programa comparaba resultados simulados con experimentales y cuando encontraba un valor que ajustaba bien i.e., cuando el cuadrado de la diferencia entre el experimental y el teórico se aproximaba a cero, lo almacenaba junto con los valores de $\mathrm{K}_{\mathrm{s}}$ y $\mathrm{m}_{\mathrm{s}}$ para cada punto experimental, y (iii) el procedimiento de comparación y almacenamiento se realizó para ambas la cinéticas, la de crecimiento y la de consumo de glucosa. Los resultados se muestran en la Figura 26.4. En las corridas del ajuste, se obtienen cuatro funciones con respecto al tiempo: (i) dos funciones del mantenimiento con respecto al tiempo $\mathrm{m}_{\mathrm{s}}(\mathrm{t})$, una contiene el conjunto de valores de $m_{s}$ que mejor ajustaron para el crecimiento celular o $m_{s}(t)$ (Biomasa) y otra con los valores de $m_{s}$ para el consumo de sustrato o $m_{s}(t)($ Glucosa), ver Figura 26.4 (a) y; (ii) dos funciones $\mathrm{K}_{s}(\mathrm{t})$ una que ajusta bien para el crecimiento celular o $\mathrm{K}_{\mathrm{s}}(\mathrm{t})$ (Biomasa) y otra para el consumo de sustrato o $\mathrm{K}_{\mathrm{s}}(\mathrm{t})$ (Glucosa), ambas mostradas en la Figura 26.4 (b). En la Figura 26.4 (a) se puede observar que:

1. Para la fase de germinación de esporas, primeras 20 horas, la cinética de $\mathrm{m}_{\mathrm{s}}$ sugiere que los valores para el mantenimiento son cero o muy próximos a cero. Esto se debe a que, en esta fase, no hay cambios en la masa de glucosa.

2. Para la etapa de crecimiento, entre las 20 y las 40 horas de cultivo, se observan tres subetapas, en donde: (i) se inicia del crecimiento, de las 20 a las 25 horas de cultivo, aquí la función $\mathrm{m}_{\mathrm{s}}(\mathrm{t})$ (Biomasa), aumenta rápidamente mientras que la función $\mathrm{m}_{\mathrm{s}}(\mathrm{t})$ (Glucosa) no cambia, aún cuando el consumo de glucosa se inicia; (ii) el crecimiento es muy rápido, de las 25 a las 35 horas de cultivo, aquí $m_{\mathrm{S}}(\mathrm{t})$ (Biomasa) se mantiene en un ascenso constante hasta lograr un máximo justo al finalizar el período, mientras que $m_{s}(t)$ (Glucosa) se manifiesta paralela a $m_{s}(t)$ (Biomasa), pero con un retraso de unas cinco horas $y$; (iii) el crecimiento y el consumo de glucosa se desaceleran, de las 35 a las 40 horas de cultivo. Mientras que $\mathrm{m}_{\mathrm{s}}(\mathrm{t})$ (Biomasa) coincide con el cambio, descendiendo suavemente, $\mathrm{m}_{\mathrm{s}}(\mathrm{t})$ (Glucosa) continúa en franco ascenso.

La forma particular de las dos funciones encontradas durante esta etapa, en especial para el caso de $\mathrm{m}_{\mathrm{s}}(\mathrm{t})$ (Biomasa), se puede explicar como una respuesta a la necesidad de atender el suministro energético requerido durante el crecimiento celular, pero una vez que la demanda queda satisfecha, el mantenimiento disminuye también.

3. En la fase de crecimiento cero o estacionaria, después de las 40 horas de cultivo, $\mathrm{m}_{\mathrm{s}}(\mathrm{t})$ (Biomasa) continúa descendiendo pero con una pendiente menor, sugiriendo valores bajos y casi constantes, mientras que $m_{s}(t)($ Glucosa) se manifiesta con un máximo para luego descender bruscamente llegando inclusive a ser cero. 

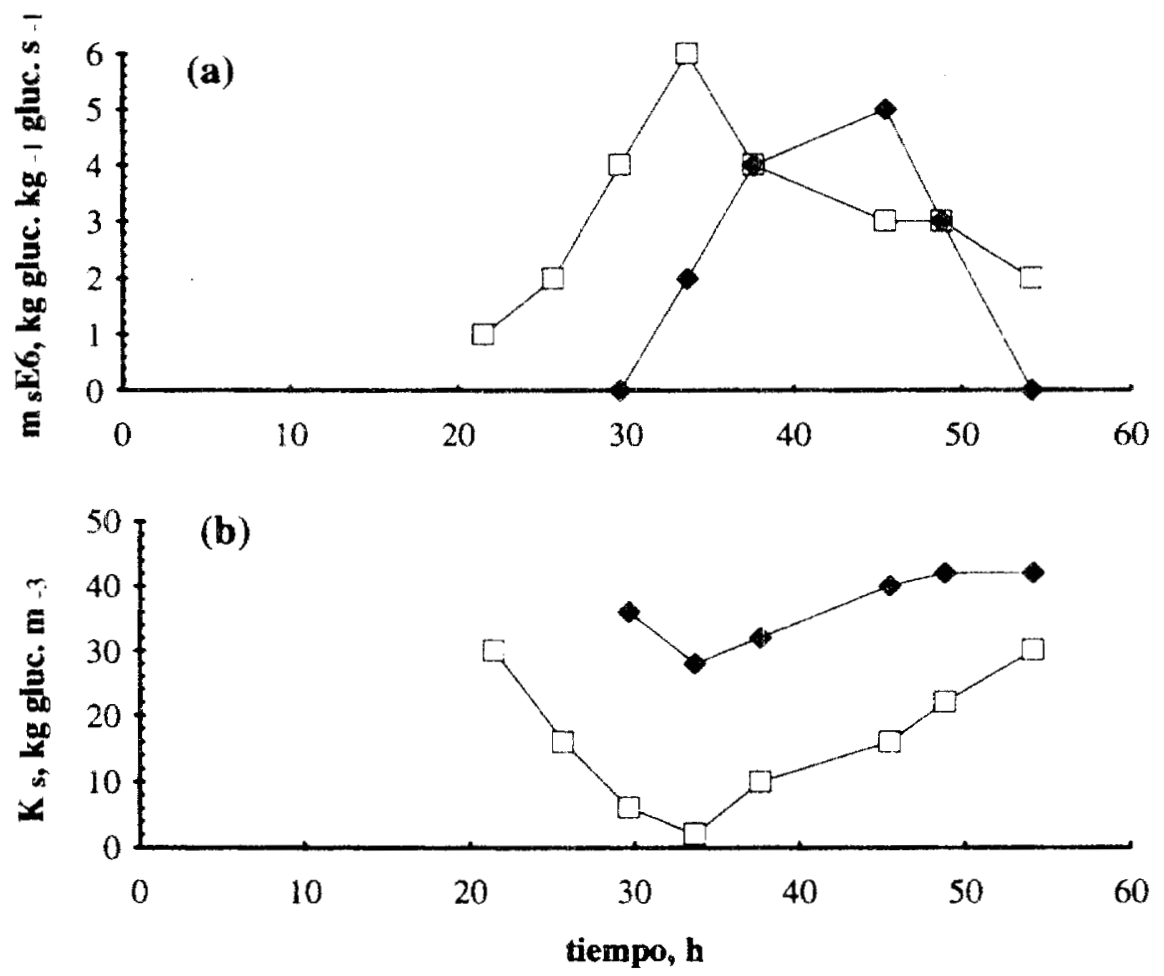

Figura 26.4. Valores encontrados con el modelo para los parámetros que ajustan mejor las cinéticas experimentales conservando constante a $K_{i}=300 \mathrm{~kg}$ glucosa $\mathrm{m}^{-3}$. (a) Coeficientes $m_{s}$ para crecimiento (- - -), y consumo de glucosa $(-\bullet)$; (b); coeficientes $K_{s}$ para crecimiento $(-\bullet-), y$ consumo de glucosa $(-\bullet-)$.

La discusión precedente sugiere que la función $\mathrm{m}_{\mathrm{s}}(\mathrm{t})(\mathrm{Biomasa})$ responde con más fidelidad a los cambios metabólicos observados en los datos experimentales, que su homóloga $m_{\mathbf{s}}(t)$ (Glucosa). Con un análisis similar para las funciones $\mathrm{K}_{\mathrm{s}}(\mathrm{t})$, en la Figura 26.4 (b) se puede observar que:

1. Para la etapa de germinación, ambas funciones, $\mathrm{K}_{\mathrm{s}}(\mathrm{t})\left(\right.$ Biomasa) y $\mathrm{K}_{\mathrm{s}}(\mathrm{t})(\mathrm{Glucosa})$, sugieren los valores más altos ensayados en la simulación. Esta tendencia, congruente con esta etapa de crecimiento y consumo cero o casi cero, se puede explicar como una baja afinidad de las esporas por la glucosa y una mayor preferencia por los compuestos carbonados que ellas mismas generan durante la germinación (Smith, 1977).

2. Para la etapa de crecimiento rápido, independientemente de las tres subetapas que la componen, ambas funciones $\mathrm{K}_{\mathrm{s}}(\mathrm{t})$ (Biomasa) y $\mathrm{K}_{\mathrm{s}}(\mathrm{t})$ (Glucosa) se comportan prácticamente paralelas descendiendo hasta llegar a un mínimo, en el que coinciden ambas -alrededor de las $35 \mathrm{~h}$ - para después subir hasta los mismos valores altos encontrados al principio. Es 
interesante notar que este mínimo para las dos funciones $\mathrm{K}_{\mathrm{s}}(\mathrm{t})$, también coincide con el máximo encontrado en la Figura 26.4 (a) para $m_{s}(t)$ (Biomasa). Estos resultados sugieren que la preferencia del micelio por la glucosa aumenta gradualmente y una vez que el crecimiento miceliar se desacelera, su afinidad por la glucosa disminuye lentamente hasta llegar a un punto similar al de partida. Esta pérdida gradual de afinidad puede deberse a la formación de conidias para iniciar otra forma de reproducción asociada al consumo de otros metabolitos producidos por la autólisis que antecede siempre a la esporulación.

3. En la etapa de crecimiento cero, los valores de la función $K_{s}(t)($ Biomasa) aumentan poco $y$ prácticamente se mantienen constantes, mientras que los correspondientes a la $\mathrm{K}_{\mathrm{s}}(\mathrm{t})$ (Glucosa) de la biomasa siguen en ascenso con una pendiente menor a la de descenso. Ambas funciones coinciden en producir, al final del cultivo, valores tan altos como los iniciales

Con el análisis de la Alternativa 2, se demuestra que los valores de los dos parámetros que se estudian no pueden ser constantes, y aunque ambos parámetros se podrían expresar en función del tiempo, se decidió que esta simplificación restringiria mucho la aplicación futura del modelo. Por lo tanto, se exploraron varias combinaciones suponiendo que tanto $\mathrm{m}_{\mathrm{s}}$ como $\mathrm{K}_{\mathrm{s}}$ podían ser constantes o variables (en función de la biomasa o de la glucosa)

Los resultados del estudio de esta alternativa se muestran en la Figura 26.5. Como se puede ver, se requiere de funciones exponenciales, asociadas a nuevos conjuntos de parámetros que, si bien mejoran los coeficientes de correlación, no mejoran mucho los ajuste con respecto a los resultados encontrados con una simple aproximación conservando a $K_{s}$ y $m_{s}$.

Por otro lado, en ninguno de los casos en que se intentó ajustar con funciones, ni la función misma ni los coeficientes que mejor ajustaban, permitian una explicación fisica o biológica dentro del marco del fenómeno en estudio. En la Figura 26.5 se presenta un ejemplo de las discrepancias encontradas al tratar de ajustar las cinéticas de crecimiento, Fig. 26.5 (a) y consumo de sustrato, Fig. 26.5 (b). Como se puede apreciar, invariablemente se encontró que el mejor ajuste para una cinética no lo era para la otra, exactamente igual que para el caso de la utilización de valores constantes para $\mathrm{K}_{\mathrm{s}}$ y $\mathrm{m}_{\mathrm{s}}$

Esta discrepancia de los resultados teóricos podría deberse a que los resultados experimentales con los que se ajusta presentan una etapa de retardo demasiado prolongada, atípica en relación a las cinéticas obtenidas en cultivos sólidos con el mismo microorganismo y otros sustratos (Raimbault, 1980; Saucedo-Castañeda, 1990) y con el mismo microorganismo, soporte inerte y sacarosa (Auria et al, 1990). Sin embargo se decidió continuar con el análisis de alternativas del capítulo. 

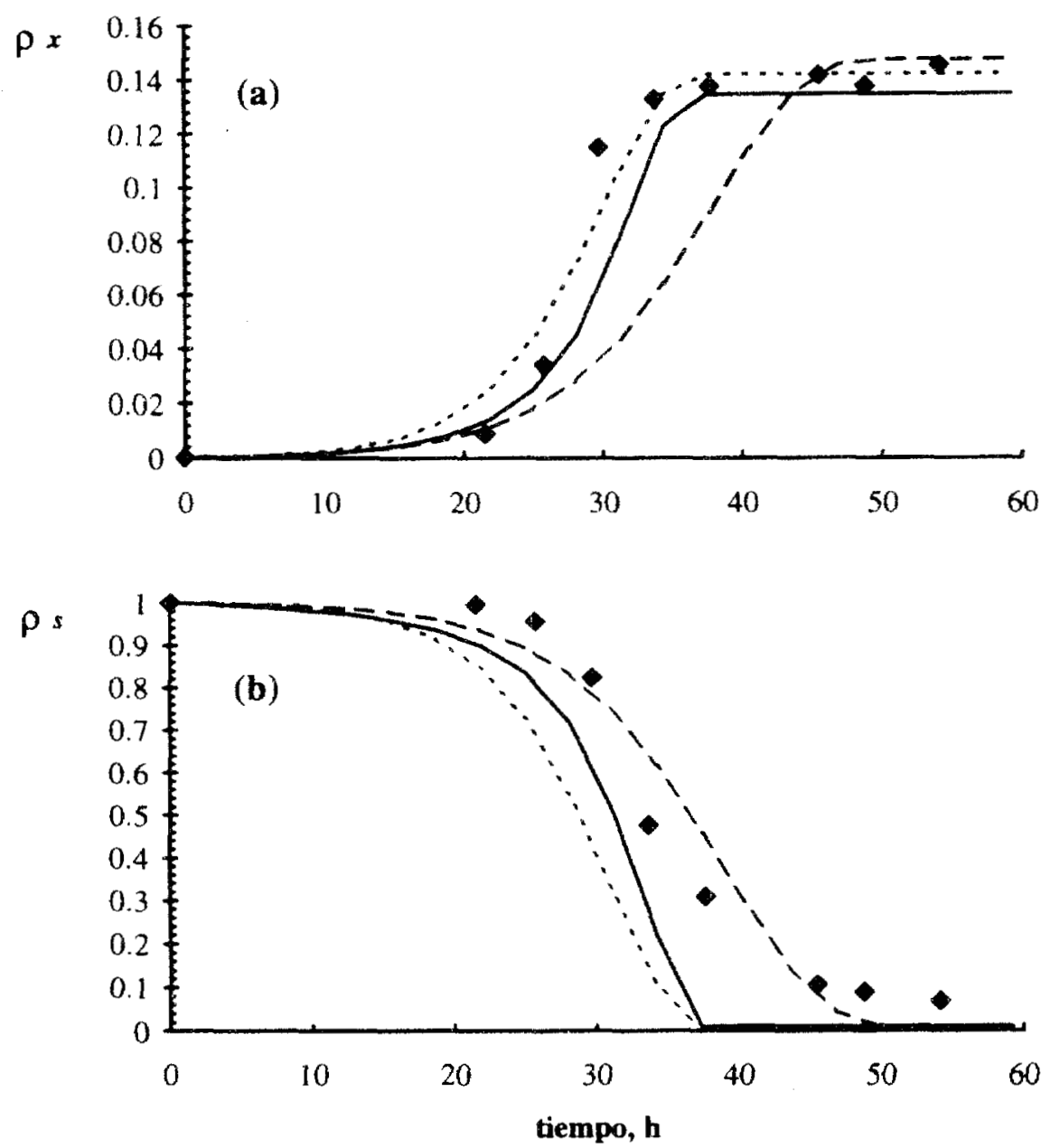

Figura 26.5. Comparación de resultados experimentales $(\bullet)$ con el modelo, con parámetros constantes: $(-) K_{s}=2.0, m_{s}=3.5 E-6$ y $\left(--\frac{-}{-}\right) K_{s}=35, m_{s}=2 \mathrm{E}-6$; $y$ con parámetros variables: $(-) K_{s}=\rho_{s} 0\left(1-\rho_{s}\right)+0.7 \rho_{s} 0 e^{\left(3.2 \rho_{s}\right)}$ y $\left.m_{s} \rho_{x} E+6=2 \rho_{s} e^{(-4.5} \rho_{s}\right)$. Para: (a) crecimiento celular y (b) consumo de glucosa.

\section{Alternativa 3.}

Manteniendo constantes los tres parámetros $K_{s}, K_{i}$ y $m_{s}$, se requería encontrar una función para el rendimiento de biomasa, base sustrato consumido, en función de una de las variables de estado, para este fin se seleccionó a la concentración de azúcares en el medio. Para el estudio de esta alternativa el procedimiento fue el siguiente:

1. A partir de los datos experimentales (ver Fig. 24.1 (a) y (b)), se calculó un valor global de $\mathbf{Y}_{\mathrm{s}}$ para cada concentración inicial de glucosa (ver Cuadro 24.2). Así para $\rho_{s}{ }^{0}=17.4,41.7,83.5$ 
1. A partir de los datos experimentales (ver Fig 24.1 (a) y (b)), se calculó un valor global de $\mathrm{Y}_{\mathrm{s}}$ para cada concentración inicial de glucosa (ver Cuadro 24.2). Así para $\rho_{\mathrm{s}}{ }^{0}=17.4,41.7,83.5$

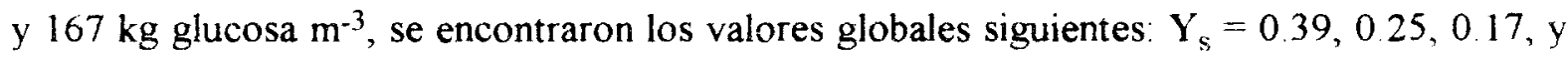
$0.15 \mathrm{~kg}$ biomasa seca $\mathrm{kg}^{-1}$ glucosa, respectivamente. Como se aprecia con estos valores, existe una clara dependencia de los rendimientos con la concentración de glucosa.

2. Con cada valor de $Y_{s}$ y utilizando la reacción estequiométrica que se presenta en el Cuadro 20.4, se calcularon los rendimientos de biomasa para: agua, oxigeno y bióxido de carbono para cada concentración inicial de glucosa. En la Figura 26.6 (a) se muestran los resultados, de las funciones graficadas, ajustandose una ordenada al origen para cada caso.

3. La función $\mathrm{Y}_{\mathrm{i}}\left(\rho_{s}\right)$ de dependencia con la glucosa queda explícita en la expresión siguiente

$$
\mathrm{Y}_{\mathrm{i}}=\mathrm{Y}_{\mathrm{iMax}}-\left(\frac{\mathrm{A}_{3} \rho_{s}}{\mathrm{~K}_{\mathrm{i}}-\rho_{\mathrm{s}}}\right)
$$

donde $Y_{\text {iMax }}$ es el máximo rendimiento de la especie i (sacarosa, agua, oxígeno y bióxido de carbono) que se puede esperar, $\mathrm{K}_{\mathrm{i}}$ es la constante de inhibición, general para cualquier especie, expresada en forma adimensional, i.e. dividida entre la concentración inicial de azúcar y $\mathrm{A}_{3}$ es una constante adimensional (0.4, para este caso) que se utilizó para ajustar con los resultados experimentales. En la Figura 26.6 (b) se muestra la función $\mathrm{Y}_{\mathrm{i}}\left(\rho_{\mathrm{s}}\right)$ de la ecuación (26-3) para cada especie i. Los valores de los parámetros $\mathrm{Y}_{\text {iMax }}$, que se utilizaron fueron los siguientes:

$$
\begin{aligned}
& Y_{\text {cMax }}=0.52 \mathrm{~kg} \text { biomasa seca } \mathrm{kg}^{-1} \mathrm{CO}_{2} \\
& \mathrm{Y}_{\mathrm{eMax}}=0.87{\mathrm{~kg} \text { biomasa seca } \mathrm{kg}^{-1} \text { agua }}^{\mathrm{Y}_{\mathrm{OMax}}}=0.93 \mathrm{~kg} \text { biomasa seca } \mathrm{kg}^{-1} \mathrm{O}_{2} \\
& \mathrm{Y}_{\text {sMax }}=0.42 \mathrm{~kg} \text { biomasa seca } \mathrm{kg}^{-1} \text { sacarosa }
\end{aligned}
$$

La utilización de la ecuación (26-3) en el modelo permitió simulaciones para cualquier concentración inicial de azúcares, manteniendo constantes los parámetros $K_{j}, K_{s}$ y $m_{s}$ con resultados satisfactorios. 

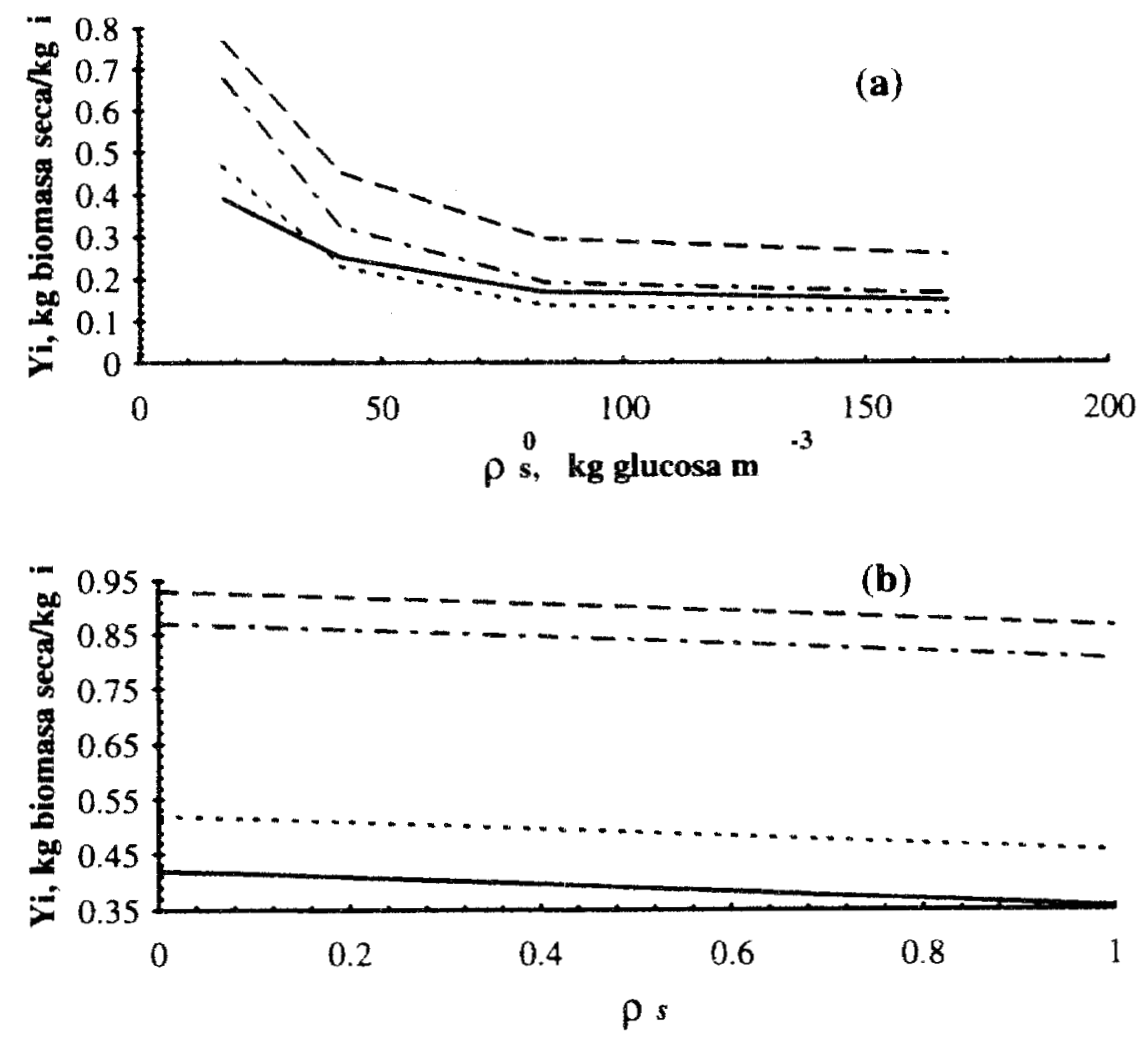

Figura 26.6. (a) Variación de los rendimientos de biomasa Yi con respecto a la concentración inicial de glucosa y Función $Y_{i}\left(\rho_{s}\right)$ que se muestra en la ecuación (26-3) para $\rho_{\mathrm{s}}{ }^{0}=41.7 \mathrm{~kg}$ glucosa $\mathrm{m}^{-3}$ (condiciones del medio $\mathrm{M}-\mathrm{C}$ ).

En la Figura 26.7 se muestran los resultados de crecimiento celular y consumo de glucosa obtenidos con esta modificación en el modelo, con las condiciones experimentales de operación cel medio M-C y con los siguientes valores constantes: $\mathrm{K}_{\mathrm{s}}=20 \mathrm{~kg}$ glucosa $\mathrm{m}^{-3}, \mathrm{~K}_{\mathrm{i}}=300 \mathrm{~kg}$ glucosa $\mathrm{m}^{-3} \mathrm{y} \mathrm{m}_{\mathrm{s}}=3.6 \mathrm{E}-6 \mathrm{~kg}$ biomasa húmeda $\mathrm{kg}^{-1}$ glucosa $\mathrm{s}^{-1}$. Como se puede observar, con respecto a las otras alternativas estudiadas, el ajuste en las dos cinéticas es el mejor. La utilización de la ecuación(26-3) en el modelo permitió utilizar un valor de $\mathrm{K}_{\mathrm{s}}$ alto sin deformar la cinética de crecimiento. 

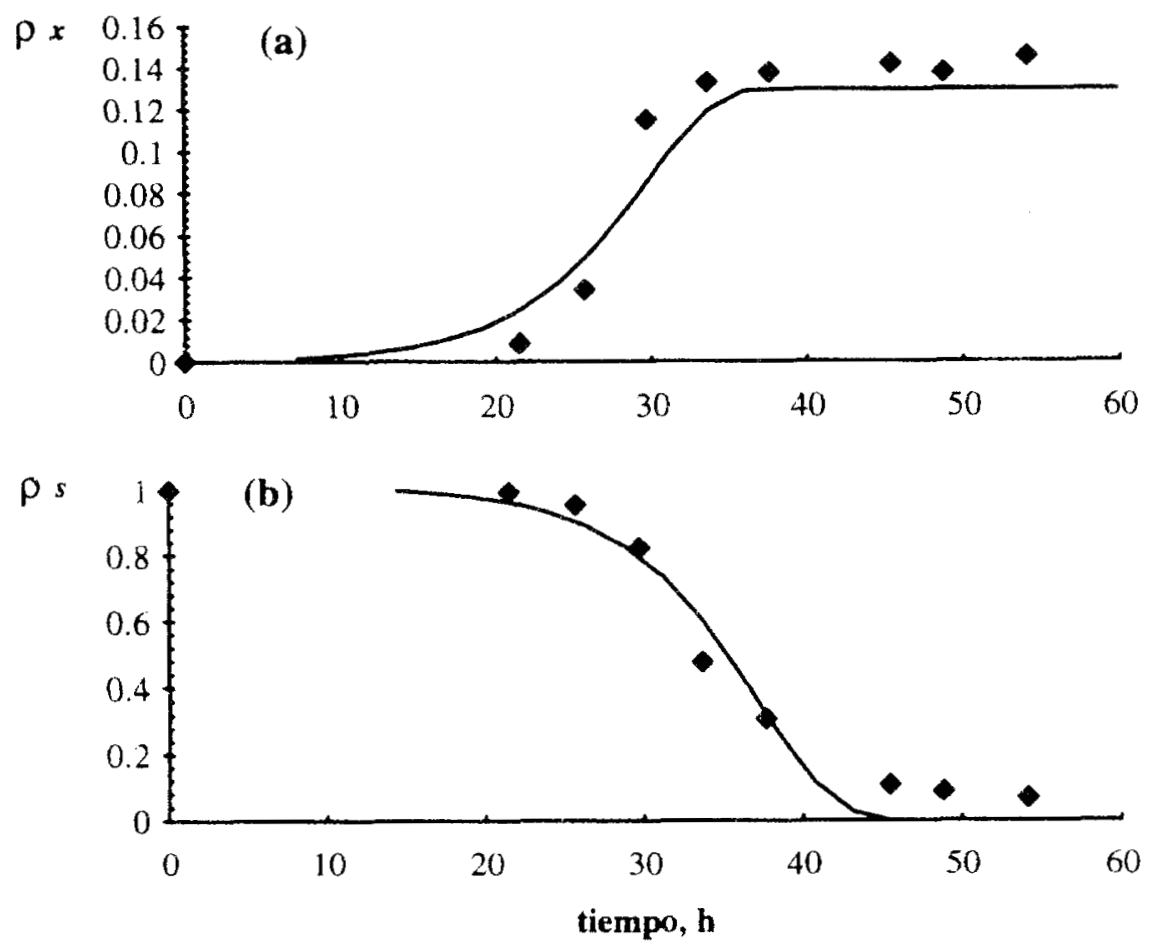

\section{Figura 26.7. Ajuste de resultados del modelo (líneas contínuas) con experimentales $(\bullet)$ para (a) crecimiento y (b) consumo de sustrato.}

Resumen y conclusiones.

Se desarrolla parte de la estrategia de validación del modelo simplificado. La estrategia se apoya en los resultados obtenidos con sistemas de experimentación similares a los concebidos en el conjunto de simplificaciones propuestas antes. Se analiza y discute un conjunto de resultados experimentales realizados con cuatro medios de cultivo en donde la concentración de glucosa es creciente. A partir de los resultados experimentales se decidió por las cinéticas producidas con el medio de cultivo M-C como referencia para el ajuste de los parámetros.

Para el ajuste de los resultados teóricos con los experimentales, se seleccionaron dos conjuntos de parámetros biológicos: (i) los rendimientos base producción de biomasa, y (ii) el coeficientes de mantenimiento, la constante de afinidad celular por el sustrato y la constante de inhibición por sustrato. Se demostró que estos parámetros biológicos no podían considerarse constantes y que debían cambiar con el tiempo de fermentación, i.e. con respecto a alguna variable de estado como los azúcares en el medio. También se demostró que para ajustar satisfactoriamente con los 
resultados experimentales sería necesario incorporar diferentes valores en los parámetros cinéticos, para el caso del crecimiento que para el caso del consumo de los azúcares, particularmente los parámetros $\mathrm{K}_{\mathrm{s}} \mathrm{y} \mathrm{m}_{\mathrm{s}}$. Por lo tanto, al tratar de ajustar los resultados del modelo con los experimentales siempres se encontró que el problema tenía múltiples soluciones. Para resolver este problema se utilizó una función que permitió asociar los rendimientos de biomasa $Y_{i}$ con los azúcares del medio. Esta función permitió emplear valores constantes de los tres parámetros $\mathrm{K}_{\mathrm{j}}, \mathrm{K}_{\mathrm{s}}$ y $\mathrm{m}_{\mathrm{s}}$ con ajustes satisfactorios a los resultados experimentales. 


\section{VALIDACIÓN DE RESULTADOS TEÓRICO, AJUSTE DE PARÁMETROS Y ESTUDIO DE CASOS}

\section{\$27. Validación y ajuste con otros resultados.}

Para descartar la posibilidad de que el ajuste de parámetros, discutido en el capítulo $\$ 26$, solamente fuera válido para el caso particular del medio $\mathrm{M}-\mathrm{C}$, se decidió comparar con los resultados experimentales de tres casos de cultivo sólido sobre soportes inertes, tomando en cuenta nuevas variables de respuesta. Para realizar estas comparaciones se utiliza la ecuación (263 ) del capítulo anterior, con algunos ajustes para el caso número tres que se discute aqui, se emplean valores constantes para los tres parámetros cinéticos $K_{s}, K_{i}$ y $m_{s}$. Los valores iniciales de los parámetros que se adoptan son los que se sugieren en el capitulo anterior y, en su caso, se obtienen nuevos valores

\section{1 Caso 1}

En este caso (Auria et al, 1990) los autores emplean Amberlita-IRA 900 y A. niger C10, la fuente de carbono es sacarosa ( $24 \mathrm{~kg}$ de sacarosa inicial $\mathrm{m}^{-3}$ ), en columnas de $2.5 \mathrm{~cm}$ de diámetro y 6.5 $\mathrm{cm}$ de altura del empaque, con un gasto de aire a la entrada, por columna, de $21 \mathrm{~h}^{-1}$, la relación carbono nitrógeno inicial es de 12 (a diferencia del medio $\mathrm{M}$-C que fue de 28.5, ver Cuadro 24.1) con sulfato de amonio y urea, el tratamiento de Amberlita es diferente que en caso del medio M-C ellos saturan al soporte con una solución amortiguadora de fosfatos y el tamaño del inoculo inicial es 10 veces mayor que para el caso del medio $\mathrm{M}-\mathrm{C}$.

Estos cambios se incorporaron al programa para simular el proceso bajo condiciones experimentales equivalentes

En las figuras 27.1 (a) y 27.1 (b) se presentan las cinéticas de crecimiento celular y consumo de sustrato respectivamente, publicados por Auria et al, (1990), en donde se muestra que la duración de la fase lag es de casi la mitad de la que se obtiene con el medio M-C y que la máxima producción de biomasa apenas es de un tercio de la que se logra con el medio M-C. Las diferencias se pueden deber a que Auria et al, (1990) determinaron la biomasa a través del contenido de proteínas; para la elaboración de la Figura 27.1 (a) se consideró que cada gramo de biomasa seca contiene $0.37 \mathrm{~g}$ de proteina.

Los resultados simulados con $\mathrm{K}_{\mathrm{i}}$ constante (300 $\mathrm{kg}$ sacarosa $\mathrm{m}^{-3}$ ) y para dos pares de valores de $\mathrm{K}_{\mathrm{s}}$ y $\mathrm{m}_{\mathrm{s}}$ se presentan en las Figuras 27.1 (a) y 27.1 (b). Como se puede apreciar el modelo produce masas celulares ligeramente mayores que las experimentales con una buena aproximación. Los resultados simulados, para ambos pares de $K_{s}$ y $m_{s}$, el crecimiento ajusta de 
manera aceptable, mientras que para el consumo de sustrato el ajuste es muy bueno sólo cuando $\mathrm{K}_{\mathrm{s}}=2.0 \mathrm{~kg}$ sacarosa $\mathrm{m}^{-3} \mathrm{y} \mathrm{m}_{\mathrm{s}}=3.5 \mathrm{E}-06 \mathrm{~kg}$ de biomasa húmeda $\mathrm{kg}^{-1}$ sacarosa $\mathrm{s}^{-1}$. Con respecto a los valores obtenidos para el medio M-C, esta discrepancia en los valores de los parámetros es razonable en tanto que las condiciones experimentales de ambos casos fueron distintas.
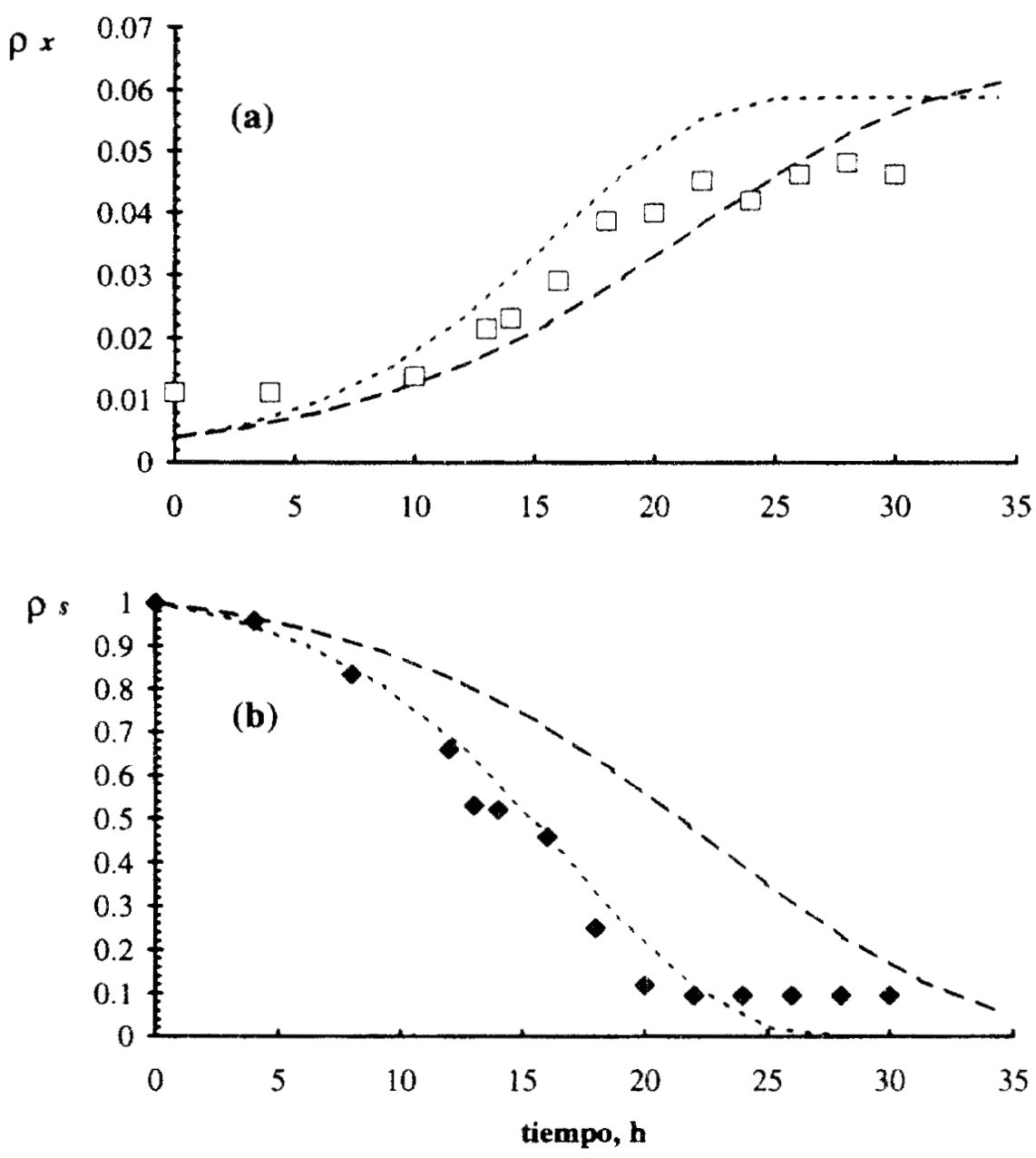

Figura 27.1. Comparación de los resultados del modelo con $K_{\mathrm{s}}=2.0 \mathrm{~kg}$ sacarosa $\mathrm{m}^{-3} \mathrm{y} \mathrm{m}_{\mathrm{s}}=$ $3.5 \mathrm{E}-6 \mathrm{~kg}$ sacarosa kg-1 biom. hum s-1 $(\ldots)$ y $\mathrm{K}_{\mathrm{s}}=35 \mathrm{~kg}^{-1}$ sacarosa $\mathrm{m}^{-3}$ y m$_{\mathrm{s}}=2.0 \mathrm{E}-6 \mathrm{~kg}$ sacarosa $\mathrm{g}^{-1}$ biom. hum s $\mathrm{s}^{-1}\left({ }_{-}\right)$. Simulados bajo las mismas condiciones de operación de la referencia (Auria et al, 1990) experimental: (a) Crecimiento celular, (D) y (b) Consumo de sacarosa, $(\bullet)$. 


\subsection{Caso 2.}

En este caso (Palacios, 1992) los experimentos fueron realizados con A. niger C10, Amberlita (IRA-900) y sacarosa como fuente de carbono. Se estudia el efecto de tres diferentes tasas de aireación: 2,8 y $17.51 \mathrm{~h}^{-1}$ para cada columna de vidrio $(2.5 \mathrm{~cm}$ de diámetro y $15 \mathrm{~cm}$ de altura). La biomasa se determinó por peso seco y la concentración inicial de sacarosa fue de $32 \mathrm{~kg} \mathrm{~m}^{-3}$. En la Figura 27.2 se muestra una comparación entre los resultados experimentales y los resultados producidos por el modelo. Como se aprecia en la Fig. 27.2 (a), entre los tres conjuntos de datos experimentales prácticamente no se detectan diferencias entre si. Los resultados producidos con el modelo, para el crecimiento celular y para el consumo de azúcares, también fueron insensiblesa estos cambios de aireación.

En la Figura 27.2 (b), se muestra una comparación para la producción de bióxido de carbono, obtenidos con columnas con $4 \mathrm{~cm}$ de diámetro, $15 \mathrm{~cm}$ de altura y un gasto de aire de $201 \mathrm{~h}^{-1}$ por columna. El máximo de bióxido de carbono, experimental y el teórico, se sitúan entre las 22 y las 24 horas de cultivo, sólo que el valor del máximo experimental es casi tres veces mayor que el de la predicción y con un perfil mucho más agudo. Aunque al calcular las integrales aproximadas de ambas funciones, los valores obtenidos resultaron muy parecidos: el bióxido de carbono teórico, producido durante las 28 horas del proceso fue un $20 \%$ menor que en el caso del detectado en el laboratorio, sugiriendo que los rendimientos para bióxido de carbono obtenidos con la ecuación (26-3) del modelo están subestimados.

En la Figura 27.2 (c) se muestra una cinética de las diferencias entre la temperatura del lecho empacado y la temperatura de entrada del aire, medidas y simuladas. Como se aprecia, el modelo predice un gradiente máximo de $0.7^{\circ} \mathrm{C}$ entre el lecho y la temperatura del aire, que coincide bien con las observaciones experimentales. Para lograr este ajuste fue necesario aumentar el coeficiente

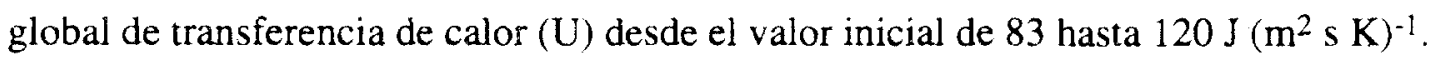

\subsection{Caso 3.}

En este caso (Gutiérrez-Rojas et al, 1995a) se estudiaron cuatro concentraciones iniciales de sacarosa: $30,55,120$ y $125 \mathrm{~kg} \mathrm{~m}^{-3}$, la relación carbono:nitrógeno se mantuvo constante (12:1). Los experimentos se realizaron en columnas de $1.8 \mathrm{~cm}$ de diámetro y $6.5 \mathrm{~cm}$ de altura, empacadas con $5.0 \mathrm{~g}$ de soporte (Amberlita IRA-900) con el medio de cultivo absorbido y el inoculo de $A$. niger $\mathrm{C} 10$. Las columnas se mantuvieron a $30^{\circ} \mathrm{C}$ con una tasa de aireación constante de $0.16 \mathrm{~m}^{3}$ aire $\mathrm{m}^{-3}$ de empaque $\cdot \mathrm{s}^{-1}$. La biomasa se estimó con el método propuesto por Auria y Revah (1994) en el que se correlaciona con la caída de presión y los coeficientes de permeabilidad efectiva. 

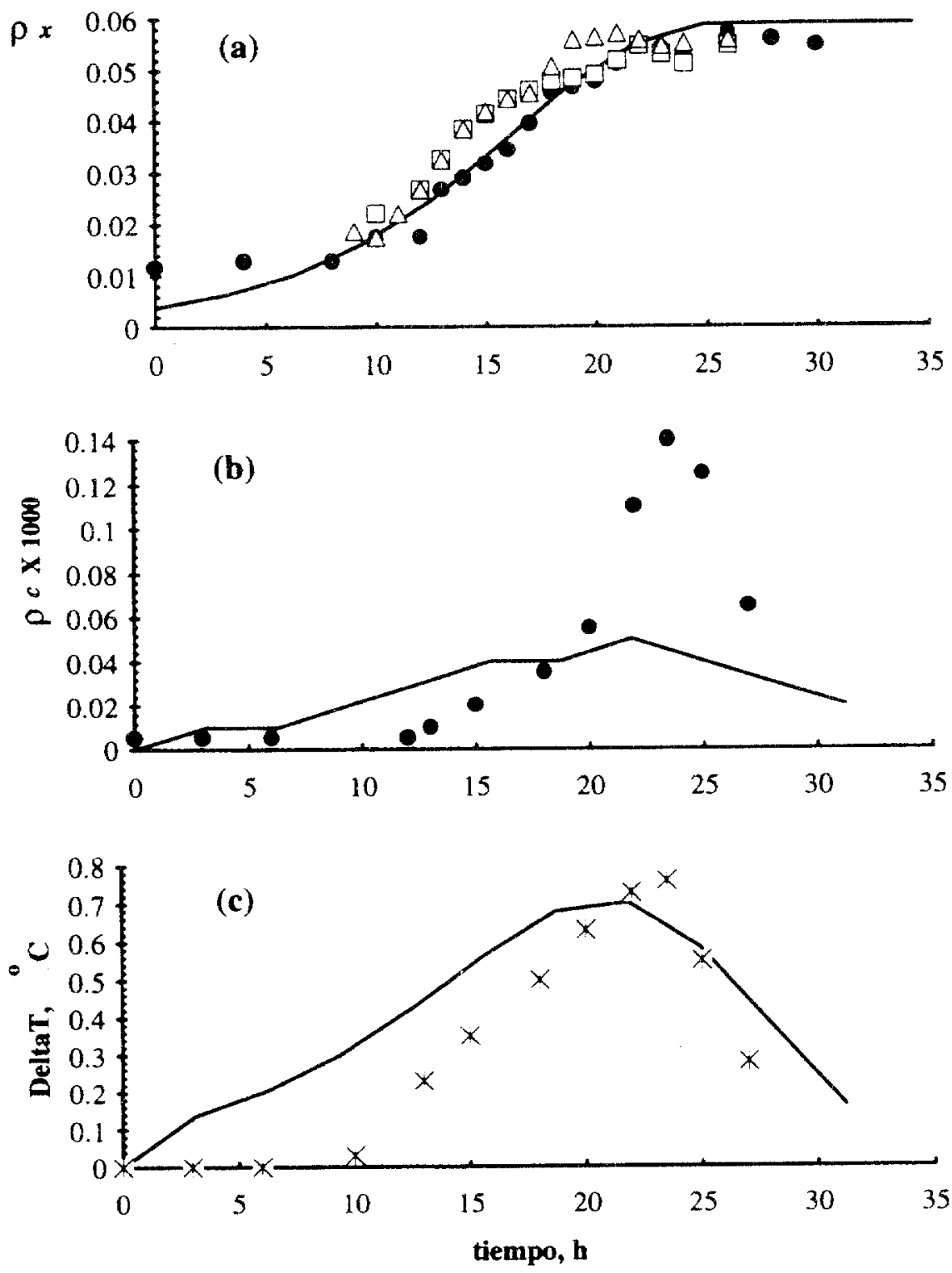

Figura 27.2. Comparación de resultados del modelo $(-)$ con $K_{i}=300 \mathrm{~kg} \mathrm{sacarosa} \mathrm{m}^{-3}, \mathrm{~K}_{\mathrm{s}}=$ $35 \mathrm{~kg}$ sacarosa $\mathrm{m}^{-3}$ y $\mathrm{m}_{\mathrm{s}}=2.0 \mathrm{E}-6 \mathrm{~kg}$ sacarosa $\mathrm{kg}^{-1}$ biom. hum. $\mathrm{s}^{-1}$, simulados bajo las mismas condiciones de operación de la referencia (Palacios, 1992). (a) Crecimiento celular a diferentes tasas de aireación $2.0(\bullet), 8.0(\bullet)$, y $17.5(\Delta)$ I aire $\mathbf{h}^{-1}$ por columna; (b) Producción de $\mathrm{CO}_{2}(\bullet)$ y (c) Diferencia de temperatura entre el lecho empacado y la entrada del aire (*). Para las condiciones de operación ver texto.

Para el ajustar los resultados del modelo con los datos experimentales de este caso, se utilizaron los siguientes valores para los parámetros: $\mathrm{K}_{\mathrm{i}}$ y $\mathrm{K}_{\mathrm{s}} 300$ y $3.0 \mathrm{~kg}$ sacarosa $\mathrm{m}^{-3}$ respectivamente y para $\mathrm{m}_{\mathrm{s}}, 2.5 \mathrm{E}-6 \mathrm{~kg}$ sacarosa $\mathrm{kg}^{-1}$ biomasa húmeda $\mathrm{s}^{-1}$. 
Para los rendimientos, se volvió a evaluar la ecuación (26-3) a partir de los datos de este caso, se calculó un nuevo valor global de $Y_{s}$ para cada concentración inicial de azúcar y por lo tanto un conjunto de rendimientos (agua, oxigeno y bióxido de carbono) para cada concentración inicial de azúcar, así para $\rho_{\mathrm{s}}^{0}=30,55,120$ y $125 \mathrm{~kg}$ sacarosa $\mathrm{m}^{-3}$, se encontraron los siguientes valores $\mathrm{Y}_{\mathrm{S}}=0.42,0.3,0.17$, y $0.2 \mathrm{~kg}$ biomasa seca $\mathrm{kg}^{-1}$ sacarosa, respectivamente. El valor para la constante adimensional $\mathrm{A}_{3}$ fue de 0.57 .

En las Figuras 27.3 (a) y 27.3 (b) se muestra la función $Y_{i}\left(\rho_{s}\right)$ de la ecuación (26-3) para cada especie i del caso de estudio.

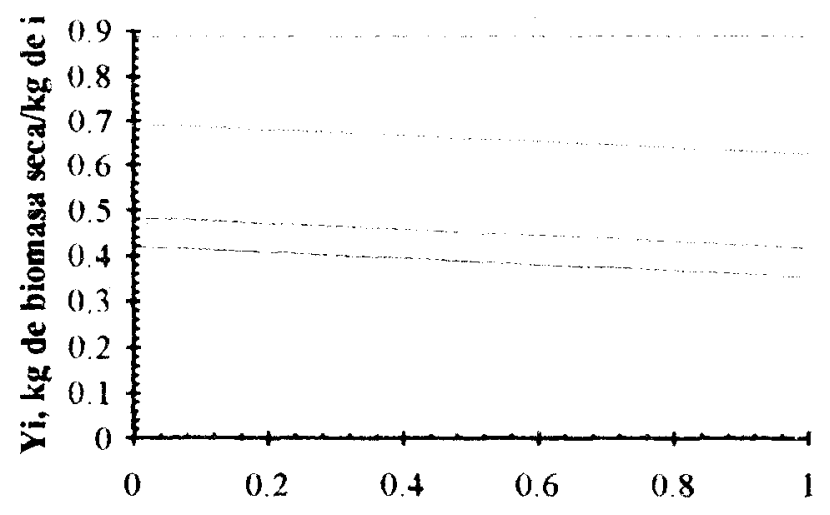

(a)

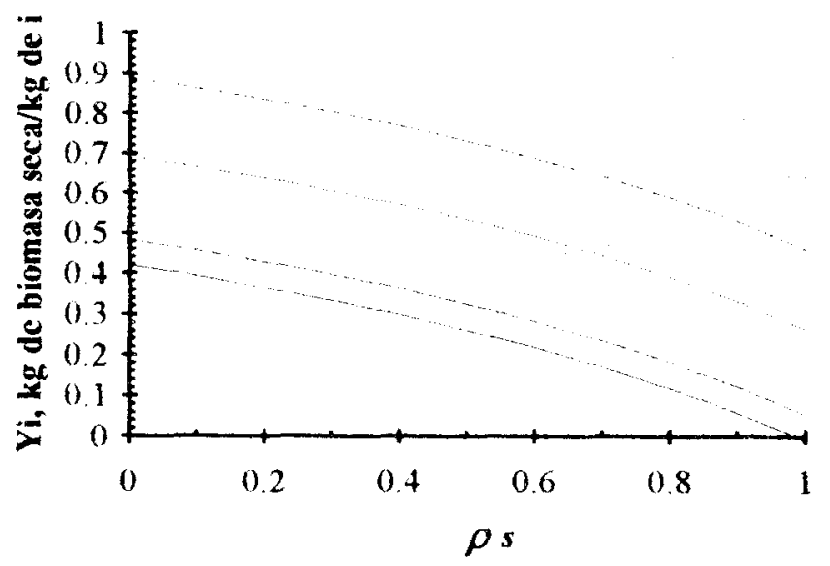

(b)

Ye

Yo

$\mathrm{Yc}$

Ys

Ye

Yo

Yc

Ys

Figura 27.3. Función $Y_{i}\left(\rho_{s}\right)$ que se muestra en la ecuación (27-1) para dos concentraciones iniciales de azúcar (a) $30 \mathrm{~kg}$ de sacarosa $\mathrm{m}^{-3}$ y (b) $125 \mathrm{~kg}$ de sacarosa $\mathrm{m}^{-3}$. 
Los valores de los parámetros $\mathrm{Y}_{\mathrm{iMax}}$, fueron:

$$
\begin{aligned}
& Y_{\mathrm{cMax}}=0.484 \mathrm{~kg} \text { biomasa seca kg-1 } \mathrm{CO}_{2} \\
& Y_{\mathrm{eMax}}=0.89 \mathrm{~kg} \text { biomasa seca } \mathrm{kg}^{-1} \text { agua } \\
& \mathrm{Y}_{\mathrm{oMax}}=0.693 \mathrm{~kg} \text { biomasa seca } \mathrm{kg}^{-1} \mathrm{O}_{2} \\
& Y_{\text {sMax }}=0.42 \mathrm{~kg} \text { biomasa seca } \mathrm{kg}^{-1} \text { sacarosa }
\end{aligned}
$$

En la Figura 27.3 (a) se ve que cuando la concentración inicial de azúcar es baja (30 kg de sacarosa $\mathrm{m}^{-3}$ ) los rendimientos permanecen prácticamente constantes mientras que para concentraciones elevadas ( $125 \mathrm{~kg}$ de sacarosa $\mathrm{m}^{-3}$ ) los rendimientos bajan bruscamente, ver 27.3 (b), incluso hasta aproximarse a cero al inicio de la fermentación. Esta aproximación es razonable, por ejemplo la misma cantidad de biomasa activa bajo una presión osmótica excesiva, como la del medio más concentrado, se esperaría que consumiera más oxígeno y produjera más bióxido de carbono que bajo las condiciones del medio menos concentrado.

Con esta modificación al modelo, con las condiciones experimentales de operación de este caso y con una estrategia de ajuste de parámetros basada en el crecimiento celular y la producción de bióxido de carbono, se realizaron las simulaciones con el modelo que se muestran a continuación.

Crecimiento celular. En la figura 27.4 se muestran los resultados del modelo y los experimentales para las cuatro concentraciones iniciales de sacarosa. Como se ve la etapa inicial del crecimiento es prácticamente la misma para las cuatro concentraciones de sacarosa y nunca es mayor a 12 horas. La biomasa máxima aumenta cuando la concentración inicial de sacarosa se incrementa, mientras que la tasa máxima de crecimiento disminuye de $0.32 \mathrm{~h}^{-1}$ para el medio menos concentrado a $0.15 \mathrm{~h}^{-1}$ para el más concentrado, confirmando la hipótesis de inhibición por sustrato incluida en el modelo. Como se ve en la figura 27.4 la aproximación del modelo a los resultados experimentales con las cuatro concentraciones iniciales de sacarosa es muy aceptable. 

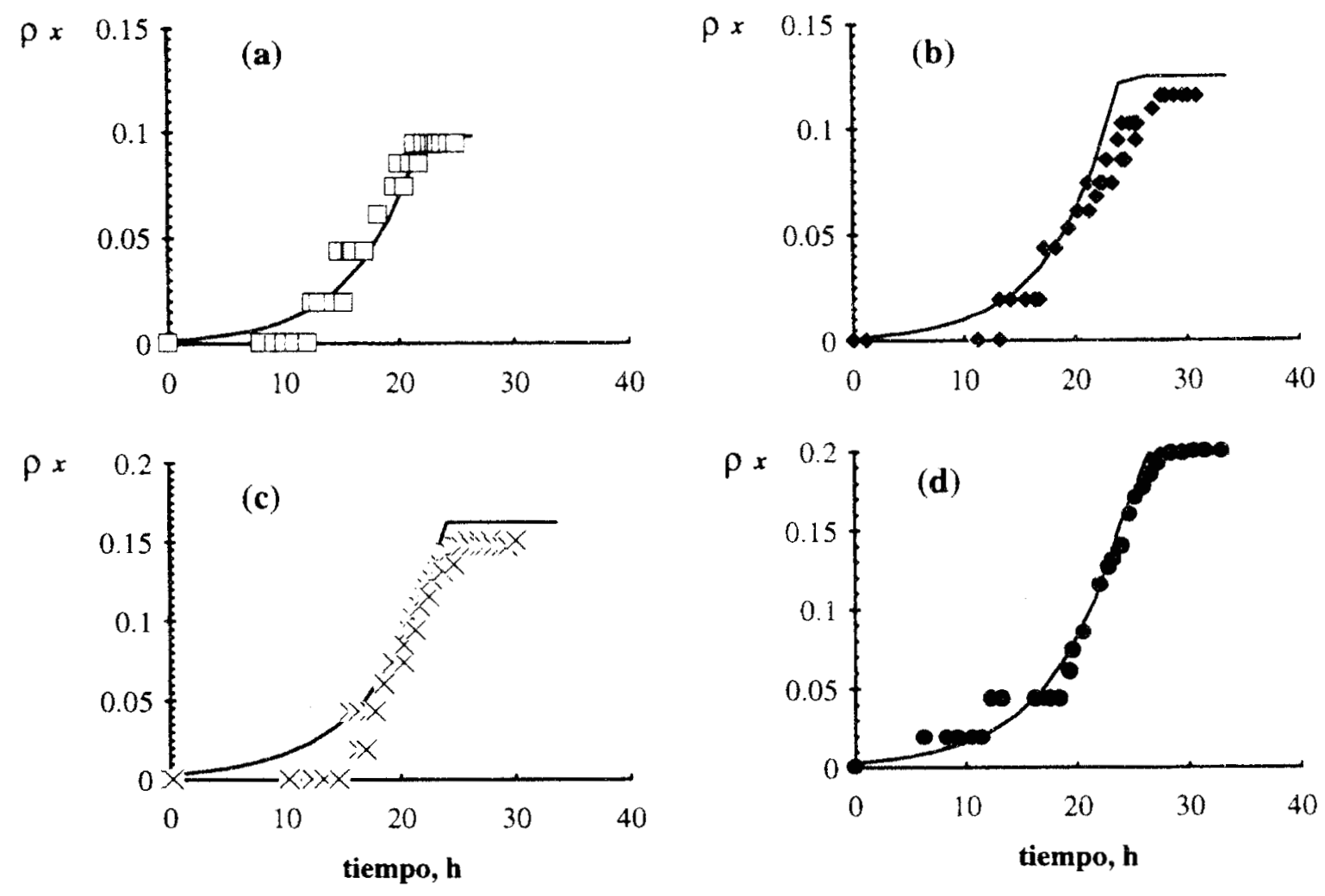

Figura 27.4. Comparación de resultados del modelo (líneas continuas) y experimentales para el crecimiento celular con cuatro concentraciones iniciales de sacarosa, en $\mathrm{kg} \mathrm{m}^{-3}$ : (a) 30, (b) 55, (c) 120, y (d) 125.

Consumo de azúcares. En la Figura 27.5 se muestra un buen ajuste entre las predicciones del modelo y los resultados experimentales, particularmente para con los medios de baja concentración inicial de sacarosa, ver Figura 27.5(a). Con los medios más concentrados, ver Figura 27.5(b), el modelo es menos exacto. Este fenómeno de desajuste con altas concentraciones también se presentó en el análisis del capítulo \$26, en donde se observó un claro desacoplamiento entre el crecimiento y el consumo de glucosa. En el estudio de este caso, cuando se comparan las Figuras 27.4 y 27.5 , especialmente cuando el medio de cultivo es el más concentrado, también se observa el mismo fenómeno de desacoplamiento, que sugiere la formación de metabolitos. Se conocen diversos trabajos con cepas de A. niger en los que se han encontrado concentraciones importantes de metabolitos como glicerol y eritrol para regular la presión osmótica del medio (Bloomberg y Adler, 1992), ácido cítrico en FMS (Hang y Woodams, 1987), en otro tipo de cultivos (Legiša y Mattey, 1986) y los tres metabolítos en FMS con Amberlita como soporte inerte y altas concentraciones de glucosa (Gutiérrez-Rojas et al, 1995b). 

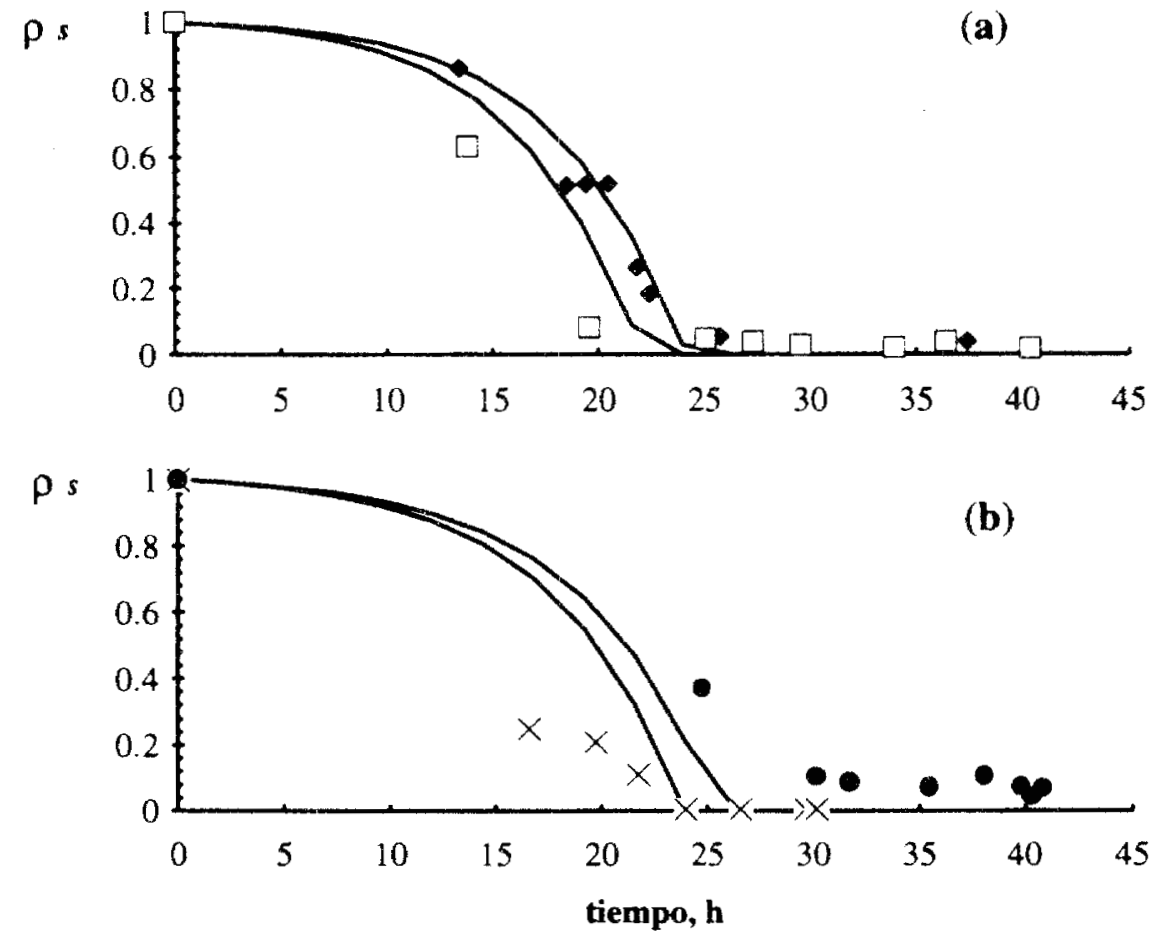

\section{Figura 27.5. Comparación de resultados del modelo (líneas continuas) y experimentales para el consumo de azúcares con cuatro concentraciones iniciales de sacarosa, en $\mathrm{kg} \mathrm{m}^{-3}$ :

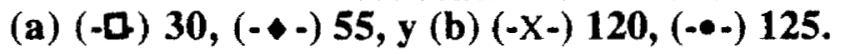

Estas observaciones sugieren, una vez más, que para simular con concentraciones elevadas de azúcares, es necesario incorporar un término que tome en ruenta la formación de productos del metabolismo.

Consumo de oxígeno y producción de bióxido de carbono. En la Figura 27.6 se muestra la comparación de los resultados de la tasa de consumo de oxígeno $\left(\mathrm{C}_{\mathrm{o}}\right)$ del modelo en relación a los datos experimentales con las cuatro concentraciones iniciales de sacarosa de este caso. Como se observa existe una buena correlación especialmente con las corridas de baja concentración de azúcar. Para las concentraciones elevadas, el modelo produce los máximos de consumo de oxígeno con un retraso de aproximadamente dos horas. Otra diferencia considerable con los resultados experimentales es el total de oxígeno consumido, este fenómeno se repite en la producción de bióxido de carbono, en teoría debe producirse más del que se produce realmente. 

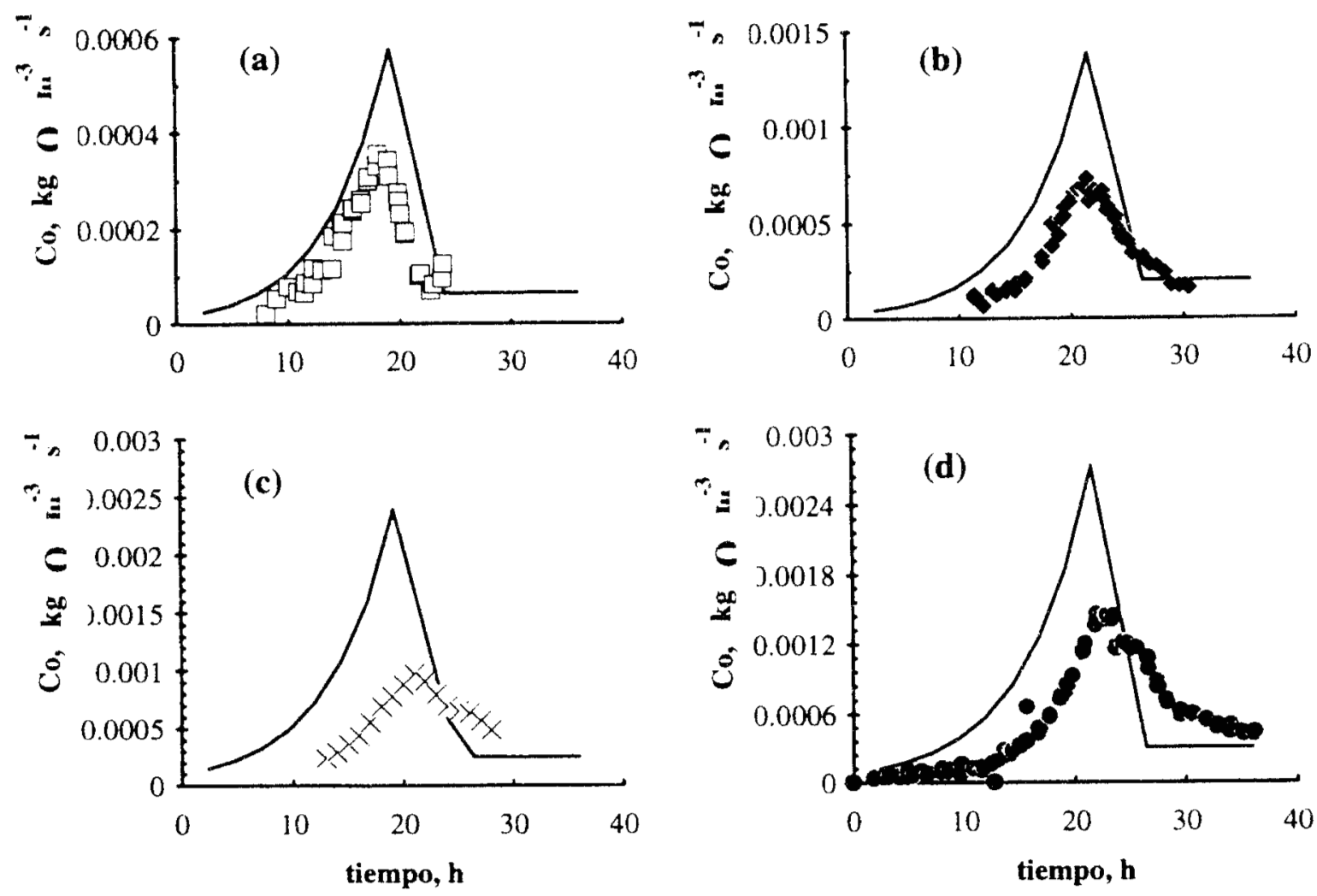

Figura 27.6. Comparación de resultados del modelo (líneas continuas) y experimentales para el consumo de oxígeno con cuatro concentraciones iniciales de sacarosa, en $\mathrm{kg} \mathrm{m}^{-3}$ : (a) $(-4) 30,(-\bullet-) 55$, y (b) (-X-) 120, (-•-) 125.

En la Figura 27.7 se muestran las cinéticas de la tasa de producción de bióxido de carbono $\left(\mathrm{C}_{\mathrm{c}}\right)$ simuladas y las experimentales. Como se observa, los resultados del modelo son aceptables. Sin embargo, nuevamente las predicciones para las concentraciones elevadas de sacarosa son mayores a las medidas en el laboratorio. Estas discrepancias se explican a continuación.

Las diferencias entre el modelo y los resultados experimentales, tanto para el consumo de oxígeno como para la producción de bióxido de carbono se pueden explicar suponiendo que se forma un producto, e.g. ácido cítrico. Al desarrollar un balance de carbono y oxígeno con los resultados experimentales, para cada concentración de sacarosa, se puede apreciar que se acumulan cantidades crecientes de carbono no celular en el medio. Cuando se transforman estas cantidades de carbono a equivalentes de ácido cítrico, se encuentra que para las concentraciones iniciales de 
sacarosa de $30,55,120$ y $125 \mathrm{~kg} \mathrm{~m}^{-3}$, se acumulan $0,8.5,130$ y $66 \mathrm{~kg}$ ácido cítrico $\mathrm{m}^{-3}$ respectivamente. Los rendimientos, expresados en $\mathrm{kg}$ de ácido cítrico $\mathrm{kg}^{-1}$ sacarosa consumida, van desde 0.15 hasta 0.53 , que coinciden bien con los obtenidos en otros cultivos de FMS (Hang y Woodams, 1987) con dos cepas de A. niger $\left(0.19\right.$ a $0.6 \mathrm{~kg}$ ácido cítrico $\mathrm{kg}^{-1}$ sacarosa) con condiciones parecidas a las del caso que se estudia.
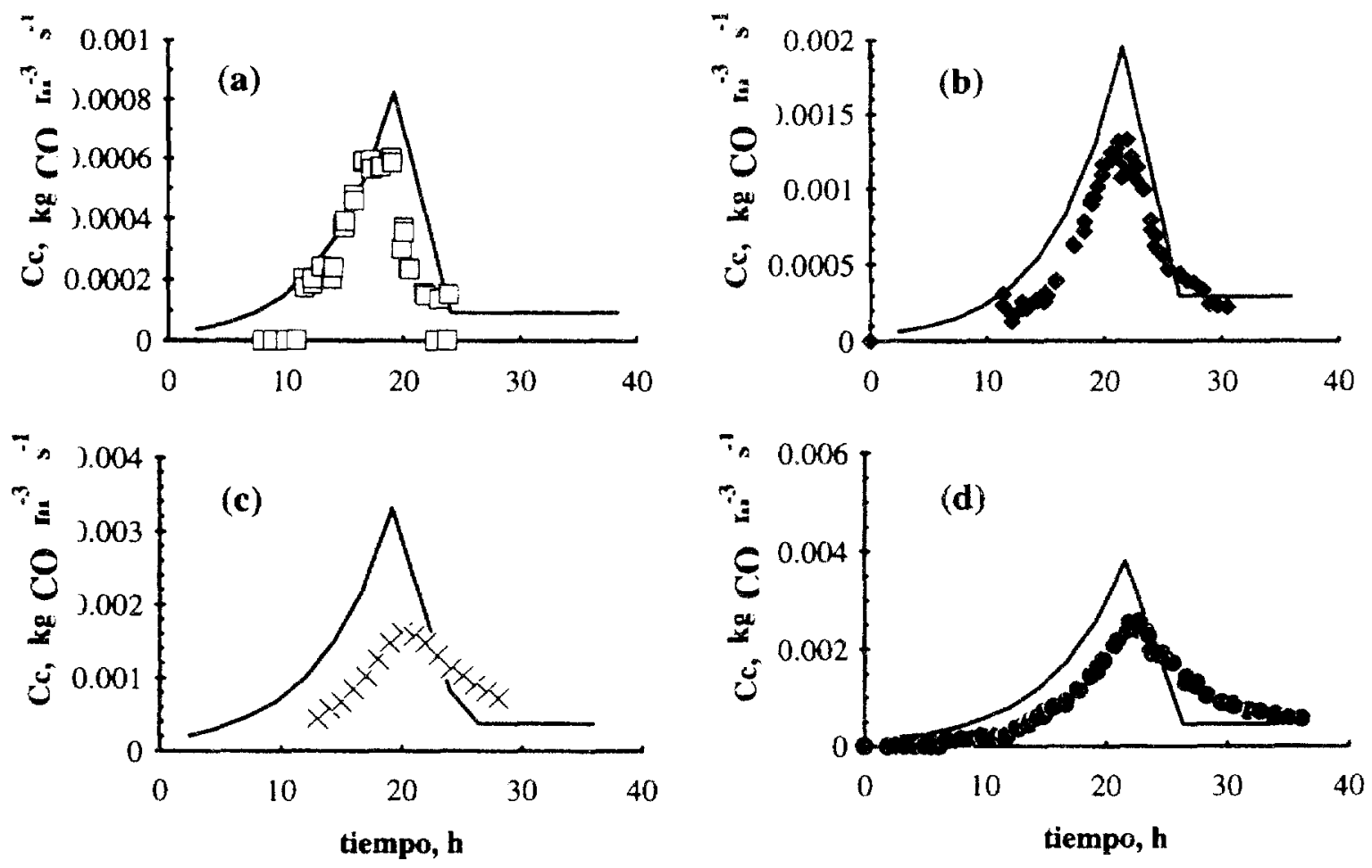

Figura 27.7. Comparación de resultados del modelo (líneas continuas) y experimentales, para la producción de bióxido de carbono con cuatro concentraciones iniciales de sacarosa,

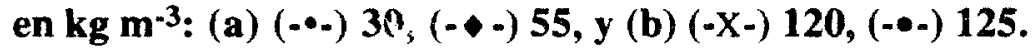

Consumo de agua libre y ocupación de espacios vacíos. En la figura 27.8(a) se presentan los resultados teóricos del consumo del agua que proviene de la fase líquida. Como se aprecia, en las cuatro concentraciones iniciales de sacarosa siempre queda una cantidad apreciable de agua, entre un 88 y un $92 \%$ del agua inicial. Estos resultados son opuestos a los reportados por Raimbault (1980) con la misma cepa de A. niger C10 en harina precocida de yuca, en donde el autor encuentra que la principal limitación al crecimiento es el agua ya que al final de la FMS encuentra un 30\% del almidón inicial. Sin embargo estudios posteriores de Oriol et al, (1988) demostraron que el agua disponible de estos cultivos se incrementa sensiblemente con la incorporación de 
soportes inertes (bagazo de caña) en los mismos cultivos con harina de yuca, en concordancia con los resultados del modelo.

En la Figura 27.8 (b) se muestran los resultados teóricos de la ocupación de los espacios vacíos en las columnas empacadas con Amberlita.Las predicciones del modelo sugieren que los espacios disponibles en las columnas empacadas están siempre subutilizados por la biomasa. Por ejemplo cuando la producción de biomasa alcanza su máximo valor solamente ocupa cerca de un $5 \%$ del espacio libre inicial. Sin embargo, esta ocupación de espacios aparentemente pobre es suficiente como para inducir caídas de presión hasta de $3.5 \mathrm{~mm}$ de agua $\mathrm{cm}^{-1}$ de empaque (Auria et al, 1993).
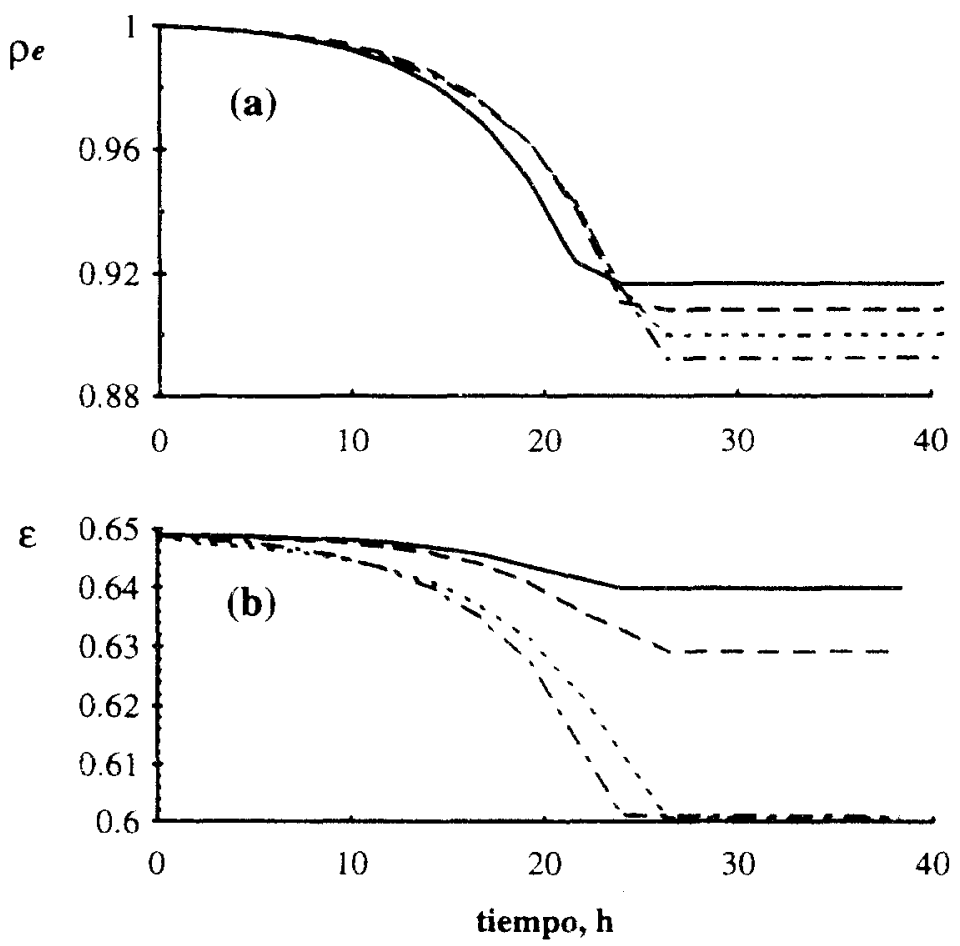

Figura 27.8 Predicciones del modelo para: (a) Cinéticas de consumo de agua, y (b) ocupación de espacios vacíos, con cuatro concentraciones iniciales de sacarosa, en $\mathrm{kg} \mathrm{m}^{-3}$ : (__ $), 30$; ), 55; (......), 120, y (......), 125.

Evolución de la temperatura y acumulación de calor metabólico. En la Figura 27.9(a) se muestran las cinéticas de temperatura del medio que produce el modelo para cada concentración inicial de sacarosa. Como se aprecia, el modelo predice aumentos en la temperatura del medio respecto a la temperatura del aire o del baño $\left(30^{\circ} \mathrm{C}\right.$ ) hasta de $0.7^{\circ} \mathrm{C}$ para el medio menos 
concentrado y hasta $2.1^{\circ} \mathrm{C}$ para los medios más concentrados. Considerando las dimensiones de las columnas $(1.8 \mathrm{~cm}$ diámetro y $8 \mathrm{~cm}$ de altura) que se emplearon en estos experimentos, los gradientes específicos radiales serían de 0.77 y $2.3{ }^{\circ} \mathrm{C} \mathrm{cm}^{-1}$, los axiales de 0.175 y $0.525{ }^{\circ} \mathrm{C} \mathrm{cm}^{-1}$ para el medio menos concentrado y el más concentrado, respectivamente. Los gradientes específicos radiales encontrados por Saucedo-Castañeda et al, (1990) con harina de yuca fueron hasta de $5{ }^{\circ} \mathrm{C} \mathrm{cm}^{-1}$, mientras que para Rathbun y Shuler, (1983) no son superiores a $2.5^{\circ} \mathrm{C} \mathrm{cm}^{-1}$. Esta comparación permite suponer que las temperaturas de las predicciones y que el coeficiente global de transporte de calor son razonables.
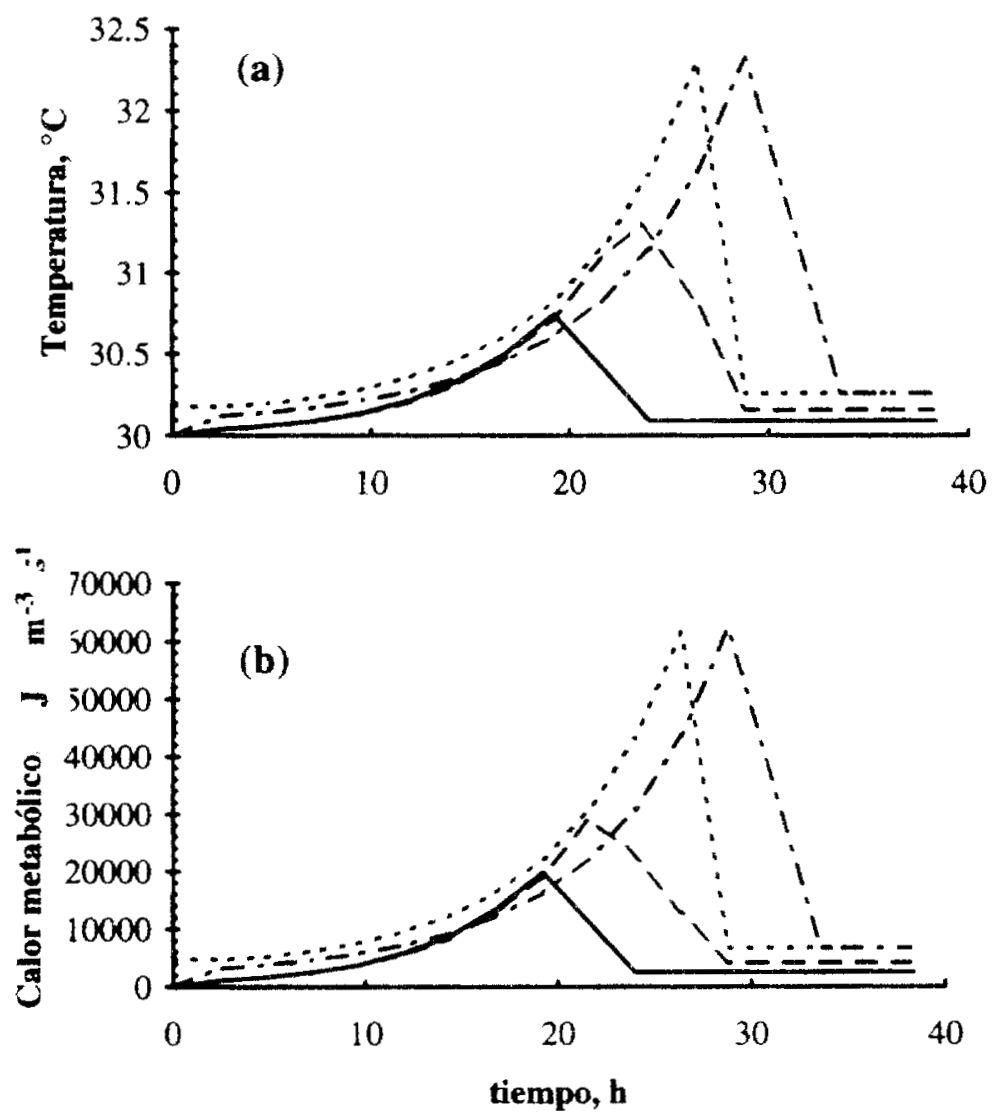

Figura 27.9 Predicciones del modelo: (a) cinéticas de temperatura del medio, y (b) evolución del calor metabólico, con cuatro concentraciones iniciales de sacarosa, en $\mathrm{kg} \mathrm{m}^{-3}$ : $(\ldots), 30 ;(\ldots \ldots), 55 ;(. . . .), 120$, y $(. . . . .), 125$.

En la Figura 27.9(b) se muestran las cinéticas de las tasas de producción de calor metabólico para las cuatro concentraciones iniciales de sacarosa. En el caso de la concentración inicial de sacarosa más baja, el máximo encontrado es de $19600 \mathrm{~J} \mathrm{~m}^{-3} \mathrm{~s}^{-1}$ i.e. para una carga de $276 \mathrm{~kg}$ de materia 
seca $\mathrm{m}^{-3}$, equivalen a $2.55 \mathrm{E}-5 \mathrm{~J} \mathrm{~h}^{-1} \mathrm{~kg}^{-1}$ de materia seca, que es un valor muy parecido al máximo que reporta Raimbault (1980) con harina de yuca, de $3.3 \mathrm{ES} \mathrm{J} \mathrm{h} \mathrm{h}^{-1} \mathrm{~kg}^{-1}$ de materia seca. Cuando se integran las curvas de la Figura 27.9(b) y se refieren a un kilogramo de materia seca fermentable i.e. restando la masa de soporte inerte, los resultados van desde $23.57 \mathrm{E} 6 \mathrm{~J} \mathrm{~kg} \mathrm{k}^{-1}$ de materia seca para la concentración más baja, hasta $19.1 \mathrm{E} 6 \mathrm{~J} \mathrm{~kg}^{-1}$ de materia seca para la más alta concentración, estos valores son ligeramente superiores a los reportados por Rathbun y Shuler, (1983) que proponen que se producen hasta $15.9 \mathrm{E} 06 \mathrm{~J} \mathrm{~kg}^{-1}$ de materia seca.

Los resultados del modelo sugieren que en el transcurso de la fermentación la cantidad de calor generado cambia y, como se aprecia en la Figura 27.9(b), es menor al principio y mayor durante la fase de crecimiento logarítmico.

$\S 28$. Resumen de los parámetros.

A partir de la comparación de resultados discutidos en los capítulos $\$ 26$ y $\$ 27$, particularmente con base en las comparaciones realizadas en el estudio del caso 3 , y para poder continuar con la simulación del proceso utilizando modelos más completos, se proponen los siguientes valores constantes para los parámetros del crecimiento:

$$
\begin{aligned}
& \mathrm{K}_{\mathrm{i}}=300 \mathrm{~kg} \text { azúcar m-3 } \quad \mathrm{m}_{\mathrm{s}}=2.6 \mathrm{E}-06 \mathrm{~kg}^{-3} \text { azúcar } \mathrm{kg}^{-1} \text { biomasa húmeda } \mathrm{s}^{-1} \\
& \mathrm{~K}_{\mathrm{s}}=3.0 \mathrm{~kg} \text { azúcar } \mathrm{m}^{-3} \quad \mathrm{U}=120 \mathrm{~J} \mathrm{~m}^{-2} \mathrm{~s}^{-1} \mathrm{~K}^{-1}
\end{aligned}
$$

Para el caso de los rendimientos de biomasa se utilizará la ecuación (26-3).

Resumen y conclusiones.

Prácticamente en todos los casos en los que se valida el modelo, para diferentes variables de respuesta, se observa un ajuste aceptable del modelo. En el estudio de los diferentes casos, los resultados sugieren en mayor o menor medida, que el modelo se podría mejorar incluyendo un término de formación de producto que justifique el consumo de azúcares, el consumo de oxígeno, la producción de bióxido de carbono y de calor metabólico. El modelo que se presenta es un modelo muy simple, es un simulador que contribuye a explicar aspectos físicos y fisiológicos del fenómeno global que se estudia. Es flexible y de rápida respuesta, con un aceptable grado de fidelidad con los resultados experimentales. Puede ser de gran utilidad para proponer nuevos experimentos y nuevos modelos más complejos, como es el caso de modelos que consideren los aspectos difusivos de los nutrientes o el caso de modelos que tomen en cuenta la distribución espacial de la evolución de las variables de estado. 


\section{PARTE IV. SOLUCIÓN Y VALIDACIÓN DEL MODELO MATEMÁTICO GENERAL EN DOS DIMENSIONES.}

El modelo simplificado que se desarrolló en los capítulos anteriores y los parámetros encontrados, sirven de base para la solución del modelo general en dos dimensiones. En la parte IV A se presenta un análisis de los resultados que produce el modelo general sin las restricciones impuestas por las hipótesis H:15 y H:16. En el capítulo $\$ 29$ se discuten algunas restricciones mínimas, necesarias para desarrollar el nuevo modelo en coordenadas cilíndricas y en términos adimensionales, se proponen las condiciones iniciales y de frontera para resolver el problema. En el capítulo $\$ 30$ se justifica la selección del método numérico con el que se resuelve el problema y se presenta una breve descripción del principio del método. En los capítulos $\$ 31$ y $\$ 32$, se propone una estrategia de solución con el método de diferencias finitas y se describen los programas de cálculo. En la parte IV B (capítulos $\$ 33$ al §39) se comparan los resultados teóricos con los experimentales, de donde se desprenden las limitaciones y alcances del modelo matemático general.

El objetivo de esta parte es presentar la solución numérica del modelo general en dos dimensiones tratando de imponer el menor número posible de restricciones. En este estudio se parte del supuesto de que el menor número de restricciones impuestas producirá los resultados más próximos a la realidad.

\section{A. DESARROLLO Y SOLUCIÓN DEL MODELO.}

\$29. Planteamiento: Un problema de valor inicial y en la frontera.

29.1 Simplificaciones e hipótesis de trabajo.

El modelo que se desarrolla a continuación se basa en el conjunto de hipótesis descritas en el capítulo \$11.El modelo completo en coordenadas cilíndricas está descrito en las secciones IIIA a la IIIB, en donde se incluyen los términos cinéticos que también se conservan sin ninguna alteración. Para escribir el modelo general en su forma adimensional, se incluyen las variables independientes siguientes:

- El tiempo adimensional $t$, antes definido como:

$$
t=\frac{\mathrm{t}}{\mathrm{tf}}
$$

donde: tf es el tiempo de fermentación expresado en segundos.

- La altura adimensional $z$, del biorreactor, que se define como: 


$$
z=\frac{Z}{L}
$$

- El radio adimensional $\boldsymbol{r}$, del biorreactor, que se define como:

$$
r=\frac{r}{R a}
$$

donde: $\mathrm{z}$ es un punto axial, $\mathrm{m}$

$r$ es un punto radial, $m$

$\mathrm{L}$ y $\mathrm{Ra}$ son la altura y el radio del biorreactor expresados, $\mathrm{m}$

Para seguir con la misma lógica de los capítulos anteriores las variables adimensionales se escriben en negritas e itálicas.

Los balances de masa y energía y los términos cinéticos adimensionales, se obtienen sustituyendo el conjunto de adimensionales definidos en el capítulo $\$ 21$ (ver Cuadro 21.2), para cada una de las variables dependientes, así como las ecuaciones (29-1) a la (29-3) en las ecuaciones del ANEXO III, de donde resulta el siguiente conjunto de ecuaciones diferenciales parciales:

Fase biológica. Sustituyendo el cambio de variable propuesto en el Cuadro 21.2 y la ecuación (29-1) en la ecuación (19-2), se obtiene la siguiente expresión:

$$
\begin{aligned}
& \frac{\partial \rho_{x}}{\partial t}=\frac{t_{f}}{\rho_{x M a x}} C_{x} \\
& \text { donde } C_{x} \text { de definió en }(21-3) \text { y }(16-1)
\end{aligned}
$$

Fase líquida. Azúcares, sustituyendo el cambio de variable propuesto en la ecuación (19-3), se obtiene la siguiente expresión:

$$
\frac{\partial \rho_{s}}{\partial t}=-\frac{t_{f}}{\rho_{s}{ }^{0}} C_{s}
$$

donde $\mathrm{C}_{\mathrm{s}}$ fue definida en la ecuación (21-5)

Para el agua, partiendo de la ecuación (19-4), se obtiene:

$$
\frac{\partial \rho_{e}}{\partial t}=\frac{t_{f}}{\rho_{e}{ }^{0}} C_{e}
$$

La fase líquida $\rho_{1}$, expresada en $\mathrm{kg}$ de $1 \mathrm{~m}^{-3}$, se obtiene de la siguiente forma:

$$
\rho_{l}=\rho_{s}+\rho_{e}=\rho_{s}^{0} \rho_{s}+\rho_{e}^{0} \rho_{e}
$$


El conjunto de las fases sólida, biológica y líquida o fase estática $\rho_{\mathrm{ps}}$ expresada en $\mathrm{kg} \mathrm{m}^{-3}$, se obtiene de la siguiente forma:

$$
\rho_{\mathrm{ps}}=\rho_{\mathrm{a}}+\rho_{\mathrm{x}}+\rho_{\mathrm{s}}+\rho_{\mathrm{e}}=\rho_{\mathrm{a}}{ }^{0} \rho_{a}+\rho_{\mathrm{xMax}} \rho_{x}+\rho_{1}
$$

Fase gaseosa. Para el oxígeno, a partir de las definiciones del Cuadro 21-2 y de las ecuaciones (17-5), (29-1) y (29-2), se obtiene la siguiente expresión:

$\frac{\partial \rho_{a}}{\partial t}=-\left(\frac{\mathrm{tf} \mathrm{v}_{\mathrm{g}}}{\mathrm{L}}\right) \frac{\partial \rho_{a}}{\partial z}-\left(\frac{\mathrm{tf}}{\rho_{0}^{0}}\right) C_{\mathrm{o}}$

donde $\mathrm{C}_{\mathrm{o}}$ : se definió en la ecuación (21-8)

Para el bióxido de carbono, por analogía con el oxígeno:

$$
\frac{\partial \rho_{c}}{\partial t}=-\left(\frac{\mathrm{tf} \mathrm{v}_{\mathrm{g}}}{\mathrm{L}}\right) \frac{\partial \rho_{c}}{\partial z}-\left(\frac{\mathrm{tf}}{\rho_{\mathrm{cMax}}}\right) \mathrm{C}_{\mathrm{c}}
$$

donde $\mathrm{C}_{\mathrm{c}}$ : se definió en la ecuación (21-10)

La fase gaseosa $\rho_{g}$, expresada en $\mathrm{kg} \mathrm{m}^{-3}$, se obtiene de la siguiente forma:

$$
\rho_{g}=\rho_{N}+\rho_{v}+\rho_{o}+\rho_{c}=\rho_{N}{ }^{0} \rho_{N}+\rho_{v}{ }^{0} \rho_{v}+\rho_{o}{ }^{0} \rho_{o}+\rho_{c M a x} \rho_{c}
$$

El conjunto global de las fases $\rho_{\mathrm{i}}$, expresado en $\mathrm{kg} \mathrm{m}^{-3}$ esta dado por:

$$
\rho_{\mathrm{i}}=\rho_{\mathrm{ps}}+\rho_{\mathrm{g}}
$$

Es importante notar a través de las ecuaciones (29-7), (29-8), (29-11) y (29-12) que representan el acoplamiento físico de todos los constituyentes del sistema y que el modelo, al tomar en cuenta los cambios en la composición del sistema durante el proceso, incluye también los cambios implícitos en las propiedades físicas del mismo.

Estas observaciones se aprecian con mayor claridad en la ecuación de balance de calor que se presenta a continuación.

Temperatura. A partir de los balances de calor, ecuación (17-15), sustituyendo las variables adimensionales correspondientes, se obtiene la siguiente expresión:

$$
\frac{\partial T}{\partial t}=-N_{a x i}\left(\frac{\partial T}{\partial z}\right)-N_{r a d}\left(\frac{1}{r} \frac{\partial T}{\partial r}+\frac{\partial^{2} T}{\partial r^{2}}\right)-N_{r e a}
$$

Los grupos adimensionales $N_{a x i}, N_{r a d}$ y $N_{r e a}$ se definen como sigue: 


$$
\begin{aligned}
& N_{a x i}=\left(\frac{\rho_{g} c_{g}}{\rho_{\mathrm{i}} \mathrm{c}_{\mathrm{i}}}\right)\left(\frac{\mathrm{tf} \mathrm{v}_{\mathrm{g}}}{\mathrm{L}}\right) \\
& N_{\text {rad }}=\left(\frac{\lambda}{\rho_{\mathrm{i}} \mathrm{c}_{\mathrm{i}}}\right)\left(\frac{\mathrm{tf}}{R \mathrm{a}^{2}}\right) \\
& \boldsymbol{N}_{\text {rea }}=\left(\frac{\mathrm{C}_{\mathrm{i}} \mathrm{h}_{\mathrm{i}}}{\rho_{\mathrm{i}} \mathrm{c}_{\mathrm{i}}}\right)\left(\frac{\mathrm{tf}}{\left(\mathrm{T}_{\mathrm{in}}-\mathrm{T}_{\mathrm{p}}\right)}\right)
\end{aligned}
$$

En la ecuación (29-14), el término $\rho_{\mathrm{g}} c_{\mathrm{g}}$ se obtiene introduciendo los calores específicos de cada constituyente de la fase gaseosa. Partiendo de la ecuación (29-11)

$$
\rho_{g} c_{g}=\rho_{N}^{0} \rho_{N} c_{N}+\rho_{v}^{0} \rho_{v}+\rho_{o}^{0} \rho_{o} c_{o}+\rho_{c M a x} \rho_{c} c_{c}
$$

donde $\mathrm{c}_{\mathrm{i}}$ : es el calor másico de $\mathrm{i}$ a presión o volumen constante, $\mathrm{J}(\mathrm{kg} \text { de i } \mathrm{K})^{-1}$

En las ecuaciones (29-14) a la (29-16), el término $\rho_{\mathrm{i}} \mathrm{c}_{\mathrm{i}}$ se obtiene introduciendo los calores específicos de cada constituyente del conjunto de las fases. Las ecuaciones (29-8) y (29-17) implican que:

$$
\begin{aligned}
& \rho_{p s} c_{p s}=\rho_{a}^{0} \rho_{a} c_{a}+\rho_{x M a x} \rho_{x} c_{x}+\rho_{l} c_{l} \\
& \rho_{i} c_{i}=\rho_{g} c_{g}+\rho_{p s} c_{p s}
\end{aligned}
$$

En la ecuación (29-16), el término $C_{i} h_{i}$ se define antes en la ecuación (15-12).

El conjunto de ecuaciones diferenciales parciales que se pretende resolver con métodos numéricos esta constituido por las ecuaciones:

$(29-4),(29-5),(29-6),(29-9),(29-10)$ y $(29-13)$

\subsection{Condiciones iniciales y en la frontera.}

Para resolver el modelo general, las condiciones iniciales que se utilizan para el tiempo $t=0 \mathrm{y}$ para todo punto en el espacio radial y axial son las mismas definidas antes en el Cuadro 21.2 .

Las condiciones en los límites espaciales de las coordenadas cilíndricas en que se expresa el modelo, se establecen a partir de las coordenadas adimensionales definidas por las ecuaciones (29-2) y (29-3). Las condiciones frontera son: 
- Para $z=0$, y para cualquier valor de $t$ y/o de $r$ :

Para el oxígeno:

$$
\rho_{o}=\frac{\rho_{0}^{0}}{\rho_{0}{ }^{0}}=1.0
$$

Para el bióxido de carbono:

$$
\rho_{c}=\frac{\rho_{c}{ }^{0}}{\rho_{c M a x}}
$$

Para la temperatura:

$$
T=\frac{\left(T_{\text {air }}-T_{p}\right)}{\left(T_{\text {in }}-T_{p}\right)}
$$

- Para $r=0$, y para cualquier valor de $t$ y/o de $z$ :

$$
\frac{\mathrm{d} \boldsymbol{T}}{\mathrm{d} \boldsymbol{r}}=0
$$

- Para $r=R a$, y para cualquier valor de $t$ y/o de $z$ :

$$
T=\frac{\left(T_{j}-T_{p}\right)}{\left(T_{i n}-T_{p}\right)}
$$

\subsection{Valores de los parámetros}

Los valores de los parámetros físicos y biológicos se presentan de manera detallada en el capítulo $\S 20$. Los parámetros que se emplean en el modelo general que se describe aquí, son esencialmente los mismos, también se adoptan aquí los parámetros que se modificaron en el capítulo §28, excepto que el coeficiente global de transferencia de calor (U), no aparece en el modelo general y en su lugar queda incluida la conductividad térmica efectiva $(\lambda)$ del conjunto de las fases sólida, biológica y líquida. Para conocer el orden de magnitud de este parámetro se realizaron una serie de experimentos utilizando el método propuesto por Benet (1981) para la medición experimental de la conductividad térmica de materiales porosos heterogéneos tales como suelos húmedos. Los resultados mostraron que la conductividad térmica del sistema amberlita-medio de cultivo-hongos filamentosos prácticamente no varía en relación a la evolución de la fermentación, probablemente debido a que la cantidad de biomasa producida en estos sistemas siempre fue baja. Con estos experimentos se encontró que los valores de la conductividad térmica fluctuaron entre 0.05 y 0.1 $\mathrm{J} \mathrm{m}^{-1} \mathrm{~s}^{-1} \mathrm{~K}^{-1}$. Estas cifras son del mismo orden de magnitud de la conductividad térmica del aire 
$\left(0.02 \mathrm{~J} \mathrm{~m}^{-1} \mathrm{~s}^{-1} \mathrm{~K}^{-1}\right)$ y entre 5 y 10 veces menores que la del agua $\left(0.5 \mathrm{~J} \mathrm{~m}^{-1} \mathrm{~s}^{-1} \mathrm{~K}^{-1}\right)$. Por lo que se consideraron como aceptables y durante las simulaciones se trabajó con un valor de $\lambda$ de $0.06 \mathrm{~J} \mathrm{~m}^{-}$ ${ }^{1} \mathrm{~s}^{-1} \mathrm{~K}^{-1}$.

§30. Selección y descripción del método de integración.

Por las características del modelo que se propone, el problema puede considerarse como de valor inicial en el tiempo y en la coordenada axial, sin embargo la ecuación para la temperatura indica que el problema también debe considerarse como de valores en la frontera. Para resolver un sistema de ecuaciones simultáneas como el propuesto en el capítulo $\$ 29$ debe seleccionarse cuidadosamente el método de solución numérico buscando siempre una alternativa que produzca resultados estables, confiables y de respuesta rápida. Las alternativas numéricas existentes en la literatura son muchas y una selección eficiente del método implicaría ensayar varios y compararlos entre sí, evaluando con diferentes criterios. En tanto esto último sale del alcance establecido en este trabajo, se selecciona el método de diferencias finitas por las siguientes razones:

1. Es el método de más fácil comprensión y aplicación (Press et al, 1989).

2. Se aplica extensivamente en sistemas de coordenadas cilindricas con resultados aceptables (Finlayson, 1971), (Raghavan y Ruthven, 1983).

3. En problemas similares al del modelo que se presenta aquí, invariablemente el método de diferencias finitas se utiliza como el método de referencia que produce los resultados más próximos a la solución analítica (Finlayson, 1971; 1980), Segall, et al (1984).

Algunas desventajas del método de diferencias finitas son: (i) la simplicidad del método puede conducir a obtener soluciones inestables que limitan mucho su aplicación, (ii) por lo general, el método requiere de una malla de elementos discretos muy cerrada y por lo tanto el tiempo de cómputo puede ser muy prolongado en relación al requerido por otros métodos como por ejemplo el de colocación ortogonal desarrollado por Villadsen y Michelsen (1978).

De los métodos existentes de aproximación numérica para resolver ecuaciones diferenciales parciales, los más utilizados son aquellos que emplean alguna modalidad de las diferencias finitas. El método es un método de aproximación en el sentido que las derivadas se aproximan a un punto a través de cocientes de diferencias en intervalos muy pequeños, pero las soluciones no se consideran como aproximadas en el sentido de ser estimados burdos o crudos (Smith, 1985). En términos generales, la información experimental invariablemente esta sujeta a errores de medición, de manera similar todo trabajo de análisis aritmético esta sujeto a un cierto número finito de valores significativos que contienen errores de redondeo, de tal manera que aún las soluciones 
analíticas proporcionan solo respuestas aproximadas. El método de diferencias finitas proporciona soluciones precisas y confiables, en la misma proporción en que los datos experimentales son precisos o, en otras palabras, las soluciones del método son tan precisas como se requieren en problemas tecnológicos en donde se busca una solución.

El principio del método consiste en sustituir cada derivada parcial por un cociente de diferencias finitas. Esto conduce a transformar un conjunto de ecuaciones diferenciales parciales en un conjunto de ecuaciones algebraicas a resolver por métodos matriciales de manera simultánea, siguiente alguno de los esquemas de solución que se describen más adelante. Para aplicar el método es necesario definir, en primer lugar, una espacio delimitado por las dimensiones del biorreactor. El espacio de integración se debe expresar a través de una malla imaginaria de dimensiones finitas. A partir del dominio de integración discretizado, es posible aproximar a cada una de las derivadas parciales a su equivalente de diferencias finitas resolviendo simultáneamente el conjunto de ecuaciones resultantes, en donde las incógnitas pueden o no estar de manera explícita, por métodos de aproximación numérica en donde las variables independientes cambian paso a paso. Estas etapas y su aplicación particular al problema del modelo general se discuten en los subcapítulos que siguen.

\subsection{Discretización del dominio de integración.}

El dominio de integración esta compuesto por un conjunto de puntos o nodos bien definidos en el espacio. En la Figura 30.1 se presenta gráficamente el dominio de integración en las coordenadas radial y axial. Si se define a $\Delta r$ y a $\Delta z$ como el paso en el espacio en la dirección de las ordenadas radial y axial respectivamente, entonces un punto de coordenadas $(r, z)$ representará un nodo $(i, j)$, asociado al punto a través de:

$$
\begin{array}{ll}
\mathrm{r}=\mathrm{i} \Delta \mathrm{r} ; & \mathrm{z}=\mathrm{j} \Delta \mathrm{z} \\
\forall \mathrm{i}=0,1,2,3, . . & \forall \mathrm{j}=0,1,2,3,
\end{array}
$$

\subsection{Aproximación de las derivadas parciales}

La primera y segunda derivada de una función continua cualquiera $W$ de $r$ y de $t$, se puede aproximar en términos de series truncadas de Taylor hasta el primero y segundo orden, produciendo las expresiones generales siguientes: 


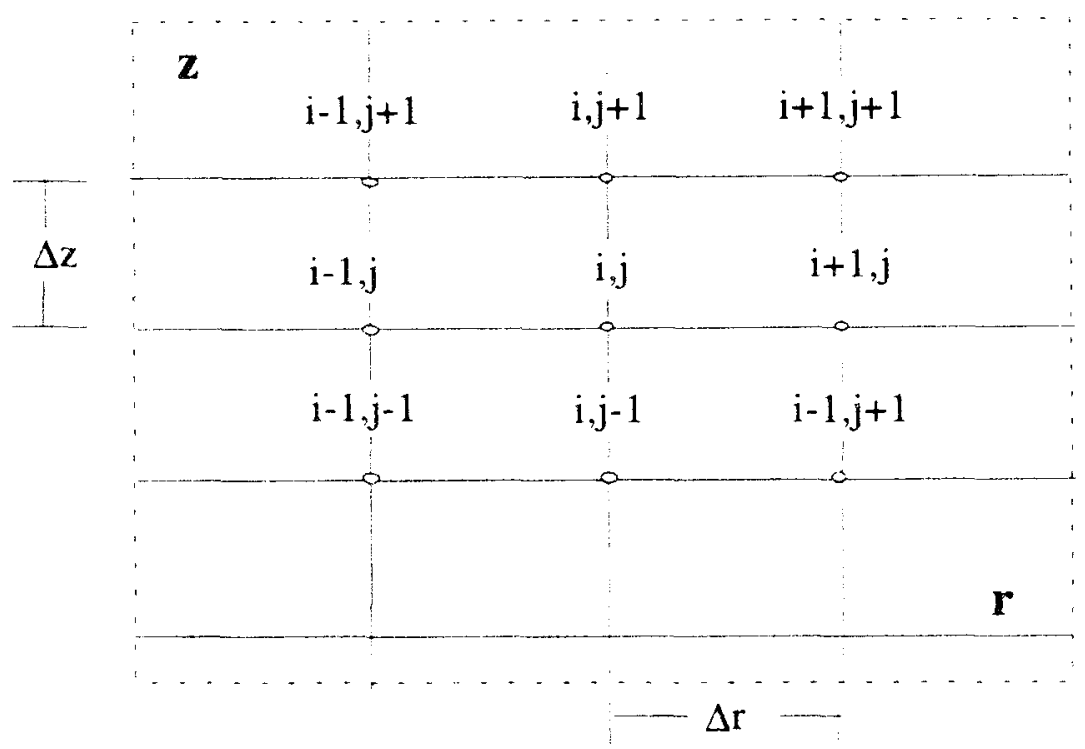

Figura 30.1. Discretización del dominio de integración. En donde $r$ es la coordenada radial y $\mathrm{z}$ es la coordenada axial.

La primera derivada de $\mathrm{W}$ con respecto a t o a $\mathrm{r}$ evaluada en el punto (i,n) donde $\mathrm{r}=\mathrm{i} \Delta \mathrm{r}$ y $\mathrm{t}=\mathrm{n}$ $\Delta t$, se puede expresar como sigue:

Diferencia central

con respecto al tiempo

$\frac{\partial W(i, n)}{\partial t}=\frac{W(i, n+1)-W(i, n-1)}{2 \Delta t}$

con respecto al radio

$\frac{\partial W(i, n)}{\partial r}=\frac{W(i+1, n)-W(i-1, n)}{2 \Delta r}$

Diferencia hacia adelante (forward difference)

con respecto al tiempo

$\frac{\partial W(i, n)}{\partial t}=\frac{W(i, n+1)-W(i, n)}{\Delta t}$

con respecto al radio 
$\frac{\partial W(i, n)}{\partial r}=\frac{W(i+1, n)-W(i, n)}{\Delta r}$

Diferencia hacia atrás (backward difference)

con respecto al tiempo

$\frac{\partial W(i, n)}{\partial t}=\frac{W(i, n)-W(i, n-1)}{\Delta t}$

con respecto al radio

$\frac{\partial W(i, n)}{\partial r}=\frac{W(i, n)-W(i-1, n)}{\Delta r}$

Finalmente, la segunda derivada con respecto al radio se expresa como sigue:

$$
\frac{\partial^{2} W(i, n)}{\partial r^{2}}=\frac{W(i+1, n)-2 W(i, n)+W(i-1, n)}{\Delta r^{2}}
$$

NOTA: Las definiciones de las derivadas con respecto a la coordenada axial z son idénticas que las que se muestran. 
30.3 Selección del esquema de integración.

Se conocen muchos esquemas de integración con el método de diferencias finitas, cada esquema representa una estrategia de cálculo y de solución diferente, sin embargo, todos los esquemas se basan en el mismo principio: una vez definidos los valores de las variables en los nodos iniciales y en los límites, el problema se reduce a calcular simultaneamente, los valores que corresponden a los puntos vecinos, en el espacio y en el tiempo hasta lograr la cobertura total del dominio especificado antes. En la discusión que sigue un esquema explícito o implícito se refiere a si la variable en cuestión se puede obtener de manera directa o indirecta respectivamente.

Esquema explícito-explicito

Esta estrategia se refiere a tratar de dejar al tiempo y a la coordenada espacial, ambas de manera explícita. En este esquema se parte del principio que los valores de las variables se conocen en los nodos definidos por $(\mathrm{i}-1, \mathrm{n})$ y $(\mathrm{i}, \mathrm{n}-1)$ y que con estos valores se puede calcular un nuevo valor en el nodo (i,n). En la figura 30.2 se muestra el principio de este esquema de integración, en donde se pueden observar, a manera de ejemplo, los primeros tres pasos de integración.

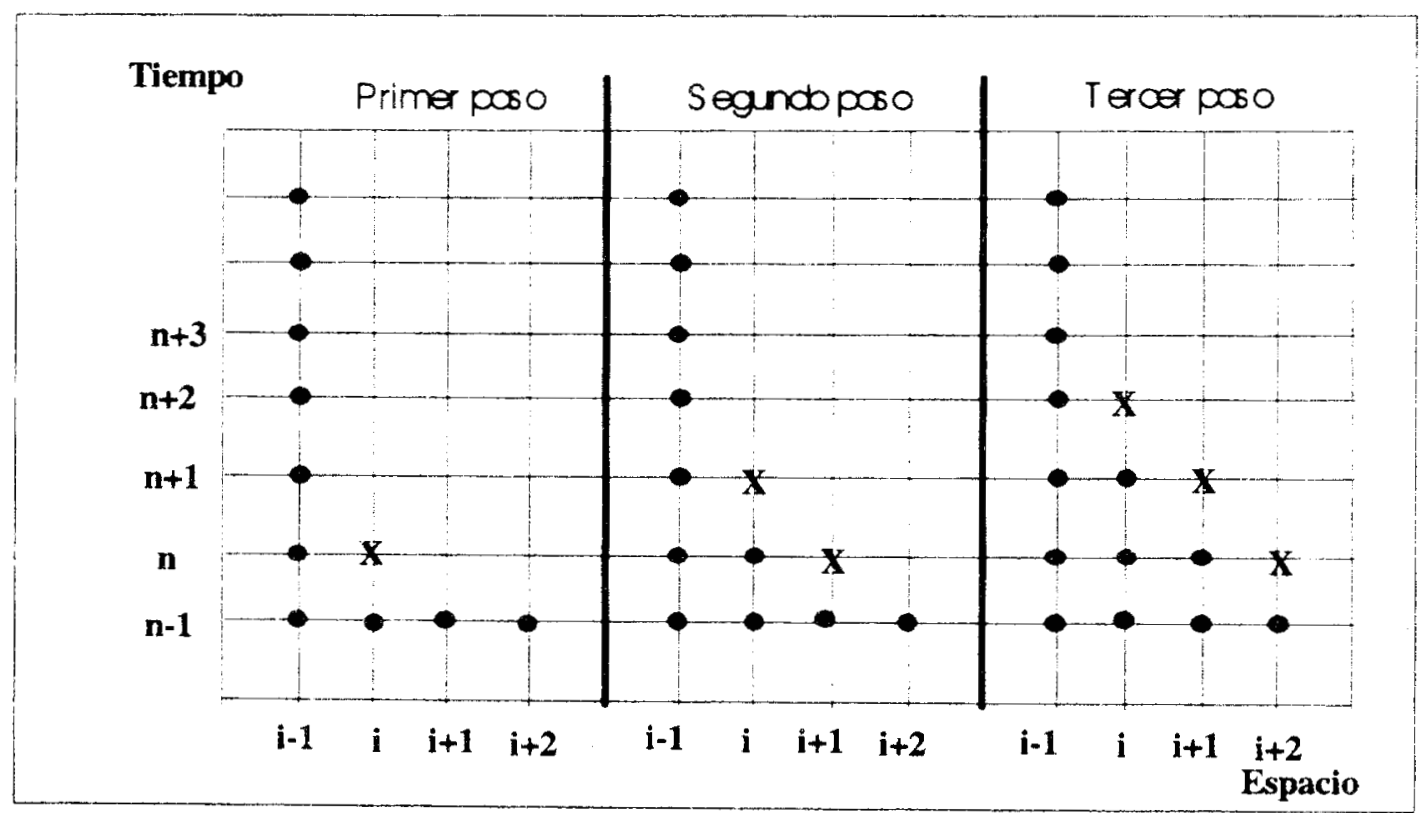

Figura 30.2 Estrategia de cálculo para el caso explícito-explícito: las tres etapas iniciales del cálculo numérico. Los círculos cerrados representan los datos conocidos y la cruces las incógnitas 
Esquema explícito-implícito.

En esta estrategia de cálculo se considera que la solución puede obtenerse con el tiempo de forma explícita y solo es implícita en el espacio. Para el tiempo $t+\Delta t$, se realizan los cálculos de los valores de la función $\mathrm{W}$ de manera simultánea para todos los nodos vecinos del mismo tiempo de cálculo, solo hasta obtener todas las incógnitas se pasa al siguiente nivel de tiempo. En la figura 30.3 se presentan los primeros tres pasos de integración con este esquema.

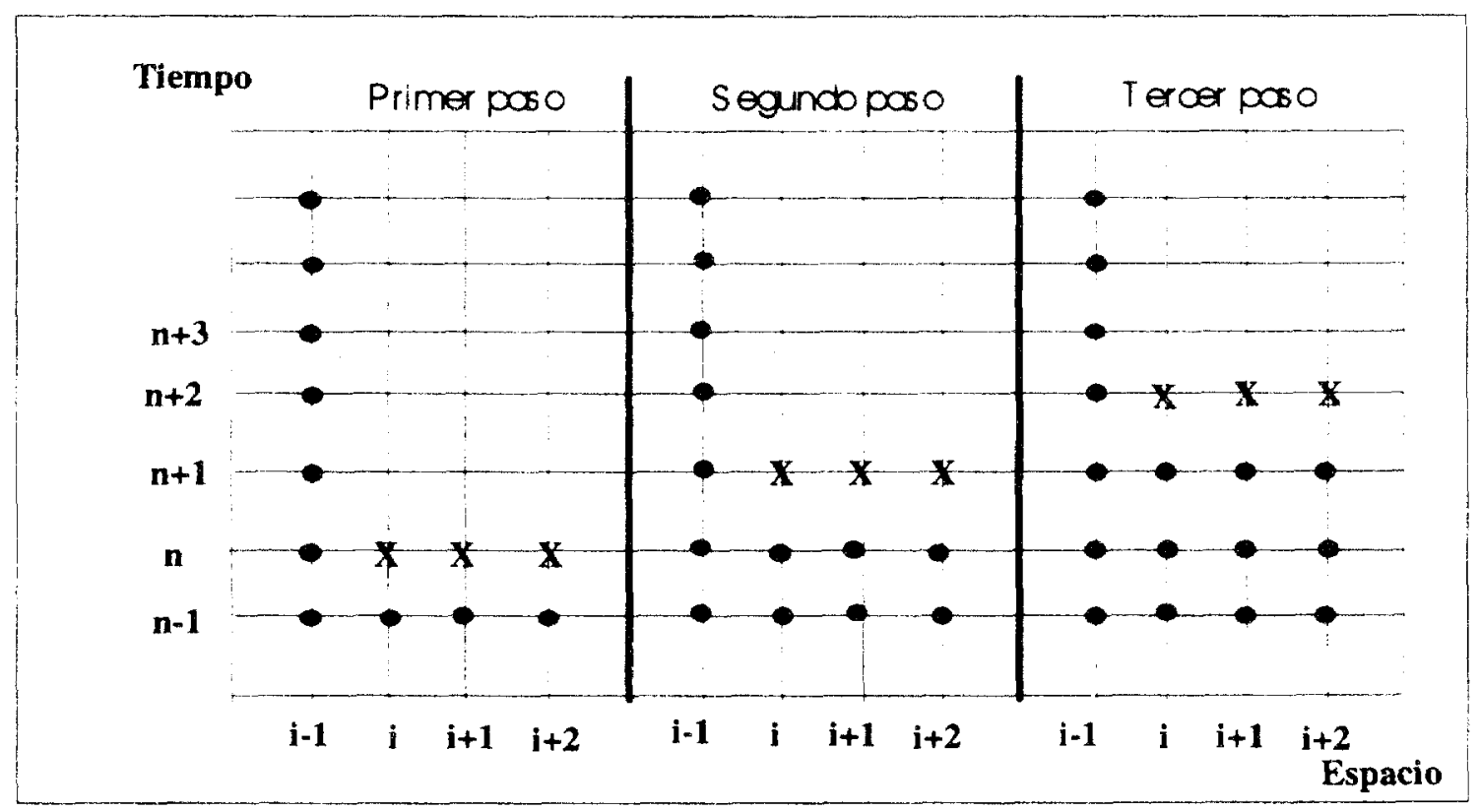

Figura 30.3 Estrategia de cálculo para el caso explícito-implícito: las tres etapas iniciales del cálculo numérico. Los círculos cerrados representan los datos conocidos y la cruces las incógnitas.

El esquema de integración implícito supone que la función $\mathrm{W}$ es conocida al menos en los límites espaciales de la malla de trabajo. Como se puede apreciar en la figura 30.3 la solución simultánea de la función en todo nodo i al mismo tiempo, implica que se debe producir un número de ecuaciones igual al número de incógnitas en la malla. Una vez desarrollado el sistema de ecuaciones la solución se encuentra utilizando un ordenamiento matricial tridiagonal que, a su vez se obtiene de la discretización de las derivadas parciales y con los valores conocidos en el espacio y el tiempo precedente. En estos sistemas las incógnitas y los valores conocidos se agrupan en las ecuaciones para resolver de manera simultánea los vectores de incógnitas. 
Esquema de las direcciones alternas

Este esquema es una variante del anterior. Consiste en tratar el problema de manera sucesiva hacia cada una de las direcciones siempre fijando las otras. Por lo general el tiempo es la variable que queda fija mientras se cubre la malla espacial alternando las coordenadas espaciales. En la figura 30.4 se muestra esta estrategia de cálculo para los primeros tres pasos de integración, en donde el tiempo se mantiene constante, es decir explícito, mientras que en el espacio puede ser implícito-implícito o bién implícito explícito. En problemas bidimensionales este esquema es el más práctico y fácil de aplicar, siempre y cuando se conozca el valor de la función a integar en todos los límites espaciales.

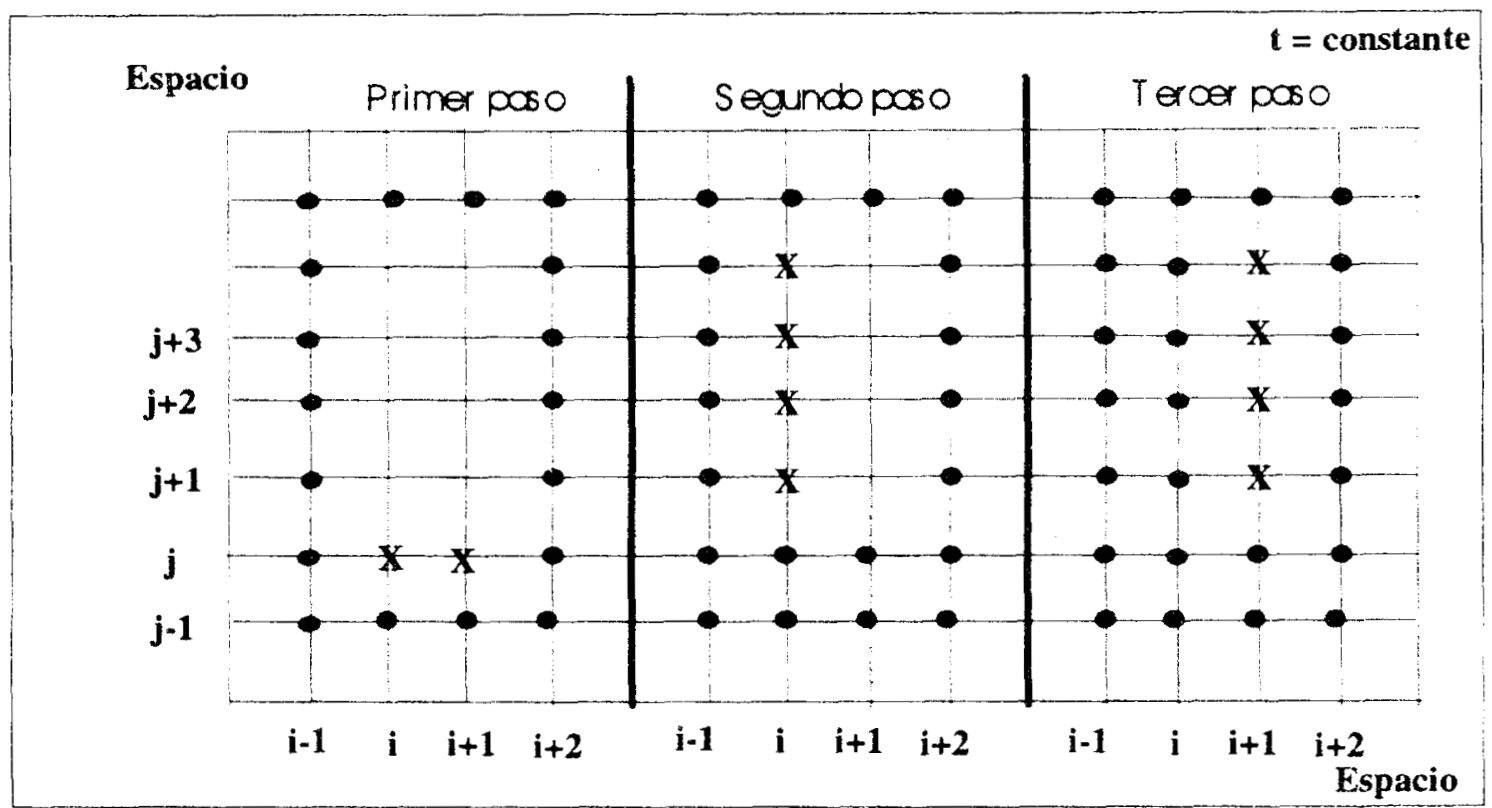

Figura 30.4 Estrategia de cálculo para el caso de las direcciones alternas: las tres etapas iniciales del cálculo numérico. Los círculos cerrados representan los datos conocidos y la cruces las incógnitas

Para la solución del problema que plantea el modelo matemático general con el método de diferencias finitas, se propone la malla de trabajo que se muestra en la figura 30.5 , en donde el plano $\mathrm{r}-\mathrm{z}$ adimensional se muestra discretizado en elementos cuadrados o rectangulares generando los nodos a los que se aproximarán las diferentes derivadas parciales. En la figura se observa la dirección de integración que se propone para cada coordenada espacial. 


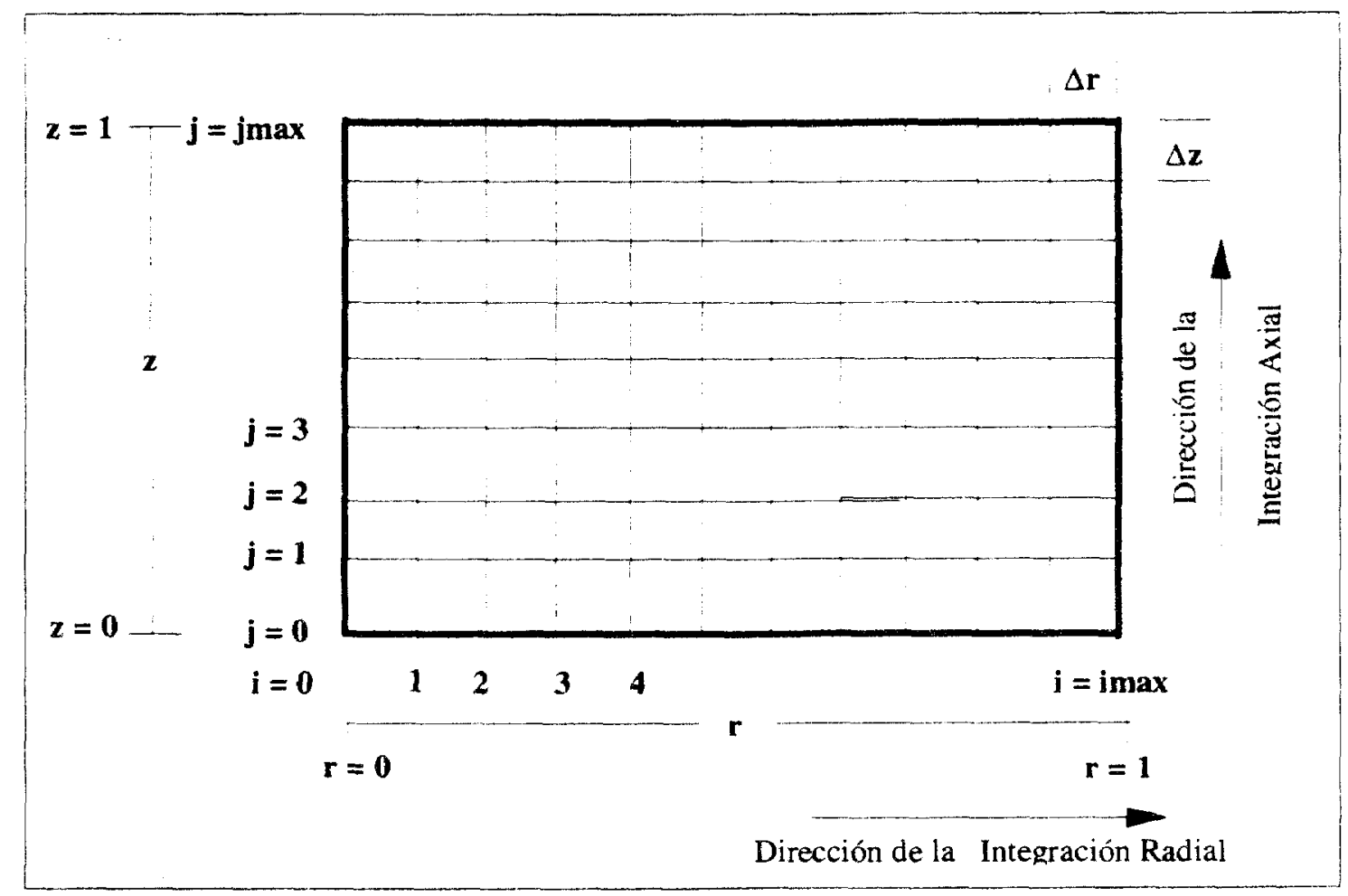

Figura 30.5. Discretización del dominio de integración para el plano r-z del problema cilíndrico del modelo general.

En lo subsecuente se sigue la convención de indices que se detalla a continuación:

1. Los índices $\mathrm{i}, \mathrm{j}, \mathrm{n}$ están siempre asociados a las coordenadas adimensionales $r, z, t$ y $\operatorname{los}$ incrementos $\Delta \boldsymbol{r}, \Delta \boldsymbol{z}, \Delta t$ mediante:

$$
\begin{array}{lllll}
r=\mathrm{i} \Delta \boldsymbol{r} & \text { en el límite: } & \text { si } & \mathrm{r}=\mathrm{Ra} \text { entonces } & r=\mathrm{imax} \Delta r \\
z=\mathrm{j} \Delta z & \text { en el límite: } & \text { si } & \mathrm{z}=\mathrm{L} \text { entonces } & z=\mathrm{jmax} \Delta z \\
t=\mathrm{n} \Delta t & \text { en el límite: } & \text { si } & \mathrm{t}=\mathrm{tf} \text { entonces } & t=\mathrm{nmax} \Delta t
\end{array}
$$

2. La función $\boldsymbol{T}$ (por ejemplo) evaluada en el punto $(\mathrm{i}, \mathrm{j}$ ) al tiempo n queda representada por:

$$
\boldsymbol{T}(\mathrm{i}, \mathrm{j}, \mathrm{n})
$$

3. La derivada parcial con respecto al tiempo, evaluada en el mismo punto $(\mathrm{i}, \mathrm{j})$ al tiempo $\mathrm{n}$ queda representada por:

$$
\left.\frac{\partial T}{\partial t}\right|_{i, j, n}
$$


4. Los índices espaciales $i, j$ adquieren valores que van desde 0 hasta imax y jmax respectivamente (ver figura 30.5 ). El índice $n$ asociado al tiempo solo adquiere los valores 0 y 1 , que se refieren al tiempo precedente y al tiempo de cálculo respectivamente

El esquema de cálculo numérico que se selecciona es el siguiente:

$$
\begin{aligned}
& \text { Explícito en el tiempo } \\
& \text { Explícito en el espacio axial } \\
& \text { Implícito en el espacio radial }
\end{aligned}
$$

En el capítulo siguiente se detalla la estrategia de solución que se propone.

\$31. Solución del modelo por el método de diferencias finitas.

La solución del modelo supone una estrategia especialmente diseñada para el caso, ésta comprende la discretización de las ecuaciones diferenciales, la discretización del modelo asi como de las condiciones iniciales y frontera y, finalmente supone también un conjunto de programas que ejecuten con precisión y rapidez la estrategia de la solución y la lógica secuencial que esto implica. A continuación se presenta, de manera muy simple la lógica global con que se aborda el problema, aplicando el método de diferencias finitas.

\subsection{Estrategia de la solución.}

La estrategia de solución que se ha seleccionado para resolver el problema se puede resumir en las siguientes etapas:

1. Definición de los valores para todas las variables de estado al inicio del proceso: $n=0$ y para el límite espacial de la base del biorreactor: $\mathrm{j}=0$.

2. Las variables independientes se hacen explícitas para el tiempo de cálculo $n=1$.

3. Para $\mathrm{j}=1$, se calculan los valores de la función con derivadas en $\mathrm{r}$ sobre la misma ordenada radial, desde $\mathrm{i}=0$ hasta $\mathrm{i}=$ imax, en donde para cada paso de integración $\Delta r$ se escribe una ecuación algebráica $y$, el conjunto de ecuaciones hasta imax, permite encontrar las incógnitas que se muestran con una cruz en la figura 30.3, utilizando el algorítmo de GaussSeidel.

4. Sin cambiar el valor del tiempo, $j$ aumenta hasta $j+1$ en donde se vuelven a calcular implicitamente las imax-2 incógnitas radiales en el "nivel" $\mathrm{j}+1$. 
5. El paso 4 se repite hasta cubrir los jmax "niveles" de la malla de integración que equivale a alcanzar la parte superior del biorreactor cilíndrico que se pretende simular. Los resultados se almacenan sucesivamente en la matriz del tiempo de cálculo con el índice $\mathrm{n}=\mathrm{I} \forall$ i y $\forall \mathrm{j}$.

6. La matriz de resultados con índice $n=1$ se fija como el nuevo valor inicial y se le asigna el índice $n=0$ para regresar al paso 2 y repetir la secuencia completa.

7. Los cálculos se detienen cuando el tiempo de fermentación alcanzó el valor tf preestablecido.

La aplicación de la estrategia que se detalla en este subcapítulo parte de la base de que se dispone del conjunto de ecuaciones que constituyen el modelo en su forma discreta. En los subcapítulos que siguen se desarrollan estos conceptos.

\subsection{Discretización de las derivadas parciales.}

Para una función adimensional cualquiera $\rho$ evaluada en el nodo $(\mathrm{i}, \mathrm{j}, \mathrm{n})$, asociado al punto de integración $(\boldsymbol{r}, \boldsymbol{z}, \boldsymbol{t})$, las derivadas parciales se pueden aproximar utilizando cocientes de diferentes finitas, según la malla de trabajo y los esquemas de integración seleccionados y discutidas antes, como sigue:

Para la primera derivada con respecto al tiempo, se selecciona la expresión de diferencia hacia atrás, dada por la ecuación (30-6), es decir:

$$
\left.\frac{\partial \rho}{\partial t}\right|_{i, j, n}=\frac{\rho(i, j, n)-\rho(i, j, n-1)}{\Delta t}
$$

Para la primera derivada con respecto a la coordenada axial, se selecciona la expresión explícita de diferencia hacia atrás, dada por la ecuación (30-6), es decir:

$$
\left.\frac{\partial \rho}{\partial z}\right|_{i, j, n}=\frac{\rho(i, j, n)-\rho(i, j-1, n)}{\Delta z}
$$

Para la primera derivada con respecto a la coordenada radial, se selecciona la expresión implícita de la diferencia central, definida por (30-3) y ahora dada por:

$$
\left.\frac{\partial \rho}{\partial r}\right|_{i, j, n}=\frac{\rho(i+1, j, n)-\rho(i-1, j, n)}{2 \Delta r}
$$

Para la segunda derivada con respecto a la coordenada radial, según (30-8), queda como:

$$
\left.\frac{\partial^{2} p}{\partial r^{2}}\right|_{i, j, n}=\frac{\rho(i+1, j, n)-2 \rho(i, j, n)+\rho(i-1, j, n)}{\Delta r^{2}}
$$


31.3 Discretización del modelo.

Fase biológica. Sustituyendo (31-1) en la ecuación (29-4), se obtiene la siguiente expresión:

$$
\frac{\rho_{x}(i, j, n)-\rho_{x}(i, j, n-1)}{\Delta t}=\frac{t_{f}}{\rho_{x M a x}} C_{x}
$$

La ecuación (31-5) se puede escribir de manera explícita en el tiempo:

$$
\rho_{x}(i, j, n)=\rho_{x}(i, j, n-1)+\frac{t_{f} \Delta t}{\rho_{x \operatorname{Max}}} C_{x}
$$

Fase líquida. Para los azúcares, sustituyendo (31-1) en la ecuación (29-5) y pasando a la forma discretizada, se obtiene la siguiente expresión:

$$
\rho_{s}(\mathrm{i}, \mathrm{j}, \mathrm{n})=\rho_{s}(\mathrm{i}, \mathrm{j}, \mathrm{n}-1)-\frac{\mathrm{t}_{\mathrm{f}} \Delta t}{\rho_{\mathrm{s}}{ }^{0}} \mathrm{C}_{\mathrm{s}}
$$

Para el agua, sustituyendo $(31-1)$ en $(29-6)$ y procediendo de manera análoga que con la fase biológica, se obtiene:

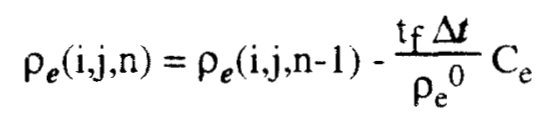

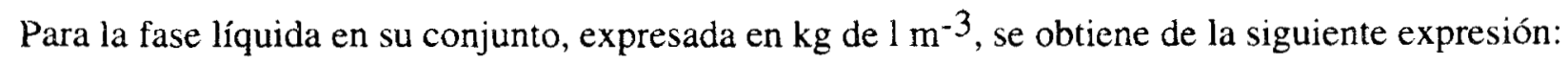

$$
\rho_{l}(i, j, n)=\rho_{s}^{0} \rho_{s}(i, j, n)+\rho_{e}^{0} \rho_{e}(i, j, n)
$$

El conjunto de las fases sólida, biológica y líquida o fase estática, expresada en $\mathrm{kg} \mathrm{m}^{-3}$, se obtiene de la siguiente forma:

$$
\rho_{p s}(i, j, n)=\rho_{a}^{0} \rho_{a}+\rho_{x M a x} \rho_{x}(i, j, n)+\rho_{l}(i, j, n)
$$

Fase gaseosa. Para el oxígeno, a partir de la ecuación (29-9) y las ecuaciones (31-1) y (31-2), se obtiene la siguiente expresión:

$$
\frac{\rho_{0}(\mathrm{i}, \mathrm{j}, \mathrm{n})-\rho_{0}(\mathrm{i}, \mathrm{j}, \mathrm{n}-1)}{\Delta t}=-\left(\frac{\mathrm{tf} \mathrm{v}_{\mathrm{g}}}{\mathrm{L}}\right) \frac{\rho_{0}(\mathrm{i}, \mathrm{j}, \mathrm{n})-\rho_{0}(\mathrm{i}, \mathrm{j}-1, \mathrm{n})}{\Delta z}-\left(\frac{\mathrm{tf}}{\rho_{\mathrm{o}}{ }^{0}}\right) \mathrm{C}_{\mathrm{o}}
$$


Como se puede observar, en la ecuación (31-11) se tiene una sola incógnita $\rho_{o}(\mathrm{i}, \mathrm{j}, \mathrm{n})$, ya que el término $\rho_{o}(i, j-1, n)$ que corresponde a la masa de oxígeno en $z$ precedente se conoce siempre, por lo tanto, para el oxígeno la expresión explícita en el tiempo y explícita en la coordenada axial se obtiene resolviendo (31-11) para la única incógnita, es decir:

$\rho_{o}(\mathrm{i}, \mathrm{j}, \mathrm{n})=\left(\frac{\Delta z}{\Delta z+\Delta t N_{g}}\right) \rho_{o}(\mathrm{i}, \mathrm{j}, \mathrm{n}-1)+\left(\frac{\Delta t N_{g}}{\Delta z+\Delta t N_{g}}\right) \rho_{o}(\mathrm{i}, \mathrm{j}-1, \mathrm{n})-\left(\frac{\Delta \Delta z}{\Delta z+\Delta t N_{g}}\right) \frac{t_{f}}{\rho_{0}^{0}} \mathrm{C}_{\mathrm{o}}$

donde:

$$
N_{g}=\left(\frac{\mathrm{tf} v_{g}}{\mathrm{~L}}\right)
$$

Para el bióxido de carbono, a partir de la ecuación (29-10) y las ecuaciones (31-1) y (31-2), procediendo de manera análoga que con el oxígeno, la expresión explícita en el tiempo y explícita en la coordenada axial es la siguiente:

$$
\rho_{c}(\mathrm{i}, \mathrm{j}, \mathrm{n})=\left(\frac{\Delta z}{\Delta z+\Delta t N_{g}}\right) \rho_{c}(\mathrm{i}, \mathrm{j}, \mathrm{n}-1)+\left(\frac{\Delta t N_{g}}{\Delta z+\Delta t N_{g}}\right) \rho_{c}(\mathrm{i}, \mathrm{j}-1, \mathrm{n})-\left(\frac{\Delta t \Delta z}{\Delta z+\Delta t N_{g}}\right)^{\wedge} \frac{\mathrm{t}_{f}}{\rho_{c M a x}} \mathrm{C}_{\mathrm{c}}
$$

La fase gaseosa $\rho_{\mathrm{g}}(\mathrm{i}, \mathrm{j}, \mathrm{n})$, expresada en $\mathrm{kg} \mathrm{m}^{-3}$, se obtiene a partir de (29-11) y de las ecuaciones $(31-12)$ a la (31-14) de donde se obtiene:

$$
\rho_{g}(i, j, n)=\rho_{N}^{0} \rho_{N}+\rho_{v}^{0} \rho_{v}(i, j, n)+\rho_{o}^{0} \rho_{o}(i, j, n)+\rho_{c M a x} \rho_{c}(i, j, n)
$$

El conjunto global de las fases $p_{i}(i, j, n)$, expresado en $\mathrm{kg} \mathrm{m}^{-3}$ se obtiene con las ecuaciones $(31-10)$ y (31-15):

$$
\rho_{i}(i, j, n)=\rho_{p s}(i, j, n)+\rho_{g}(i, j, n)
$$

Temperatura. A partir de la ecuación de balance de calor, ecuación (29-13) y sustituyendo las ecuaciones (31-1) a la (31-4), se obtiene la siguiente expresión:

$$
\begin{aligned}
\frac{T(\mathrm{i}, \mathrm{j}, \mathrm{n})-T(\mathrm{i}, \mathrm{j}, \mathrm{n}-1)}{\Delta t} & =-N_{a x i}\left(\frac{T(\mathrm{i}, \mathrm{j}, \mathrm{n})-T(\mathrm{i}, \mathrm{j}-1, \mathrm{n})}{\Delta z}\right) \\
& -N_{\text {rad }}\left(\frac{1}{r(\mathrm{i})}\left(\frac{T(\mathrm{i}+1, \mathrm{j}, \mathrm{n})-T(\mathrm{i}-1, \mathrm{j}, \mathrm{n})}{2 \Delta r}\right)+\left(\frac{T(\mathrm{i}+1, \mathrm{j}, \mathrm{n})-2 T(\mathrm{i}, \mathrm{j}, \mathrm{n})+T(\mathrm{i}-1, \mathrm{j}, \mathrm{n})}{\Delta \boldsymbol{r}^{2}}\right)\right) \\
& -N_{\text {rea }}
\end{aligned}
$$


Donde los grupos adimensionales $N_{a x i}, N_{\text {rad }}$ y $N_{\text {rea }}$, definidos con las ecuaciones (29-14) a la (2916), se calculan siempre en el tiempo precedente, es decir, en lo subsecuente y solo para facilitar la escritura de las ecuaciones, los coeficientes escritos como $N_{a x i}, N_{\text {rad }}$ y $N_{\text {rea }}$ son equivalentes a $N_{a x i}(\mathrm{i}, \mathrm{j}, \mathrm{n}-1), N_{\text {rad }}(\mathrm{i}, \mathrm{j}, \mathrm{n}-1)$ y $\boldsymbol{N}_{\text {rea }}(\mathrm{i}, \mathrm{j}, \mathrm{n}-1)$.

Como se puede apreciar, en la ecuación (31-17) aparecen tres incógnitas: $\boldsymbol{T}(\mathrm{i}-1, \mathrm{j}, \mathrm{n}), \boldsymbol{T}(\mathrm{i}, \mathrm{j}, \mathrm{n})$ y $\boldsymbol{T}(\mathrm{i}+1, \mathrm{j}, \mathrm{n})$ todos los demás términos son conocidos. Para calcular las temperaturas de manera implícita a lo largo del radio adimensional del biorreactor, es decir para todos los valores de $\mathrm{i}$ ( $\mathrm{i}=$ $0,1,2,3, \ldots$.imax) asociados al dominio $0 \leq r \leq 1$, la discretización produce un sistema de imax +1 ecuaciones con imax +1 incógnitas. Para resolver un sistema de ecuaciones como el que se genera con la ecuación (31-17), es necesario recurrir a métodos numéricos matriciales. Entre los métodos matriciales útiles para abordar el problema, en este trabajo se selecciona el método de Gauss-Seidel. Para la aplicación de este método se requiere de las definiciones que se presentan a continuación:

1. Sea $\alpha$ la matriz de los coeficientes de la ecuación (31-17), de dimensión imax; $I$ el vector de incógnitas y $\boldsymbol{C}$ el vector de términos conocidos y constantes, ambos también de dimensión $\operatorname{imax}$.

2. La ecuación matricial con la que se resuelve la ecuación (31-17) esta dada por:

$$
\alpha I=C
$$

3. La ecuación (31-18) también se puede escribir de la forma siguiente:

$$
\left(\begin{array}{c}
\alpha(0,0) \alpha(0,1) \\
\alpha(\mathrm{i}, \mathrm{i}-1) \alpha(\mathrm{i}, \mathrm{i}) \alpha(\mathrm{i}, \mathrm{i}+1) \\
\alpha(\text { imax,imax-1) } \alpha(\text { imax,imax })
\end{array}\right)\left(\begin{array}{c}
I(0) \\
I(\mathrm{i}) \\
I(\mathrm{imax})
\end{array}\right)=\left(\begin{array}{c}
C(0) \\
C(\mathrm{i}) \\
\\
\\
\\
\\
\\
\end{array}\right)
$$

Con la ecuación matricial precedente se pretende que al incorporar el vector transpuesto de términos constantes a la matriz tridiagonal de coeficientes y al invertir la nueva matriz aumentada, el vector resultante sea el correspondiente vector de resultados para un valor de j y un valor de tiempo. 
Para poder aplicar la ecuación (31-18) a la ecuación (31-17), es necesario encontrar cada uno de los términos utilizando la ecuación de balance de calor (31-17); primero para los puntos interiores del dominio y luego para las condiciones frontera.

31.4 Discretización de los puntos interiores de integración.

Para un punto interior del dominio de integración $\mathrm{i} \perp \mathrm{i}=1,2,3, \ldots$ imax-1, los coeficientes $\alpha(\mathrm{i}, \mathrm{i})$ se obtienen agrupando, del lado izquierdo, las tres incógnitas $T(\mathrm{i}-1, \mathrm{j}, \mathrm{n}), \boldsymbol{T}(\mathrm{i}, \mathrm{j}, \mathrm{n})$ y $\boldsymbol{T}(\mathrm{i}+1, \mathrm{j}, \mathrm{n})$ de la ecuación (31-17) y dejando del lado derecho los términos constantes correspondientes a $C$ (i), de la manera siguiente:

$$
\begin{aligned}
& \left(\frac{\Delta t}{\Delta r^{2}} N_{\text {rad }}-\frac{\Delta t N_{\text {rad }}}{\Delta r 2 r(\mathrm{i})}\right) T(\mathrm{i}-1, \mathrm{j}, \mathrm{n}) \\
& +\left(1+\frac{\Delta t}{\Delta z} N_{a x i}-\frac{2 \Delta t}{\Delta r^{2}} N_{r a d}\right) T(\mathrm{i}, \mathrm{j}, \mathrm{n}) \\
& +\left(\frac{\Delta t}{\Delta r^{2}} N_{r a d}+\frac{\Delta t N_{\text {rad }}}{\Delta r 2 r(\mathrm{i})}\right) T(\mathrm{i}+1, \mathrm{j}, \mathrm{n})=T(\mathrm{i}, \mathrm{j}, \mathrm{n}-1)+\frac{\Delta t}{\Delta z} N_{a x i} T(\mathrm{i}, \mathrm{j}-1, \mathrm{n})-\Delta N_{r e a}
\end{aligned}
$$

Las ecuaciones $(31-18)$ y $(31-19)$ implican que para $i=1,2,3, \ldots$, imax -1 :

(i) Para la matriz de coeficientes:

$$
\begin{aligned}
& \alpha(\mathrm{i}, \mathrm{i}-1)=\left(\frac{\Delta t}{\Delta \mathrm{r}^{2}} N_{\text {rad }}-\frac{\Delta t N_{\text {rad }}}{\Delta r 2 r(\mathrm{i})}\right) \\
& \alpha(\mathrm{i}, \mathrm{i})=\left(1+\frac{\Delta t}{\Delta z} N_{a x i}-\frac{2 \Delta t}{\Delta r^{2}} N_{r a d}\right) \\
& \alpha(\mathrm{i}, \mathrm{i}+1) \quad=\left(\frac{\Delta t}{\Delta r^{2}} N_{r a d}+\frac{\Delta N_{\text {rad }}}{\Delta r 2 r(\mathrm{i})}\right)
\end{aligned}
$$

(ii) Para el vector de términos constantes:

$$
C(\mathrm{i})=T(\mathrm{i}, \mathrm{j}, \mathrm{n}-1)+\frac{\Delta t}{\Delta z} N_{a x i} T(\mathrm{i}, \mathrm{j}-1, \mathrm{n})-\Delta t N_{r e a}
$$

Como se puede observar el primer renglón de la matriz, correspondiente al punto $\mathrm{i}=0$ y el último de la misma, para el punto imax, no se pueden obtener solo con la ecuación (31-17). Para 
encontrar estos elementos de la matriz y del vector de incógnitas, es necesario discretizar las condiciones en los límites.

31.5 Discretización de las condiciones en la frontera.

En el punto $i=0$.

Para la discretización para el punto $i=0$, debe recordarse que la condición establecida originalmente es que la derivada de la temperatura con respecto al radio es cero, esto conduce a suponer un máximo en este punto y a considerar que existe una cierta simetría en los perfiles radiales de temperatura. Estas dos consideraciones se aplican en este subcapítulo.

Antes de comenzar con la discretización en el punto en que $r$ se hace cero, para evitar una indeterminación en la expresión:

$$
\frac{1}{r} \frac{\partial T}{\partial r}+\frac{\partial^{2} T}{\partial r^{2}}
$$

que proviene de la ecuación (29-13), Smith (1985) propone que se puede aproximar, por series de MacLaurin, al doble de la segunda derivada, es decir que:

$$
\frac{1}{r} \frac{\partial T}{\partial r}+\frac{\partial^{2} T}{\partial r^{2}} \approx 2 \frac{\partial^{2} T}{\partial r^{2}}
$$

Por lo tanto, para $\mathrm{i}=0$ se puede sustituir (31-20) en la ecuación de calor original (29-13) obteniéndose la expresión siguiente:

$$
\frac{\partial T}{\partial t}=-N_{a x i}\left(\frac{\partial T}{\partial z}\right)-2 N_{r a d} \frac{\partial^{2} T}{\partial r^{2}}-N_{r e a}
$$

Sustituyendo las ecuaciones (31-1), (31-2) y (31-4) en (31-21), se obtiene la siguiente expresión que es válida solo para el punto en el que i es igual a cero, es decir en el centro radial del biorreactor:

$$
\begin{aligned}
\frac{T(0, \mathrm{j}, \mathrm{n})-T(0, \mathrm{j}, \mathrm{n}-1)}{\Delta t} & =-N_{a x i}\left(\frac{T(0, \mathrm{j}, \mathrm{n})-T(0, \mathrm{j}-1, \mathrm{n})}{\Delta z}\right) \\
& -2 N_{\text {rad }}\left(\frac{T(1, \mathrm{j}, \mathrm{n})-2 T(0, \mathrm{j}, \mathrm{n})+T(-1, \mathrm{j}, \mathrm{n})}{\Delta r^{2}}\right) \\
& -N_{\text {rea }}
\end{aligned}
$$


Si se considera que la temperatura en el punto $i=-1$ es igual a la temperatura del punto $i=1$, por simple simetria, entonces la ecuación (31-22) tiene dos incógnitas: $\boldsymbol{T}(0, \mathrm{j}, \mathrm{n})$ y $\boldsymbol{T}(1, \mathrm{j}, \mathrm{n})$, por lo tanto agrupando términos semejantes se obtiene:

$$
\begin{aligned}
& \left(1+\frac{\Delta t}{\Delta z} N_{a x i}-\frac{4 \Delta t}{\Delta r^{2}} N_{r a d}\right) T(0, \mathrm{j}, \mathrm{n}) \\
& +\left(\frac{4 \Delta t}{\Delta r^{2}} N_{r a d}\right) T(1, \mathrm{j}, \mathrm{n})=T(0, \mathrm{j}, \mathrm{n}-1)+\frac{\Delta t}{\Delta z} N_{a x i} T(0, \mathrm{j}-1, \mathrm{n})-\Delta t N_{r e a}
\end{aligned}
$$

Las ecuaciones $(31-22)$ y $(31-23)$ implican que, exclusivamente en el punto $i=0$ :

(i) Para la matriz de coeficientes:

$$
\begin{aligned}
& \alpha(0,0)=\left(1+\frac{\Delta t}{\Delta z} N_{\text {axi }}-\frac{4 \Delta t}{\Delta r^{2}} N_{\text {rad }}\right) \\
& \alpha(0,1)=\left(\frac{4 \Delta t}{\Delta r^{2}} N_{\text {rad }}\right)
\end{aligned}
$$

(ii) Para el vector de términos constantes:

$$
C(0)=T(0, \mathrm{j}, \mathrm{n}-1)+\frac{\Delta t}{\Delta z} N_{a x i} T(0, \mathrm{j}-1, \mathrm{n})-\Delta N_{r e a}
$$

En el punto $\mathrm{i}=\mathrm{imax}$.

Tomando en cuenta que las temperaturas en el punto $r=1$, correspondientes a $i=$ imax, son conocidas, se aproximan a la temperatura de la chaqueta, a lo largo de toda la coordenada axial y para todo tiempo, sustituyendo el índice imax por el índice i en la ecuación (31-17), se obtiene:

$$
\begin{gathered}
\frac{T(\mathrm{imax}, \mathrm{j}, \mathrm{n})-T(\mathrm{imax}, \mathrm{j}, \mathrm{n}-1)}{\Delta t}=-N_{a x i}\left(\frac{T(\mathrm{imax}, \mathrm{j}, \mathrm{n})-T(\mathrm{imax}, \mathrm{j}-1, \mathrm{n})}{\Delta z}\right) \\
-N_{\text {rad }}\left(\frac{1}{r(\mathrm{imax})}\left(\frac{T(\mathrm{imax}+1, \mathrm{j}, \mathrm{n})-T(\mathrm{imax}-1, \mathrm{j}, \mathrm{n})}{2 \Delta r}\right)+\left(\frac{T(\mathrm{imax}+1, \mathrm{j}, \mathrm{n})-2 T(\mathrm{imax}, \mathrm{j}, \mathrm{n})+T(\mathrm{imax}-1, \mathrm{j}, \mathrm{n})}{\Delta \mathbf{r}^{2}}\right)\right) \\
-N_{\text {rea }}
\end{gathered}
$$


en donde la temperatura evaluada en el punto ficticio imax +1 ( el punto es ficticio por que se sitúa fuera de la malla de trabajo), se puede aproximar al valor de la temperatura en el punto imax y ambas: $\boldsymbol{T}(\mathrm{imax}, \mathrm{j}, \mathrm{n})$ y $\boldsymbol{T}(\mathrm{imax}+1, \mathrm{j}, \mathrm{n})$ a la temperatura de la chaqueta que, en este caso, es siempre constante. Por otro lado el punto r(imax), corresponde al radio del biorreactor Ra. Con estas consideraciones y agrupando los términos semejantes a uno y otro lado de la igualdad, se puede observar que (31-24) contiene una sola incógnita: $\boldsymbol{T}(\mathrm{imax}-1, \mathrm{j}, \mathrm{n})$, resolviendo para la incógnita se obtiene:

$$
T(\operatorname{imax}-1, \mathrm{j}, \mathrm{n})=\left(\frac{N_{\text {rea }}}{\frac{N_{\text {rad }}}{2 \operatorname{Ra} \Delta r}-\frac{N_{\text {rad }}}{\Delta r^{2}}}\right)
$$

Esta simplificación conduce a resolver el sistema de imax-2 ecuaciones, definidos arriba, y el último renglón de la matriz tridiagonal queda explícito con $T$ (imax,j,n) conocida $\forall$ j y $\forall \mathrm{n}$ y donde $\boldsymbol{T}($ imax-1,j,n) también queda explícita con la ecuación (31-25).

\section{§32. Programas de simulación.}

Para resolver el sistema de ecuaciones diferenciales parciales que se presentan en los capítulos anteriores, se utilizó el lenguaje Turbo-Pascal. El conjunto de programas esta constituido por un total de doce procedimientos o subprogramas y dos unidades de Turbo-Pascal que contienen la mayoría de los programas de presentación en pantalla y los formatos de almacenamiento en disco. En el Cuadro 32.1 se presenta una lista de los programas y unidades y una breve descripción de la función de cada uno.

El proceso de cálculo se inicia con la declaración de constantes, tipos, procedimientos y las variables principales. En la Figura 32.1 se muestra un diagrama de la lógica seguida con el procedimiento CALCUL2.PAS. Como se puede apreciar, la secuencia es equivalente a la reseñada en el capítulo $\$ 31$ (ver 31.1). El programa continúa con la lectura de los valores de los parámetros, presenta una lista de los parámetros para dar la opción de modificarlos o aceptarlos. El programa abre un archivo para cada variable de estado en donde almacenará la información producida, presentando en la pantalla, a medida que calcula. Los cálculos de las variables en su forma explícita se realizan con el programa CALCUL2.PAS en dos bucles: el primero cubriendo la dirección radial, calculando siempre con el apoyo de los valores conocidos de z y del tiempo precedentes; el segundo calcula cubriendo la dirección axial. Al finalizar el primer bucle se dispone de la información suficiente como para calcular las temperaturas que se utilizarán en la 
siguiente "capa" axial, estos cálculos se realizan con el algoritmo de Gauss-Seidel. Al finalizar el segundo bucle se realiza un cambio de índice en las matrices calculadas y las nuevas matrices cumplen la función equivalente a las nuevas condiciones iniciales, para continuar con el método recursivo (ver figura 32.1, segunda parte). El tiempo evoluciona solo después de que se cierra el segundo bucle o bucle axial.

\section{CUADRO 32.1 LISTA Y DESCRIPCIÓN DE LOS PROGRAMAS UTILIZADOS EN LA SOLUCIÓN DEL MODELO GENERAL EN SU FORMA BIDIMENSIONAL}

\begin{tabular}{|c|l|}
\hline PROGRAMA & \multicolumn{1}{|c|}{ DESCRIPCIÓN } \\
\hline PRINCIPAL.PAS & $\begin{array}{l}\text { Define constantes, tipos, variables y a los principales procedimientos } \\
\text { que se emplearán. }\end{array}$ \\
\hline LECTURA.PAS & Asigna valores a 53 variables. Lo invoca PRINCIPAL.PAS. \\
\hline VALIDA.PAS & $\begin{array}{l}\text { Calcula condiciones de operación y permite la modificación de } 27 \\
\text { variables previamente leídas, esto mediante la presentación de cinco } \\
\text { pantallas. Cada pantalla tiene la doble opción de modificar o aceptar } \\
\text { todos los valores. Al final recalcula conforme a las modificaciones } \\
\text { propuestas. Lo invoca PRINCIPAL.PAS. }\end{array}$ \\
\hline CALCUL1.PAS & $\begin{array}{l}\text { Define variables, arreglos vectoriales y matriciales propios del } \\
\text { procedimiento CALCUL2.PAS. Lo invoca PRINCIPAL.PAS }\end{array}$ \\
\hline CALCUL2.PAS & $\begin{array}{l}\text { Establece las reglas de impresión y almacenamiento de datos. A } \\
\text { partir de las condiciones iniciales y de frontera calcula las variables } \\
\text { en su forma explícita en toda la malla de trabajo. Construye las } \\
\text { matrices tridiagonales y los vectores de términos constantes. Invoca } \\
\text { a la mayoría de los procedimientos. Detecta la finalización del } \\
\text { proceso y detiene la simulación. Lo invoca PRINCIPAL.PAS. }\end{array}$ \\
\hline ABRE.PAS & $\begin{array}{l}\text { Calcula las condiciones iniciales y de frontera. Lo invoca } \\
\text { CALCUL2.PAS }\end{array}$ \\
\hline CONDINI.PAS & $\begin{array}{l}\text { Abre un archivo para cada una de las variables de estado. Imprime el } \\
\text { encabezado para cinco puntos radiales, cinco puntos axiales y el } \\
\text { tiempo, esto para cada variable. Lo invoca CALCUL2.PAS. }\end{array}$ \\
\hline &
\end{tabular}




\section{CUADRO 32.1 LISTA Y DESCRIPCIÓN DE LOS PROGRAMAS UTILIZADOS EN LA SOLUCIÓN DEL MODELO GENERAL EN SU FORMA BIDIMENSIONAL (CONTINUA)}

\begin{tabular}{|c|c|}
\hline PROGRAMA & DESCRIPCIÓN \\
\hline UAMI.TPU & $\begin{array}{l}\text { Unidad de Turbo-Pascal que contiene los procedimientos de } \\
\text { presentación en pantalla, detección de errores y variables globales. } \\
\text { Lo invocan PRINCIPAL.PAS y CALCUL2.PAS. }\end{array}$ \\
\hline ARCHIVA0.PAS & Imprime las condiciones iniciales. Lo invoca ABRE.PAS \\
\hline IMPREINI.PAS & $\begin{array}{l}\text { Imprime en la pantalla la misma información que los procedimientos } \\
\text { ABRE.PAS y ARCHIVA0.PAS. Lo invoca CALCUL2.PAS. }\end{array}$ \\
\hline MATRIX.TPU & $\begin{array}{l}\text { Unidad de Turbo-Pascal (Borland Inc.) que contiene los } \\
\text { procedimientos de inversión de matrices y el algoritmo de Gauss- } \\
\text { Seidel. La invoca CALCUL2.PAS }\end{array}$ \\
\hline A_PANTALLA.PAS & $\begin{array}{l}\text { Imprime en la pantalla la matriz de resultados, para cada variable, al } \\
\text { tiempo t. Lo invoca CALCUL2.PAS. }\end{array}$ \\
\hline A_DISCO.PAS & $\begin{array}{l}\text { Almacena en el archivo preparado por ABRE.PAS, la matriz de } \\
\text { resultados, para cada variable, al tiempo t.. Lo invoca } \\
\text { CALCUL2.PAS. }\end{array}$ \\
\hline ANALISIS.PAS & $\begin{array}{l}\text { Compara valores calculados y contiene los criterios para detener los } \\
\text { programas. Lo invoca CALCUL2.PAS }\end{array}$ \\
\hline
\end{tabular}

El programa tiene definidos tres contadores de cada ciclo completo de cálculo indican si la información debe almacenarse en disco, imprimir en pantalla o, en su caso, detener los programas. Al finalizar cada ciclo completo de cálculo, el programa ANALISIS.PAS realiza una comparación de resultados calculados; si encuentra valores inadecuados (i.e. temperaturas negativas o mayores a la máxima permitida; masa de azúcares u oxígeno negativos o absurdos), entonces fija un valor y/o detiene los programas. El procedimiento ANALISIS.PAS utiliza los siguientes criterios para detener los programas: a. azúcares agotados, b. oxígeno agotado y c. tiempo de fermentación concluido; en alguno de los dos primeros casos el crecimiento celular, para el punto espacial en 
cuestión, se hace cero, permitiendo que si los azucares o el oxígeno no se agotan en otros puntos, el crecimiento celular continúe.

En el ANEXO $V$ se presentan los listados de los programas más importantes para la solución del modelo general en dos dimensiones, los siguientes procedimientos se listan en el ANEXO V:

$\begin{array}{ll}\text { (i) } & \text { PRINCIPAL.PAS } \\ \text { (ii) } & \text { LECTURA.PAS } \\ \text { (iii) } & \text { CONDINI.PAS } \\ \text { (iii) } & \text { CALCUL1.PAS } \\ \text { (iv) } & \text { CALCUL2.PAS. }\end{array}$

En el citado ANEXO se incluyen las notas y aclaraciones pertinentes de cada caso. El conjunto de programas, escritos en Turbo-Pascal, simulan 40 horas de fermentación en aproximadamente 2.5 h de tiempo real en una computadora personal provista de un coprocesador 486 y 40 Megahertz. En el capítulo siguiente se muestran resultados correspondientes a simulaciones bajo diferentes condiciones de operación. 


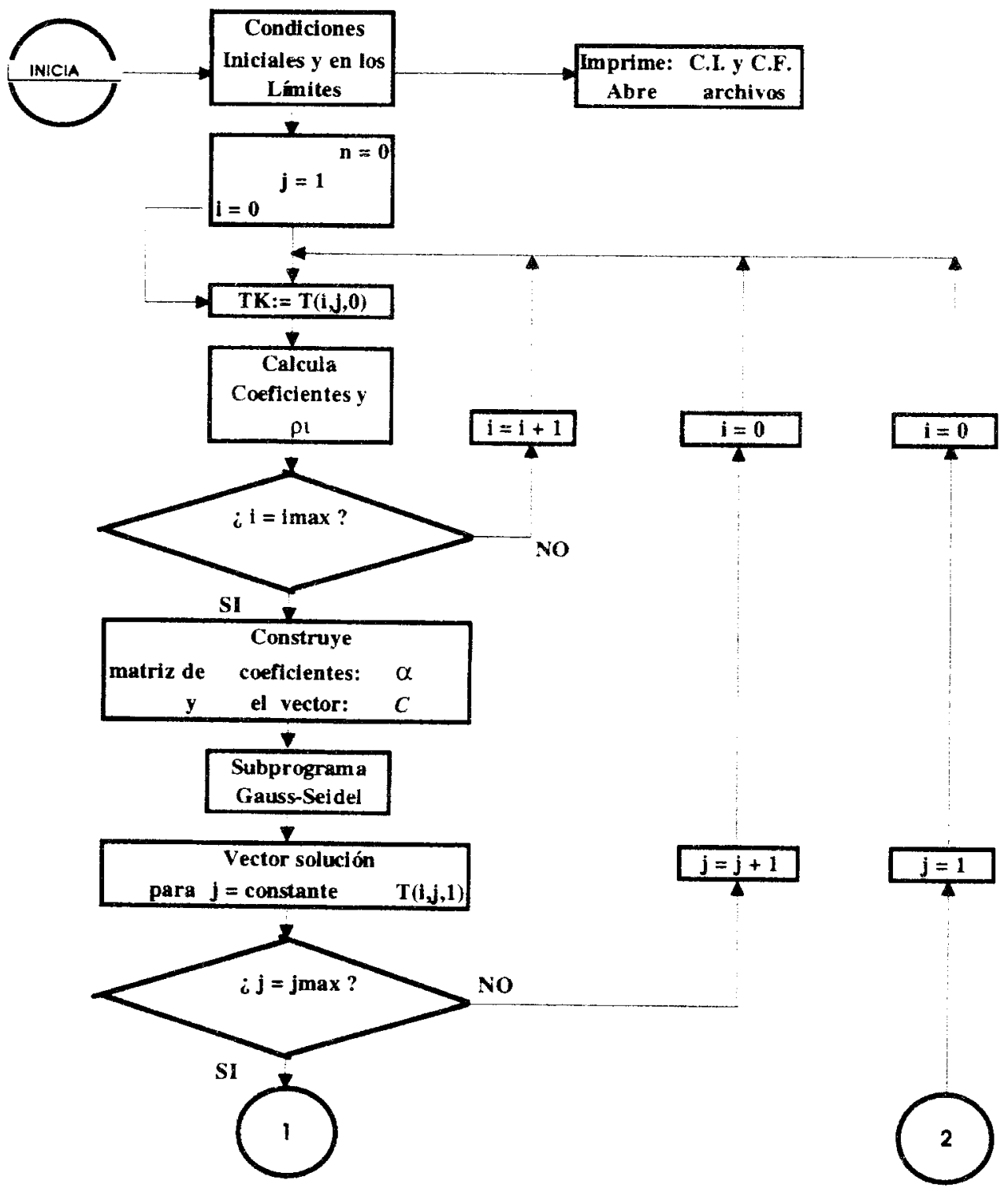

Figura 32.1 Lógica de cálculo del programa CALCUL2.PAS empleado para la solución del modelo general en su forma bidimensional. Diagrama de bloques, primera parte. 

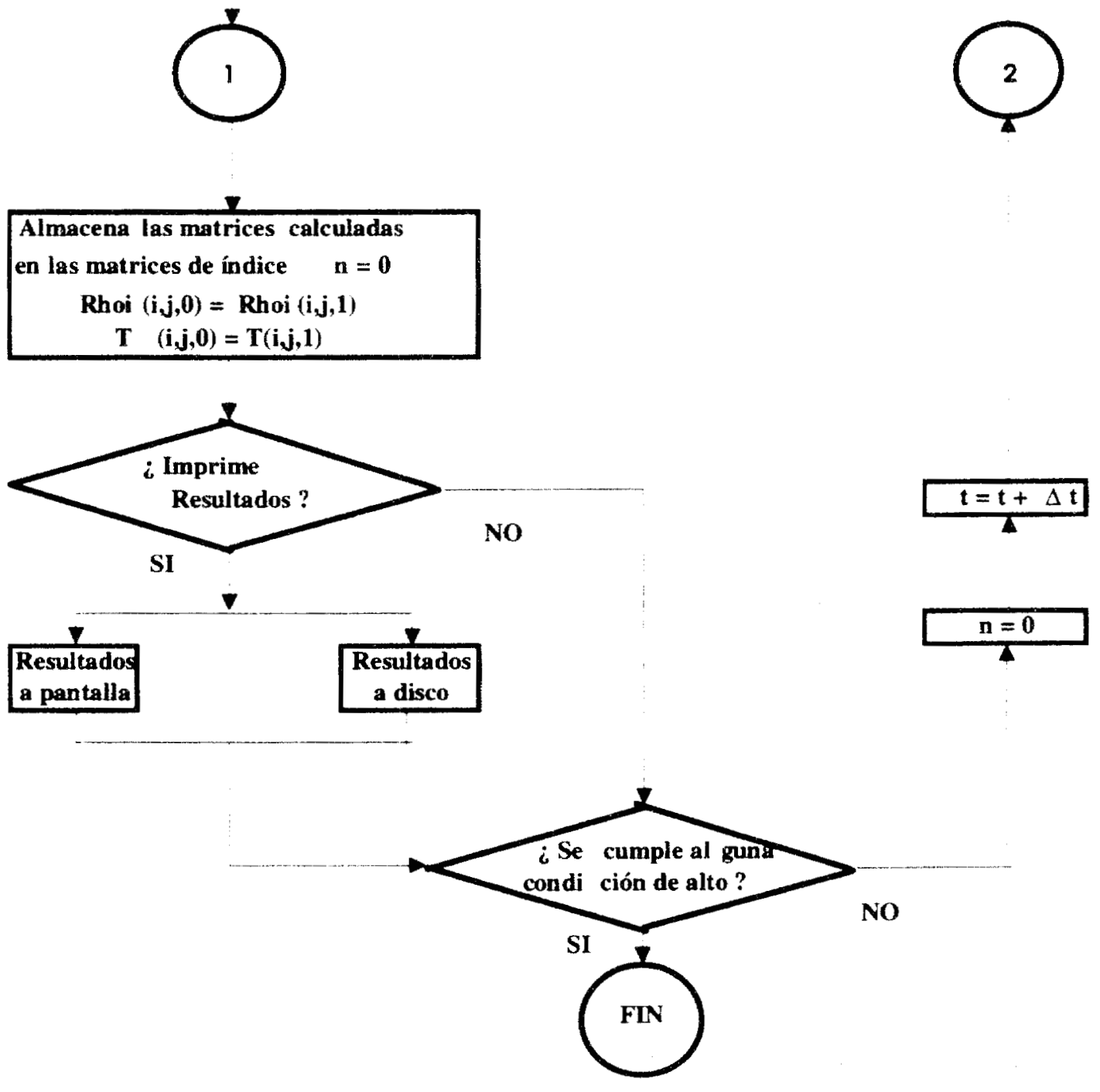

Figura 32.1 Lógica de cálculo del programa CALCUL2.PAS empleado para la solución del modelo general en su forma bidimensional. Diagrama de bloques, segunda parte. 


\section{Resumen y conclusiones.}

En esta parte, el modelo se conserva en su forma general, i.e. dependiente del tiempo y del espacio. Se propone una serie de condiciones iniciales y en la frontera $y$, para resolver el problema, se selecciona el método de integración de diferencias finitas. El model, en coordenadas cilíndricas, se normaliza y discretiza dentro de un dominio de integración bien definido. Para la integración se utiliza una estrategia explícta en el tiempo, explícita en en la coordenada axial e implícita en la coordenada radial.

Para la solución numérica se desarrolla un conjunto de programas de cálculo en donde se utilizan los mismos valores de los parámetros encontrados para el modelo simplificado y se proponen valores para los valores restantes. 


\section{B. VALIDACIÓN DEL MODELO GENERAL}

En esta parte del trabajo se simula la operación de un biorreactor de laboratorio de $0.25 \mathrm{~m}$ de altura y un radio de $0.1 \mathrm{~m}$. El modelo general se resuelve con el método de diferencias finitas en dos dimensiones con los programas que se describen en el §32. Las respuestas de la simulación se comparan con los resultados experimentales, obtenidos en columnas pequeñas de $1.8 \mathrm{~cm}$ de diámetro y $6.5 \mathrm{~cm}$ de altura de empaque, que se describen en el capítulo $\$ 27$, estudio del caso 3 , y con mayores detalles en una publicación reciente (Gutiérrez-Rojas, et al, 1995b). Los programas de cálculo se adaptan a las condiciones iniciales y de operación del caso citado y se incluyen los parámetros siguientes:

$$
\begin{aligned}
& \Delta \mathrm{t}=1.0 \mathrm{~s} \quad \text { Paso de integración en el tiempo } \\
& \text { imax }=5 \quad \text { Máximo de nodos radiales } \\
& \text { jmax }=20 \quad \text { Máximo de nodos axiales }
\end{aligned}
$$

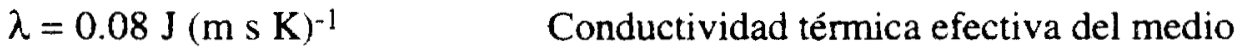

$$
\begin{aligned}
& \mathrm{v}_{\mathrm{g}}=0.015 \mathrm{~m} \mathrm{~s}^{-1} \quad \text { Velocidad de la fase gaseosa }
\end{aligned}
$$

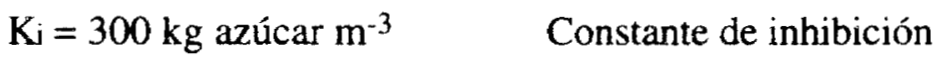

$$
\begin{aligned}
& \mathrm{K}_{\mathrm{s}}=3.0 \mathrm{~kg} \text { azúcar } \mathrm{m}^{-3} \quad \text { Constante de afinidad por sustrato } \\
& \mathrm{m}_{\mathrm{s}}=3.6 \mathrm{E}-06 \mathrm{~kg} \text { azúcar Coeficiente de mantenimiento } \\
& (\mathrm{kg} \text { biom } \mathrm{s})^{-1} \\
& \rho_{\mathrm{s}}{ }^{0}=55 \mathrm{~kg} \text { azúcar } \mathrm{m}^{-3} \quad \text { Azúcar inicial }
\end{aligned}
$$

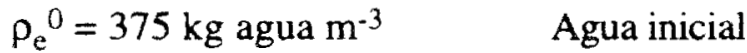

$$
\begin{aligned}
& \text { Tair, } \mathrm{T}_{\mathrm{j}}=30^{\circ} \mathrm{C} \quad \text { Temperatura del aire y de la chaqueta }
\end{aligned}
$$

Los valores de los parámetros que no se especifican, son los mismos del capítulo $\$ 20$, sección 20.3

\section{§33. Producción de biomasa.}

En la Figura 33.1 se presentan las cinéticas de producción de biomasa, para diferentes alturas del biorreactor: base, $0 \mathrm{~m}$; centro axial, $0.125 \mathrm{~m} \mathrm{y}$, parte alta $0.25 \mathrm{~m}$, los resultados se muestran para el centro, (Figura 33.1 a) y para la pared del biorreactor, (Figura 33.1 b). Como se ve, los valores numéricos de la simulación ajustan bien con los resultados experimentales. El modelo predice una producción de biomasa ligeramente mayor en la parte alta de la columna solamente en el centro 
del biorreactor, en las paredes no se aprecian diferencias. Esto se debe que la temperatura en la pared es constante e igual a la temperatura de la chaqueta, mientras que en el centro del biorreactor se encontraron las mayores fluctuaciones de temperatura que se reflejan en tasas de crecimiento variables.
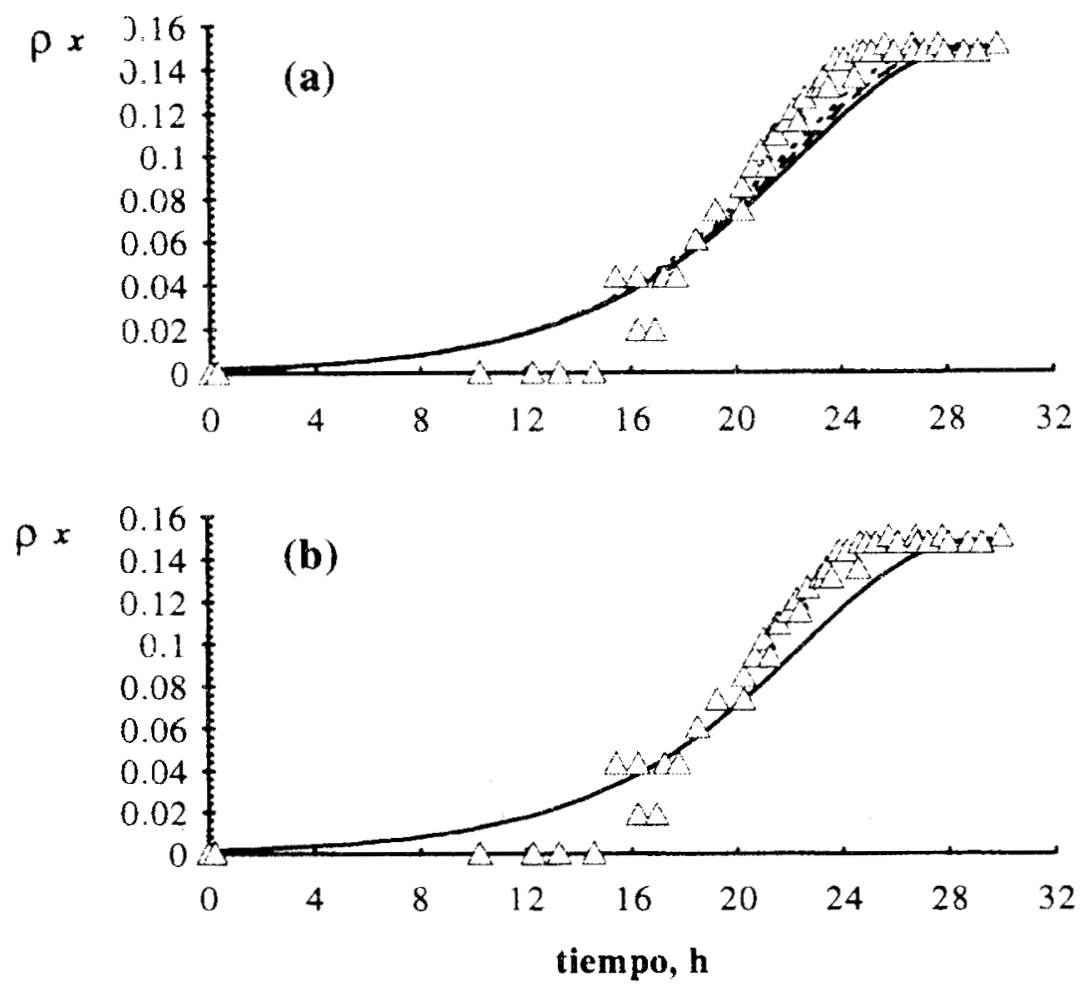

Figura 33.1. Comparación de resultados experimentales de producción de biomasa $(\Delta)$ con la simulación del modelo: (a) En el centro y (b) en las paredes, para diferentes alturas del biorreactor (-) $0 \mathrm{~m},(--) 0.125 \mathrm{~m} \mathrm{y},(\ldots \ldots) 0.25 \mathrm{~m}$.

\section{§34. Consumo de azúcares.}

En la Figura 34.1 se muestran las cinéticas de consumo de azúcares en los mismos puntos radiales y axiales que se discuten en el capítulo $\$ 33$. Como en el caso de la producción de biomasa, el modelo se ajusta bien a los resultados experimentales. También predice con una mayor claridad perfiles de consumo de azúcares en la dirección axial. 

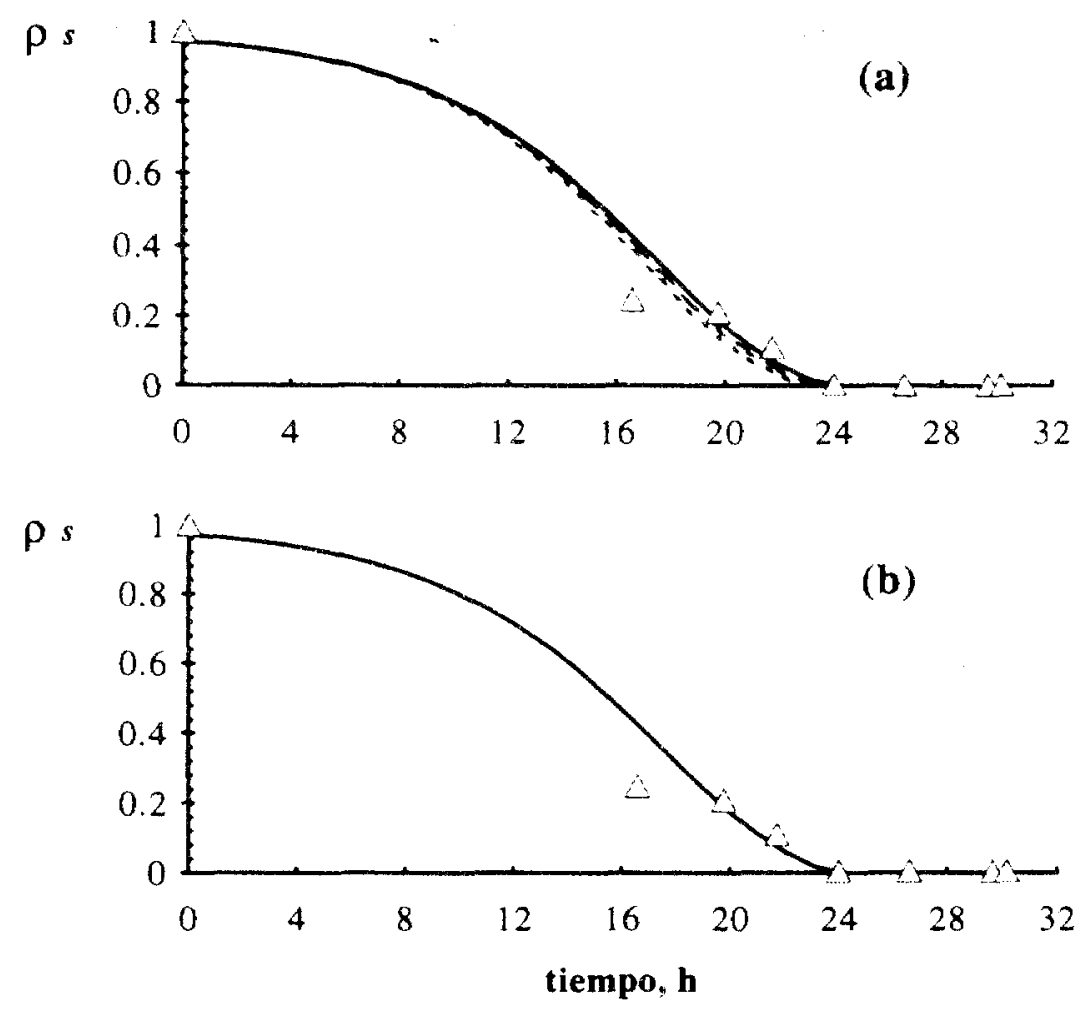

Figura 34.1. Comparación de resultados experimentales de consumo de azúcares $(\Delta)$ con la simulación del modelo: (a) En el centro y (b) en las paredes, para diferentes alturas del biorreactor (-) $0 \mathrm{~m},(--) 0.125 \mathrm{~m}, \mathrm{y}(-\ldots .) .0.25 \mathrm{~m}$.

En la zona en donde se observa un mayor consumo de la fuente de carbono es en la parte superior del biorreactor, también es donde se lleva a cabo un mejor crecimiento (ver Fig. 33.1 a).

Un ejemplo de las cifras exactas calculadas y las diferencias en los puntos radiales y axiales se puede ver en el Cuadro 34.1; en donde se presentan valores para la masa de azúcares $\left(\rho_{s}\right)$ a diferentes tiempos de fermentación en tres alturas: la base $(j=0)$, el centro $(j=10)$ y la parte más alta $(j=20)$ del biorreactor, así como dos puntos radiales: el centro $(i=0)$ y la pared $(i=5)$. En el Cuadro destacan dos resultados: (i) los azúcares primero se agotan en el centro y en la parte más alta del biorreactor y (ii) en la dirección axiạl, pero en la pared del biorreactor, las cifras calculadas para el consumo de azúcares son prácticamente las mismas. 


\section{CUADRO 34.1. CONSUMO DE AZÚCARES. RESULTADOS NUMÉ́RICOS DURANTE LA FERMENTACIÓN PARA DOS PUNTOS RADIALES Y TRES AXIALES.}

\begin{tabular}{|c|c|c|c|c|c|c|}
\hline Tiempo & & $\mathrm{i}=0$ & & & $\mathrm{i}=5$ & \\
\hline $\mathrm{h})$ & $\mathrm{j}=0$ & $\mathrm{j}=10$ & $\mathrm{j}=20$ & $\mathrm{j}=0$ & $\mathrm{j}=10$ & $\mathrm{j}=20$ \\
\hline 0 & 1 & 1 & 1 & 1 & 1 & 1 \\
\hline 1.1 & 0.97211 & 0.972029 & 0.971918 & 0.97211 & 0.97211 & 0.97211 \\
\hline 13.2 & 0.712533 & 0.705835 & 0.697181 & 0.712533 & 0.712533 & 0.712533 \\
\hline 19.8 & 0.265868 & 0.242226 & 0.217133 & 0.265868 & 0.265868 & 0.265868 \\
\hline 24.2 & 0.019482 & 0.008154 & 0 & 0.019482 & 0.019482 & 0.019482 \\
\hline 25.3 & 0 & 0 & 0 & 0 & 0 & 0 \\
\hline
\end{tabular}

NOTA: Los valores corresponden a $\rho_{s}$ y son adimensionales.

El mismo esquema que se observa para la producción de biomasa y para el consumo de azúcares, se repite para el consumo de agua y para la ocupación de los espacios vacíos, es decir las máximas diferencias calculadas, en el centro del biorreactor y para un mismo tiempo de fermentación, entre la base y la parte más alta no exceden un $2 \%$. De manera análoga, en las paredes del biorreactor el modelo produce prácticamente los mismos valores de consumo de agua y de espacios ocupados. Estos resultados son razonables en tanto que ambas variables dependen sólo de la biomasa producida.

\section{§35. Consumo de oxígeno.}

En este caso, las diferencias calculadas, en especial las axiales, son más claras que en los casos de producción de biomasa y consumo de azúcares. En la Figura 35.1 se muestran las cinéticas de la masa de oxígeno $\left(\rho_{o}\right)$ que se obtienen con el modelo. En la Figura 35.1 (a) se presentan los resultados en el centro, y en la Figura 35.1 (b) en las paredes, para diferentes alturas. Como se puede ver, en el centro del biorreactor las diferencias entre la parte baja y la parte alta son ligeramente mayores que en las paredes.

En el centro, el máximo gradiente de oxígeno entre la base y la parte alta, se presenta a las 24 horas de cultivo y equivale aproximadamente a una disminución de un dos porciento del total de oxígeno en la base del reactor, i.e. en $0.25 \mathrm{~m}$. Este valor es muy parecido al que obtiene SaucedoCastañeda, (1991) en una columna de $0.9 \mathrm{~m}$ empacada con bagazo de caña y con Schwanniomyces castelii, en donde en el punto axial de $0.3 \mathrm{~m}$, encuentra cerca de un $19 \%$ de oxígeno en la fase gaseosa, como el máximo gradiente en el punto experimental. 

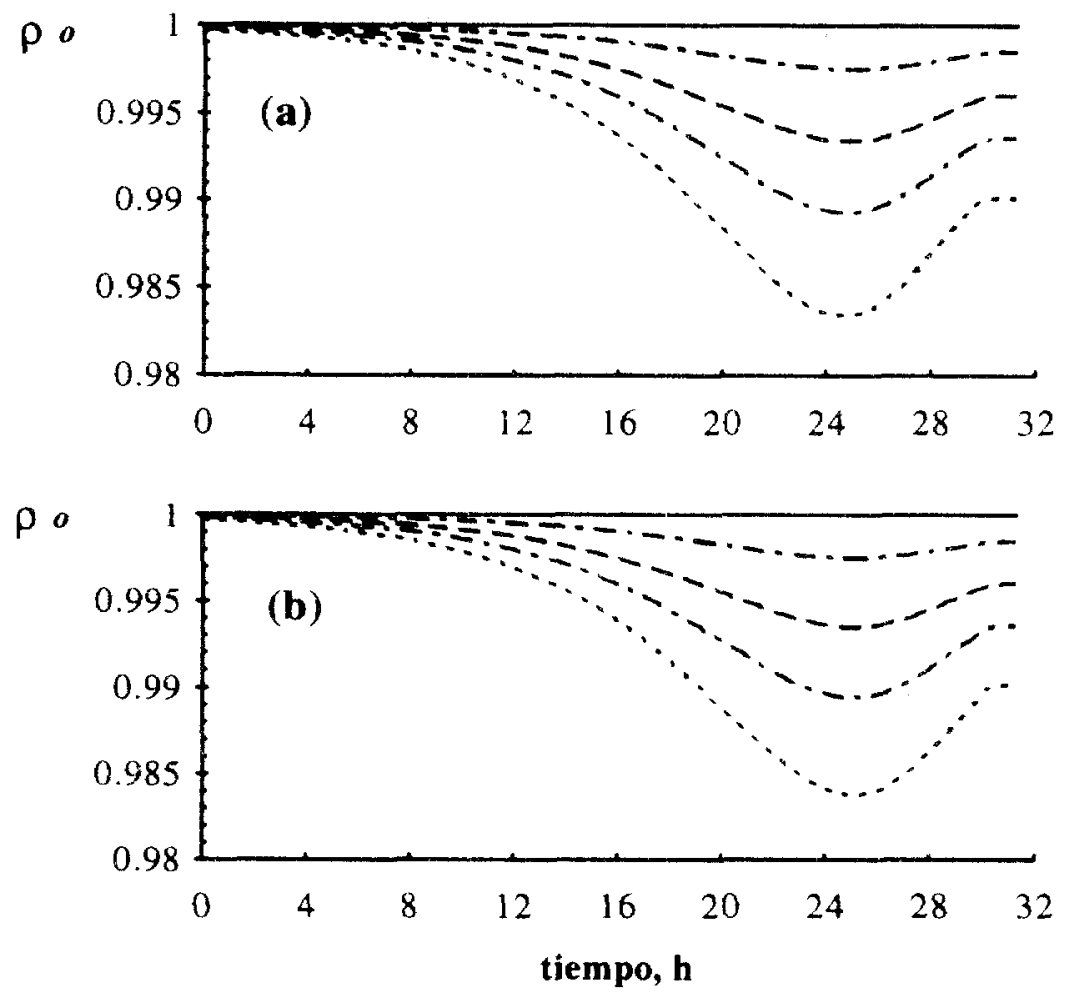

Figura 35.1. Resultados del modelo para el consumo de oxígeno: (a) En el centro y, (b) en la pared del biorreactor, para diferentes alturas: (-), $0 \mathrm{~m}$; (- - $-0.037 \mathrm{~m} ;(--)$, $0.125 \mathrm{~m} ;(-\cdots \rightarrow), 0.2125 \mathrm{~m}$ y $(-\cdots-\cdots), 0.25 \mathrm{~m}$.

Los perfiles de la Figura 35.1 indican que el consumo de oxígeno es mayor a medida que la coordenada axial progresa. Esto se debe a que en el biorreactor se presenta una mayor actividad microbiana en la parte alta que en la parte baja, como se demuestra en la Figura 35.2 donde se presentan las tasas de consumo de oxígeno $\left(\mathrm{C}_{\mathrm{o}}\right)$ calculadas con el modelo y comparadas con la cinética experimental del caso con que se valida el modelo. Como se puede apreciar las tasas de consumo de oxígeno son ligeramente mayores, también a medida que la coordenada axial progresa.

Si se comparan las Figuras 35.1 y 35.2 se observa que, mientras los mínimos de oxígeno se producen a las 25 horas de cultivo, las máximas tasas de consumo de oxígeno se manifiestan unas tres horas antes, coincidiendo con la mitad, aproximadamente, de la fase de crecimiento rápido o de máxima actividad microbiana. 


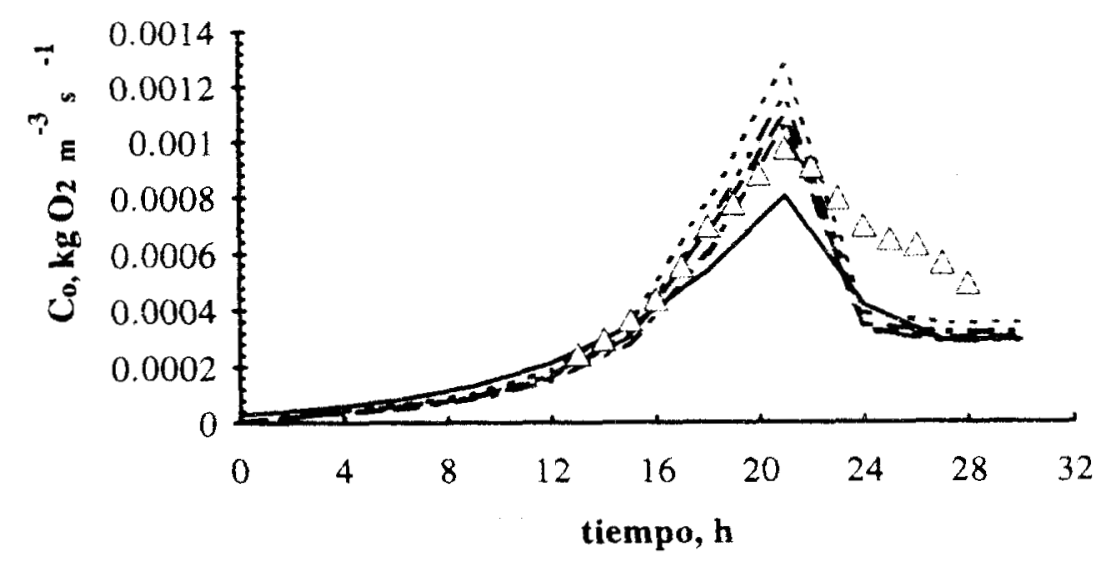

Figura 35.2. Comparación de las tasas de consumo de oxígeno experimentales $(\Delta)$ con las del modelo. Centro del biorreactor para diferentes alturas: (- - , $0 \mathrm{~m}$; (- - - $), 0.037 \mathrm{~m}$; $(--), 0.125 \mathrm{~m} ;(-\cdots-), 0.2125 \mathrm{~m}$ y $(--\cdots), 0.25 \mathrm{~m}$.

En la Figura 35.2 destacan dos aspectos importantes:

(i) El modelo ajusta con mucha precisión con los resultados experimentales durante la etapa de crecimiento, hasta la mitad de la fase de crecimiento rápido ( 22 horas de cultivo); durante el descenso de actividad microbiana, el modelo predice una rápida caída que no coincide con la caída de los resultados experimentales. En el laboratorio se detecta una actividad metabólica entre las 24 y las 30 horas, cuando los azúcares se agotaron y el crecimiento es cero, probablemente debido a la formación de productos que no considera el modelo.

(ii) El modelo predice una cinética de consumo de oxígeno en la base de la columna que difiere hasta en un $25 \%$ del promedio de los valores calculados en las otras predicciones en la dirección ascendente. La diferencia es notable ya que entre las predicciones, diferentes a la de la base, no existe más de un 5\% de diferencia entre ellas. Esta discrepancia puede deberse a que el método de solución impone siempre una condición, de tipo inicial, en la base que inclusive produce resultados que, graficados, son de forma diferente al resto.

En la Figura 35.3 se muestran las variaciones de la masa de oxígeno con respecto a la coordenada axial para a diferentes tiempos de fermentación y para un punto radial que corresponde al centro entre el centro del biorreactor y la pared del mismo. Para poder presentar más información en forma gráfica, en la elaboración de la Figura 35.3 se utilizaron 24 nodos en la coordenada axial y 8 en la coordenada radial, sin modificar la altura del biorreactor. Como se puede observar, los 
perfiles son prácticamente lineares a lo largo de la coordenada axial. Este comportamiento se debe a que en el modelo siempre se mantiene constante la velocidad de la fase gaseosa $\left(v_{g}\right)$.

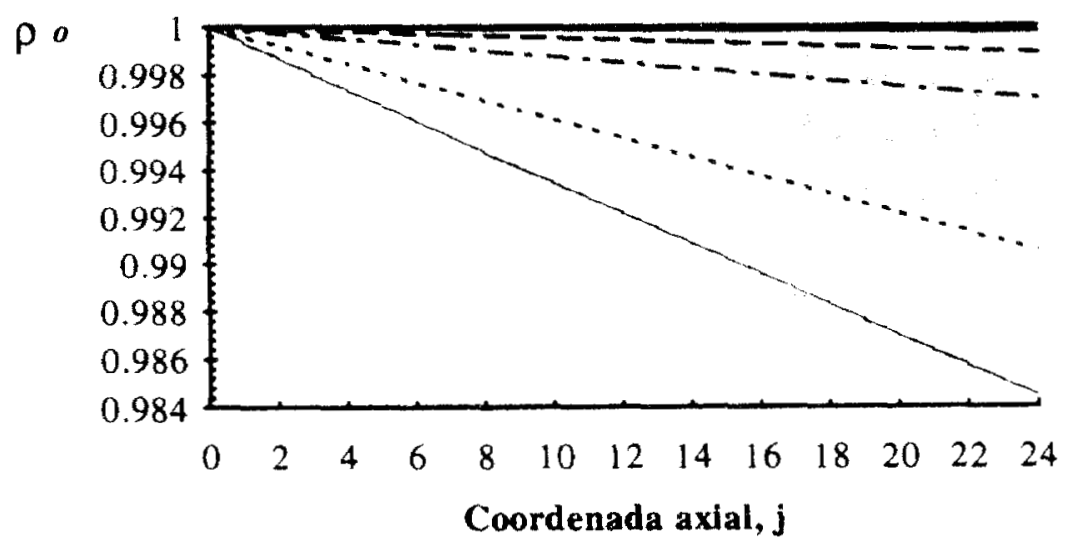

Figura 35.3 Perfiles axiales de la masa de oxígeno con respecto a la altura, en el punto radial $0.025 \mathrm{~m}$, a diferentes tiempos de cultivo: $(-) 0 \mathrm{~h}$; (-) $2.3 \mathrm{~h}$; (- $-6.2 \mathrm{~h}$;

$$
(-- \text { - } 11.5 \mathrm{~h} \text {; (-..-) } 17 \mathrm{~h} \mathrm{y}(\ldots \ldots) 25 \mathrm{~h} \text {. }
$$

La predicción de perfiles lineares teóricos es importante porque permite establecer criterios de control en tiempo real, tomando como principio e.g. el tratar de corregir cualquier desviación de un comportamiento linear respecto a la altura del biorreactor.

\$3 Producción de bióxido de carbono.

En la Figura 36.1 se muestran las cinéticas teóricas de la masa de bióxido de carbono $\left(\rho_{c}\right)$ que se produce en el biorreactor que se simula. En la Figura 36.1 (a) se presentan los resultados en el centro, y en la Figura 35.1 (b) en las paredes, para diferentes alturas. Como se puede apreciar la producción de bióxido de carbono presenta un comportamiento similar al del consumo de oxígeno. Comparando la Figura 35.1 con la Figura 36.1 se ve que ambos coinciden, uno como imagen especular del otro. Las dos cinéticas, también coinciden con la etapa de crecimiento rápido y consumo de azúcares (ver Fig. 33.1). 

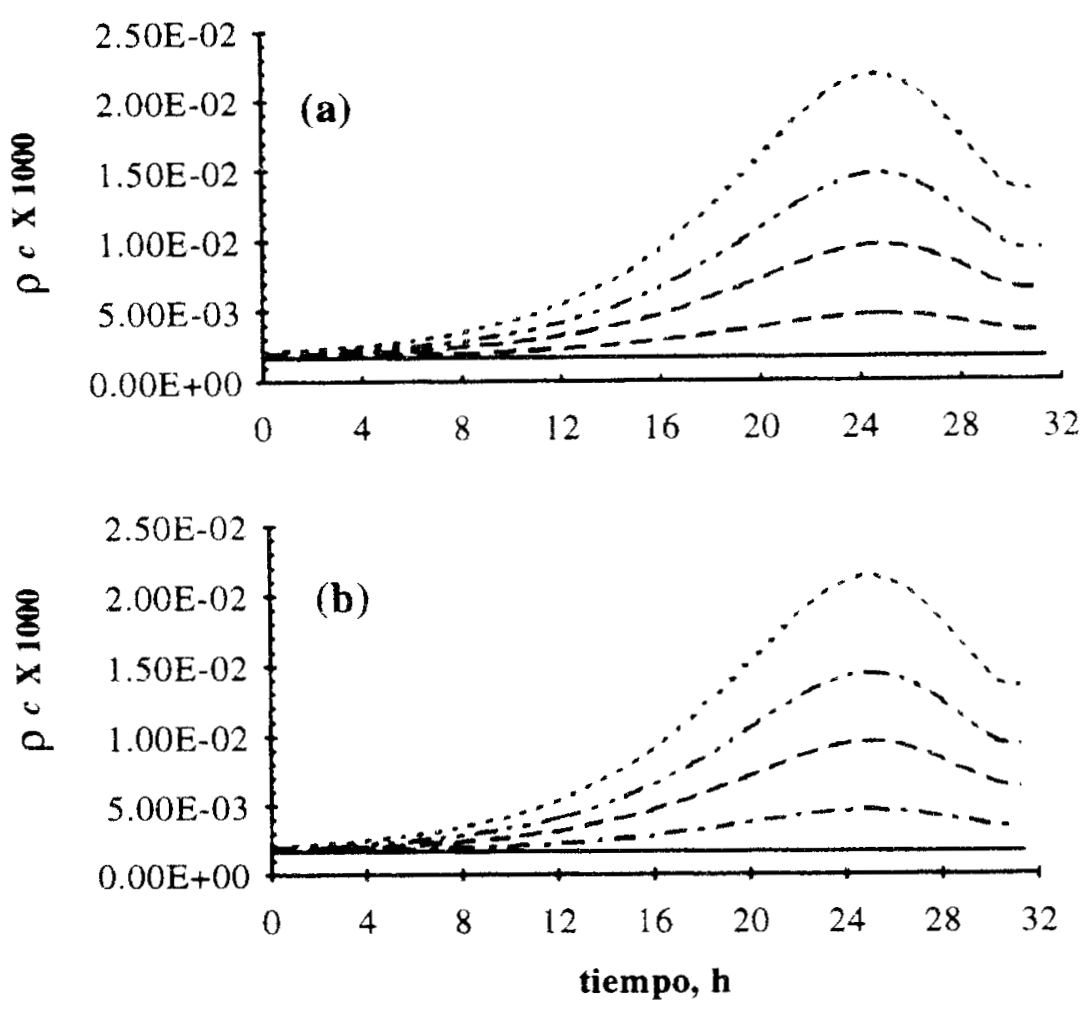

Figura 36.1. Resultados del modelo para producción de bióxido de carbono: (a) En el centro y, (b) en la pared del biorreactor, para diferentes alturas: (-), $0 \mathrm{~m}$; (- - - ), $0.037 \mathrm{~m} ;(-\longrightarrow), 0.125 \mathrm{~m}$; ( - - - $), 0.2125 \mathrm{~m} \mathrm{y}(--\cdots), 0.25 \mathrm{~m}$.

Los gradientes máximos de bióxido de carbono que predice el modelo, en el centro radial y a las 25 horas de cultivo (ver Fig. 36.1 a) para 0.037, 0.125, 0.215 y $0.25 \mathrm{~m}$ de altura, son mas o menos equivalentes, a 2, 4, 6 y 9 veces, respectivamente, la masa de bióxido de carbono que se alimenta en la corriente de aire. En un estudio reciente (Gowthaman, et al, 1993) en una columna de $34 \mathrm{~cm}$ de altura y $15 \mathrm{~cm}$ de diámetro, empacada con salvado de trigo inoculado con Aspergillus niger se encontró que para $0.033,0.08,0.17$ y $0.28 \mathrm{~m}$ de altura, la composición de la fase gaseosa, en el máximo de producción, se enriquecía en bióxido de carbono $2,2.5,5$ y 7 veces, respectivamente, la masa de bióxido de carbono que se alimenta en la corriente de aire. Como se aprecia, los resultados concuerdan bien con los simulados. Los resultados citados (Gowthaman, et al, 1993) corresponden a experimentos en donde la velocidad de la fase gaseosa fue de $0.014 \mathrm{~m} \mathrm{~s}^{-1}$. En estas simulaciones la velocidad de la fase gaseosa fue de $0.015 \mathrm{~m} \mathrm{~s}^{-1}$. 
En la Figura 36.2 se muestran las tasas de producción de bióxido de carbono $\left(\mathrm{C}_{\mathrm{c}}\right)$ calculadas con el modelo y comparadas con la cinética experimental del caso con que se valida el modelo. Como en el caso del consumo de oxígeno, a medida que la coordenada axial aumenta, aumenta la actividad metabólica. Como se puede ver el promedio de las predicciones axiales coinciden bien con los resultados experimentales, excepto durante el descenso de la actividad metabólica. La explicación de este desajuste aparente se discute en el capítulo $§ 35$.

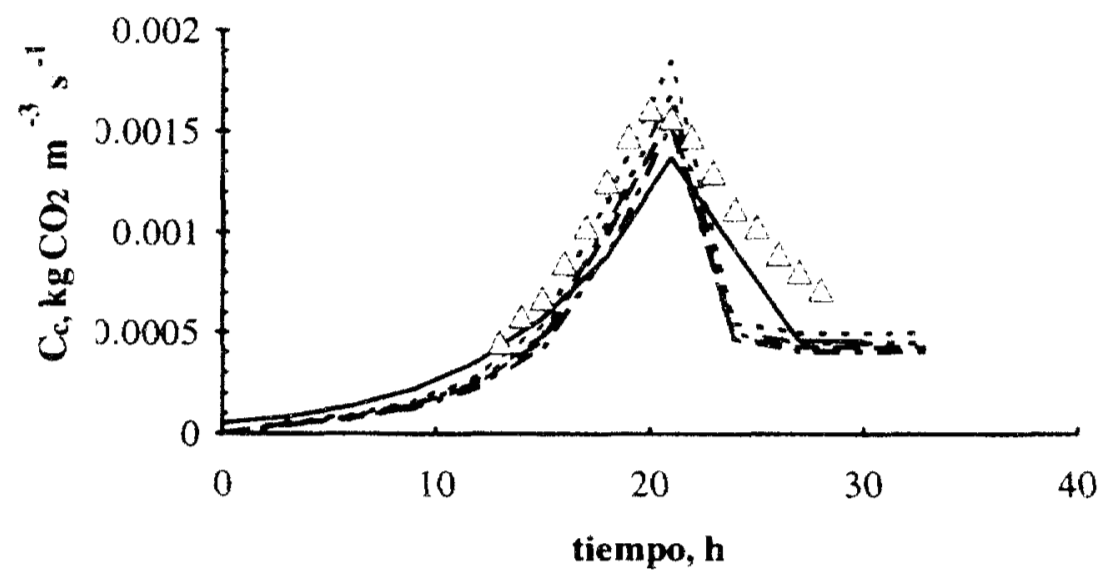

Figura 36.2. Comparación de las tasas de producción de bióxido de carbono experimentales $(\Delta)$ con el modelo. Centro del biorreactor para diferentes alturas: $(-) 0 \mathrm{~m}$; ( - $0.037 \mathrm{~m} ;(--), 0.125 \mathrm{~m}$; ( $-\ldots), 0.2125 \mathrm{~m}$ y $(-\cdots), 0.25 \mathrm{~m}$.

En los resultados del modelo que se muestran en las Figuras 35.2 y 36.2 se observa que cuando el crecimiento se detiene, por que los azúcares se agotaron, las tasas de consumo de oxígeno y de producción de bióxido de carbono no se hacen cero y se mantienen en un nivel final bajo, pero nunca cero. Esto se debe a que el programa no se detiene cuando los azúcares se agotan. El programa hace cero la masa de azúcares y, con esto, la tasa de crecimiento se hace siempre cero. Pero la tasa de consumo de oxígeno y la de producción de bióxido de carbono no sólo dependen de los azúcares sino que también dependen de un sumando que es función de la biomasa, este sumando es el mantenimiento. Como se aprecia el término del mantenimiento produce un efecto, durante la etapa de no crecimiento, que coincide bien con los resultados experimentales. 


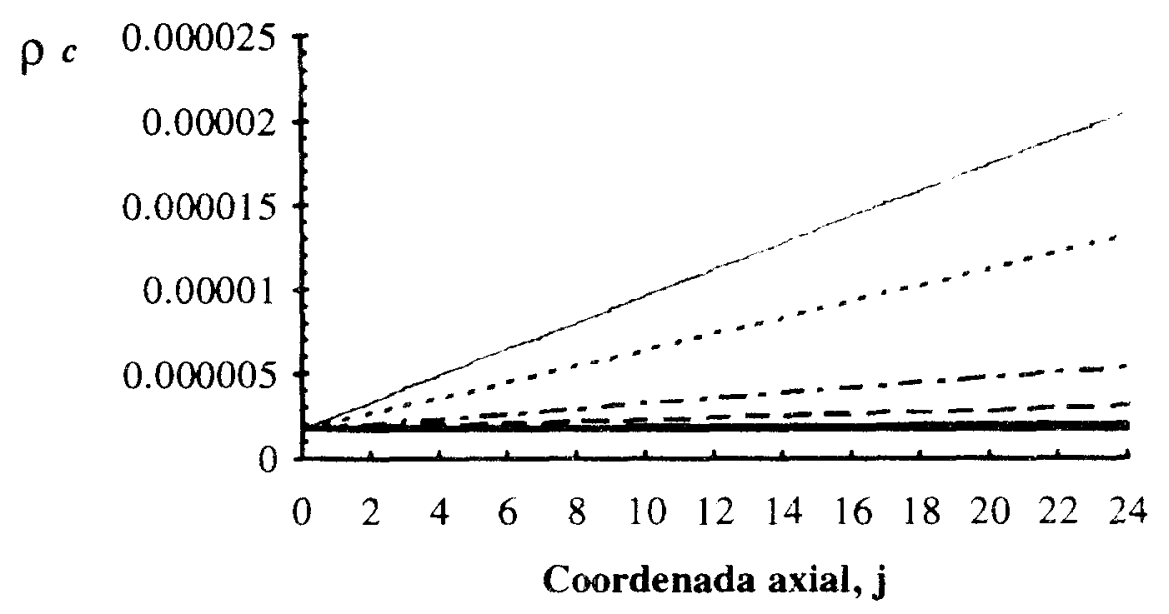

Figura 36.3 Figura 35.3 Perfiles axiales de la masa de bióxido de carbono, con respecto a la altura, en el punto radial $0.025 \mathrm{~m}$, a diferentes tiempos de cultivo: $(-) 0 \mathrm{~h}$; (-) $2.3 \mathrm{~h}$; ( — - $6.2 \mathrm{~h}$; ( - - $11.5 \mathrm{~h} ;(\ldots \ldots) 17 \mathrm{~h} \mathrm{y} \mathrm{(.....)} 25 \mathrm{~h}$.

En la Figura 36.3 se presentan las variaciones de la masa de bióxido de carbono en función de la coordenada axial, calculadas en las mismas condiciones que se describen para la Figura 35.3. Como en el caso del consumo de oxígeno, los perfiles de la producción de bióxido de carbono son también lineares. En el trabajo de Gowthaman et al, (1993), los autores presentan perfiles axiales de consumo de oxígeno y producción de bióxido de carbono que son prácticamente iguales a los de las Figuras 35.3 y 36.3 respectivamente. Con la diferencia de que, en el citado trabajo, utilizan un biorreactor más alto que el que se simula con el modelo y, para la máxima altura, observan una tendencia asintótica de la masa de oxígeno y la de bióxido de carbono con respecto a la abcisa. También observan que la tendencia linear de los perfiles se pierde a medida que disminuyen el gasto de aire.

Una de las ventajas más claras del modelo que se presenta, es que los valores de las variables de estado están expresados en unidades de masa por volumen de lecho empacado. Esto es importante, particularmente en el caso de los gases consumidos o producidos, por que la composición de la fase gaseosa puede variar por cualquiera de las razones siguientes: (i) un constituyente desaparece debido a una reacción, o bien (ii) se incorpora otro constituyente gaseoso y la proporción de los demás constituyentes disminuye. Como el segundo argumento no se aplica al caso del modelo que se valida, se considera que los resultados de las simulaciones para los constituyentes de la fase gaseosa que se discuten en este capítulo y en el $\$ 35$, se apegan bién a los resultados experimentales y a las bases teóricas con que se estructura el modelo. 
$\S 37$ Evolución de la temperatura.

En relación a la distribución de temperaturas en la columna empacada, en la Figura 37.1 se muestran las cinéticas, en el centro del biorreactor y en un punto radial intermedio entre el centro y la pared, a diferentes alturas. Como se observa la máxima diferencia de temperatura que se produce, con respecto a la temperatura de la chaqueta y del aire de entrada $\left(30^{\circ} \mathrm{C}\right)$, se localiza en el centro y es de $2.2^{\circ} \mathrm{C}$. La parte baja del biorreactor se mantiene siempre a la temperatura del aire de entrada y medida que la coordenada axial progresa la temperatura aumenta.
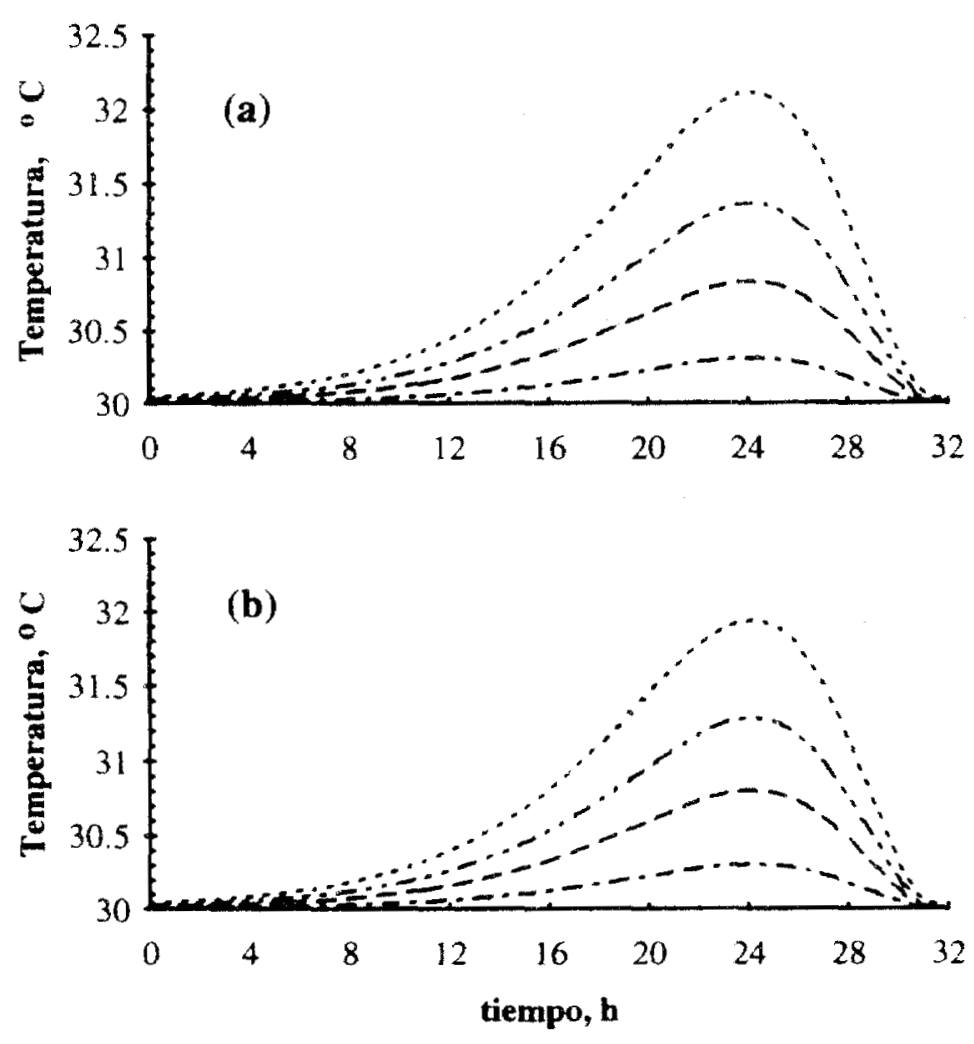

Figura 37.1 Cinéticas de la temperatura del lecho empacado: (a) Centro radial y (b) en el punto radial $0.025 \mathrm{~m}$ para diferentes alturas: $(-) 0 \mathrm{~m}$; $(--) 0.037 \mathrm{~m} ;(--),$, $\mathrm{m} ;(---), 0.2125 \mathrm{~m}$ y $(-\cdots-), 0.25 \mathrm{~m}$.

El máximo gradiente calculado, en el centro, entre la parte alta del biorreactor y la temperatura del aire fue de $0.088^{\circ} \mathrm{C} \mathrm{cm}^{-1}$ y el promedio de los gradientes calculados a las 24 horas de cultivo fue de $0.075^{\circ} \mathrm{C} \mathrm{cm}^{-1}$. La magnitud de los gradientes axiales que se obtienen con el modelo son de cerca de la mitad de los que se obtienen con yuca gelatinizada y A. niger (Saucedo-Castañeda et 
al, 1990) pero comparados a los encontrados (Palacios, 1992) con Amberlita y A. niger en una columna de $15 \mathrm{~cm}$ de altura, de $0.053{ }^{\circ} \mathrm{C} \mathrm{cm}^{-1}$ las predicciones del modelo son ligeramente mayores pero razonablemente aceptables.

Un resultado interesante de las simulaciones con el modelo es el que se muestra en la Figura 37.2, los perfiles de temperatura del lecho empacado con respecto a la coordenada axial. Como se puede ver la temperatura no muestra un comportamiento linear como en el caso de la distribución axial de los constituyentes de la fase gaseosa.
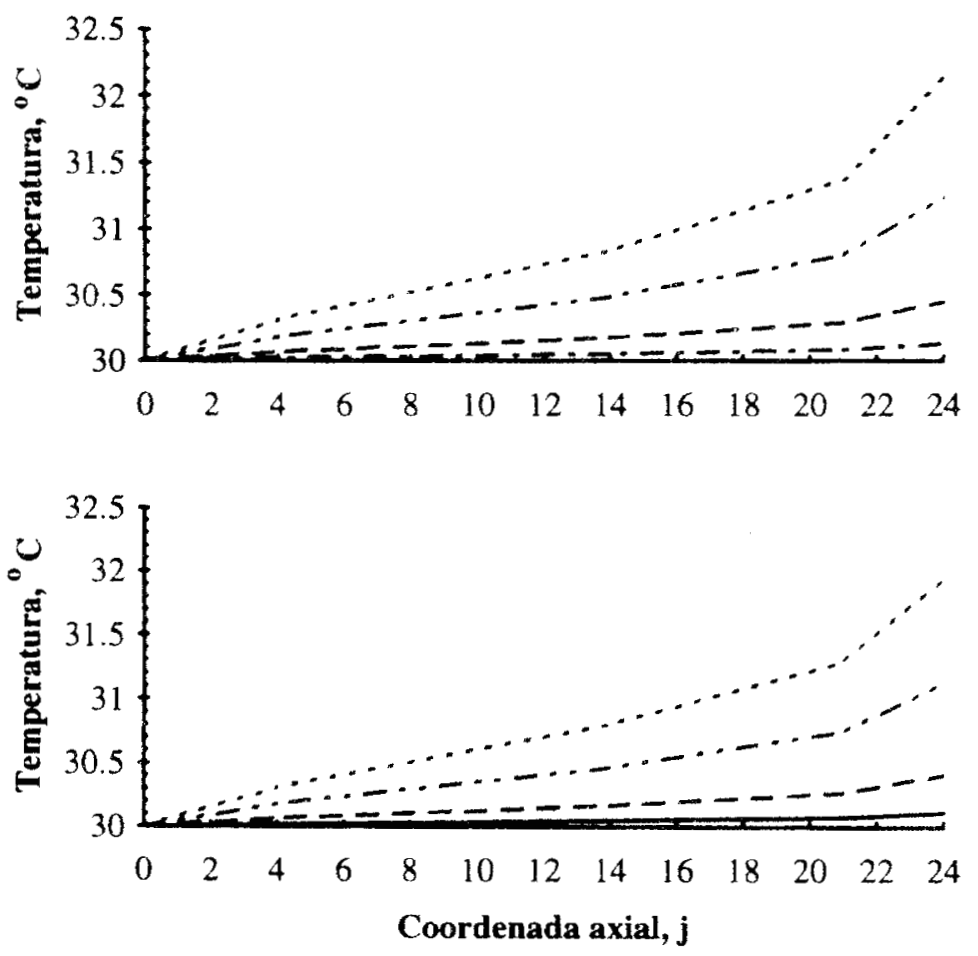

Figura 37.2. Distribución de temperaturas en la coordenada axial: (a) Centro radial y (b) en el punto radial $0.025 \mathrm{~m}$ para diferentes tiempos de cultivo: (-) $5.5 \mathrm{~h}$; (- - $13 \mathrm{~h}$; ( - - ) 18.5, (---) 24.5.

De acuerdo con las predicciones del modelo, la acumulación del calor metabólico en las zonas superiores del biorreactor que se simula es sensiblemente mayor que en la base, reflejandose en un cambio brusco de la temperatura a partir de una cierta altura, próxima al punto más alto.

La información experimental con columnas empacadas con Amberlita y A. niger (resultados no publicados obtenidos en nuestro laboratorio; Palacios, 1992) demuestra que los perfiles axiales no 
son del tipo linear pero discrepan de las predicciones del modelo en tanto que los máximos de temperatura se localizan en el centro radial y en el centro axial de las columnas.

Al comparar los perfiles axiales experimentales con los del modelo facilmente se puede concluir que las predicciones del modelo son más razonables en tanto que las mediciones experimentales de temperatura, con mucha frecuencia, se distorsionan por problemas de una mayor humedad, asociada a fenómenos de condensación, en la parte superior de las columnas, que producen temperaturas menores que las del centro axial.

Un aspecto importante es el que se refiere a la forma de las curvas de las temperaturas en la dirección radial. Durante la aplicación del método de diferencias finitas, particularmente en el proceso de búsqueda de los valores de los parámetros del método (número de nodos axiales, radiales y pasos de integración), uno de los problemas más persistentes que se encontró fue el de obtener respuestas inestables en la función $\boldsymbol{T}(\boldsymbol{r})$. Por esta razón no se muestran los perfiles de temperatura en la dirección radial.

La inestabilidad se presentó siempre, desde un principio, y a medida que el tiempo de fermentación transcurría la inestabilidad se acentuaba más, inclusive deteniendo el programa. de cálculo. El problema se logró evitar integrando la ecuación de calor desde el centro del biorreactor, $\mathrm{i}=0$, hasta el punto imax-2 y con la suposición de que la temperatura en el punto imax +1 (punto fuera de la malla de integración) se aproximaba a la temperatura de la pared ( $\mathrm{i}=$ imax) y a la temperatura de la chaqueta. Con estas suposiciones, la temperatura en imax-1 quedaba explícita (ver ecuación 31-25) y sólo en función de los coeficiente $N$ rea, Nrad y otras constantes. Desafortunadamente esto no fue suficiente, i.e. el problema de inestabilidad de la temperatura en las inmediaciones de la pared del biorreactor no se logró superar sino que se evitó menteniendo las temperaturas oscilantes dentro de los valores vecinos que se calculaban. Esto permitió que los programas corrieran adecuadamente y sin interferencias en los cálculos de las variables de estado en el resto de la malla de integración.

La solución del problema de inestabilidad numérica detectado en las inmediaciones de la pared queda como uno de los retos más interesantes a resolver en el futuro.

Resumen y conclusiones.

Se presenta una solución al modelo matemático general en la que se incluyen las variaciones de las variables de estado en la dirección de las coordenadas axial y radial. El modelo contiene prácticamente los mismos parámetros que el modelo simplificado que se desarrolla y discute en la 
parte III. Para los nuevos parámetros que surgen en el nuevo modelo, se proponen valores obtenidos con bases experimentales o calculados.

Se discuten y comparan los resultados del modelo con experimentales. Los resultados demuestran que el modelo general reproduce con mucha fidelidad los perfiles del modelo simplificado aportando nuevos elementos de discusión como las variaciones axiales de la temperatura y de los constituyentes de la fase gaseosa.

Los resultados producidos por el modelo general sugieren que, para la variaciones en la dirección radial, los cambios en la producción de biomasa y consumo de azúcares son apenas perceptibles, así como tampoco se aprecian cambios importantes en el caso del consumo de oxígeno o en la producción de bióxido de carbono. Por el contrario, los resultados del modelo sugieren marcados perfiles, de tipo linear, para el oxígeno y el bióxido de carbono a lo largo de la coordenada axial y marcados perfiles axiales no lineares en el caso de la temperatura. 



\section{CONCLUSIONES GENERALES}

1. La dependencia de los procesos metabólicos con los fenómenos de transporte de masa y de calor, es un tema de investigación que no se ha desarrollado de manera intensa y queda mucho por hacer. Es necesario desarrollar más estudios teóricos en una dimensión intermedia, que incluyan propiedades microscópicas sin olvidar la dimensión macroscópica de los biorreactores.

2. Los sistemas experimentales ideales, como el soporte inerte que se utiliza en este trabajo, facilita el estudio de sistemas heterogéneos complejos como es el caso de los cultivos en medios sólidos. La utilización de soportes inertes de forma regular son también un medio ideal para la elaboración de modelos matemáticos.

3. El modelo matemático general que se propone permite simplificaciones a cualquier nivel de complejidad.

4. El modelo simplificado, que se deriva del modelo general, produce resultados que se apegan razonablemente a la información experimental. Por su simplicidad, fácil comprensión y manejo, es útil para: (i) conocer aproximaciones cualitativas de las tendencias de las variables que intervienen; (ii) aproximar valores a los parámetros implicados; (iii) desarrollar estudios de sensibilidad paramétrica $y$, (iv) proponer nuevos modelos más complejos y nuevos experimentos.

5. El modelo general contiene las variables de estado que describen los fenómenos que ocurren en la fermentación en medios sólidos. No obstante a su grado de complejidad, produce respuestas tan apegadas a los resultados experimentales como las respuestas del modelo simplificado, con la diferencia de que aporta una mayor y más completa información sobre el fenómeno.

6. La solución propuesta para el modelo general con el método de diferencias finitas probablemente no sea la más adecuada, en tanto que presenta una inestabilidad persistente en la coordenada radial. No obstante, las respuestas que se obtienen dan una idea muy clara de la manera como se desarrolla el proceso en estudio.

7. Los programas desarrollados muestran flexibilidad para la simulación del fenómeno en estudio. El lenguaje de programación empleado resulta muy práctico en cuanto la facilidad de programación y en cuanto a la lógica, comprensión y adaptación de los mismos. 


\section{REFERENCIAS BIBLIOGRÁFICAS.}

1. Ahmed S. Y., Lonsane B. K., Ghildyal N. F., Ramakrishna S.V. 1987. Design of solid state fermentor for production of fungal metabolites on large scale. Biotechnol. Lett. 1: 97-102.

2. Acuña-Argüelles M. E., Gutiérrez-Rojas M., Viniegra-González G., Favela-Torres, E. 1994a. The effect of water activity on exo-pectinase production by Aspergillus niger $\mathrm{CH} 4$ on solid state fermentation. Biotechnol. Lett. 16: 23-28.

3. Acuña-Argüelles M. E., Gutiérrez-Rojas M., Viniegra-González G., Favela-Torres, E. 1994b. Production and properties of three pectinolytic activities produced by Aspergillus niger by submerged and solid state fermentation. Applied. Microbiol. Biotechnol. (Aceptado).

4. Alazard D., Raimbault M. 1981. Comparative study of amylolyitic enzymes production by Aspergillus niger in liquid and solid cultivation. Eur. J. Appl. Microbiol. Biotechnol., 12: 113 117

5. Auria R., Hernández S., Raimbault M., Revah S. 1990. Ión exchange resin: A model support for solid state growth fermentation of Aspergillus niger. Biotechnol. Techniques, 4: 391-396.

6. Auria R., Palacios J., Revah S. 1992. Determination of the interparticular effective diffusion coefficient for $\mathrm{CO}_{2}$ and $\mathrm{O}_{2}$ in solid state fermentation. Biotechnol. Bioeng. 39: 898-902.

7. Auria R., Morales M., Villegas E., Revah S. 1993. Influence of mold growth on the presssure drop in aerated solid state fermentors. Biotechnol. Bioeng. 41: 1007-1013.

8. Auria R., Revah S. 1994. Pressure drop as a method to evaluate mold growth in solid state fermentation. En: Advances in Bioprocess Engineering. Galindo E., Ramírez O. I. (Eds.), Kluwer Academic, The Netherlands: 289-284

9. Barrios-González J., Castillo T. E., Mejía A. 1993. Development of high penicillin producing strains for solid state fermentation. Biotech. Adv. 11: 525-537.

10. Barrios-González J. 1994. Producción de metabolitos secundarios por fermentación sólida. Tesis Doctorado. Fac. de Ciencias. México. 138 pp.

11. Barstow L. M., Dale B. E., Tengerdy R. P. 1988. Evaporative temperature and moisture control in solid substrate fermentation. Biotechnol. Techniques 2: 237-242.

12. Bloomberg A., Adler L. 1992. Physiology of osmotolerance in fungi. Adv. Microbial Physiol. 33: $145-212$.

13. Benet J. C. 1981. Contribution à l'étude thermodynamique des milieux poreux non saturés avec changement de phase. USTL. Thèses Doctorat d'état. France.

14. Boccas F., Roussos S., Gutiérrez-Rojas M., Serrano L., Viniegra-González G. 1994. Production of pectinase from coffee pulp in solid state fermentation system: selection of wild fungal isolate of high potency by a simple three step screening technique. J. Food Sci. Technol. 31: 22-26.

15. Bull A. T., Trinci A. P. J. 1977. The physiology and metabolic control of fungal growth. Adv. Microbial Physiol. 15: 1-84.

16. Carrizales V., Jaffe W. 1986. Solid state fermentation: An apropriate technology for developing countries. Interciencia. 11: 9-15.

17. Córdova J. 1994. Efecto de la concentración de glucosa en el crecimiento y la producción de ácido cítrico en Aspergillus niger por fermentación en estado sólido.Tesis Maestría. UAMIDCBS, México. 96pp. 
18. Cliffe K. 1988. Bioreactors. En Biotechnology for Engineers, Biological systems in technological processes. (Alan Scragg Editor). Ellis Horwood Lmtd.: 277-301.

19. Christen P., Auria R., Vega C., Villegas E., Revah S. 1993. Growth of Candida utilis in solid state fermentation. Biotechnol. Adv. 11: 549-557.

20. Daubert T. E. 1985. Chemical Engineering Thermodynamics. McGraw-Hill, Int. Student Edition, New York

21. Durand A., Chereau D. 1988. A New pilot reactor for solid-state fermentation: Application to the protein enrichment of sugar beet pulp. Biotechnol. Bioeng., 31: 476-486.

22. Edelstein L., Hadar Y., Chet I., Hennis Y., Segel L. A. 1983. A model for fungal colony growth applied to Sclerotium rofsii. J. Gen. Microbiol. 129: 1873-1881.

23. Endo I., Nagamune T., Nishimura M, Kobayashi T. 1987. Ceil culture method. Patente Europea No. 87106710.

24. Esener A. A., Roels J. A., Kossen N. W. F. 1981. The influence of temperature on the maximum specific rate of Klebsiella pneumoniae. Biotechnol. Bioeng. 23: 1401-1405.

25. Favela-Torres E., Huerta S., Roussos S., Olivares G., Nava G. Viniegra G. y Gutiérrez-Rojas M. 1990. Producción de enzimas a partir de pulpa de café y su aplicación a la industria cafetalera. En I Seminario Internacional de la Biotecnologia en la Industria Cafetalera. Roussos S., Licona F., Gutiérrez-Rojas M. (Eds.) Xalapa, Ver. México, pp. 145-151.

26. Finger S. M., Hatch R. T., Regan T. M. 1976. Aerobic microbial growth in semi-solid matrices. Biotechnol. Bioeng. 18: 1193-1218.

27. Finlayson B. A. 1971. Packed bed reactor analysis by ortogonal allocation. Chem. Eng. Sc. 26: $1081-1091$.

28. Finlayson B. A. 1980. Non-Linear Analysis in Chemical Engineering. McGraw-Hill Inc. Book Co. Nueva YorK.

29. Fras, G. 1989. Macroscopisation des transferts en disperses multiphasiques. Application à l'étude de l'interface entre un milieu poreux et une atmosphère séchante. USTL. Thèses Doctorat d'état. France.

30. Fujishima T., Uchida K., Yoshino H. 1972. Enzyme production by molds in sponge culture. J. Ferment. Technol. 50: 724-730.

31. Gbewoyno K., Wang D. I. C. 1983. Confining mycelial growth to porous microbeads: a novel technique to alter the morphology of non-newtonian mycelial cultures. Biotechnol. Bioeng. 25: $967-983$.

32. Georgiou G., Shuler M. L. 1986. A computer model for the growth, differentiation of a fungal colony on solid substrate. Biotechnol. Bioeng. 28: 405-416.

33. Gervais P., Molin, P., Grajek W., Bensoussan M. 1988. Influence of water activity of a solid substrate on the growth rate and sporogenesis of filamentous fungi. Biotechnol. Bioeng. 31: 457-463.

34. Ghildyal N.P., Ramakrishna S.V., Nirmala Devi P., Lonsane B. K., Asthana, H. N. 1981. Large scale production of pectolytic enzyme by solid state fermentation. J. Food Sci. Technol. 18: $248-257$

35. Gibbons W.A., Westby C.A., Dobbs, T.L. 1986. Intermediate-scale, semicontinuous solid phase fermentation process for production of fuel ethanol from sweet sorghum. Appl. Env. Microbiol. 51, 115-122. 
36. González-Blanco P., Saucedo-Castañeda G., Viniegra-González G. 1990. Protein enrichment of sugar cane by-products using solid-state cultures of Aspergillus terreus. J. Ferment. Bioeng. 70: $351-354$

37. Gowthaman M. K., Ghildal N. P., Raghava Rao K. S. M. S., Karanth N. G. 1993. Interaction of transport resistances with biochemical reaction in packed bed solid state fermenters: the effect of gaseous concentration gradients. J. Chem. Tech. Biotechnol. 56: 233-239.

38. Grajek W. 1988. Cooling aspects of solid state cultures of mesophilic and thermophilic fungi. J. Ferment. Technol. 66: 675-679.

39. Gutiérrez-Rojas M., Huerta S., López U. R., Saucedo G., Favela E., Viniegra-González G. 1989. Solid state fermentations: Scaling-up, prototypes and strategies. En Applications des Fermentations en Mileu Solide à la Valorization des Produits Agricoles. Raimbault M. (Ed.), ORSTOM Montpellier France: 40-46.

40. Gutiérrez-Rojas, M. 1991. Contribution à la modelisation mathematique de la fermentation en milieu solide sur supports inertes. Mémoire de Stage. Université de Montpellier II, France, $119 \mathrm{pp}$.

41. Gutiérrez-Rojas M., Auria R., Benet J. C., Revah S. 1995a. A mathemetical model for solid state fermentation of mycelial fungi on inert support. Chem. Eng. J. (Enviado).

42. Gutiérrez-Rojas M., Córdova J., Auria R., Revah S., Favela-Torres E. 1995b. Citric acid and polyols production by Aspergillus niger at high glucose concentration in solid state fermentation on inert support. Biotechnol. Lett. (Aceptado).

43. Hang Y. D., Woodams E. E. 1987. Effect of substrate moisture content on fungal production of citric acid in a solid state fermentation system. Biotechnol. Lett., 9: 183-186.

44. Hesseltine C.W. 1972. Solid State Fermentation. Biotechnol. Bioeng., 24: 517-532.

45. Himmelblau D.M., Bischoff K.B. 1976. Análisis y Simulación de Procesos. Ed. Reverté, S.A.Barcelona, España, 757 pp.

46. Hong K., Park D., Tanner R., Malaney G.W., Danzo B.J. 1989. Protein entrainment during baker's yeast fermentation on a semi-solid substrate in air-fluidized bed fermentor. Bioprocess Eng. 4: 209-215.

47. Honig P. 1969. Principios de Tecnología Azucarera. Tomo I. C.E.C.S.A. México.

48. Huerta-Ochoa S., Gutiérrez-Rojas M, López U. R., Massuco A. E. y Viniegra-González G.. 1986. Caracterización de un fermentador dinámico para sustratos sólidos en planta piloto. Revista de la Academia Nacional de Ingeniería, 5: 46-53.

49. Huerta-Ochoa S., Favela-Torres E., López, U. R., Fonseca A., Viniegra-González G, Gutiérrez-Rojas M 1994. Absorbed substrate fermentation for pectinase production with Aspergillus niger. Biotechnol. Techniques. (Aceptado)

50. Jones W. L., Dockery J. D., Vogel C. R., Sturman P. J. 1993. Diffusio and reaction within porous packing media: a phenomenological model. Biotechnol. Bioeng. 41: 947-956.

51. Karanth N. G., Lonsane B. K. 1989. Laboratory and pilot scale production of enzymes and biochemicals by SSF at CFTRI, Mysore. En Applications des Fermentations en Mileu Solide à la Valorization des Produits Agricoles. Raimbault M., (Ed.), ORSTOM Montpellier France: 113-120.

52. Koch A. L. 1975. The kinetics of mycelial growth. J. Gen. Microbiol. 89: 209-216.

53. Kumar P. K. R., Lonsane B. K. 1987. Potential of feed-batch culture in solid state fermentation for production of gibberelic acid. Biotechnol. Lett., 9: 179-182. 
54. Larralde-Corona C. P., López-Isunza F., Viniegra-González G. 1992. A kinetic model for germ tube elongation of Aspergillus niger. 9th Int. Biotechnol. Symp. Abstract 335, Agosto 16-21, Crystal City, VA.

55. Larroche C., Gross J. B. 1989. Strategies for spore production by Penicillium roquefortii using solid state fermentation techniques. Process Biochem. : 97-103.

56. Legiša M., Mattey M. 1986. Glycerol as an initiator of citric acid accumulation in Aspergillus niger. Enzyme Microb. Technol. 8:258-259.

57. Laukevics J. J., Apsite A. F., Viesturs U. S.and Tengerdy R. P. 1985. Steric hindrance of growth of filamentous fungi in solid substrate fermentation of wheat straw. Biotechnol. Bioeng. 27: 1687-1681.

58. Lonsane B. K., Ghildyal N. P., Budiatman S., Ramakrishna S. V. 1985. Engineering aspects of solid state fermentation. Enzyme Microbiol. Technol. 7: 285-265.

59. Lonsane B. K., Saucedo-Castañeda G., Raimbault M., Roussos S., Viniegra-González G., Ghildyal N. P. , Ramakrishna M., Krishnaiah M.M. 1992. Scale-up strategies for solid state fermentation systems: A review. Proc. Biochem. 27: 259-273.

60. López R. 1989. La cachaza como materia prima. En La Industria de los Derivados de la Caña de Azúcar. ICIDCA, Cuba, pp 179-184.

61. Luyben W. L. 1973. Process modeling, simulation, and control for chemical engineers, Int. Student. Ed. McGraw-Hill Kogakusha, México, pp 558.

62. Macris B.V., Kekos D., Evangelidou X., Galitou-Panayotou M., Rodis P. 1987. Solid State Fermentation of straw with Neurospora crassa CM-Case and B-glucosidase production. Biotechnol. Lett., 9: 661-664.

63. Marison I. W. 1988. Grow kinetics. En: Biotechnology for Engineers, biological systems in technological processes. Scragg A. (Ed.). Ellis Horwood, England.

64. Mitchell D. A., Greenfield P. F., Doelle H. W. 1986. A model substrate for solid statefermentation. Biotechnol. Lett. 8: 827-832.

65. Mitchell D. A., Greenfield P. F., Doelle H. W. 1988. Development of a model solid statefermentation system. Biotechnol. Techniques. 2: 1-6.

66. Mitchell D. A., Do D. D., Greenfield P. F., Doelle H. W. 1991. A semi-mechanistic mathematical model for growth of Rhizopus olligosporus in a model solid state fermentation system. Biotechnol. Bioeng. 38: 353-362.

67. Mitchell D. A. 1992a. Growth patterns, growth kinetics and the modelling of growth in solid state cultivation. En Solid Substrate Cultivation, Doelle H., Mitchel D. A. and Rolz C. (Eds.) Elsevier Science Pub. England: 87-114.

68. Mitchell D. A., Lonsane B. K., Durand A., Renaud R., Almanza S., Maratray J., Desgranges C., Croocke P. S., Hong K., Tanner R. D., Malaney G. W. 1992b. General principles of reactor design and operation for solid substrate cultivation. En Solid Substrate Cultivation, Doelle H., Mitchel D. A., Rolz C. (Eds.) Elsevier Science Pub. England: 115-139.

69. Molin P., Gervais P., Lemiere J. P. 1993. A computer model based on reaction-difussion equations for the growth of filamentous fungi on solid substrate. Biotechnol. Prog. 5: 385393.

70. Moo-Young M. A., Moreira R., Tengerdy R. P. 1983. Principles of solid substrate fermentation, in the filamentous fungi. En Fungal Technology. Vol. IV. Smith S. E., Berry D. R., Vristiunsen B. (Eds.) Amold, London: 117-144. 
71. Narahara H. 1984. Control of water content in a solid state culture of Aspergillus oryzae. J. Ferment. Technol. 62:, 453-459.

72. Okasaki N., Sugama S., Tanaka T. 1980. Mathematical model for surface culture of koji mold. J. Ferment. Technol. 58: 471-476.

73. Oliver S. J., Trinci A. P. J. 1985. Modes of growth of bacteria and fungi. En Comprehensive Biotechnology, Vol. 1, Moo-Young M. (Ed.). Pergamon Press, New York: 159-187.

74. Oriol E., Raimbault M., Roussos S., Viniegra G. 1988a. Water and water activity in the solid state fermentation of cassava starch by Aspergillus niger. Appl. Microbiol. Biotechnol., 27: 498-503.

75. Oriol E., Schettino B., Viniegra G., Raimbault M., 1988b. Solid state culture of Aspergillus on support. J. Ferment. Technol. 66:57-62.

76. Palacios L. J. 1992. Fermentación en estado sólido: Determinación de los coeficientes de difusión efectivos de $\mathrm{CO}_{2}$ y de $\mathrm{O}_{2}$, y de la permeabilidad relativa de la fase gaseosa. Tesis Maestría en Ciencias, DCBI-UAMI. México.

77. Pandey A. 1992. Recent process developments in solid state fermentation. Process Biochemistry. 27:109-117.

78. Perry R. H., Green D. 1984. Chemical engineering's handbook. 6th. Edition, McGraw-Hill, New York.

79. Pirt S. J. 1967. A kinetic study of the mode of of growth of surface cultures of bacteria and fungi. J. Gen. Microbiol. 47: 181-197.

80. Pirt S. J. 1975. Principles of microbe and cell cultivation. Blackwell Scientific Publications, Oxford.

81. Press W. H., Flannery B. P., Teukolsky S. A., Vetterling W. T. 1989. Numerical Recipes in Pascal. The Art of Scientific Computing. Cambridge University Press. London.

82. Prebois J., Raimbault M., Roussos S. 1985. Biofermenteur statique pour la culture de champignons filamenteux en milieu solide. Patente francesa No. 8517934.

83. Raghavan N. S., Ruthven D. M. 1983. Numerical solution of a fixed bed adsorption column by the method of orthogonal collocation. AICHE J. 29: 922-925.

84. Raimbault M. 1980. Fermentation en milieu solide. Croissance des champignons filamenteux sur substrate amylacé. ORSTOM, Paris.

85. Raimbault M., Roussos S., Oriol E., Viniegra G., Gutiérrez-Rojas M., Barrios J. 1989. Procedè de culture de microorganismes sur un mileu solide constituè d'un support solide, absorbant, compressible et non fermentable. Patente Francesa No. 8906558.

86. Ramesh M.V., Lonsane B.K. 1991. Regulation of alpha-amylase production in Bacillus licheniformis $\mathrm{M} 27$ by enzyme end-products in submerged fermentation and its overcoming in solid fermentation system. Biotechnol. Lett. 13: 355-360.

87. Rathbun B.L., Shuler M.L. 1983. Heat and mass transfer effects in solid substrate fermentation: design of fermentation chambers. Biotechnol. Bioeng., 15, 929-938.

88. Revah S., Lebault J. 1989. Accelerated production of blue cheese flavors by fermentation of granular curds with lipase addition. Le Lait, 69: 281-289.

89. Righelato R. C. 1975. Growth kinetics of mycelial fungi. En The Filamentous Fungi, Vol 1. Smith J. E. y Berry D. E. (eds.). Edward Arnold Publishers, London. 79-103 
90. Rodríguez L. J. A., Bechstedt W., Echevarría J., Sierra N., Delgado G., Daniel A, Martínez O. 1986. Optimization of solid state fermentation of citrus dried peel by Aspergillus niger in a packed bed column. Acta Biotechnol. 6: 253-258.

91. Roels, A.J. 1980. Application of macroscopic principles to microbial metabolism. Biotechnol. Bioeng. 22: 2457-2514.

92. Roussos S., Olmos A., Raimbault M., Saucedo-Castañeda G.,, Lonsane, B.K. 1991. Strategies for large scale inoculum development for solid state fermentation system: conidiospores of Trichoderma harzianum. Biotechnol. Techniques. 5: 415-420.

93. Roussos S., Raimbault M., Saucedo-Castañeda G., Lonsane B. K. 1992. Efficient leaching of cellulases produced by Trichoderma harzianum in solid state fermentation. Biotechnol. Techniques. 6: 429-432.

94. Roussos S., Raimbault M., Prebois J. P., Lonsane B. K. 1993. Zymotys, a large scale solid state fermenter: Design and evaluation. Appl. Biochem. Biotechnol. 42: 37-52.

95. Ryoo D., Murphy V. G., Karim M. N., Tengerdy R. P. 1991. Evaporative temperature and moisture control in a rocking reactor for solid substrate fermentation. Biotechnol. Techniques. 5: $19-24$.

96. Sargantinis J., Karim M. N., Murphy V. G., Ryoo D., Tengerdy, R. P. 1993. Effect of operating conditions on solid substrate fermentation. Biotechnol. Bioeng. 42: 149-158.

97. Sato K., Nagatani M., Sato S. 1982. A method of supplyng moisture to the medium in a solid state culture with forced aeration. J. Ferment. Technol. 60: 607-610.

98. Sato K., Nagatani M., Nakamuri K. I., Sato S. 1983. Growth estimation of Candida lipolytica from oxygen uptake in a solid state culture with forced aeration. J. Ferment. Technol. 61: 623-629.

99. Saucedo-Castañeda G., Gutiérrez-Rojas M., Bacquet G., Raimbault M., Viniegra-González G. 1990. Heat transfer simulation in solid substrate fermentation. Biotechnol. Bioeng. 35: 802-808.

100. Saucedo-Castañeda G. 1991. Contrôle du metabolisme de Schwanniomyces castelii cultive sur support solide. Tesis Doctorat Université Montpellier II. Sciences et Techniques du Languedoc. Francia. pp. 212.

101. Saucedo-Castañeda G., Lonsane B. K., Krishnaiah M. M, Navarro J. M., Roussos S., Raimbault M. 1992. Maintenance of heat and water balances as a scale-up criterion for production of ethanol by Schwanniomyces castellii in solid state fermentation system. Proc. Biochem. 27: 97-107.

102. Segali N. L., MacGregor J. F., Wright J. D. 1984. Collocation methods for solving packed bed reactor models with radial gradients. Can. J. Chem. Eng. 63: 808-817.

103. Smith J. E. 1977. Asexual sporulation in filamentous fungi. En: The Filamentous Fungi, Vol 3. Smith J. E., Berry D. R. (Eds.) Edward Arnold Pub. London.

104. Smith G.D. 1985. Numerical Solution of Partial Differential Equations: Finite Difference Methods. 3rd Edition. Oxford Applied Mathematics and Computing Science Series, Oxford University Press, London.

105. Soccol C., Rodríguez L., Marin B., Roussos S., Raimbault M. 1993. Growth kinetics of Rhizopus arrhizus in solid state fermentation of treated cassava. Biotechnol. Techniques. 7: 563-568.

106. Solís P. S. E., Favela-Torres E., Viniegra-González G., Gutiérrez-Rojas M. 1993. Effect of different carbon sources on the synthesis of pectinases by Aspergillus niger in submerged and solid state fermentation. J. Appl. Microbiol. Biotechnol. 39: 36-41. 
107. Steinkraus K.H. 1984. Solid-state (solid substrate) food/beverage fermentations involving fungi. Acta Biotechnol. 4, $2: 83-88$.

108. Tani Y., Fuji A., Nishise H. 1988. Production of raw cassava starch-digestive glucoamylase by a 2-deoxyglucose resistant mutant of Rhizopus sp. J. Ferment. Technology. 66: 545-551.

109. Trambouze P. 1979. Reactor scale-up philosophy. Chem. Eng. September, 10:122-130.

110. Trinci A. P. J. 1971. Influence of the width of the peripheral growth zone on the radial growth rate of fungal colonies on solid media. J. Gen. Microbiol. 67: 325-344.

111. van Wezel A.L. 1967. Growth of cell strains and primary cells on microcarriers in homogeneous culture. Nature, 216, 64.

112. Verschoor H. 1985. Developments in bioreactors. The Chem. Eng. 415: 39-41.

113. Villadsen J., Michelsen M. L. 1978 Solution of Differential Equation Models by Polynomial Approximation. Prentice-Hall, Englewood Cliffs, New Jersey.

114. Viniegra-González. G., Saucedo-Castañeda G., López-Isunza F., Favela-Torres E. 1993. Symmetric branching model for the kinetics of mycelial growth. Biotechnol. Bioeng. 42: 1-10.

115. Weast, R. C. 1977. Handbook of Chemistry and Physics. 57th Edition. CRC Press, Ohio.

116. Weiz P. W. 1973. Difussion and chemical transformation, an interdisciplinary excursion. Science, 179: 433-.

117. Zuluoaga J. 1990. Utilización integral de los subproductos del café. En I Seminario Internacional sobre Biotecnología en la Agroindustria Cafetalera. Roussos S., Licona F., Gutiérrez-Rojas M. (Eds.) Xalapa, Ver. México: 63-76. 


\section{ANEXO I \\ CONVENCIÓN DE ÍNDICES Y SÍMBOLOS UTILIZADOS.}

1. Vectores y tensores. La notación $\mathbf{v} \mathbf{k}$ se reserva para el vector $\mathbf{v}$ de $\mathbf{k}$ coordenadas:

$$
\mathbf{v}^{\mathbf{k}}=\left(\begin{array}{c}
\mathrm{v}^{1} \\
\mathbf{v}^{2} \\
\mathrm{v}^{3}
\end{array}\right)
$$

La notación $\mathbf{T}^{\mathbf{k m}}$ se refiere a un tensor definido espacialmente por $\mathrm{k}$ y por $\mathrm{m}$ de la siguiente manera:

$$
\mathbf{T}^{\mathbf{k m}}=\left(\begin{array}{lll}
\mathbf{T}^{11} & \mathbf{T}^{12} & \mathbf{T}^{13} \\
\mathbf{T}^{21} & \mathbf{T}^{22} & \mathbf{T}^{23} \\
\mathbf{T}^{31} & \mathbf{T}^{32} & \mathbf{T}^{33}
\end{array}\right)
$$

2. Índices muertos e índices libres. Un índice muerto es uno que aparece duplicado en un monomio cualquiera. Representa la suma de $\mathrm{k}$ monomios en los que $\mathrm{k}$ toma valores sucesivos ( 1 , $2,3, \ldots$, etc.). Por ejemplo el producto escalar de los vectores A y $\mathrm{B}$ de dimensión $\mathrm{k}$, se puede escribir como:

$$
A^{k} B^{k}=A^{1} B^{1}+A^{2} B^{2}+A^{3} B^{3}
$$

El producto tensorial de $\mathbf{T}^{\mathbf{k m}}$ y el vector $\mathbf{v}^{\mathbf{m}}$ producirá un vector en donde cada uno de los $\mathrm{k}$ componentes tiene la forma siguiente:

$$
T^{k m} v^{m}=T^{k 1} v^{1}+T^{k 2} v^{2}+T^{k 3} v^{3}
$$

Un índice muerto puede cambiarse en un monomio sin alterar el significado del mismo; a diferencia de un índice libre, que esta presente una sola vez en un monomio, que no se puede cambiar. Por ejemplo, en el producto $\mathbf{T}^{\mathbf{k m}} \mathbf{v} \mathbf{m} \mathbf{k}$ es un índice libre, mientras que $\mathrm{m}$ es un índice inuerto.

3. Gradiente y divergencia. El gradiente de una función escalar $\Phi$ se representa como:

$$
\Phi, \mathrm{k}
$$

y es un vector cuyas $k$ coordenadas son las derivadas parciales de $\Phi$, es decir: 


$$
\Phi_{, k}=\left(\begin{array}{c}
\frac{\partial \Phi}{\partial x} \\
\frac{\partial \Phi}{\partial y} \\
\frac{\partial \Phi}{\partial z}
\end{array}\right)
$$

El gradiente de una función vectorial, por ejemplo $\mathbf{v} \mathbf{k}$, se representa como:

$$
\mathbf{v}^{\mathbf{k}}, \mathrm{m}
$$

y es un tensor cuya matriz asociada es la siguiente:

$$
\begin{array}{r}
\frac{\partial v^{1}}{\partial x} \frac{\partial v^{1}}{\partial y} \frac{\partial v^{1}}{\partial z} \\
\mathbf{k}_{, k}=\quad \frac{\partial v^{2}}{\partial x} \frac{\partial v^{2}}{\partial y} \frac{\partial v^{2}}{\partial z} \\
\frac{\partial v^{3}}{\partial x} \frac{\partial v^{3}}{\partial y} \frac{\partial v^{3}}{\partial z}
\end{array}
$$

La divergencia de una función vectorial, por ejernplo $\mathbf{v}^{\mathbf{k}}$, se representa como:

$$
\mathbf{v} \mathbf{k}_{\mathrm{k}}
$$

y es un escalar con elementos como los que siguen:

$$
\mathbf{v}_{, k}=\frac{\partial v \mathbf{x}}{\partial x}+\frac{\partial v y}{\partial y}+\frac{\partial v^{z}}{\partial z}
$$

donde: $k$ es un índice muerto.

La divergencia de un tensor, por ejemplo $\mathbf{T}^{\mathbf{k m}}$, se representa como:

$$
\mathbf{T k m}_{, k}
$$

y es un vector definido como:

$$
\begin{array}{r}
\mathbf{T}_{\mathbf{k}_{\mathbf{k}}=} \frac{\partial \mathrm{T}^{11}}{\partial \mathrm{x}}+\frac{\partial \mathrm{T}^{12}}{\partial \mathrm{y}}+\frac{\partial \mathrm{T}^{13}}{\partial \mathrm{z}} \\
\frac{\partial \mathrm{T}^{21}}{\partial \mathrm{x}}+\frac{\partial \mathrm{T}^{22}}{\partial \mathrm{y}}+\frac{\partial \mathrm{T}^{23}}{\partial \mathrm{z}} \\
\frac{\partial \mathrm{T}^{31}}{\partial \mathrm{x}}+\frac{\partial \mathrm{T}^{32}}{\partial \mathrm{y}}+\frac{\partial \mathrm{T}^{33}}{\partial \mathrm{z}}
\end{array}
$$




\section{ANEXO II \\ DEDUCCION DE UNA ECUACIÓN PARA LA MASA DE VAPOR DE AGUA EN FUNCION DE LA TEMPERATURA}

La variable $\rho_{v}$ (masa aparente del vapor de agua por unidad de volumen) es una función de las condiciones de operación del biorreactor, por lo tanto es importante encontrar una función que describa su comportamiento, para cualquier cambio en las condiciones de trabajo. Para encontrar esta función se parte de las siguientes premisas:

1. El aire que se suministra al biorreactor está siempre saturado, independientemente de la temperatura de alimentación.

2. Una vez dentro del biorreactor, en cada punto del mismo, siempre se observa la misma temperatura en cada una de las fases por lo que no hay cambio de fase, esto es, se espera que el aire entre y salga siempre saturado.

3. El vapor de agua, dentro de la fase gaseosa, se puede considerar como gas ideal.

Por definición la humedad absoluta del aire, $\mathrm{H}$ expresada en $\mathrm{kg}_{\text {de }}$ agua $\mathrm{kg}^{-1}$ de aire seco está dada por:

$$
\mathrm{H}=\frac{\text { PMe } \mathrm{p}_{\mathrm{V}}^{*}}{\text { PMaire }\left(\mathrm{P}-\mathrm{p}_{\mathrm{v}}^{*}\right)}
$$

donde: PMi: Peso molecular de $\mathrm{i}, \mathrm{kg}$ de $\mathrm{i}(\mathrm{mol} \text { de } \mathrm{i})^{-1}$

$\mathrm{P}: \quad$ Presión total del sistema, $\mathrm{Pa}$

$\mathrm{p}_{\mathrm{v}}{ }^{*}: \quad$ Presión parcial del agua en la fase vapor, $\mathrm{Pa}$

$\mathrm{Si}_{\mathrm{p}}{ }^{*}$ a una cierta temperatura es igual a la presión de vapor del agua líquida $\mathrm{p}_{\mathrm{e}}{ }^{*}$, a la misma temperatura, entonces la ecuación (II-1) describirá la humedad de saturación Hs:

$$
\mathrm{H}_{\mathrm{s}}=\frac{\mathrm{PMe} \mathrm{pe}_{\mathrm{e}}^{*}}{\text { PMaire }\left(\mathrm{P}-\mathrm{p}_{\mathrm{e}}^{*}\right)}
$$

Si la misma humedad de saturación $H s$ se puede expresar en función de la masa aparente volumétrica $\rho_{\mathrm{V}}$ como:

$$
H s=\frac{\rho_{\mathrm{V}}}{\rho_{\text {aire seco }}}[=] \mathrm{kg} \text { vapor de agua }(\mathrm{kg} \text { aire seco })^{-1}
$$




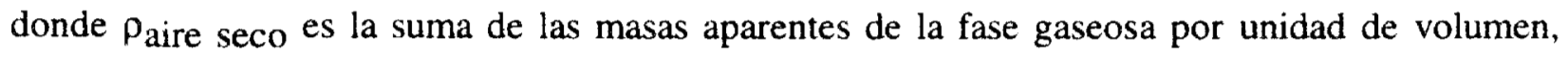
excepto el vapor de agua, es decir:

$$
\rho_{\text {aire seco }}=\rho_{N}+\rho_{o}+\rho_{c}
$$

Sustituyendo (II-3) y (II-4) en (II-2), se obtiene la siguiente expresión:

$$
\rho_{v}=\left(\rho_{N}+\rho_{o}+\rho_{c}\right) \frac{\text { PMe } p_{e}^{*}}{\text { PMaire }\left(P-p_{e}^{*}\right)}
$$

donde el término $\mathrm{pe}^{*}$ se puede aproximar, partiendo de la ecuación de Clasius-Clapeyron, con la siguiente ecuación:

$$
\mathrm{p}_{\mathrm{e}}^{*}=\exp \left(25.775-\frac{5281.1}{\mathrm{~T}}\right)
$$

donde:

$$
\begin{aligned}
& \mathrm{p}_{\mathrm{e}}{ }^{*} \text { queda expresada en } \mathrm{Pa}, \\
& \mathrm{T} \text { en } \mathrm{K}
\end{aligned}
$$

Las ecuaciones (II-5) y (II-6) permiten obtener una aproximación de la variable $\rho_{v}$ en función de la temperatura de la fase gaseosa, $T$. 


\section{ANEXO III \\ DEDUCCIÓN DE UNA ECUACIÓN PARA EL MÁXIMO CRECIMIENTO CELULAR ESPERADO EN FUNCIÓN DE LOS ESPACIOS VACIOS DISPONIBLES}

Una de las hipótesis centrales de este trabajo (ver H:12), es la que considera que el crecimiento celular depende de los espacios disponibles en la superficie del soporte inerte. Por esta razón se decidió desarrollar una expresión especial para el caso de un soporte inerte de geometría esférica de diametro promedio conocido.

El crecimiento de estos microorganismos filamentosos se realiza principalmente de manera superficial; aunque el crecimiento aéreo se presenta simultaneamente, aqui se considera el primero como el más relevante. La manera y la intensidad de colonización de una superficie determinada por un microorganismo filamentoso no sólo depende de las características genéticas del microorganismo sino también de las características de la superficie a colonizar. Si se define a $R_{c p}$ como la capacidad de un cierto hongo filamentoso para colonizar la superficie del soporte inerte que ocupa a este trabajo (Amberlita), expresando a $R_{c p}$ en $\mathrm{kg}$ de biomasa por unidad de superficie, entonces la máxima cantidad de biomasa que puede obtenerse $\rho_{x M a x}$ sería aquella que se formara sobre el total de superficie disponible al tiempo igual a cero $S_{0}$ es decir:

$$
\rho_{x \operatorname{Max}}=S_{0}\left(\frac{R_{c p}}{(1-\emptyset)}\right)
$$

donde:

$$
\begin{aligned}
& S_{0} \text {, es la superficie de soporte inerte inicial disponible por unidad de } \\
& \text { volumen de referencia, } \mathrm{m}^{2} \text { de soporte } \mathrm{m}^{-3} \text { de VER } \\
& \mathrm{R}_{\mathrm{cp}} \text {, es una constante que se debe estimar experimentalmente, } \\
& \mathrm{kg} \text { biomasa seca } \mathrm{m}^{-2} \text { de soporte } \\
& \emptyset \text {, es la fracción de agua contenida en la biomasa húmeda, } \\
& \mathrm{kg} \text { de agua } \mathrm{kg}^{-1} \text { de biomasa húmeda }
\end{aligned}
$$

por lo que, pxMax queda expresada en $\mathrm{kg}$ de biomasa húmeda $\mathrm{m}^{-3}$ de VER

La superficie de soporte inerte inicial disponible, $\mathrm{S}_{0}$ se puede estimar con el producto del número total de esferas por la superficie que ocupa una esfera de radio $(\Phi / 2)$, como sigue:

$$
\text { Número total esferas }=\left(\frac{\text { Volumen que ocupa el soporte }}{\text { Volumen de una esfera }}\right)
$$


o de otra forma:

$$
\begin{aligned}
& \text { Número total esferas }=\left(\frac{\left(1-\varepsilon_{0}\right)}{(4 / 3) \pi(\Phi / 2)^{3}}\right) \\
& \qquad S_{0}=\left(\frac{\left(1-\varepsilon_{0}\right)}{(4 / 3) \pi(\Phi / 2)^{3}}\right)\left(4 \pi(\Phi / 2)^{2}\right)
\end{aligned}
$$

simplificando:

$$
S_{0}=\left(\frac{6\left(1-\varepsilon_{0}\right)}{\Phi}\right)
$$

donde:

$\varepsilon_{0}$, es la porosidad macroscópica o fracción de espacios vacios al tiempo cero

$\Phi$, es el diametro promedio de las esferas del soporte

despreciando la porosidad o espacios vacíos internos del soporte (ver hipótesis $\mathbf{H : 2}$ ), $\varepsilon_{0}$ se puede estimar mediante la siguiente expresión:

$$
\varepsilon_{0}=1-\left(\frac{\rho_{a}^{0}}{\rho_{a}^{*}}+\frac{\rho_{x}^{0}}{\rho_{x}^{*}}+\frac{\rho_{1}^{0}}{\rho_{1}^{*}}\right)
$$

donde:

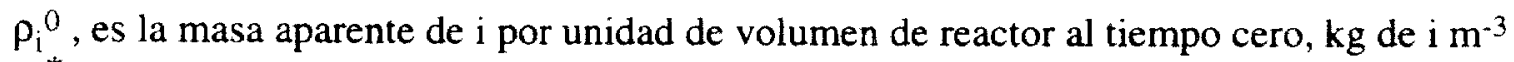
$\rho_{\mathrm{i}}{ }^{*}$, es la masa real del constituyente $\mathrm{i}$, por unidad de volumen ocupado por $\mathrm{i} \mathrm{kg}$ de $\mathrm{i} \mathrm{m}^{-3}$ Sustituyendo (III-3) en (III-1), se obtiene:

$$
\rho_{\mathrm{xMax}}=\left(\frac{6\left(1-\varepsilon_{0}\right)}{1-\varphi}\right)\left(\frac{\mathrm{R}_{ }}{\Phi}\right)
$$




\section{ANEXO IV \\ LISTADOS DE LOS PROGRAMAS PARA LA SOLUCIÓN DEL MODELO SIMPLIFICADO}

En este anexo se presentan los listados de los programas más importantes para la solución del modelo simplificado. Los programas se elaboraron en lenguaje Turbo Pascal, versión 6.0 aprovechando la posibilidad de escribir cada programa de manera estructurada y con jerarquías descendentes. Los programas que se listan a continuación están siempre constituídos de tres partes: el encabezado o identificador del programa, la sección de definición o declaración de tipos, variables y procedimientos y, finalmente, la sección de instrucciones de cálculo siempre acompañadas de comentarios entre paréntesis \{ \}. Las instrucciones que inician la línea con el signo $\$$, se refieren a órdenes de compilación e inserción de subprocedimientos. Las variables que anteceden al signo ${ }^{\wedge}$, corresponden a variables de tipo dinámicas que se utilizan sólo durante el cálculo y no se almacenan permanentemente en la memoria. Para la solución del modelo simplificado se utilizan nueve procedimientos, los cinco más importantes son:
1. PRINCIPAL.PAS,
4. RK4.PAS y
2. LECTURA.PAS,
5. ANALISIS.PAS.

3. DERIVA.PAS,

Cada uno de los listados se presenta a continuación.

\section{PROGRAMA PRINCIPAL.PAS.}

PROGRAM PRINCIPAL;

\{Resuelve el MODELO SIMPLIFICADO con 6 Variables de estado:

\{Azúcar, Agua, Oxígeno, CO2 y T en el tiempo. Presenta resultados \{en pantalla y, los almacena en el archivo que asigne el usuario.

\{Permite modificar parámetros desde un principio mediante menús

$\{\$ N+\} \quad$ Coprocesador a doble precisión

USES CRT, DOS, UAMI;

CONST

NVAR $=6 ; \quad$ Número de variables dependientes $\}$

tf $=216000 ; \quad$ TTiempo de fermentación en segundos $=60 \mathrm{~h}$ \}

TYPE

Real = Double; VAR

RealArrayNVAR = ARRAY [1..NVAR] of REAL;

yout, yi, dyidx :

Marca, i, kk,n, k

Arcdata

Nombre

ybuf, tiempo

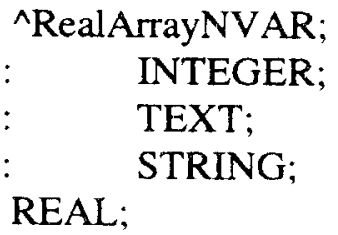


Rhoaet, Rhoxet, Rholet RhoxMax, RhocMax

Rhov, RhoN :

hx, hs, he, ho, hc

Cpx, Cpe, Cpa, Cpl,Cpair :

ms, mo

$\mathrm{Cx}, \mathrm{Cs}, \mathrm{Ce}, \mathrm{Co}, \mathrm{Cc}$,

CxMax

FI

Diam, Rcp

$\mathrm{L}, \mathrm{Ra}$

Rhoa0, Rhox0, Rhoe0,

Rhos0, Rhol0, Rhoo0,

Rhov0, Rhoc0, RhoAire fpN, fpo, fpc

Epsilon, Eps, Epsilon0

Gasto, U

AtVol

vg

A1, A2, Ea1, Ea2, Rg

Yprima, Ye, YeMax, Ys,

YsMax, Yc, YcMax, Yo,

YoMax

Tin, Tjaq, Tp, Tair

$P$

peet

$\mathrm{Ks}$

$\mathrm{Ki}$

Hhprue
REAL; \{ Masa volúmica real de i

REAL; ( Máxima biomasa, $\mathrm{CO} 2$ y vap.agua

REAL; \{ Masa de i

REAL; \{ Calores de formación de i

REAL; \{ Calor espec;fico de i

REAL; \{ Coeficientes de mantenimiento

REAL; $\{$ Término cinético de $\mathrm{i}$

REAL; \{ Humedad de la biomasa

REAL; I Parámetros propuestos

REAL; \{ Altura y radio del biorreactor

REAL; \{ Condiciones iniciales propuestas

REAL; (Fracción en peso: constituyente i $\{$ en el aire de entrada

REAL; \{ Espacio macroscópico VACIO

REAL; \{ Gasto de aire y Coeficiente global \}

REAL; \{ Area de transferencia volumétrica

REAL; \{ Velocidad de la fase gaseosa

REAL; \{ Parámetros de Cxmax

REAL; | Rendimientos

REAL; I Temperaturas de ref. y de la chaqueta.

REAL; ( Presión total del sistema

REAL; I Presión parcial vapor de agua

REAL; ( Constante de afinidad por azúcar

REAL; \{ Constante de inhibición

REAL; \{ Paso de integración del Runge-Kutta

(1)

PROCEDURE LECTURA;

\{\$I LECTURA.PAS \}

PROCEDURE ABRE

\{\$I ABRE.PAS

PROCEDURE IMPRESION

\{\$I IMPRE.PAS \}

PROCEDURE DERIVA

\{\$I DERIVA.PAS

PROCEDURE RK4

\{\$I RK4.PAS \}

( VAR Name : String);

( VAR y : RealArrayNVAR; Var time : Real; nn: Integer; Var Eps : Real);

( $x$ : REAL; VAR y, dydx : RealArrayNVAR;

Var Eps: Real; VAR Marca : Integer);

(VAR y, dydx : RealArrayNVAR; $n$ : Integer; $x, h$ :

Real; VAR yout : RealArrayNVAR; VAR Eps : Real); 
PROCEDURE ANALISIS

\{\$I ANALISIS.PAS $\}$

PROCEDURE VALIDA;

\{\$I VALIDA.PAS $\}$

PROCEDURE A_PANTALLA;

\{\$I A_PANTAL.PAS

PROCEDURE A_DISCO;

\{\$I A_DISCO.PAS\}

$\{* * * * * * * * * * * * * * * * * * * * *$ COMIENZA PROGRAMA PRINCIPAL.PAS $* * * * * * * * * * * *\}$

BEGIN

New(yout);New(yi);New(dyidx);

ClrScr;

Gotoxy $(1,10)$; Writeln('Nombre del archivo en el que se almacenarán estos datos');

Readln(Nombre);

LECTURA;

Hhprue: $=0.00002$;

tiempo: $=0.0$

VALIDA;

\{ Aceptación o corrección de las condiciones de operación

\{ y de los parámetros para los análisis de sensibilidad

$\{$ Expresada en horas

yi^[1]:= Rhox0/RhoxMax;

\{Condiciones iniciales.... . ADIMENSIONALES

$\mathrm{yi}^{\wedge}[2]:=$ Rhos0/Rhos0;

$\mathrm{yi}^{\wedge}[3]:=$ Rhoe0/Rhoe0;

yi^[4]:= Rhoo0/Rhoo0;

$\mathrm{yi}^{\wedge}[5]:=($ Rhoc0 - Rhoc0 $) /($ RhocMax - Rhoc0 $)$;

$\mathrm{yi}^{\wedge}[6]:=(\mathrm{Tp}-\mathrm{Tp}) /(\mathrm{Tin}-\mathrm{Tp})$;

\{ Biomasa

\{ Azúcar

\{ Agua

\{ Oxígeno

$\{\mathrm{CO} 2$

T Temperatura

ABRE (Nombre); \{ Abre un archivo *.dat para almacenar datos de la corrida \}

IMPRESION (yi^, tiempo, n, Epsilon0);

$\mathrm{k}:=1$;

Eps:=Epsilon0;

Marca: $=1$;

While tiempo $<=1.0$ do

Begin

DERIVA (tiempo, $\mathrm{yi}^{\wedge}$, dyidx^ ${ }^{\wedge}$, Eps, Marca);

RK4 (yi^ ${ }^{\wedge}$ dyidx $^{\wedge}$, n, tiempo, Hhprue, yout ${ }^{\wedge}$, Eps);

ANALISIS (yout ${ }^{\wedge}$, Eps, Marca);

If $k=2600$ then

begin;

$$
\begin{aligned}
& \text { A_PANTALLA; } \\
& \text { A_DISCO; } \\
& \mathrm{k}:=1
\end{aligned}
$$


end;

$\mathrm{k}:=\operatorname{Succ}(\mathrm{k})$;

tiempo:=tiempo+Hhprue;

For $\mathrm{i}:=1$ to NVAR do $\mathrm{yi}^{\wedge}[\mathrm{i}]:=$ yout $^{\wedge}[\mathrm{i}]$

end; $\quad$ del While \{del While \} END.

Dispose(dyidx); Dispose(yi); Dispose(yout); [ Libera las variables dinámicas ]

Como se puede apreciar el programa PRINCIPAL.PAS utiliza las unidades DOS y CRT propias de Turbo Pascal y la unidad UAMI, que fue creada especialmente para estos programas y los del modelo general en dos dimensiones.

2. PROGRAMA LECTURA.PAS

\{PROCEDIMIENTO LECTURA.PAS

BEGIN;

\begin{tabular}{|c|c|}
\hline Rhoaet: $=1070$ & \{ Masa vol. real, $\mathrm{kg} \mathrm{Amb} . / \mathrm{m}^{3}$ de Amberlita \\
\hline Rhoxet: $=1150$ & \{ Masa vol. real, $\mathrm{kg}$ Biom. Hum. $/ \mathrm{m}^{3}$ Biom. Hum. \\
\hline $\mathrm{A} 1:=2.7 \mathrm{E} 11$ & \{ Constante para calcular Cxmax, $\mathrm{h}^{-1}$ \\
\hline $\mathrm{A} 2:=1.38 \mathrm{E} 47$ & \{ Constante para calcular Cxmax, Adimensional \\
\hline Ea $1:=70255$ & \{ Energía de activación, J/Mole de Biomasa \\
\hline $\mathrm{Ea} 2:=283256$ & \{ Energía de desactivación, $\mathrm{J} /$ Mole de Biomasa \\
\hline $\mathrm{Rg}:=8.314$ & \{ Constante de los gases perfectos, J/Mole $\mathrm{K}$ \\
\hline $\mathrm{FI}:=0.8$ & \{ Contenido de agua en la biomasa, $\mathrm{kg} / \mathrm{kg}$ biom. $\mathrm{H}$ \\
\hline Diam: $=6 \mathrm{E}-04$ & \{ Diámetro de partículas de Amberlita, $\mathrm{m}$ \\
\hline $\mathrm{Rcp}:=0.017$ & ( Crecimiento superf. MAX. kg biom. hum $/ \mathrm{m}^{2}$ \\
\hline Gasto: $=0.1$ & ( Gasto específico, $\mathrm{m}^{3}$ de aire/ $\mathrm{s} \mathrm{m}^{3}$ de VER \\
\hline$L:=0.1$ & Altura del biorreactor, $\mathrm{m}$ \\
\hline $\mathrm{Ra}:=0.005$ & \{ Radio del biorreactor, $\mathrm{m}$ \\
\hline $\mathrm{U}:=120$ & [ Coef. global de transf. calor Joules $/ \mathrm{m}^{2} \mathrm{~s} \mathrm{~K}$ \\
\hline Rhoa0: $=275$ & \{ Masa vol. inicial, $\mathrm{kg}$ Amberlita seca $/ \mathrm{m}^{3}$ \\
\hline Rhox $0:=0.2$ & \{ Masa vol. inicial, $\mathrm{kg}$ Biomasa húmeda $/ \mathrm{m}^{3}$ \\
\hline Rhoe0: $=345$ & [ Masa vol. inicial, $\mathrm{kg}$ de agua $/ \mathrm{m}^{3}$ \\
\hline Rhos $0:=41.7$ & ( Masa vol. inicial, $\mathrm{kg}$ Azúcar $/ \mathrm{m}^{3}$ \\
\hline $\mathrm{fpN}:=0.75443$ & \{ Fracción en peso, $\mathrm{kg}$ nitrógeno / $\mathrm{kg}$ aire húmedo \\
\hline fpo: $=0.21143$ & \{ Fracción en peso, $\mathrm{kg}$ oxígeno / kg aire húmedo \\
\hline$f p c:=0.00045$ & \{ Fracción en peso, $\mathrm{kg} \mathrm{CO} / \mathrm{kg}$ aire húmedo \\
\hline$P:=92633$ & ( Presión total del sist. ( $10 \%$ arriba de la atm), $\mathrm{Pa}$ \\
\hline RhoAire:= 1.29 & \{ Densidad del aire, $\mathrm{kg}$ aire $/ \mathrm{m}^{3} @ 0^{\circ} \mathrm{C}$ y 1 ATM \\
\hline Tin: $=50$ & ( Temperatura PROHIBIDA, de referencia en ${ }^{\circ} \mathrm{C}$ \\
\hline Tjaq:= 35; & ( Temperatura de la chaqueta, e ${ }^{\circ} \mathrm{C}$ \\
\hline Tair: $=35$ & $\left\{\right.$ Temperatura (bulbo seco) entrada aire, $\mathrm{en}^{\circ} \mathrm{C}$ \\
\hline $\mathrm{Ks}:=35$ & \{ Afinidad por el sustrato, $\mathrm{kg}$ azúcar $/ \mathrm{m}^{2}$ \\
\hline
\end{tabular}




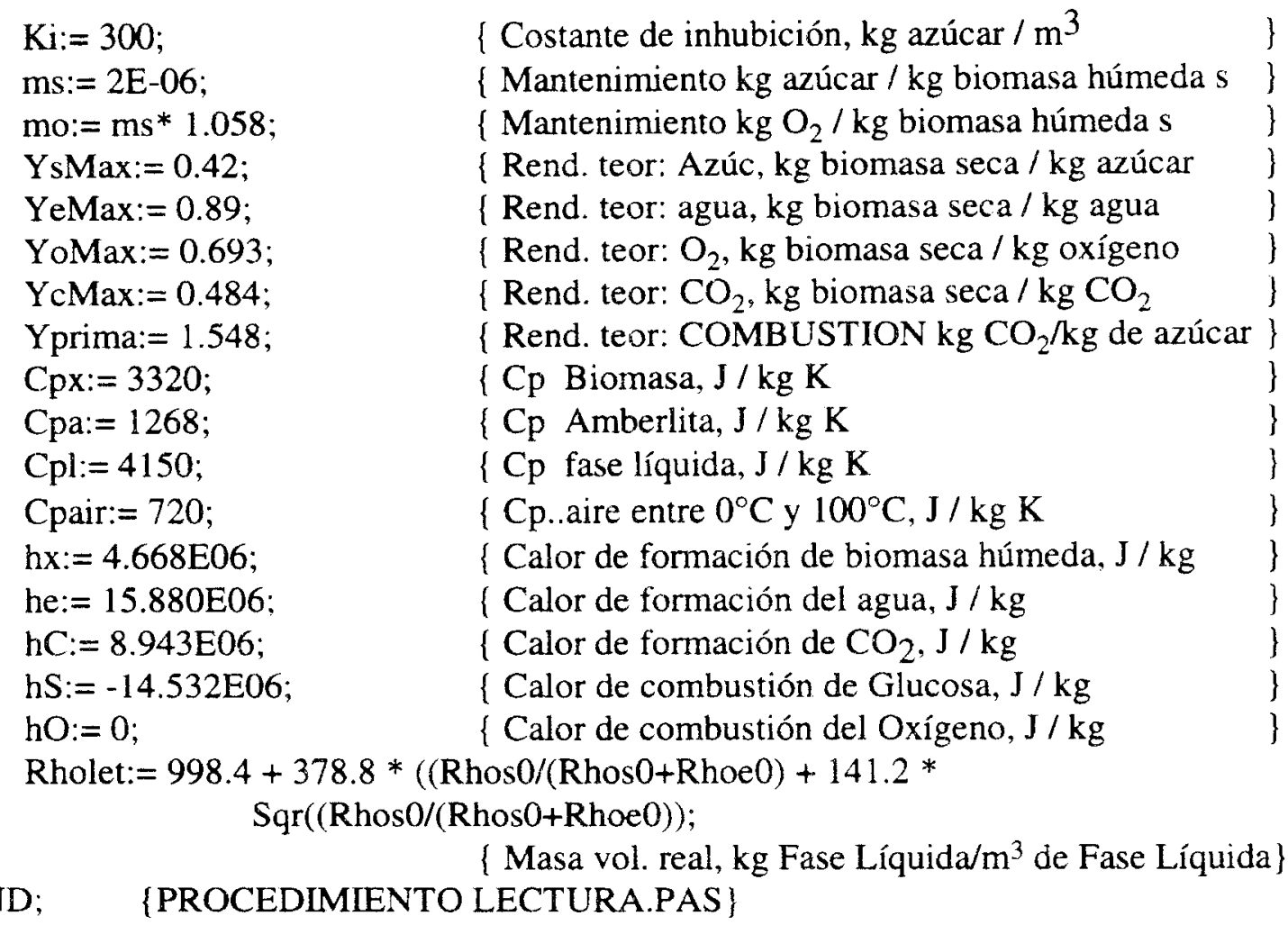

\section{PROGRAMA DERIVA.PAS}

\{PROCEDIMIENTO DERIVA.PAS

\{CALCULA LOS VALORES DE LAS
DERIVADAS EN CADA TIEMPO

VAR

TK : REAL; $\quad$ T Temperatura del biorreactor en $\mathrm{K}$

Rhoair : REAL; $\quad$ Densidad del aire @ TK y P

Kstest, Kitest : REAL; $\quad$ Constantes adimensionales

\{ Masa de la fase líquida y gas

$\mathrm{O} 2$ in, $\mathrm{CO} 2 \mathrm{in}$,

O2out, CO2out

DeltaHr, PeH, Bi,

REAL; \{ Masas de entrada y salida de gases \}

DeltaTb, DeltaTa :

REAL; $\quad$ Adimensionales

RhoiCpi,

RhopgCpg

Rho, dydt

REAL; $\quad$ Producto de la masa de i por su Cp

${ }^{\wedge}$ RealArrayNVAR;

\section{BEGIN}

New (Rho); New(dydt);

$\mathrm{n}:=$ NVAR;

For $\mathrm{kk}:=1$ to $\mathrm{n}$ do

\{ Llama los valores ANTERIORES de las

$$
R h 0^{\wedge}[k k]:=y[k k] ;
$$

I NVAR variables dependientes

$\{$ y los almacena en el vector temporal

\{ Rho^

,

(1)

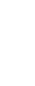




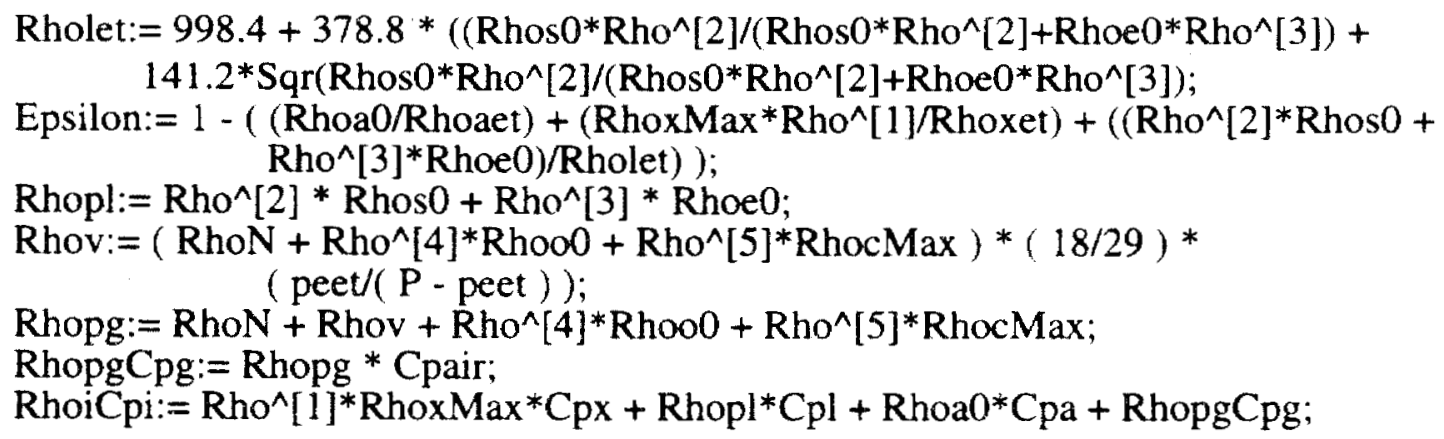


$\{$ - Temperatura- $\}$

$\mathrm{PeH}:=\mathrm{tf} *(\mathrm{vg} / \mathrm{L}) *($ RhopgCpg / RhoiCpi $)$;

$\mathrm{Bi}:=(2 * \mathrm{tf} * \mathrm{U}) /\left(\mathrm{Ra}^{*}\right.$ RhoiCpi);

DeltaHr: $=\mathrm{tf}^{*}\left(\mathrm{Cx}^{*} \mathrm{hx}+\mathrm{Cs}^{*} \mathrm{hs}+\mathrm{Ce}^{*} \mathrm{he}+\mathrm{Co}^{*} \mathrm{hO}+\mathrm{Cc}^{*} \mathrm{hC}\right)$;

DeltaTa: $=$ Rho^$^{\wedge}[6]-(($ Tair - Tp $) /($ Tin - Tp $))$;

DeltaTb:=Rho^[6]-((Tjaq - Tp $) /($ Tin - Tp $))$;

$\operatorname{dydt}^{\wedge}[6]:=-($ PeH $*$ DeltaTa $)-(B i *$ DeltaTb $)-\operatorname{DeltaHr}($ RhoiCpi * (Tin - Tp $\left.)\right) ;$

Eps:= Epsilon;

\{ Devuelve los valores de las derivadas calculadas y de Epsilon \}

For $\mathrm{kk}:=1$ to NVAR do $\mathrm{dydx}[\mathrm{kk}]:=\mathrm{dydt}^{\wedge}[\mathrm{kk}]$

Dispose(dydt); Dispose(Rho);

END; $\quad$ [PROCEDIMIENTO DERIVA.PAS

\{Libera las variables dinámicas \}

4. PROGRAMA RK4.PAS

\{PROCEDIMIENTO RK4.PAS \} \{PROGRAMA DE CÁLCULO CON EL \} \{ ALGORÍTMO DE RUNGE-KUTTA DE $4^{\circ}$ \} \{ ÓRDEN

VAR

i : INTEGER;

xh, hh, h6 : REAL;

dym, dyt, yt : $\quad$ RealArrayNVAR;

BEGIN

new(dym); new(dyt); new(yt);

$\mathrm{h}:=$ Hhprue;

$\mathrm{hh}:=\mathrm{h} * 0.5$

$\mathrm{h} 6:=\mathrm{h} / 6.0$;

$\mathrm{xh}:=\mathrm{x}+\mathrm{hh}$;

For $\mathrm{i}:=1$ to $\mathrm{n}$ do $y t^{\wedge}[i]:=y[i]+h h^{*} d y d x[i]$

DERIVA (xh, $\mathrm{yt}^{\wedge}, \mathrm{dyt}^{\wedge}$, Eps,Marca);

For $\mathrm{i}:=1$ to $\mathrm{n}$ do $\mathrm{yt}^{\wedge}[\mathrm{i}]:=\mathrm{y}[\mathrm{i}]+\mathrm{hh}^{*} \mathrm{dyt}^{\wedge}[\mathrm{i}]$

DERIVA (xh, $\mathrm{yt}^{\wedge}, \mathrm{dym}^{\wedge}$, Eps,Marca);

For $\mathrm{i}:=1$ to $\mathrm{n}$ do

Begin

$y t^{\wedge}[i]:=y[i]+h^{*} d y m^{\wedge}[i]$

end; $\operatorname{dym}^{\wedge}[\mathrm{i}]:=d y t^{\wedge}[\mathrm{i}]+\mathrm{dym}^{\wedge}[\mathrm{i}]$

DERIVA $\left(x+h, y^{\wedge}{ }^{\wedge}, \mathrm{dyt}^{\wedge}\right.$, Eps, Marca $)$;

\{CUARTO paso del Runge \}

For $\mathrm{i}:=1$ to $\mathrm{n}$ do

\{PRIMER paso del Runge \}

\{SEGUNDO paso del Runge \}

\{TERCER paso del Runge \} 

yout $[i]:=y[i]+h 6^{*}\left(d y d x[i]+d y t^{\wedge}[i]+2.0^{*} d y m^{\wedge}[i]\right) ;$
Eps:= Epsilon;
Dispose(yt); Dispose(dyt); Dispose(dym);
END;
\{PROCEDIMIENTO RK4.PAS \}
\{Libera las variables dinámicas\}

\section{PROGRAMA ANALISIS.PAS \\ \{PROCEDIMIENTO ANALISIS.PAS\} \{ COMPARA LOS VALORES CALCULADOS\} VAR

$\begin{array}{cll}\mathrm{i} & : & \text { INTEGER; } \\ \mathrm{yt} & : & \text { ARealArrayNVAR; }\end{array}$

\section{BEGIN}

new $(\mathrm{yt})$;

For $\mathrm{i}:=1$ to NVAR do

begin

$\mathrm{yt}^{\wedge}[\mathrm{i}]:=\mathrm{y}[\mathrm{i}]$

If $y[2]<=0$ then

( Lectura de las NVAR calculadas

I Análisis de las NVAR calculadas

$\{$ Se agotaron los AZUCARES

begin

$$
\begin{aligned}
& \mathrm{y}[2]:=0 \\
& \mathrm{~ms}:=0
\end{aligned}
$$$$
\text { Marca:=-1 }
$$

$\{$ RhoS no puede ser $<$ a cero

$\{$ Ni hay para el mantenimiento

$\{$ Este es un daño irreversible

end;

If $y[3]<=0.1$ then

begin

\{ Se agotó el A G U A disponible \}

end;

$$
\begin{aligned}
& y[3]:=0.1 ; \\
& \text { Marca: }=-1 ;
\end{aligned}
$$

If $y[4]<=0$ then

begin

$$
y[4]:=0 \text {; }
$$$$
\text { Marca:=-1; }
$$

end;

If $y[6]>=1.0$ then

begin

$$
\begin{aligned}
& y[6]:=1.0 \\
& \text { Marca:=-1; }
\end{aligned}
$$

( Se agotó el OXíGENO

end;

end;

If Eps $>=1.0$ then

begin

$$
\text { Eps: }=1.0
$$

\{La TEMPERATURA rebasó el límite

$\{\mathrm{T}$ no puede ser $>$ a $50 \mathrm{C}$ 


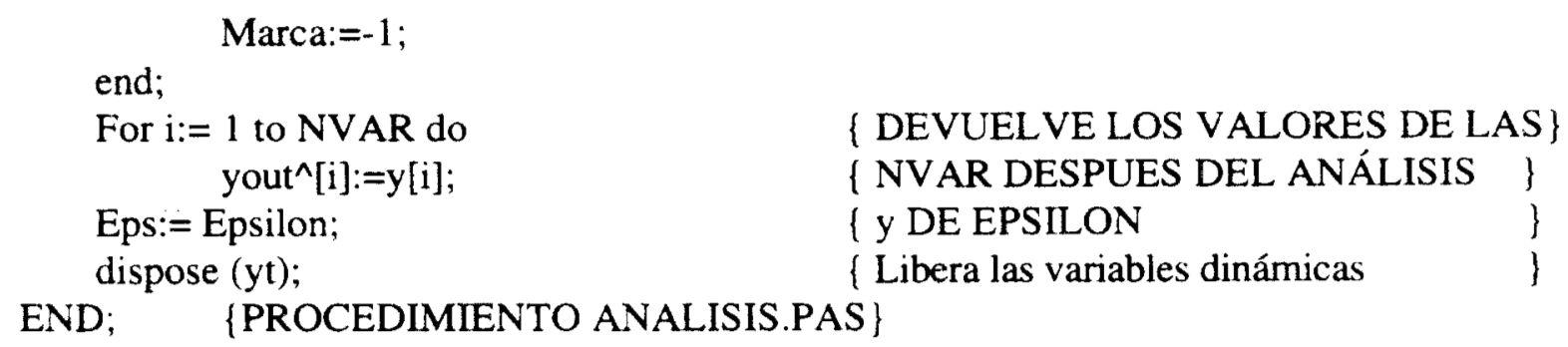




\section{ANEXO V \\ LISTADOS DE LOS PROGRAMAS UTILIZADOS PARA LA SOLUCIÓN DEL MODELO GENERAL EN DOS DIMENSIONES}

En este anexo, se presentan los listados de los programas más importantes para la solución del modelo general en dos dimensiones. Los programas se elaboraron en lenguaje Turbo Pascal, versión 6.0 aprovechando la posibilidad de escribir cada programa de manera estructurada y con jerarquías descendentes. Los programas que se listan a continuación están siempre constituídos de tres partes: el encabezado o identificador del programa, la sección de definición o declaración de tipos, variables y procedimientos y, finalmente, la sección de instrucciones de cálculo siempre acompañadas de comentarios entre paréntesis \{\} . Las instrucciones que inician la línea con el signo $\$$, se refieren a órdenes de compilación e inserción de subprocedimientos. Las variables que anteceden al signo ${ }^{\wedge}$, corresponden a variables de tipo dinámicas que se utilizan sólo durante el cálculo y no se almacenan permanentemente en la memoria. Para la solución del modelo general en dos dimensiones se utilizan once procedimientos, los cinco más importantes son los siguientes:
1. PRINCIPAL.PAS,
4. CALCUL1.PAS,
2. LECTURA.PAS,
5. CALCUL2.PAS y
3. CONDINI.PAS,

A continuación se presentan los listados de cada uno de los programas.

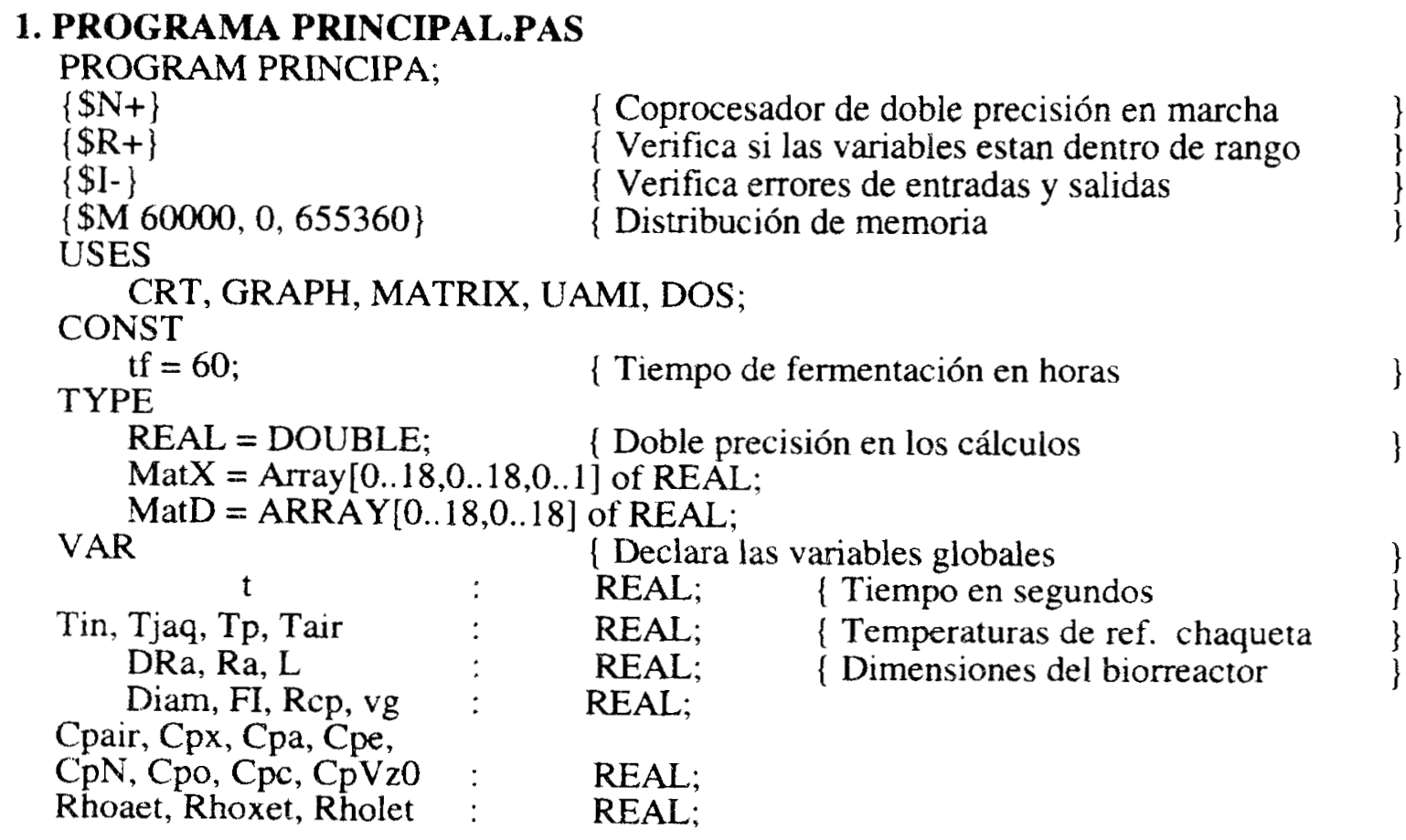


Yprima, Yc, Ye, Yo, Ys

YcMax, YeMax, YoMax, YsMax

Gasto, Me, Mmgs :

Ks, Kstest, Ki, Kitest,

ms, mo

Rhoa0, Rhox0, Rhoe0,

Rhos0, RhoN0, Rhoo0,

Rhoc0, Rhog0, Rhoaire,

Rhovz0, Rhov0

i, j, imax, jmax, Entrada,

Cuenta

LAMDAef, P, pet

Epsilon0, Rhoxmax,

Rhocmax

Rhoa, RhoN, Rhov

Pasoenr, Pasoenz,

$\mathrm{Dr}, \mathrm{Dz}, \mathrm{Dt}$

Pasoent

$\mathrm{A} 1, \mathrm{~A} 2, \mathrm{Ea} 1, \mathrm{Ea} 2, \mathrm{Rg}$

$\mathrm{hx}, \mathrm{hS}$, he, hO, hC $\mathrm{fpN}, \mathrm{fpo}, \mathrm{fpc}$

PROCEDURE LECTURA;

\{\$I LECTURA.pas\}

PROCEDURE VALIDA;

\{\$I VALIDA.PAS\}

PROCEDURE CALCULO;

\{\$I CALCUL1.pas\}

\{\$I CALCUL2.pas\}
REAL;

REAL;

REAL;

REAL;

INTEGER;

REAL;

REAL;

REAL;

REAL;

REAL;

REAL;

REAL;

REAL;

$\{* * * * * * * * * * * * *$ INICIA PROGRAMA PRINCIPAL.PAS

BEGIN

[ Inserta la parte de lectura de datos iniciales

\{ Inserta la parte de validación de información \}

\{ Inserta: definición de variables e inicialización \}

\{ Inserta: cálculo de las ecuaciones discretizadas \}

Clrscr; Highvideo;

Drawbox (10,5, 60, 8,'M E U PROGR A M A P I N I PAL',14,14);

Normvideo;

ShowMenuLine('1. Validar ANTES de calcular ',1,5,15,7);

Show MenuLine('2. Calcular SLN validar los datos', 1,5,15,9);

Show MenuLine('3. Salir',1,5,15,11);

ShowMenuLine('TU ELECCIÓN ?',16,5,25,18); Read(Entrada);

Case Entrada of

1: Begin

LECTURA;

VALIDA;

end;

CALCULO;

2: Begin

LECTURA;

end;

CALCULO;

3: Clrscr;

end; $\{$ Case of $\}$ 
END.

\{PORGRAMA PRINCIPAL.PAS \}

\section{PROGRAMA LECTURA.PAS}

\section{BEGIN}

Cpx: $=3320$

Cpa: $=1268$

$\mathrm{CpN}:=720$

Cpe: $=4150$

Cpo: $=589$;

$\mathrm{Cpc}:=670$

Cpair:=720;

Tin: $=50$

Tjaq: $=35$

Tair: $=35$;

$P:=92633$

RhoAire: $=1.29$;

$\mathrm{FI}:=0.8$

Diam: $=6 \mathrm{E}-04$

Rcp: $=0.017$

Gasto: $=0.1$

$L:=1.0$

$\mathrm{DRa}:=0.25$;

imax: $=15$

$j \max :=16$

Pasoent: $=7$;

Rhoaet $:=1070$;

Rhoxet: $=1150$;

$\mathrm{Ks}:=2$;

$\mathrm{Ki}:=300$;

$\mathrm{ms}:=3.5 \mathrm{E}-06$;

YsMax: $=0.42$;

YeMax:=0.89;

YoMax: $=0.693$;

YcMax: $=0.484$;

Yprima: $=1.548$;

$\mathrm{Me}:=18$;

Mmgs: $=30$;

Rhoa $0:=275$;

Rhox0:=0.2;

Rhoe0:=345;

Rhos $0:=41.7$;

$\mathrm{hx}:=4.668 \mathrm{E} 06$;

he:= 15.880E06;

hc: $=8.943 \mathrm{E} 06$;

$h S:=-14.532 E 06$;

hO: $=0$;

$\mathrm{Al}:=2.7 \mathrm{E} 11$

$\mathrm{A} 2:=1.38 \mathrm{E} 47$

$\mathrm{Ea} 1:=70255$;

$\mathrm{Ea} 2:=283256$;

$\mathrm{Rg}:=8.314$;
/ Cp..Biomasa, J/ kg K

( Cp..Amberlita, J/ kg K

\{ Cp..Nitrógeno, J/ kg K

\{ Cp..Agua, J/kg K

( Cp..Oxigeno, J/ kg K

( Cp..CO2, J/kg K

Cp.aire entre $0^{\circ} \mathrm{C}$ y $100^{\circ} \mathrm{C}, \mathrm{J} / \mathrm{kg} \mathrm{K}$

( Temperatura PROHIBIDA, de ref., ${ }^{\circ} \mathrm{C}$

$\left\{\right.$ Temperatura de la chaqueta, ${ }^{\circ} \mathrm{C}$

\{ Temperatura (bulbo seco) entrada aire, ${ }^{\circ} \mathrm{C}$

(Presión del sist. (10\% arriba de la atm), $\mathrm{Pa}$

Densidad del aire, $\mathrm{kg}$ aire $/ \mathrm{m}^{3} @ 0^{\circ} \mathrm{C}$ y 1 ATM

\{ Contenido de agua en biomasa, $\mathrm{kg} / \mathrm{kg}$ biom. $\mathrm{H}$.

Diametro de partículas de Amberlita, $\mathrm{m}$

\{ Crecimiento superf. MAX. kg biom. hum $/ \mathrm{m}^{2}$

\{ Gasto específico, $\mathrm{m}^{3}$ de aire/ $\mathrm{s} \mathrm{m}^{3}$ de VER

$\{$ Altura del biorreactor, $\mathrm{m}$

( Diametro del biorreactor, $m$

\{ Número de pasos de integración en $r$

( Número de pasos de integración en $z$

( Paso de integracion TEMPORAL, $s$

\{ Masa vol. real, $\mathrm{kg}$ Amberlita $/ \mathrm{m}^{3}$ de Amberlita Masa vol. real, $\mathrm{kg}$ Biom. Hum. $/ \mathrm{m}^{3}$ Biom. Hum. Afinidad por al sustrato, $\mathrm{kg}$ azúcar $/ \mathrm{m}^{3}$

\{ Constante de inhibiciónkg azúcar $/ \mathrm{m}^{3}$

\{ Mantenimiento $\mathrm{kg}$ azúcar / $\mathrm{kg}$ biomasa húmeda s

\{ Rend. teor: Azúc, kg biomasa seca / kg azúcar

\{ Rend. teor: agua, $\mathrm{kg}$ biomasa seca / kg agua

\{ Rend. teor: $\mathrm{O}_{2}, \mathrm{~kg}$ biomasa seca / $\mathrm{kg}$ oxígeno

\{ Rend. teor: $\mathrm{CO}_{2}, \mathrm{~kg}$ biomasa seca $/ \mathrm{kg} \mathrm{CO}$

( Rend: COMBUSTION kg de $\mathrm{CO}_{2} / \mathrm{kg}$ de azúcar

\{ Peso molecular del agua, $\mathrm{kg}$ agua / mole agua

( Peso molecular fase gas seca, $\mathrm{kg}$ fase gas/mol

Masa vol. inicial, $\mathrm{kg}$ Amberlita seca $/ \mathrm{m}^{3}$

\{ Masa vol. inicial, $\mathrm{kg}$ Biomasa húmeda $/ \mathrm{m}^{3}$

\{ Masa vol. inicial, $\mathrm{kg}$ de agua $/ \mathrm{m}^{3}$

\{ Masa vol. inicial, $\mathrm{kg} \mathrm{Azfcar} / \mathrm{m}^{3}$

Calor de formación de la biomasa húmeda, $\mathrm{J} / \mathrm{kg}$

( Calor de formación del agua, $\mathrm{J} / \mathrm{kg}$

\{ Calor de formación del $\mathrm{CO}_{2}, \mathrm{~J} / \mathrm{kg}$

( Calor de combustión de la Glucosa, J / kg

\{ Calor de combustión del Oxígeno, J/ kg

I Constante para calcular Cxmax, h

Constante para calcular Cxmax, Adimensional

[ Energía de activación, $\mathrm{J} / \mathrm{mol}$ de Biomasa

[ Energía de desactivación, $\mathrm{J} / \mathrm{mol}$ de Biomasa

f Constante de los gases perfectos, J/ mol K 


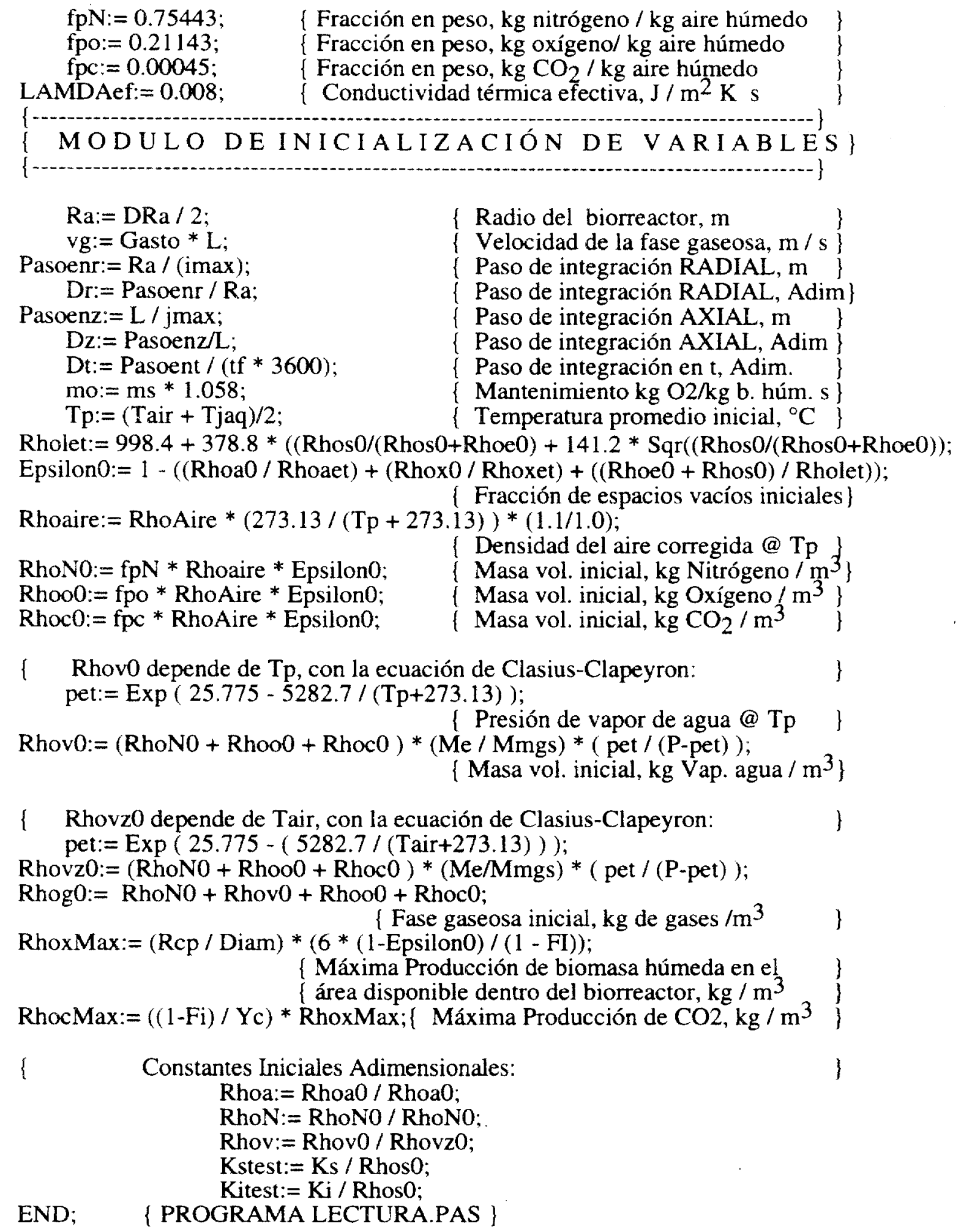




\section{PROGRAMA CONDINI.PAS}

BEGIN

$$
\text { For } \mathrm{j}:=\begin{aligned}
& 0 \text { to jmax do } \\
& \text { Begin }
\end{aligned}
$$

$$
\text { For } i:=0 \text { to imax do }
$$

$$
\left\{\begin{array}{l}
\text { En } t:=0 \\
\text { A partir de } \mathrm{z}=0
\end{array}\right\}
$$

$\{$ A partir de $\mathrm{r}=0\}$

Begin

END;

end; $\{$ For j... $\}$

RhoXX^[i,j,0]:= Rhox0/Rhoxmax;

$\operatorname{RhoSS}^{\wedge}[\mathrm{i}, \mathrm{j}, 0]:=1$;

$\operatorname{RhoEE}^{\wedge}[\mathrm{i}, \mathrm{j}, 0]:=1$;

$\operatorname{RhoOO}^{\wedge}[\mathrm{i}, \mathrm{j}, 0]:=1$;

RhoCC^$\wedge[i, j, 0]:=$ Rhoc0 / Rhocmax; $\{$ Para las variables $\mathrm{TT}^{\wedge}[\mathrm{i}, \mathrm{j}, 0]:=0$;

\{con derivadas en $t$

$\mathrm{RhoOO}^{\wedge}[\mathrm{i}, 0,0]:=1$;

$\{$ Para las variables

end; $\{$ For i... $\}$

RhoCC $\wedge[i, 0,0]:=$ Rhoco / Rhocmax; \{con derivadas en $z$ \}

$\mathrm{TT}^{\wedge}[\mathrm{imax}, \mathrm{j}, 0]:=0$

$\operatorname{TT}^{\wedge}[\operatorname{imax}, j, 1]:=0$;

\{PROGRAMA CONDINI.PAS \}

\section{PROGRAMA CALCUL1.PAS}

\{PROCEDIMIENTO CALCUL1.PAS\}

\{ ESTE SEGMENTO DECLARA VARIABLES
$\{$ PROPIAS DEL PROCEDIMIENTO $\}$
$\{$ CALCUL2.PAS

VAR

TK, TT

RhoXX, RhoSS, RhoEE, RhoOO, RhoCC

Rhol, RhoVV

RholCl, RhopsCs, RhogCg, RhoiCi, CCx, Cxmax

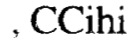

Naxi, Nrad, Nrea

$\mathrm{CCs}, \mathrm{CCe}, \mathrm{CCo}, \mathrm{CCc}$

Qresp

tfG, tfbuf

LT, LTz0, Cpv

Dimen

Coeficientes, MatrixBuff :

Constantes

Iter, MaxIter

Tol
${ }^{\wedge} \mathrm{MatX} ;\{$ Matrices de temperaturas en $\mathrm{K}$ y adimensionales

${ }^{\wedge}$ MatX; $\{$ Matrices de masas vol. adimensionales

${ }^{\wedge}$ MatX; $\left\{\right.$ Matrices de masas vol. $\mathrm{kg}$ de $\mathrm{i} / \mathrm{m}^{3}$

${ }^{\wedge}$ MatD; $\left\{\right.$ Aporte de calor, $\mathrm{J} / \mathrm{m}^{3} \mathrm{~s}$

MatD; \{ Crecimiento celular, $\mathrm{kg}$ biom. húmeda $/ \mathrm{m}^{3} \mathrm{~s}$ \}

MatD; ( Calor metabólico, $\mathrm{J} / \mathrm{m}^{3} \mathrm{~s}$

MatD; \{ Matrices Adimensionales transporte calor \}

REAL; ( Ci, tasas de reacción de i, $\mathrm{kg}$ de $\mathrm{i} / \mathrm{m}^{3} \mathrm{~s}$

REAL; $\left\{\right.$ Coeficiente respiratorio, $\mathrm{mol} \mathrm{CO} 2 / \mathrm{mol} \mathrm{O}_{2}$ \}

REAL; \{ Variables generales

REAL; \{ Calor latente y $\mathrm{Cp}$ del vapor

INTEGER; \{ Dimensión de la matriz tridiagonal cuadrada

TNmatrix; \{ Matriz de Coeficientes y Matriz Bufer

TNvector; \{ Vector de términos independientes

INTEGER; $\{$ Número de iteraciones

REAL; $\{$ Tolerancia 
Solucion

Error

Renglon, Columna

Total, gj, gi, Disco, li

hour, $\min , \mathrm{sec}$, hora
TNvector; ( Solución al sistema de ecuaciones

BYTE; ( Detector de errores

INTEGER; \{ Renglones y columnas de la matriz

INTEGER; \{ Contadores

WORD; $\{$ Contadores

\section{PROgRama CalCul2.PAS}

\{PROGRAMA CALCUL2.PAS \} \{PROGRAMA DE CÁLCULO RECURSIVO DE LAS \}

I VARIABLES EN SU FORMA DISCRETA

\{ Declaración de procedimientos propios del programa \}

PROCEDURE ABRE;

\{\$I ABRE.PAS\}

PROCEDURE CONDINI;

\{\$I CONDINI.PAS\}

PROCEDURE Imprime_Inicial (time : REAL; Jmax, Imax : INTEGER;

TEMPE, RhoX, RhoS, RhoE, RhoO, RhoC : MatX;

Penz, Penr : REAL);

\{\$I IMPREINI.PAS\}

PROCEDURE A_la_Pantalla;

\{\$I A_PANTAL.PAS\}

PROCEDURE A_disco

(time : REAL; Jmax, Imax : INTEGER;

TEMPE, RhoX, RhoS, RhoE, RhoO, RhoC : MatX);

\{\$I A_DISCO.PAS $\}$

$\{* * * * * * * * * * * * * * *$ INICIA PROGRAMA CALCUL2.PAS **********************\}

BEGIN

New(TT); New(TK); New(RhoXX); New(RhoSS); New(RhoEE); New(RhoOO);

New(RhoCC);

$\mathrm{t}:=0$;

CONDINI; [Lectura de las condiciones iniciales y en los límites\}

For li:= 1 to 6 do

begin

ABRE; (Abre SEIS archivos, uno para cada variable e imprime \}

end;

A_disco (t, Jmax, Imax, $\mathrm{TT}^{\wedge}, \mathrm{RhoXX}^{\wedge}, \mathrm{RhoSS}^{\wedge}, \mathrm{RhoEE}^{\wedge}, \mathrm{RhoOO}^{\wedge}, \mathrm{RhoCC}^{\wedge}$ );

Clrscr;

Imprime_Inicial ( $\mathrm{t}$, jmax, imax $\mathrm{TT}^{\wedge}, \mathrm{RhoXX}^{\wedge}, \mathrm{RhoSS}^{\wedge}, \mathrm{RhoEE}^{\wedge}, \mathrm{RhoOO}^{\wedge}$,

RhoCC^, Pasoenz, Pasoenr);

$\{$ Impresión de las condiciones iniciales 
Presentacion (imax,Pasoent,Pasoenz,Pasoenr,Dt,Dz,Dr);

\{ Impresión de encabezados y formato de presentación \}

Total $:=0 ;$ Cuenta: $=0 ;$ Disco: $=0$;

WHILE $\mathrm{t}<=$ tf do

$\{$ Comienzan los cálculos recursivos

Begin \{ finalizan cuando el tiempo sea tf

New(Rhol); New(RholCl); New(RhopsCs); New(RhoVV); New(RhogCg);

New(RhoiCi);

For $\mathrm{j}:=1$ to $\mathrm{jmax}$ do

\{ Bucle AXLAL principal, en $\mathrm{j}$

Begin

For $\mathrm{i}:=0$ to imax do ( Bucle RADIAL principal, en $\mathrm{i}$

Begin

\{ Temperatura de operación en $\mathrm{K}$ \}

$$
\begin{array}{ll}
\mathrm{TK}^{\wedge}[\mathrm{i}, 0,0]:=\left(\mathrm{TT}^{\wedge}[\mathrm{i}, 0,0] *(\mathrm{Tin}-\mathrm{Tp})+\mathrm{Tp}\right)+273.13 ; & \{\text { en } \mathrm{j}=0 \\
\mathrm{TK}^{\wedge}[\mathrm{i}, \mathrm{j}, 0]:=\left(\mathrm{TT}^{\wedge}[\mathrm{i}, \mathrm{j}, 0] *(\operatorname{Tin}-\mathrm{Tp})+\mathrm{Tp}\right)+273.13 ; & \{\text { en } \mathrm{j}=\mathrm{j}
\end{array}
$$

\{- Biomasa - \}

$$
\begin{aligned}
& \operatorname{Cxmax}[i, 0]:=\left(A 1 * \operatorname{Exp}\left(-\operatorname{Eal} /\left(\operatorname{Rg}^{*} \mathrm{TK}^{\wedge}[\mathrm{i}, 0,0]\right)\right)\right) / \\
& \left(1+\mathrm{A} 2 * \operatorname{Exp}\left(-\operatorname{Ea} 2 /\left(\operatorname{Rg}^{*} \mathrm{TK}^{\wedge}[\mathrm{i}, 0,0]\right)\right)\right) ; \quad\{\text { en } \mathrm{j}=0 \quad\} \\
& \operatorname{Cxmax}[\mathrm{i}, \mathrm{j}]:=\left(\mathrm{Al} * \operatorname{Exp}\left(-\operatorname{Eal} /\left(\operatorname{Rg}^{*} \mathrm{TK}^{\wedge}[\mathrm{i}, \mathrm{j}, 0]\right)\right)\right) / \\
& \left(1+\mathrm{A} 2 * \operatorname{Exp}\left(-\operatorname{Ea} 2 /\left(\operatorname{Rg}^{*} \operatorname{TK}^{\wedge}[\mathrm{i}, \mathrm{j}, 0]\right)\right)\right) ; \quad\{\text { en } \mathrm{j}=\mathrm{j}\}
\end{aligned}
$$

Kstest:=Ks/Rhos0;

Kitest:= Ki/Rhos0;

$\operatorname{CCx}[i, 0]:=\operatorname{Cxmax}[i, 0] * \operatorname{Rhoxmax} * \operatorname{RhoXX}^{\wedge}[\mathrm{i}, 0,0] *\left(1-\operatorname{RhoXX}^{\wedge}[1,0,0]\right) *$

$\left(\operatorname{RhoSS}^{\wedge}[\mathrm{i}, 0,0] /\left(\right.\right.$ Kstest $+\left(\operatorname{Sqr}\left(\operatorname{RhoSS}^{\wedge}[\mathrm{i}, 0,0] /\right.\right.$ Kitest $\left.\left.)+\operatorname{RhoSS}^{\wedge}[1,0,0]\right)\right) / 3600$;

tfbuf: $=\mathrm{Dt} *(\mathrm{tf} * 3600) *(\mathrm{CCx}[\mathrm{i}, 0] /$ Rhoxmax $)$;

RhoXX^$X^{\wedge}[i, 0,1]:=\operatorname{RhoXX}^{\wedge}[i, 0,0]+$ tfbuf; $\quad\{$ en $j=0 \quad\}$

$\operatorname{CCx}[\mathrm{i}, \mathrm{j}]:=\operatorname{Cxmax}[\mathrm{i}, \mathrm{j}] * \operatorname{Rhoxmax} * \operatorname{RhoXX} X^{\wedge}[\mathrm{i}, \mathrm{j}, 0] *\left(1-\operatorname{RhoXX}^{\wedge}[\mathrm{i}, \mathrm{j}, 0]\right) *$

$\left(\operatorname{RhoSS}^{\wedge}[\mathrm{i}, \mathrm{j}, 0] /\left((\mathrm{Ks} / \mathrm{Rhos} 0)+\operatorname{RhoSS}^{\wedge}[\mathrm{i}, \mathrm{j}, 0]\right)\right) / 3600 ;$

tfbuf:= Dt * $(\mathrm{tf} * 3600) *(\mathrm{CCx}[\mathrm{i}, \mathrm{j}] /$ Rhoxmax $)$;

RhoXX^[i,j,1]:= $\operatorname{RhoXX}^{\wedge}[i, j, 0]+$ tfbuf;

$\{$ en $j=j\}$

$\{$ - Azúcar - \}

Ys: $=$ YsMax $-\left(\left(0.57^{*} \operatorname{RhoSS}^{\wedge}[i, 0,0]\right) /\left(\right.\right.$ Kitest $\left.\left.-\operatorname{RhoSS}^{\wedge}[i, 0,0]\right)\right)$;

$\mathrm{CCs}:=\left(((1-\mathrm{FI}) / \mathrm{Ys}) * \mathrm{CCx}[\mathrm{i}, 0]+\mathrm{ms} * \operatorname{Rhoxmax} * \operatorname{RhoXX}{ }^{\wedge}[\mathrm{i}, 0,0]\right)$;

tfbuf:= Dt * (tf *3600)*( CCs / Rhos 0$)$;

RhoSS^[i,0,1]:= RhoSS^[i,0,0] - tfbuf;

$\{$ en $j=0 \quad\}$

$\mathrm{CCs}:=\left(((1-\mathrm{FI}) / \mathrm{Ys}) * \operatorname{CCx}[\mathrm{i}, \mathrm{j}]+\mathrm{ms} * \operatorname{Rhoxmax} * \mathrm{RhoXX}^{\wedge}[\mathrm{i}, \mathrm{j}, 0]\right)$;

tfbuf:=Dt* (tf *3600)*( CCs / Rhos0);

$\operatorname{RhoSS}^{\wedge}[\mathrm{i}, \mathrm{j}, 1]:=\operatorname{RhoSS}^{\wedge}[\mathrm{i}, \mathrm{j}, 0]-$ tfbuf;

$\{$ en $\mathrm{j}=\mathrm{j}\}$

$\{-$ Agua - $\}$

$\mathrm{Ye}:=\operatorname{YeMax}-\left(\left(0.57^{*} \operatorname{RhoSS}^{\wedge}[1,0,0]\right) /\left(\right.\right.$ Kitest $\left.\left.-\operatorname{RhoSS}^{\wedge}[i, 0,0]\right)\right)$;

$\mathrm{CCe}:=(((1-\mathrm{FI}) / \mathrm{Ye})-\mathrm{FI}) * \mathrm{CCx}[\mathrm{i}, 0]$; 
tfbuf: $=\mathrm{Dt} *(\mathrm{tf} * 3600) *(\mathrm{CCe} / \mathrm{Rhoe} 0)$;

$\operatorname{RhoEE}^{\wedge}[\mathrm{i}, 0,1]:=\operatorname{RhoEE}^{\wedge}[\mathrm{i}, 0,0]+$ tfbuf;

$\{$ en $\mathrm{j}=0 \quad\}$

$\mathrm{CCe}:=(((1-\mathrm{FI}) / \mathrm{Ye})-\mathrm{FI}) * \mathrm{CCx}[\mathrm{i}, \mathrm{j}]$

tfbuf:= Dt* (tf *3600)*( CCe / Rhoe0 $)$;

$\operatorname{RhoEE}^{\wedge}[\mathrm{i}, \mathrm{j}, 1]:=\operatorname{RhoEE}^{\wedge}[\mathrm{i}, \mathrm{j}, 0]+$ tfbuf;

$\{$ en $j=j \quad\}$

\{- Fase $1_{\text {iquida }}$ \}

Rhol^[i,0]:= Rhoe $0 * \operatorname{RhoEE}^{\wedge}[i, 0,0]+\operatorname{Rhos}^{*} \operatorname{RhoSS}^{\wedge}[i, 0,0] ; \quad\{$ en $j=0 \quad\}$

$\operatorname{Rhol}^{\wedge}[i, j]:=\operatorname{Rhoe} 0 * \operatorname{RhoEE}^{\wedge}[\mathrm{i}, \mathrm{j}, 0]+\operatorname{Rhos} 0 * \operatorname{RhoSS}^{\wedge}[i, j, 0] ; \quad\{$ en $j=j\}$

\{ expresado en $\mathrm{kg}$ de $1 / \mathrm{m}^{3}$ \}

\{- Aporte calórico de las fases sólida y líquida - \}

RholCl^[i,0]:= Rhol^[i,0] * Cpe;

RhopsCs ${ }^{\wedge}[i, 0]:=\mathrm{Rhoa}^{*}$ Rhoa $* \mathrm{Cpa}+$

RhoxMax * RhoXX^[i,0,0]* Cpx $+\operatorname{RholCl}^{\wedge}[\mathrm{i}, 0] ; \quad\{$ en $\mathrm{j}=0 \quad\}$

RholCl^[i,j]:= Rhol^[i,j] * Cpe;

RhopsCs^[i,j]:= Rhoa0 $*$ Rhoa $* \mathrm{Cpa}+$

RhoxMax * $\operatorname{RhoXX}^{\wedge}[i, j, 0] * \operatorname{Cpx}+\operatorname{RholCl}^{\wedge}[i, j] ; \quad\{$ en $\mathrm{j}=\mathrm{j} \quad\}$

\{ expresado en $\mathrm{J} / \mathrm{m}^{3} \mathrm{~K}$ \}

$\{-$ Oxígeno - $\}$

Yo: $=$ YoMax $-\left(\left(0.57^{*} \operatorname{RhoSS}^{\wedge}[\mathrm{i}, 0,0]\right) /\left(\right.\right.$ Kitest $\left.\left.-\operatorname{RhoSS}^{\wedge}[\mathrm{i}, 0,0]\right)\right)$;

$\mathrm{CCo}:=((1-\mathrm{FI}) / \mathrm{Yo})^{*} \mathrm{CCx}[\mathrm{i}, \mathrm{j}]+\operatorname{mo} * \mathrm{RhoxMax}^{*} \operatorname{RhoXX} \mathrm{X}^{\wedge}[\mathrm{i}, \mathrm{j}, 0]$;

tfbuf: $=$ tf $* 3600 *($ CCo $/$ Rhoo0 $)$;

$\mathrm{tfG}:=\mathrm{tf} * 3600 * \mathrm{vg} / \mathrm{L}$;

RhoOO^[i,0,1]:=1.0;

$\mathrm{RhoOO}^{\wedge}[\mathrm{i}, \mathrm{j}, 1]:=\left(\mathrm{Dz} /\left(\mathrm{Dz}+\mathrm{Dt}^{*} \mathrm{tfG}^{\mathrm{f}}\right)\right)^{*} \mathrm{RhoOO}^{\wedge}[\mathrm{i}, \mathrm{j}, 0]+$

$\{$ en $\mathrm{j}=0 \quad\}$

$(\mathrm{Dt} * \mathrm{tfG} /(\mathrm{Dz}+\mathrm{Dt} * \mathrm{tfG})) * \mathrm{RhoOO}^{\wedge}[\mathrm{i}, \mathrm{j}-1,0]-$

$(\mathrm{Dt} * \mathrm{Dz} /(\mathrm{Dz}+\mathrm{Dt} * \mathrm{tfG})) * \mathrm{tfbuf}$

$\{e n j=j \quad\}$

\{- Bióxido de carbono - \}

$Y c:=Y c M a x-\left(\left(0.57^{*} \operatorname{RhoSS}^{\wedge}[i, 0,0]\right) /\left(\right.\right.$ Kitest $\left.\left.-\operatorname{RhoSS}^{\wedge}[i, 0,0]\right)\right) ;$

$\mathrm{CCc}:=((1-\mathrm{Fl}) / \mathrm{Yc}) * \mathrm{CCx}[\mathrm{i}, \mathrm{j}]+\mathrm{Yprima} * \mathrm{~ms} * \mathrm{RhoXX}^{\wedge}[\mathrm{i}, \mathrm{j}, 0] *$ RhoxMax; tfbuf: $=\mathrm{tf} * 3600 *(\mathrm{CCc} / \mathrm{RhocMax})$

RhoCC^[i,0,1]:= Rhoc0 / RhocMax;

$\operatorname{RhoCC}^{\wedge}[\mathrm{i}, \mathrm{j}, 1]:=\left(\mathrm{Dz} /\left(\mathrm{Dz}+\mathrm{Dt}^{*} \mathrm{tfG}\right)\right) * \mathrm{RhoCC}^{\wedge}[\mathrm{i}, \mathrm{j}, 0]+$

$$
\{\text { en } j=0 \quad\}
$$

$(\mathrm{Dt} * \mathrm{tfG} /(\mathrm{Dz}+\mathrm{Dt} * \mathrm{tfG})) * \mathrm{RhoCC}^{\wedge}[\mathrm{i}, \mathrm{j}-1,0]+$ $(\mathrm{Dt} * \mathrm{Dz} /(\mathrm{Dz}+\mathrm{Dt} * \mathrm{tfG})) *$ tfbuf;

$\{e n j=j \quad\}$

$\{$ - Coeficiente respiratorio -$\}$

Qresp: $=(\mathrm{CCc} / \mathrm{CCo}) *(32 / 44)$;

$\{$ - Vapor de agua - $\}$

pet: $=\operatorname{Exp}\left(25.775-\left(5282.7 / \mathrm{TK}^{\wedge}[\mathrm{i}, \mathrm{j}, 0]\right)\right)$;

$\operatorname{RhoVV}^{\wedge}[\mathrm{i}, \mathrm{j}]:=\left(\operatorname{RhoN}+\operatorname{RhoOO}^{\wedge}[\mathrm{i}, \mathrm{j}, 0]+\operatorname{RhoCC}^{\wedge}[\mathrm{i}, \mathrm{j}, 0]\right)^{*}(\mathrm{Me} / \mathrm{Mmgs})^{*}($ pet $/(\mathrm{P}-$ pet $)) ;$ 
$\mathrm{LT}:=2.54 \mathrm{E} 6-2.9 \mathrm{E} 3 * \mathrm{TK}^{\wedge}[\mathrm{i}, \mathrm{j}, 0]$

$\mathrm{LTzO}:=2.54 \mathrm{E} 6-2.9 \mathrm{E} 3 *(\mathrm{Tair}+273.13)$;

$\mathrm{Cpv}:=\mathrm{Cpe}+\mathrm{LT}-(\mathrm{Rg} / \mathrm{Me})$

Cpvz0:= Cpe $+\mathrm{LTz0}-(\mathrm{Rg} / \mathrm{Me})$

$\{$ - Aporte calórico de la fase gaseosa - $\}$

RhogCg^[i,0]:= RhoN0 * $\mathrm{RhoN} * \mathrm{CpN}+\mathrm{Rhov0}^{*} \mathrm{Rhovz0}^{*} \mathrm{Cpvz0}+$ Rhoo ${ }^{*} \operatorname{RhoOO}^{\wedge}[i, 0,0]^{*}$ Cpo $+\operatorname{RhocMax}^{*} \operatorname{RhoCC}^{\wedge}[i, 0,0] * \operatorname{Cpc} ;\{$ en $\mathrm{j}=0\}$

$\mathrm{RhogCg}^{\wedge}[\mathrm{i}, \mathrm{j}]:=\mathrm{RhoN0} * \mathrm{RhoN}^{*} \mathrm{CpN}+\mathrm{Rhov0}^{*} \mathrm{RhoVV}^{\wedge}[\mathrm{i}, \mathrm{j}] * \mathrm{Cpv}+$ Rhoo $* \mathrm{RhoOO}^{\wedge}[\mathrm{i}, \mathrm{j}, 0] * \mathrm{Cpo}+\mathrm{RhocMax}^{*} \mathrm{RhoCC}^{\wedge}[\mathrm{i}, \mathrm{j}, 0] * \mathrm{Cpc}$;

\{- El aporte calórico del conjunto de las fases - \}

RhoiCi^$[i, 0]:=\left(\operatorname{RhopsCs}^{\wedge}[\mathrm{i}, 0]+\operatorname{RhogCg}^{\wedge}[i, 0]\right)$;

$\{$ en $j=0$

$\operatorname{RhoiCi}^{\wedge}[i, j]:=\left(\operatorname{RhopsCs}^{\wedge}[i, j]+\operatorname{RhogCg}^{\wedge}[i, j]\right)$;

$\{$ en $\mathrm{j}=\mathrm{j}$

\{ Temperatura \}

CCihi $[i, 0]:=\mathrm{CCx}[i, 0]^{*} \mathrm{hx}+\mathrm{CCs}^{*} \mathrm{hS}+\mathrm{CCe}^{*} \mathrm{he}+\mathrm{CCo}^{*} \mathrm{hO}+\mathrm{CCc}^{*} \mathrm{hC} ;\{$ en $\mathrm{j}=0\}$

$\mathrm{CCihi}[\mathrm{i}, \mathrm{j}]:=\mathrm{CCx}[\mathrm{i}, \mathrm{j}] * \mathrm{hx}+\mathrm{CCs}^{*} \mathrm{hS}+\mathrm{CCe}^{*} \mathrm{he}+\mathrm{CCo}^{*} \mathrm{hO}+\mathrm{CCc}^{*} \mathrm{hC} ;\{$ en $\mathrm{j}=\mathrm{j}\}$

\{ El calor de la REACCIÓN \}

$\operatorname{Naxi}[i, 0]:=\left(\mathrm{tfG}^{*} \operatorname{RhogCg}^{\wedge}[\mathrm{i}, 0]\right) / \operatorname{RhoiCi}^{\wedge}[\mathrm{i}, 0] ; \quad\{$ en $\mathrm{j}=0 \quad\}$

$\operatorname{Naxi}[i, j]:=\left(t^{\prime} G * \operatorname{RhogCg}^{\wedge}[i, j]\right) / \operatorname{RhoiCi}^{\wedge}[i, j]$

$\{e n j=j \quad\}$

$\operatorname{Nrad}[i, 0]:=($ LAMDAef $*(\operatorname{tf} * 3600)) /\left(\operatorname{Sqr}(\mathrm{Ra}) *\right.$ RhoiCi^$\left.{ }^{\wedge}[\mathrm{i}, 0]\right)$;

$\operatorname{Nrad}[i, j]:=($ LAMDAef $*(\operatorname{tf} * 3600)) /\left(\operatorname{Sqr}(\mathrm{Ra}) * \operatorname{RhoiCi}^{\wedge}[i, j]\right)$;

Nrea $[i, 0]:=($ tf $* 3600 *$ CCihi $[i, 0]) /\left((\operatorname{Tin}-T p) * \operatorname{RhoiCi}^{\wedge}[i, 0]\right)$;

Nrea $[i, j]:=($ tf $* 3600 * \operatorname{CCihi}[i, j]) /(($ Tin $-\mathrm{Tp}) * \operatorname{RhoiCi\wedge }[i, j])$

end; $\quad$ FIN bucle RADIAL principal en i \}

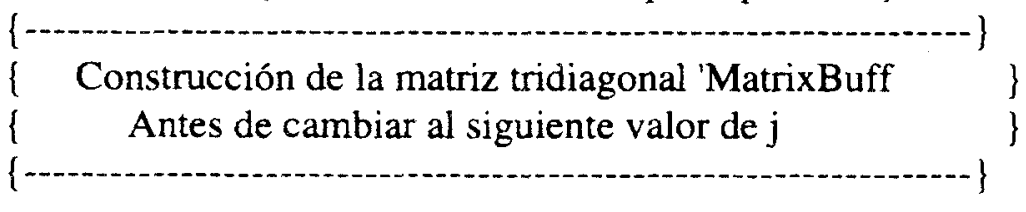

Begin

For Renglon: $=1$ to imax +1 do

Begin

For Columna: $=1$ to imax +1 do

Begin

MatrixBuff[Renglon,Columna]:=0; [ llena de ceros \} end; $\{$ For Columna \}

\{ la matriz tridiagonal

end; \{For Renglon \}

For Renglon: $=2$ to imax do

Begin

For Columna: $=1$ to imax do 


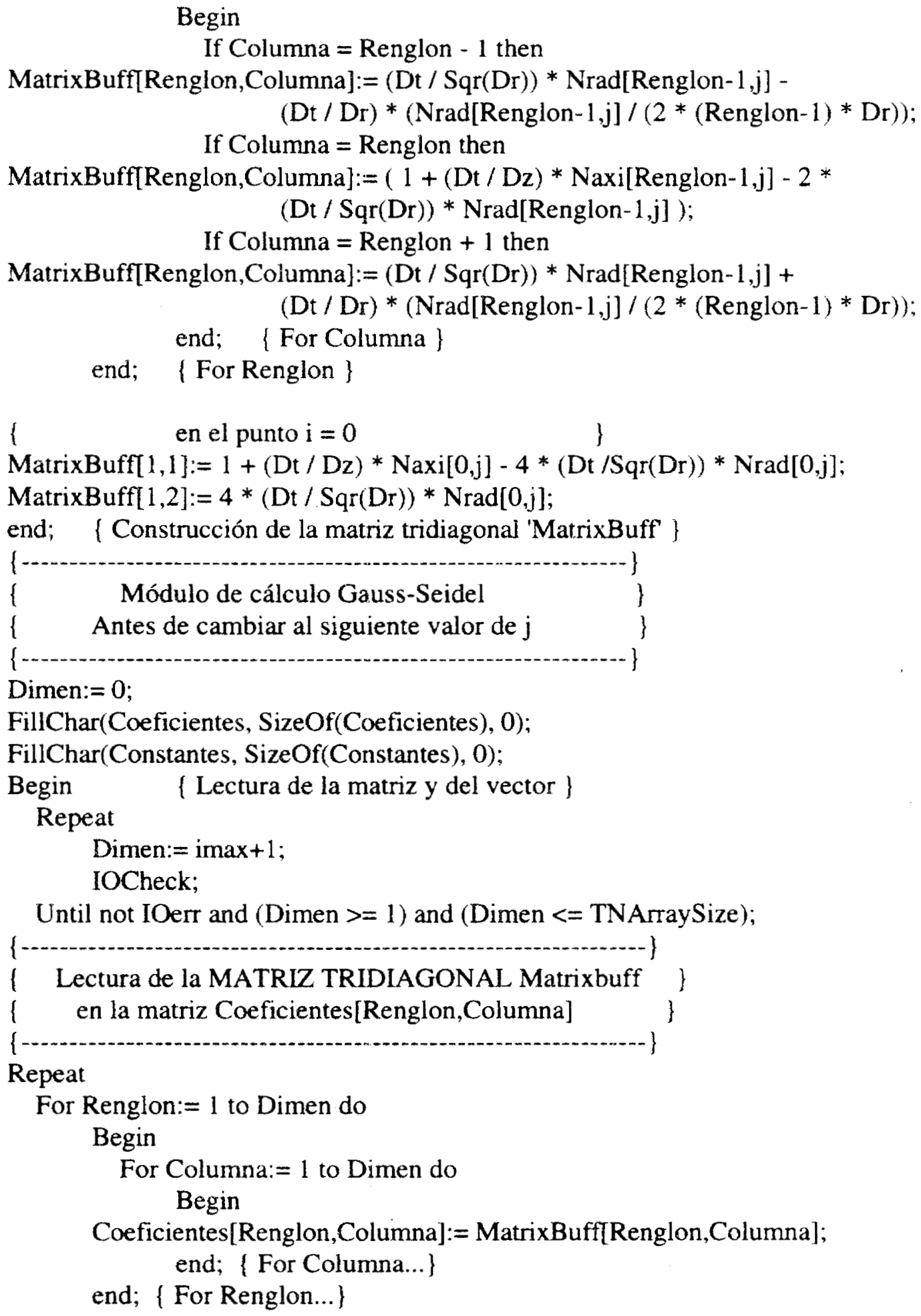




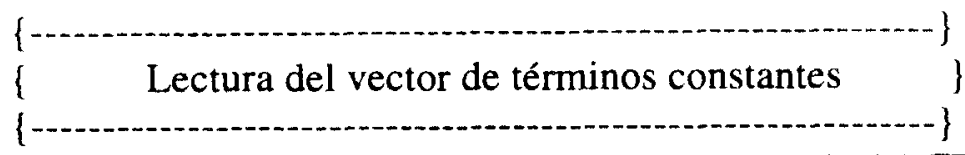

Constantes $[1]:=\operatorname{TT}^{\wedge}[0, j, 0]+(D t / D z) * \operatorname{Naxi}[0, j-1] * \operatorname{TT}^{\wedge}[0, j-1,1]-$

Dt * Nrea[0,j];

For Renglon: $=2$ to Dimen-1 do

Constantes[Renglon]: $=\operatorname{TT}^{\wedge}[$ Renglon $-1, \mathrm{j}, 0]+$

(Dt / Dz) * Naxi[Renglon-1,j-1]* TT^[Renglon-1,j-1,1]- Dt *

Nrea[Renglon-1,j];

IOCheck;

Until not IOerr;

Tol := 1E-10;

Maxiter : $=400$;

end; \{ Lectura de Matriz y vector \}

\{ En el procedimiento Gauss_Seidel: la inversión de la matriz y cálculo del vector Solucion \}

Gauss_Seidel (Dimen, Coeficientes, Constantes, Tol, MaxIter, Solucion, Iter, Error);

\{ La solución a $\mathrm{j}=$ constante es la siguiente:

For renglon: $=1$ to dimen do

$\mathrm{TT}^{\wedge}[$ renglon $-1, \mathrm{j}, 0]:=$ Solucion[renglon];

$\mathrm{TT}^{\wedge}[\operatorname{imax}-1, \mathrm{j}, 0]:=($ Nrea[imax-1,j] / ( (Nrad / Ra*2Dr $\left.)-(\operatorname{Nrad} / \mathrm{Sqr}(\mathrm{Dr}))\right)$;

$\mathrm{TT}^{\wedge}[\operatorname{imax}, \mathrm{j}, 0]:=0$;

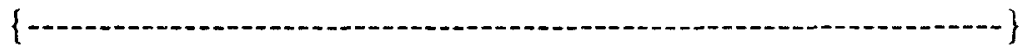

( Reenvío de las temperaturas calculadas en éste j y

\{ almacenamiento de los datos en la matriz de índice $n=1$ \}

$\{$ -

For $\mathrm{i}:=0$ to imax do

$\operatorname{TT}^{\wedge}[\mathrm{i}, \mathrm{j}, 1]:=\operatorname{TT}^{\wedge}[\mathrm{i}, \mathrm{j}, 0]$

end; \{FIN bucle AXIAL principal en $j$ \}

Dispose(Rhol); Dispose(RholCl); Dispose(RhopsCs); Dispose(RhoVV);

Dispose(RhogCg); Dispose(RhoiCi);

$\{$ Reenvío de las variables calculadas en cada tiempo $\}$

For $\mathrm{gj}:=0$ to $\mathrm{jmax}$ do

begin

For gi: $=0$ to imax do

begin

RhoXX^[gi,gj,0]:= RhoXX^[gi,gj,1];

RhoSS^[gi,gj,0]:= RhoSS^[gi,gj,1];

$\operatorname{RhoEE}^{\wedge}[\mathrm{gi}, \mathrm{gj}, 0]:=\operatorname{RhoEE}^{\wedge}[\mathrm{gi}, \mathrm{gj}, 1]$;

RhoOO^[gi,gj,0]:= $\operatorname{RhoOO}^{\wedge}[\mathrm{gi}, \mathrm{gj}, 1]$;

RhoCC ${ }^{\wedge}[\mathrm{gi}, \mathrm{gj}, 0]:=\operatorname{RhoCC}^{\wedge}[\mathrm{gi}, \mathrm{gj}, 1]$;

$\mathrm{TT}^{\wedge}[\mathrm{gi}, \mathrm{gj}, 0]:=\mathrm{TT}^{\wedge}[\mathrm{gi}, \mathrm{gj}, 1]$; 


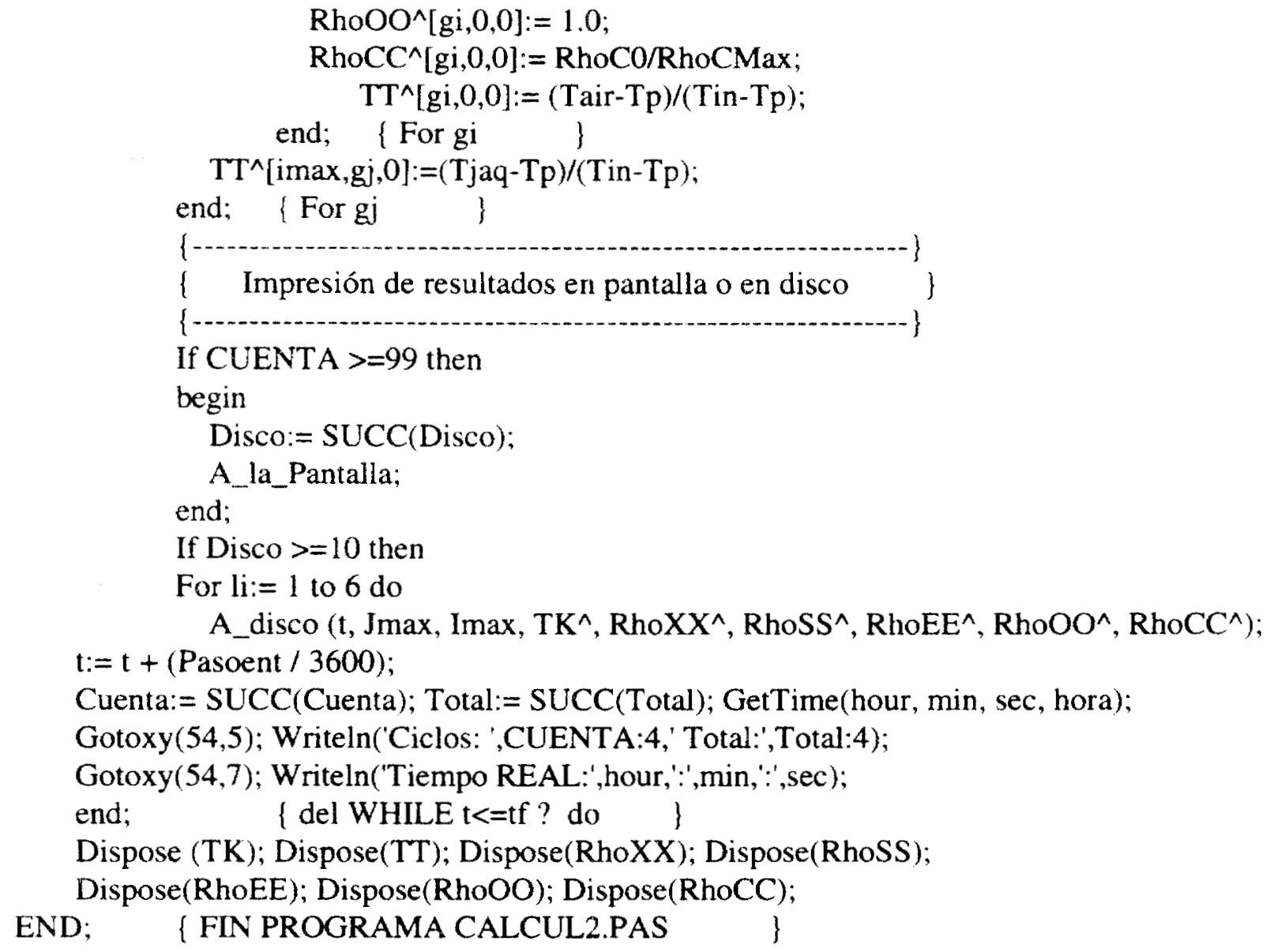




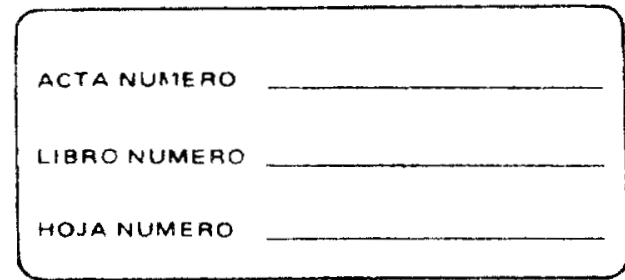

DENOMINACION DE LA TESIS

CONTRIBUCION AL ESTUDIO DEL

MODELADO MATEMATICO DE LA

FERMENTACION SOLIDA DE

HONGOS FILAMENTOSOS EN

\section{SOPORTES INERTES.}
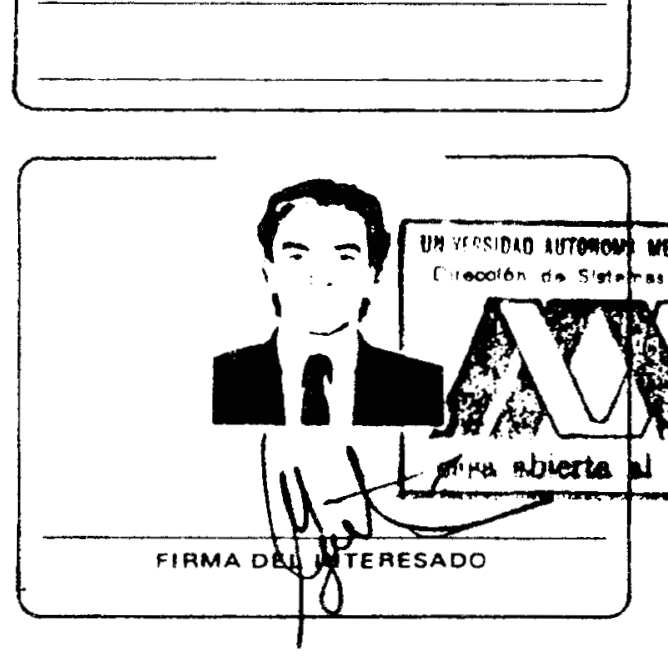

REVISO
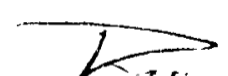

Cisitre

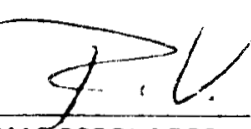

DIREC ION DE SISTEMASESCOLARES

En México. D F. SE PRESENTARON

del dia 22 del mes c'e MARzo del año 1995

en la Unidad IZTAPALAPA

Metropolitana. los suscritos miembros del Jurado

DR. AGUSTIN LOPEZ-MUNGUIA CANALES; DR . EDUARDO BARZANA

GARCIA; DR. FELIPE LOPEZ ISUNZA; DR. RICHARD AURIA Y

DR. SERGIO REVAH MOISEEV.

bajo la Presidencia del primero y con el carácter de Secretario

el último se reunieron para proceder al examen de grado

de

\section{DOCTOR EN CIENCIAS}

MARIANO GUTIERREZ ROJAS

quie presentó una comunicación de resultados, cuya deno-

infión aparece al margen y de acuerdo con el articulo 40. fiones I III y IV del Reglamento de Estudios de Posgrado de esta Universidad, los miembros del Jurado resolvieron.

$$
\text { Aprobarto }
$$

Acto continuo, el Presidente del Jurado comunicó al interesado el resultado de la evaluación y, en caso aprobatorio, le fue tomada la protesta.

aquati. Liti,enel

DR. AGUSTIN LOPEZ-MUNGUIA C. PRESIDENTE

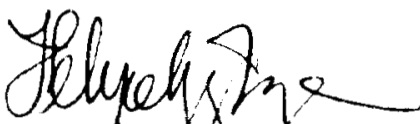

DR. FELI E WAEZ ISUNZA

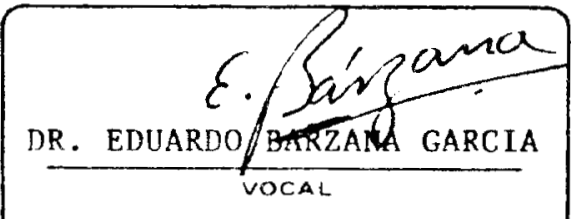

DR. RTCUARD AURIA VOCAL
DR. SERG FeteTARIO
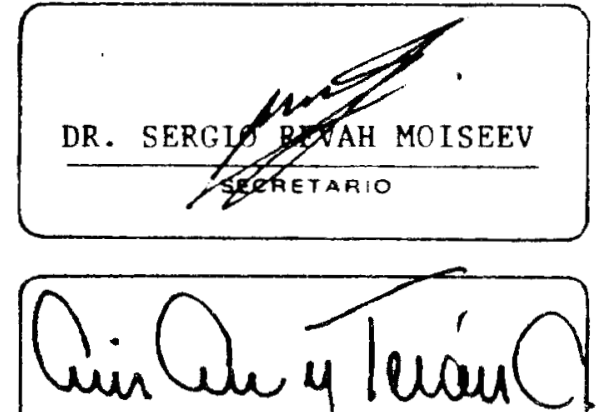

DR. LUIS MIER Y TERAN C. CIRECTOR DE OIVISION 